\title{
Aspectos da Sensibilização em Terapia Fotodinâmica: Avaliação das Propriedades Fotofísicas de Metaloporfirinas Catiônicas em Meio Homogêneo e Micro-Heterogêneo
}

\author{
Rodrigo Marchiori Liegel \\ Tese de-Doutoramento
}

Prof. Dr. Gianluca Camillo Azzellini
ORIENTADOR

SÃO PAULO

2002 


\section{DEDALUS - Acervo - CQ

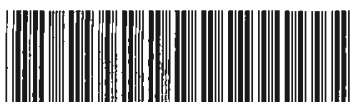 \\ 30100004868}

Ficha Catalográfica

Elaborada pela Divisão de Biblioteca e

Documentação do Conjunto das Químicas da USP.

Liegel, Rodrigo Marchiori

L721a Aspectos da sensibilização em terapia fotodinâmica : avaliação das propriedades fotofísicas de metaloporfirinas catiônicas em meio homogêneo e micro-heterogêneo / Rodrigo Marchiori Liegel. -- São Paulo, 2002. $169 \mathrm{p}$.

Tese (doutorado) - Instituto de Química da Universidade de São Paulo. Departamento de Química Fundamental.

Orientador: Azzellini, Gianluca Camillo

1. Fotoquímica inorgânica 2. Fotofísica 3. Porfirina : Química orgânica 4. Surfactante : Físico química I. T. II. Azzellini, Gianluca Camillo, orientador. 
"Aspectos da Sensibilização em Terapia

Fotodinâmica: Avaliação das Propriedades Fotofísicas de Metaloporfirinas Catiônicas em Meio Homogêneo e Micro-Heterogêneo"

\section{RODRIGO MAROYIORI LIEGEL}

Tese de Doutorado submetied go Instituto de Química da Universidade de São Paulo cono parte dos requisitos necessários à obtenção do graù de Doutor em Química Área: Química Inorgânica.

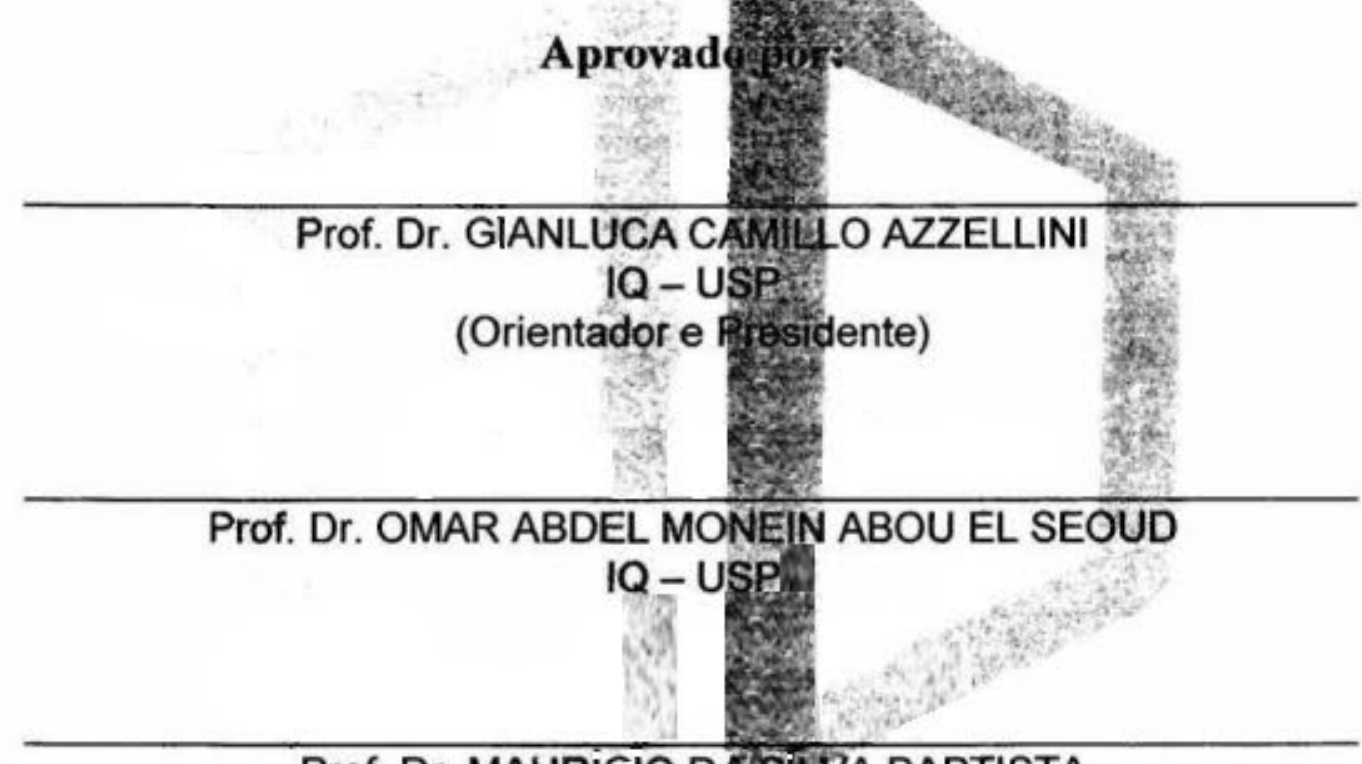

Prof. Dr. MAURICIO DASSIEVA BAPTISTA

$1 Q-U S P$

Prof. Dr. ROSÂNGELA ITRI

IF - USP

Profa. Dra. IEDA LÚCIA VIANA ROSA

UF SC

SÃo PAULO

12 DE JULHO 2002. 
BIBLIOTECA

INSTITUTO DE QUIMICA

Undversidado do São Paule

20.142

À Nanci,

companheira, namorada e esposa

Ao Yuri,

e toda alegria que sua presença traz 


\section{AGRADECIMENTOS}

À Nanci pelo amor e compreensão.

Aos meus pais pela confiança.

A Darcy, Wagner e Fernanda pela sincera acolhida.

Ao prof. Gianluca Camillo Azzellini, pela orientação e pelo tratamento informal e correto durante todo a nossa longa convivência.

Ao amigo Jorge pelos conselhos e ajudas técnicas.

A Marcela pelo convívio agradável no laboratório.

Ao Luiz Fernando, seus conselhos e companhia de corridas.

Aos profs. do bloco 2T, Denise, Victória, Vera, Henrique, Ana Maria e Neyde sempre prestativos ao compartihar reagentes, equipamentos e conhecimento.

À Cida, por resolver tão bem os nossos problemas burocráticos.

A Ivone e Alzilene pelos seus serviços e seu bom humor constante.

Aos colegas do bloco 2 .

Ao Dr. Sérgio Dovidauskas pelo auxílio nas técnicas de voltametria cíclica e espectroeletroquímica.

À profa. Helena Ferraz pelas conversas agradáveis, conselhos valiosos e incentivos.

Aos profs. Claudio e Baader pelos reagentes emprestados e dicas em síntese e fotoquímica.

Ao prof. Omar pela sua contribuição nas discussões de RMN e interações com surfactantes.

Ao prof. Frank e seus alunos Paulo e Chang pela assessoria na técnica de fotólise por pulso de laser.

Ao prof. Etelvino e à Adriana pelo empréstimo das cubetas de caminho ótico $0,2 \mathrm{~cm}$.

Ao prof. Politi e pelo empréstimo da cubeta adaptada para degaseificar amostras.

Ao prof. Henrique Catalani (Lique) pelo auxilio nos experimentos de determinação do rendimento quântico de formação de oxigênio singlete, bem pela valiosa discussão dos resultados.

À profa. Dalva por ter obtido os espectros raman ressonante.

Ao prof. Hermi pelo incentivo ao meu trabalho. 
Aos profs. Frank e Omar pelas contribuições durante o exame de qualificação. À Marcela pela leitura crítica desse trabalho.

Ao Jorge e a ajuda na captura das imagens utilizadas nesta tese.

Aos profs. Lúcio, Pio e Mauro pela confiança no meu futebol.

À profa. Lilian e suas alunas Andrea e Larissa pela água deionizada e o convite para as festas do lab.

Ao prof. Jorge e seus alunos Gilberto e PC pelo empréstimo da mesa agitadora.

A profa. lolanda e seu aluno Flávio pelo empréstimo dos surfactantes, e assessoria na determinação da cmc dos mesmos.

Aos funcionários da Central Analítica, em especial à Mirian e Alessandra pelos excelentes espectros de RMN obtidos.

Aos funcionários da SPG, em especial a Cibele e Milton, pela eficiência e paciência.

Ao prof. Nelson pelos excessivos elogios ao meu trabalho.

Ao prof. Hector pela confiança e oportunidade.

Aos profs. Lucy, Zink, Mitiko e Sandra pelo incentivo e apoio sempre que necessário.

Aos professores, coordenadores e diretores do Colégio Santa Cruz pela sua participação efetiva na minha formação como aluno e agora como docente. 


\section{RESUMO}

Uma nova série de porfirinas catiônicas e seus respectivos metalocomplexos de $\mathrm{Zn}(\mathrm{II})$ e $\mathrm{Cu}(\mathrm{II})$ foi sintetizada. Esta nova série apresenta resíduos benzílicos substituídos ligados aos grupos pindínicos presentes nas posições meso do anel porfirínico. Estes compostos foram caracterizados e investigados utilizando várias técnicas, tais como: espectroscopia eletrônica de absorção e de emissão, RMN- ${ }^{1} \mathrm{H}$, espectroscopia vibracional IR e raman ressonante, voltametria cíclica, espectroeletroquímica e fotólise por pulso de laser.

Não foram observadas evidências de auto-agregação destes compostos em água, entretanto, estes apresentam agregação diferenciada em função da força iôrica do meio, do ânion do eletrólito utilizado e do tamanho do substituinte periférico.

Os potenciais de redução apresentam dependência ao caráter aceptor/doador de elétrons dos substituintes benzílicos.

As porfirinas desta série apresentam parâmetros fotofísicos da mesma ordem de grandeza e comparáveis ao composto modelo 5,10,15,20-tetrakis(1-metilpiridínio-4il)-porfirina ( $\mathrm{H}_{2}$ TMPyP) e seus metaloderivados em meio homogêneo. Em meio microhetrogêneo são observadas alterações nestes parâmetros fotofísicos, existindo um comportamento diferenciado em relação à $\mathrm{H}_{2}$ TMPyP.

Uma análise global dos resultados evidência que estes derivados são promissores fotossensibilizadores em sistemas de terapia fotodinâmica. 


\section{ABSTRACT}

A new series of cationic porphyrins and metalloporphyrins derivatives of $\mathrm{Cu}$ (II) and $\mathrm{Zn}(\mathrm{II})$ has been synthesized. These compounds show substituted benzylic residues attached to the piridil groups at the meso porphyrin ring positions. All porphyrins and metalloporphyrin have been fully characterized and investigated, employing approaches such as elemental analysis, electronic, vibrational and proton NMR spectroscopy, flash photolysis, and cyclic voltammetry.

There is no evidence of self-aggregation of the porphyrin derivatives in pure water, however the addition of inorganic electrolytes to water solution induces aggregation in different extension, which depends on the nature of the electrolyte, the total ionic strength, and the benzylic substituent.

Studies of cyclic voltammetry show that the reduction potentials are directly dependent on the electron donor/acceptor characteristics of the benzylic substituent and of the coordinated metal ion.

All photophysical parameters investigated in homogeneous media are very similar through porphyrins and metalloporphyrins studied and are comparable to the model compound, the 5, 10, 15, 20-tetrakis(1-methylpyridinium-4-yl)porphyrin $\left(\mathrm{H}_{2} \mathrm{TMPyP}\right)$. Therefore, in micro-heterogeneous media, the new series of porphyrins presents some differences in the photophysical parameters, when compared to the model compound.

In conclusion, the present results reveal that these new cationic porphyrins can be useful as photosensitizers in photodynamic therapy. 


\section{ABREVIATURAS}

$\varepsilon$ absortividade por mol

deslocamento químico

força iônica do meio

velocidade de varredura (voltametria)

deformação angular entre os átomos $\mathrm{O} \mathrm{e} \mathrm{H}$

estiramento vibracional entre os átomos $\mathrm{O}$ e $\mathrm{H}$

rendimento quântico de formação de ${ }^{1} \mathrm{O}_{2}$

rendimento quântico de fluorescência

comprimento de onda de máxima absorção

rendimento quântico de fosforescência

tempo de vida do estado singlete

rendimento quântico de formação do estado triplete

tempo de vida do ${ }^{1} \mathrm{O}_{2}$

tempo de vida do estado triplete

albumina de soro bovino

brometo de hexadeciltrimetilamônio

$\mathrm{N}, \mathrm{N}$-dimetilformamida

dimetilsulfóxido

dimetilsulfóxido deuterado

ácido desoxiribonucleico

potencial redox ou de meia onda

potencial formal do eletrodo

potencial de pico anódico

potencial de pico catódico

eletrodo padrão de hidrogênio

energia do estado triplete

5,10,15,20-tetrakis(1-alilpiridínio-4-il)-porfirina

5,10,15,20-tetrakis(trimetilaminofenil)-porfirina

5,10,15,20-tetrakis(1-(4-bromo)benzilpiridínio-4-il)-
$\mathrm{H}_{2}$ TBuPyP
5,10,15,20-tetrakis (1-butilpiridírio-4-il)-porfirina
$\mathrm{H}_{2}$ TBzPyP
5,10,15,20-tetrakis (1-benzilpiridinio-4-il)-porfirina
$\mathrm{H}_{2} \mathrm{TCH}_{3}$ BzPyP
5,10,15,20-tetrakis(1-(4-metil)benzilpiridínio-4-il)-porfirina
$\mathrm{H}_{2} \mathrm{TClBzPyP}$
5,10,15,20-tetrakis(1-(4-cloro)benzilpiridínio-4-il)-porfirina 
$\mathrm{H}_{2}$ TCNBzPyP $\quad 5,10,15,20$-tetrakis(1-(4-ciano)benzilpiridínio-4-il)-porfirina

$\mathrm{H}_{2} \mathrm{TCO}_{2} \mathrm{HBzPyP} \quad 5,10,15,20$-tetrakis(1-(4-carbóxi)benzilpiridínio-4-il)porfirina

$\mathrm{H}_{2}$ TMeOBzPyP $\quad 5,10,15,20$-tetrakis(1-(4-metoxi)benzilpiridínio-4-il)porfirina

\begin{tabular}{|c|c|}
\hline $\mathrm{H}_{2}$ TMPyP & 5,10,15,20-tetrakis(1-metilpindínio-4-il)-porfirina \\
\hline $\mathrm{H}_{2} \mathrm{TMPyP}(2)$ & 5,10,15,20-tetrakis(1-metilpiridínio-2-il)-porfirina \\
\hline $\mathrm{H}_{2} \mathrm{TMPyP}(3)$ & 5,10,15,20-tetrakis(1-metilpiridínio-3-il)-porfirina \\
\hline $\mathrm{H}_{2} \mathrm{TNO}_{2} \mathrm{BzPyP}$ & 5,10,15,20-tetrakis(1-(4-nitro)benzilpiridínio-4-il)-porfirina \\
\hline $\mathrm{H}_{2}$ TOcPyP & 5,10,15,20-tetrakis(1-octilpiridínio-4-il)-porfirina \\
\hline $\mathrm{H}_{2}$ TPhEtPyP & 5,10,15,20-tetrakis(1-(2-fenil)etilpiridínio-4-il)-porfirina \\
\hline $\mathrm{H}_{2}$ TPhPrPyP & 5,10,15,20-tetrakis(1-(3-fenil)propilpiridínio-4-il)-porfirina \\
\hline $\mathrm{H}_{2} \mathrm{TPnPyP}$ & 5,10,15,20-tetrakis(1-pentilpiridinio-4-il)-porfirina \\
\hline $\mathrm{H}_{2}$ TPP & $5,10,15,20$-tetrakis(fenil)porfirina \\
\hline $\mathrm{H}_{2} \mathrm{TPPC}$ & 5,10,15,20-tetrakis(carboxifenil)-porfirina \\
\hline $\mathrm{H}_{2}$ TPPS & 5,10,15,20-tetrakis(sulfonatofenil)-porfirina \\
\hline $\mathrm{H}_{2}$ TPyP & 5,10,15,20-tetrakis(4-piridil)porfirina \\
\hline HOMO & orbital molecular ocupado de maior energia \\
\hline HSA & albumina de soro humano \\
\hline $\mathrm{i}_{\mathrm{a}}$ & corrente de pico anódico \\
\hline $\mathbf{i}_{c}$ & corrente de pico catódico \\
\hline IR & infravermelho \\
\hline $\mathrm{k}_{\mathrm{Q}}$ & constante de supressão \\
\hline LUMO & orbital molecular desocupado de menor energia \\
\hline MM & massa por mol \\
\hline MP & metaloporfirina reduzida por 4 elétrons \\
\hline $\mathrm{MP}^{2-}$ & metaloporfirina reduzida por 6 elétrons \\
\hline $\mathrm{MP}^{2+}$ & metaloporfirina reduzida por 2 elétrons \\
\hline $\mathrm{MP}^{4+}$ & metaloporfirina \\
\hline PDT & terapia fotodinâmica \\
\hline PTE & éter tridecilpolioxietileno(10) \\
\hline $\mathrm{RMN}^{-1} \mathrm{H}$ & Ressonância magnética nuclear de próton \\
\hline RNA & ácido ribonucleico \\
\hline $\mathrm{S}_{0}$ & estado fundamental singlete \\
\hline SCE & eletrodo saturado de calomelano \\
\hline SDS & dodecil sulfato de sódio \\
\hline$S_{n}$ & estado excitado singlete \\
\hline TEAP & perclorato de tetraetilamônio \\
\hline
\end{tabular}


$T_{n}$

Triton X100

UV

Vis estado excitado triplete

éter iso-octilfenilpolioxietileno(10)

ultravioleta

visivel

TERMINOLOGIA (porfirinas)

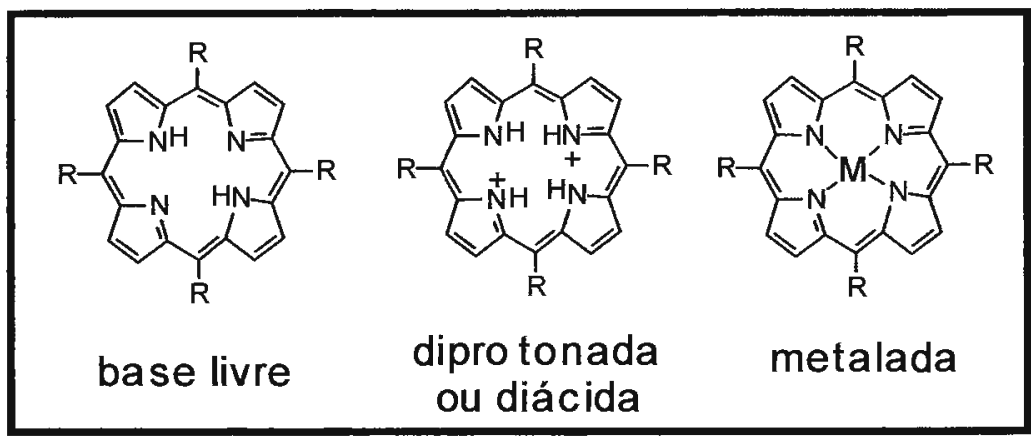

\section{ESTRUTURAS DAS PORFIRINAS ESTUDADAS}

$\mathrm{R}$

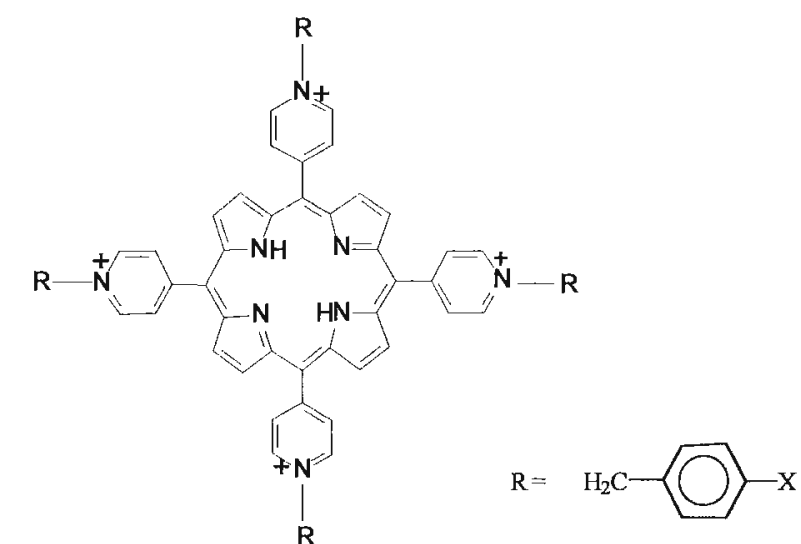

$-\mathrm{CH}_{3}$

$-\mathrm{CH}_{2} \mathrm{CHCH}_{2}$

$-\left(\mathrm{CH}_{2}\right)_{4} \mathrm{CH}_{3}$

$\mathrm{CH}_{2} \mathrm{CH}_{2}$

$-\mathrm{CH}_{2} \mathrm{CH}_{2} \mathrm{CH}_{2}$

$$
\mathrm{H}_{2} \text { TMPYP }
$$

$\mathrm{H}_{2}$ TAIPyP

$\mathrm{H}_{2}$ TPnPyP

$\mathrm{H}_{2}$ TPh Et PyP

$\mathrm{H}_{2}$ PhPrPyP
$\mathrm{X}=\mathrm{H}$

$\mathrm{X}=\mathrm{NO}_{2}$

$\mathrm{X}=\mathrm{CN}$

$\mathrm{X}=\mathrm{OCH}_{3}$

$\mathrm{X}=\mathrm{Cl}$

$\mathrm{X}=\mathrm{CO}_{2} \mathrm{H}$

$\mathrm{X}=\mathrm{Br}$

$\mathrm{X}=\mathrm{CH}_{3}$
$\mathrm{H}_{2}$ TBzPyP

$\mathrm{H}_{2} \mathrm{TNO}_{2}$ BzPyP

$\mathrm{H}_{2}$ TCNBzPyP

$\mathrm{H}_{2}$ TMeOBzPyP

$\mathrm{H}_{2}$ TClBzPyP

$\mathrm{H}_{2} \mathrm{TCO}_{2} \mathrm{HBzPyP}$

$\mathrm{H}_{2}$ TBrBzPyP

$\mathrm{H}_{2} \mathrm{TCH}_{3}$ BzPyP 
Índice

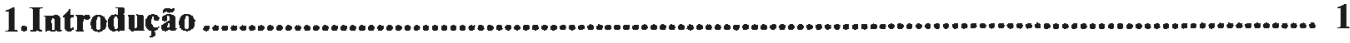

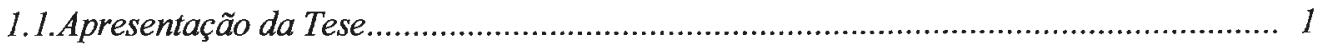

1.2.Considerações Gerais........................................................................................... 1

1.3.Aspectos Gerais da Sintese e Caracterização das Porfirinas Piridínio Substituídas........ 4

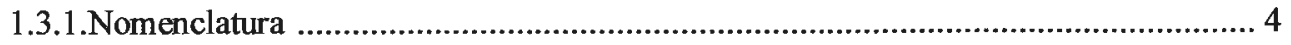

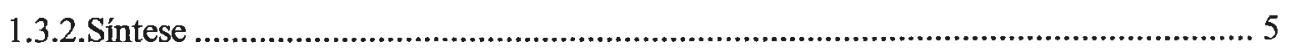

1.3.3.Espectros Eletrônicos de Absorção ............................................................ 8

1.3.4.Espectros Eletrônicos de Emissão ................................................................10

1.3.5.Formação de Homoagregados em Solução Aquosa ................................................16

1.3.6.Interação com Surfactantes .......................................................................... 22

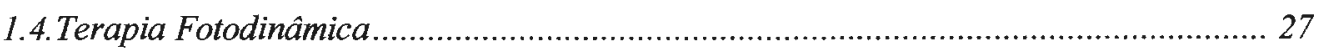

1.4.1.Sistemas Carregadores de Drogas (Drug Delivery Systems) ............................... 29

1.4.2.Interação com Ácidos Nucleicos ..................................................................31

1.5.Pares Iônicos entre Complexos Porfirinicos....................................................... 33

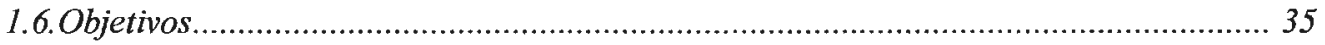

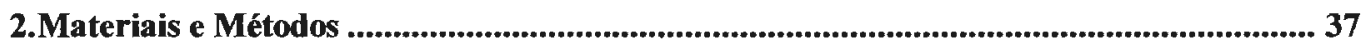

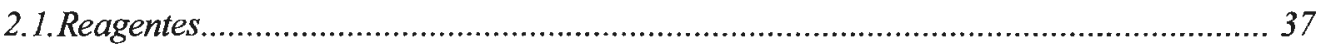

2.2.Síntese das porfirinas e metaloporfirinas ........................................................ 39

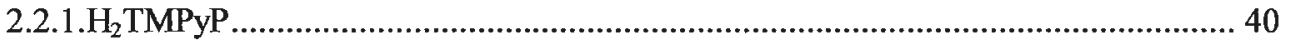

2.2.2. $\mathrm{H}_{2} \mathrm{TBz}$

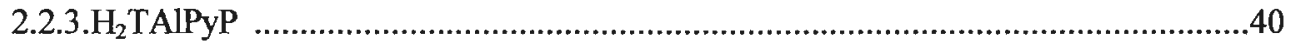

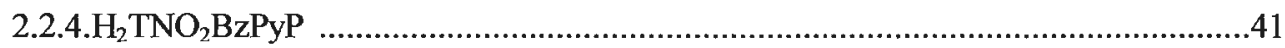

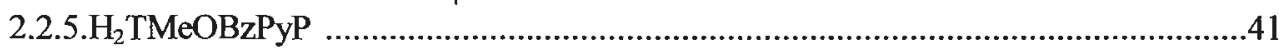

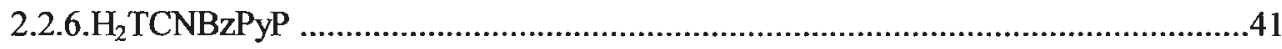

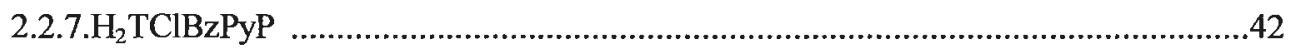

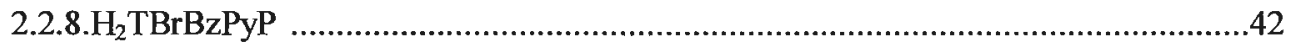

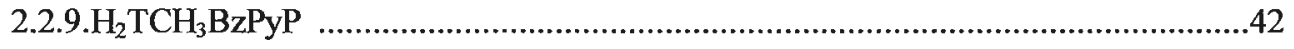

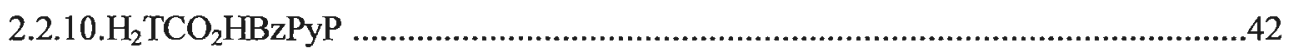

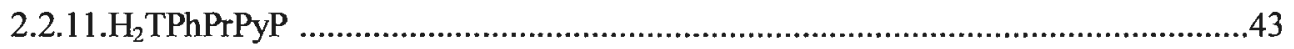

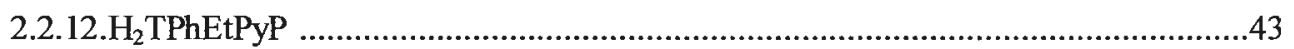

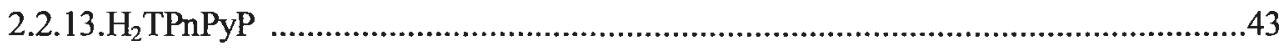

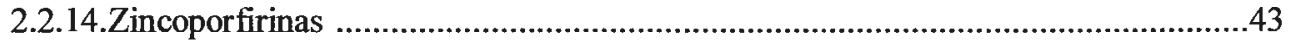

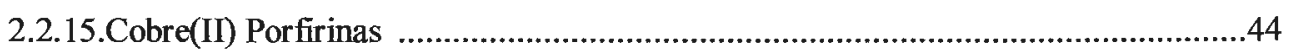

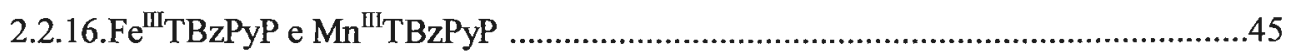

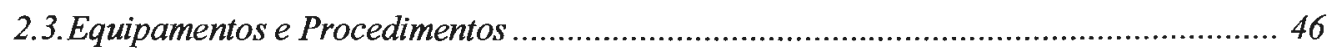


2.3.1.Espectroscopia Eletrônica ....................................................................................46

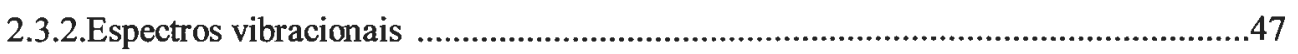

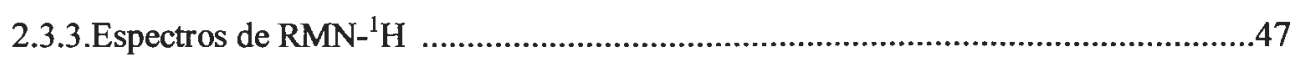

2.3.4.Eletroquímica .......................................................................................................48

2.3.5.Fotólise por Pulso de Laser (Flash Photolysis) ......................................................48

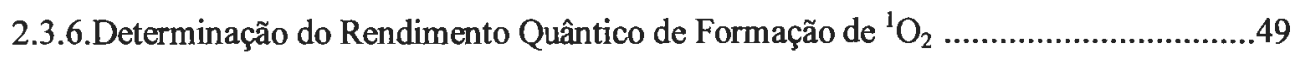

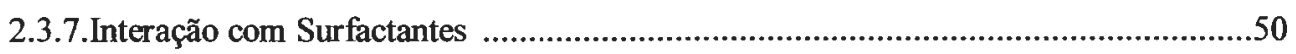

2.3.8.Interação com Antraquinona-2-sulfonato de sódio ................................................52

3.Resultados e Discussão .....................................................................................................53

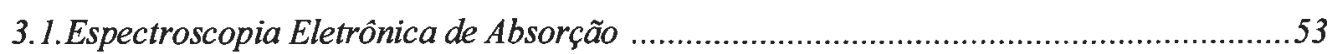

3.1.1.Comportamento Dependente dos Ânions Presentes em Solução ...............................59

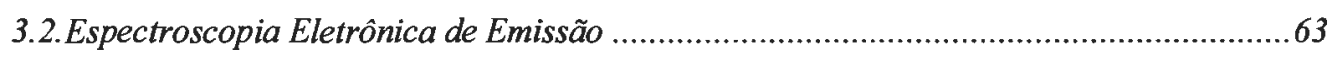

3.2.1.Emissão das Bases Livres em Solventes Orgânicos .................................................65

3.2.2.Emissão das Zincoporfirinas .............................................................................68

3.2.3. Determinação do Rendimento Quântico de Fluorescência Relativo $\left(\Phi_{\mathrm{F}}\right)$...................70

3.2.4.Perfil espectral de soluç̃es diluídas em solução aquosa ............................................73

3.2.5.Emissão em soluções congeladas ..........................................................................77

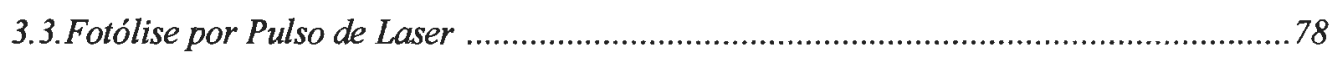

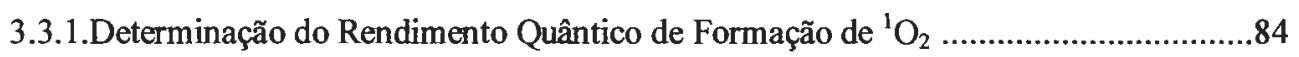

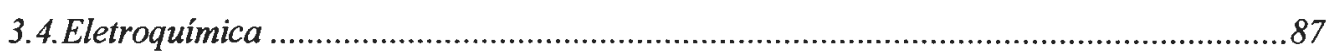

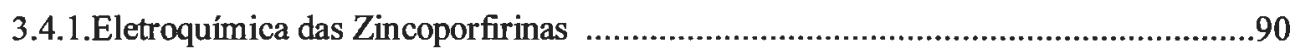

3.4.2.Eletroquímica das Cobreporfirinas ...................................................................95

3.4.3.Eletroquímica das Bases Livres ......................................................................99

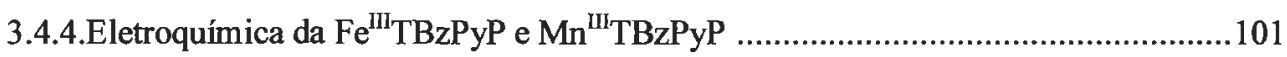

3.5. Espectroscopia Vibracional (I.R. e Raman Ressonante) ............................................. 104

3. 6. Ressonância Magnética Nuclear $\left(\mathrm{RMN}^{-1} \mathrm{H}\right)$........................................................111

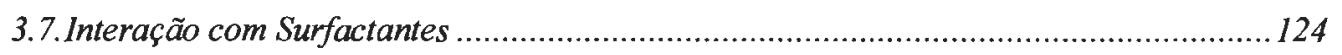

3.7.1.Espectros Eletrônicos de Absorção ……………................................................126

3.7.2.Espectros Eletrônicos de Emissão ..........................................................................136

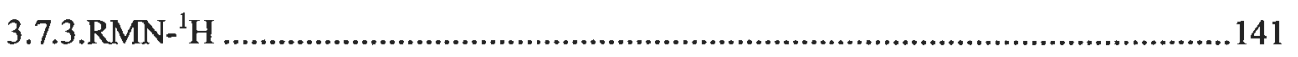

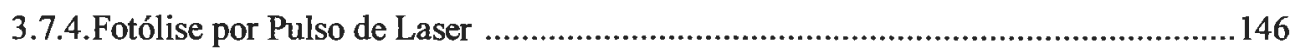

3.7.5.Determinação de Rendimento Quântico de Formação de ${ }^{1} \mathrm{O}_{2}$................................149

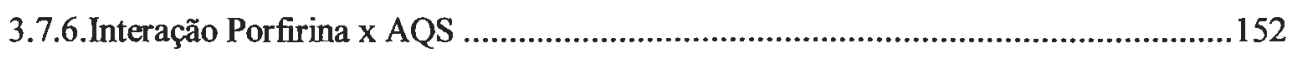

4.Considerações Finais ...................................................................................................155

5.Referências Bibliográficas ....................................................................................159 


\section{Introdução}

\subsection{Apresentação da Tese}

Essa Tese de Doutoramento está organizada em quatro capítulos: Introdução, Materiais e Métodos, Resultados e Discussões e Considerações Finais.

$\mathrm{Na}$ Introdução, é feita uma pequena revisão da química recente das porfirinas aquossolúveis meso substituídas, destacado-se o comportamento espectroscópico e de agregação em solução aquosa da $\mathrm{H}_{2}$ TMPyP e seus complexos metálicos. Em seguida, há um breve resumo sobre a aplicação dessas porfirinas em sistemas de terapia fotodinâmica.

Em Materiais e Métodos, são descritos os procedimentos para a obtenção das porfirinas e metaloporfirinas estudadas. Os métodos e aparelhos utilizados para a caracterização fotofísica, eletroquímica e espectroscópica e o estudo da interação dessas porfirinas com surfactantes são detalhados também nessa seção.

O capítulo Resultados e Discussões apresenta os resultados obtidos nos estudos de espectroscopia de absorção, emissão, fotólise por pulso de laser, rendimento quântico de formação de oxigênio singlete $\left({ }^{1} \mathrm{O}_{2}\right)$, espectroscopia vibracional no infravermelho, espectroscopia raman ressonante, eletroquímica, RMN${ }^{1} \mathrm{H}$ e interação com surfactantes. A discussão dos resultados é feita paralelamente à apresentação dos resultados, em cada item da seção.

No capítulo Considerações Finais procurou-se apresentar uma síntese dos resultados obtidos e propor algumas possibilidades de novos estudos, fundamentados nas propriedades apresentadas pelas porfirinas estudadas nesse trabalho.

\subsection{Considerações Gerais}

As interações entre as porfirinas e metaloporfirinas aquossolúveis e biomoléculas têm sido largamente estudadas, sendo inúmeras as possibilidades de aplicações foto e quimioterápicas. As singulares propriedades apresentadas por essas porfirinas meso substituídas eletricamente carregadas, tais como alta estabilidade química, longos tempos de vida do estado triplete ${ }^{1,2}$, alta absorção de luz na região do visível $^{3}$, alto rendimento quântico de formação de $\mathrm{O}_{2}$ singlete ${ }^{4,5}$, formação de agregados com macromoléculas a partir de interação eletrostática e hidrofóbica ", potenciais redox adequados para sistemas que envolvam transferência de elétrons e/ou energia ${ }^{199}$, têm sido responsáveis por incontáveis aplicações em estudos in vitro $e$ in vivo com finalidade terapêutica. 
Além disso, muitos sistemas supramoleculares que apresentam porfirinas carregadas têm sido estudados como modelos de processos biológicos importantes que envolvem a transferência de elétrons elou energia, como o special pair do sistema fotossintético ${ }^{10}$, o citocromo P450 e outros.

Dentre as porfirinas e metaloporfirinas aquossolúveis sintéticas, destacam-se duas classes: as derivadas da $\mathrm{H}_{2}$ TPP e $\mathrm{H}_{2}$ TPyP (figura 1).

As porfirinas derivadas da $\mathrm{H}_{2}$ TPP apresentam substituintes iônicos ligados ao grupo fenil, tais como carbóxi, sulfonato (aniônicos) e anilínio (catiônicos).

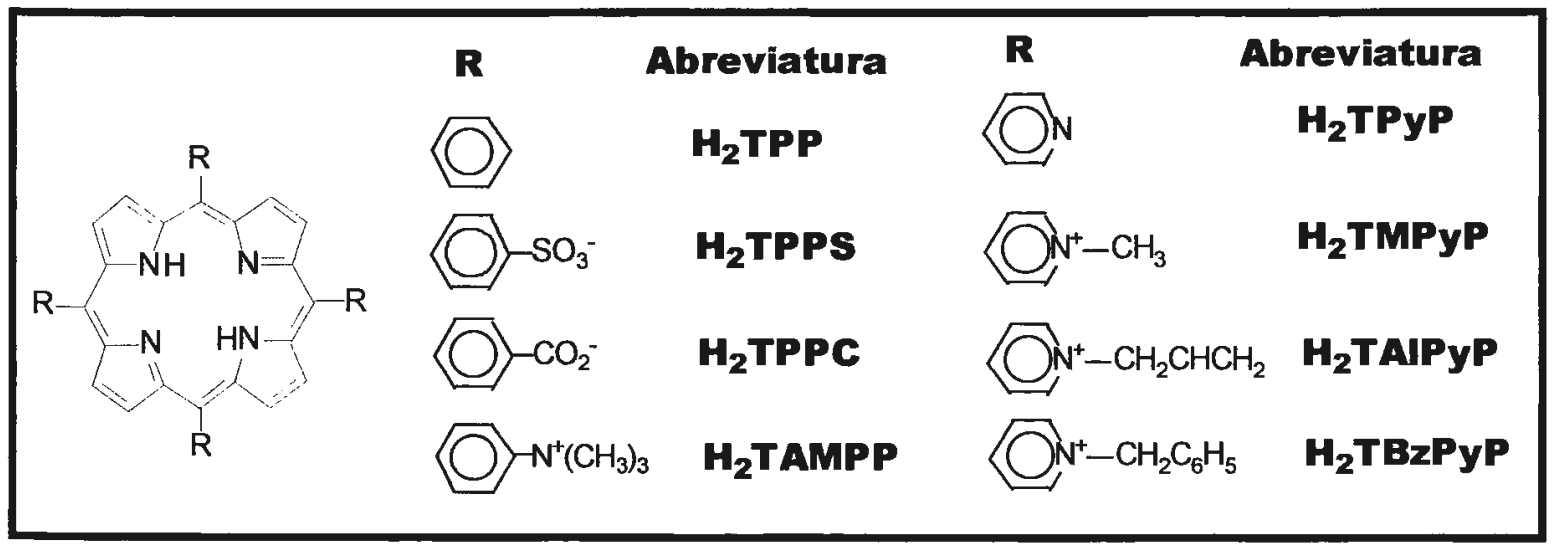

figura 1: Estrutura da $\mathrm{H}_{2}$ TPP, $\mathrm{H}_{2}$ TPyP e seus derivados com substituintes iônicos.

A inserção da carga no substituinte periférico permite a solubilidade da porfirina em água e solventes polares, entretanto, não se verifica mudanças drásticas nas propriedades eletroquímicas, espectroscópicas e fotofísicas, sendo essas similares às da $\mathrm{H}_{2}$ TPP $^{11}$. Esses resultados evidenciam a não ocorrência de uma interação significativa das cargas peniféricas com a estrutura eletrônica do macrociclo.

A solubilidade em água do derivados aniônicos $\left(\mathrm{H}_{2}\right.$ TPPC e $\mathrm{H}_{2}$ TPPS) é limitada pelo $\mathrm{pH}$ do meio, pois tanto o grupo carbóxi como o grupo sulfonato podem ser protonados, originando a respectiva forma não iônica ${ }^{12}$. É bastante conhecida a tendência desses derivados formar agregados em solução aquosa ${ }^{12}{ }^{13}$.

As porfirinas derivadas da $\mathrm{H}_{2}$ TPyP apresentam substituintes alquílicos ligados aos nitrogênios piridínicos, formando os respectivos piridínios.

Esta classe origina compostos catiônicos, sendo que a quase totalidade dos estudos foram realizados com a $\mathrm{H}_{2}$ TMPyP e seus complexos metálicos.

A aquossolubilidade destas porfirinas é independente do $\mathrm{pH}$ do meio ${ }^{12}$, exceção feita a condições excessivamente ácidas que podem ocasionar a clivagem da ligação nitrogênio-carbono do grupo piridínio.

As porfininas piridínio substituídas apresentam alterações nas propriedades eletroquimicas, espectroscópicas e fotofísicas significativas quando comparadas à 
$\mathrm{H}_{2}$ TPyP, indicando que ocorre uma interação acentuada entre as cargas periféricas e o macrociclo porfirínico ${ }^{1,11}$.

Essa interação implica em uma menor densidade eletrônica no anel porfirínico, influenciando nas propriedades do macrociclo. Analisando o equilíbrio de protonação dos nitrogênios pirrólicos internos pode-se fazer uma avaliação da densidade de carga do anel. Os valores de $\mathrm{pK}_{\mathrm{a} 3}$ e $\mathrm{pK}_{\mathrm{a} 4}$, que correspondem ao equilíbrio protonação/desprotonação do terceiro e do quarto nitrogênio pirrólico, da $\mathrm{H}_{2} \mathrm{TMPyP}$ são muito menores dos verificados para a $\mathrm{H}_{2} \mathrm{TPyP}^{14,15}$ e para os derivados $\mathrm{H}_{2}$ TPPS e $\mathrm{H}_{2}$ TMAPP $^{11}$. Essa baixa afinidade do anel pelos íons $\mathrm{H}^{+}$indica uma menor densidade eletrônica no macrociclo.

Os valores de $E_{1 / 2}$ de redução do anel porfirínico também estão realacionados com a densidade eletrônica do macrociclo. $A \mathrm{H}_{2}$ TMPyP e seus metalo derivados apresentam potenciais de redução cerca de $1,0 \mathrm{~V}$ mais positivos que os respectivos derivados da $\mathrm{H}_{2}$ TPyP e $\mathrm{H}_{2}$ TPP sob as mesmas condições experimentais ${ }^{16,17,18,19}$. A diferença entre os derivados da $\mathrm{H}_{2}$ TPPe da $\mathrm{H}_{2}$ TPPS são de cerca de $0,05 \mathrm{~V}$.

Outro fator importante é que enquanto a redução das maioria das porfirinas ocorre em duas etapas envolvendo 1 elétron a redução do anel da $\mathrm{H}_{2}$ TMPyP ocorre em uma etapa apenas envolvendo 2 elétrons ${ }^{16,17}$.

Uma das propostas para explicar este fenômeno é que esta interação ocorre pela delocalização da carga positiva dos átomos de nitrogênio dos grupos piridínios até o macrociclo porfirínico ${ }^{20}$, através de estruturas de ressonância como indicado na figura abaixo.

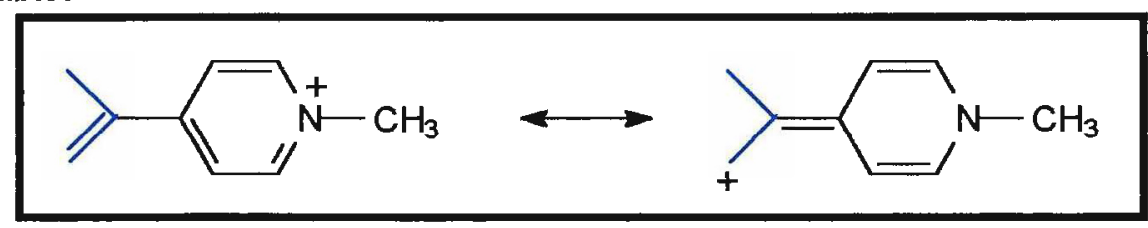

figura 2: Estruturas de ressonância mostrando a delocalização da carga positiva do grupo piridínio para o macrociclo porfirínico. As ligações entre o carbono meso e os pirróis encontram-se representadas em azul.

Recentemente foi mostrado que a substituição dos grupos metílicos ligados aos nitrogênios piridínicos da $\mathrm{H}_{2}$ TMPyP por outros grupos alquílicos (benzil e alil) origina alterações espectroscópicas, fotofísicas e eletroquímicas, na base livre e nos respectivos zinco e paládio complexos ${ }^{21,22}$. Estas alterações devem-se, provavelmente, a efeitos eletrônicos originados pelos grupos alquílicos sobre as cargas positivas localizadas nos nitrogênios piridínicos. Outro ponto importante é que a presença de grupos alquílicos mais volumosos aumenta o grau de hidrofobicidade da molécula, o que modifica o comportamento quanto à interação da metaloporfirina 
com moléculas de interesse biológico e surfactantes sintéticos ${ }^{7,21,23}$, assim como nas características de interação eletródica ${ }^{21}$.

\subsection{Aspectos Gerais da Síntese e Caracterização das Porfirinas Piridínio Substituídas}

Essa seção não tem como objetivo esgotar todas as propriedades das porfirinas piridínio substituídas e seus metaloderivados, visto que a tarefa é grandiosa demais. Entretanto, procura-se fornecer alguns subsídios para um melhor entendimento dos estudos realizados no presente trabalho.

Cada item, portanto, procura ser sucinto e direto para introduzir dados da literatura relacionados às discussões dos resultados experimentais obtidos. Sempre que oportuno são sugeridos textos que abordam de maneira mais completa a química das porfirinas.

\subsubsection{Nomenclatura}

As porfirinas são estruturas encontradas em diversas proteínas, agindo como cofatores de sistemas biológicos. Nos seres vivos diversos processos bioquímicos são realizados por proteínas associadas a porfirinas: transporte de $\mathrm{O}_{2}$ (hemoglobina), armazenamento de $\mathrm{O}_{2}$ (mioglobina), respiração celular, cadeia de transporte de elétrons (citocromo C), catálise de reações de hidroxilações e epoxidações (citocromo $\mathrm{P}-450$ ), decomposição de peróxidos (catalase). Textos gerais sobre a importância dos derivados porfirínicos nas diversas etapas do metabolismo bioquímico, bem como o mecanismo de biossíntese desses derivados são encontrados em livros básicos de bioquímica $^{24,25}$.

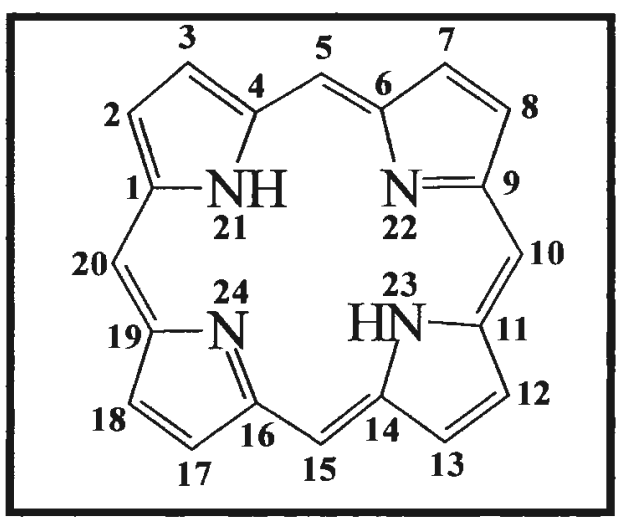

figura 3: Estrutura da porfina e numeração do anel segundo a IUPAC ${ }^{26}$.

As porfirinas são compostos que apreseritam um macrociclo central contendo 20 átomos de carbonos e 4 átomos de nitrogênio, denominado porfina, e grupos substituintes ao redor deste anel. A figura 3 apresenta a estrutura da porfina e a numeração sugerida pela IUPAC. As porfirinas que apresentam átomos de hidrogênio 
ligados aos nitrogênios 21 e 23 são chamadas "base livre"; a substituição dos hidrogênios por um metal que será coordenado pelos quatro nitrogênios é denominada metaloporfirina. A incorporação de dois prótons aos nitrogênios 22 e 24 origina a forma diácida.

As porfirinas naturais são substituídas, principalmente, por resíduos metil, etil, vinil, acetil e propionil, ligados nas posições $2,3,7,8,12,13,17$ e 18. As porfirinas encontradas em seres vivos são geralmente metaloporfirinas, sendo 0 ion $\mathrm{Fe}^{3+} 0$ centro metálico mais comum. Por se tratarem de porfirinas assimétricas as rotas sintéticas para obtenção destas são extremamente complicadas, restando a alternativa de extração de material biológico, o que implica em diversas etapas de purificação.

Entretanto, a sintese de porfirinas simetricamente substituídas por grupos fenil ou piridil nas posições $5,10,15,20$ (ou posição meso) permitiu a expansão de estudos com porfirinas sintéticas. A síntese desses derivados se dá a partir da condensação de quatro anéis de pirrol com quatro moléculas de benzaldeído $\left(\mathrm{H}_{2} T P P\right)^{27,28}$ ou com quatro moléculas de 4-piridinacarboxaldeído $\left(\mathrm{H}_{2} \mathrm{TPyP}\right)^{27}$.

A reação da $\mathrm{H}_{2}$ TPyP com p-tolueno sulfonato de metila (tosilato de metila) em $\mathrm{DMF}^{12,21}$, origina a porfirina catiônica 5,10,15,20-tetrakis(1-metilpiridínio-4-il)porfirina, ou meso-tetrametil(4-piridínio)porfirina ou ainda $\mathrm{H}_{2}$ TMPyP.

\subsubsection{Síntese}

A obtenção das porfirinas tetraalquil piridínio substituídas se dá a partir da reação de quaternização dos nitrogênios piridínicos, utilizando eletrófilos adequados, geralmente haletos ou tosilatos de alquila. A reação pode ser classificada como uma reação de substituição nucleofilica.

Dois produtos secundários podem ser formados nessa reação, porfirinas semialquiladas, ou seja aquelas que apresentam nitrogênios piridínicos não alquilados e porfirinas $\mathrm{N}$-pirrol alquiladas, com o nitrogênio pirrólico interno sendo alquilado. $\mathrm{A}$ figura 4 mostra a possibilidade dos três produtos.

A formação do produto $\mathrm{N}$-pirrol alquilado só ocorre em condições reacionais drásticas, uma vez que o nitrogênio pirrólico é pior nucleófilo que o nitrogênio piridínico, pois o par de elétrons desemparelhado do nitrogênio no pirrol está comprometido com a aromaticidade do anel, enquanto que o nitrogênio piridinico possui um par de elétrons livre ${ }^{29,30}$. Desse modo, esse produto só se forma na presença de agentes alquilantes muito reativos, que apresentam um bom grupo de partida e a formação de um carbocátion estável ${ }^{31,32}$. Reações entre porfirinas piridil porfiririas assimétricas com brometo de benzila em DMF resultam na formação de 
produtos $\mathrm{N}$-pirrol alquilados ${ }^{33}$, entretanto, a reação da $\mathrm{H}_{2} \mathrm{TPyP}$ com cloreto de benzila em DMF não apresenta nenhuma evidência de alquilação do nitrogênio pirrólico ${ }^{21,22}$.

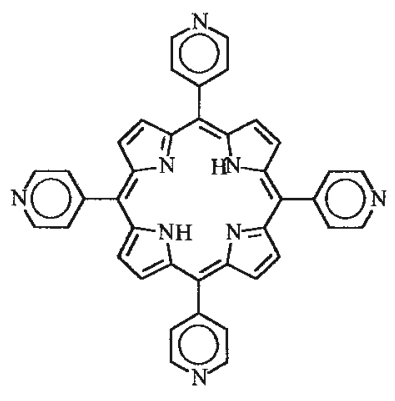

TPyP

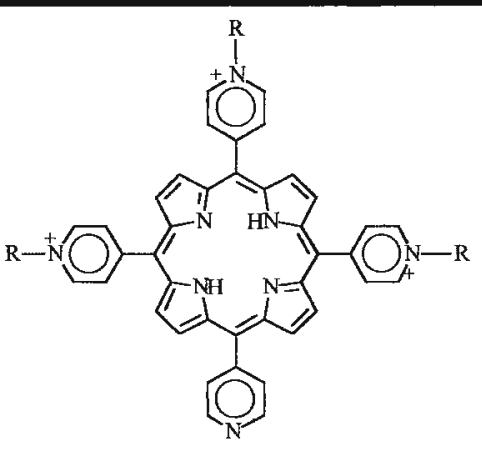

Porfirina semi alquilada

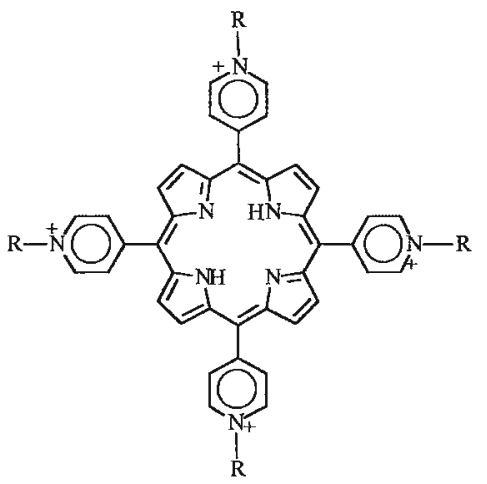

Porfirina tetraalquilada

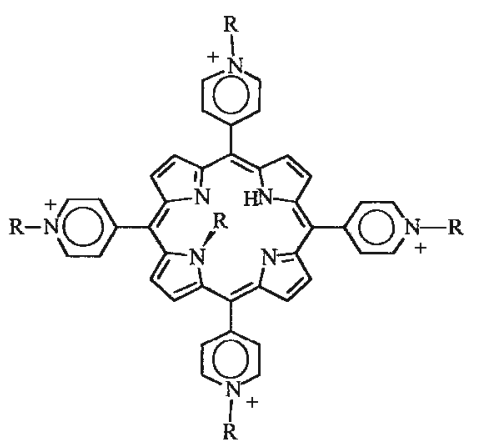

Porfirina N pirrol alquilada

figura 4: Reação de alquilação da $\mathrm{H}_{2}$ TPyP: formação das porfirinas semialquilada, tetraalquilada e $\mathbf{N}$-pirrol alquilada.

A formação de porfirinas semi-alquiladas pode ser evitada prolongando-se o tempo de reação, aumentando-se a temperatura da reação, o excesso do alquilante ou a concentração dos reagentes. Estas condições permitem um maior número de choques eritre o anel piridínico e o alquilante, facilitando a ocorrência de um choque efetivo e a conseqüente alquilação.

Em trabalho anterior ${ }^{22}$, desenvolvido neste laboratório, foram estudadas diversas condições experimentais, variando-se tempo de reação, solvente, 
concentração dos reagentes e grupos de partida, conseguindo-se otimizar as condições de reação para a obtenção de porfirinas benzil piridínio substituídas. Essas condições também se mostraram aplicáveis para as demais porfirinas piridínio substituídas, aumentando o rendimento da reação e a pureza do produto obtido.

O solvente mais adequado para a reação de alquilação da $\mathrm{H}_{2}$ TPyP é o DMF. Esse solvente polar aprótico possibilita uma boa solvatação das espécies intermediárias carregadas, sendo adequado para reaçōes de substituição nucleofílica tanto pelo mecanismo $S_{N} 1$ (unimolecular), como para o mecanismo $S_{N} 2$ (bimolecular) 31,32 .

Entretanto, o DMF é um solvente instável, que se decompõe facilmente em temperaturas acima de $50^{\circ} \mathrm{C}$ e na presença de luz ${ }^{34}$. Os produtos provenientes dessa decomposição dificultam o isolamento da porfirina tetraalquilada, resultando em um rendimento baixo ${ }^{22}$.

A condição reacional que apresenta um melhor rendimento de porfirina tetraalquilada está sumarizada nos itens abaixo ${ }^{22}$ :

- temperatura de reação ao redor de $130^{\circ} \mathrm{C}$, pois reações realizadas em refluxo de DMF apresentam uma decomposição do solvente consideravelmente maior, baixando o rendimento da reação, enquanto que reações realizadas em temperaturas abaixo de $100^{\circ} \mathrm{C}$ não produzem um rendimento de porfirinas tetraalquilada razoável;

- concentração da $\mathrm{H}_{2}$ TPyP entre 1 e $3 \mathrm{mmol} \mathrm{dm}^{-3}$, concentrações inferiores prolongam o tempo de reação, aumentando a decomposição do solvente e dificultando o isolamento do produto principal, enquanto que concentrações superiores acarretam em precipitação da porfirina durante a reação, obtendo-se quantidade considerável do produto semi alquilado;

- excesso do alquilante entre 160 a 300 vezes, dependendo da reatividade do mesmo, procurando-se terminar a reação o mais rápido possível. Entretanto, vale lembrar que o excesso de alquilante dificulta o isolamento da porfirina tetraalquilada devido sua solubilidade no agente alquilante;

- o DMF utilizado deve ser recém destilado, após tratamento com $\mathrm{CuSO}_{4}$ anidro, e armazenado sob atmosfera inerte em geladeira. A reação deve ser realizada no escuro, evitando-se a decomposição do DMF.

O produto isolado nessas condições reacionais pode ser purificado a partir de recristalizações em mistura metanol/éter dietílico, não sendo necessária a preparação de colunas de separação, obtendo-se um produto compatível com a porfirina tetraalquilada, de acordo com a análise elementar e $\mathrm{RMN}^{-1} \mathrm{H}$. 
Quanto a reatividade do agente alquilante, demonstrou-se um comprometimento entre a estabilidade do carbocátion e o grupo de partida (haleto) escolhido. Desse modo, deve-se utilizar cloretos de benzila p-substituídos no caso de grupos doadores de elétrons como metóxi, metil e o próprio benzil não substituído que apresentam, portanto, maior estabilidade do carbocátion. A utilização de brometo nesses casos pode levar à formação de porfirinas $\mathrm{N}$-pirrol alquiladas. Para os substituintes benzílicos aceptores de elétrons como cloro, bromo, carbóxi, nitro e ciano, deve-se utilizar o respectivo brometo. O cloreto de p-nitrobenzila, por exemplo, não é reativo o suficiente para obtenção do produto tetraalquilado com pureza e rendimento satisfatórios ${ }^{22}$.

\subsubsection{Espectros Eletrônicos de Absorção}

O objetivo dessa seção é apenas familiarizar o leitor aos termos básicos e às atribuições usuais dos espectros eletrônicos de porfirinas meso substituídas, para um resumo mais completo da teoria indica-se algumas teses ${ }^{21,35,36}$ e publicações ${ }^{37,38}$ que tratam o tema de maneira mais detalhada.

O espectro eletrônico de porfirinas meso substituídas na forma base livre apresenta, usualmente, cinco bandas características. A mais intensa, a banda Soret ${ }^{36}$, possui máximo de absorção entre de 410 e $450 \mathrm{~nm}$. Essa banda é também designada como banda $\mathrm{B}(0,0)$ e apresenta, no caso das porfirinas piridínio substituídas, absortividades por mol $(\varepsilon)$ na ordem de $2 \times 10^{5} \mathrm{~cm}^{-1} \mathrm{~mol}^{-1} \mathrm{dm}^{3}$. As demais bandas apresentam máximos de absorção na região entre 500 e $650 \mathrm{~nm}$ e absortividades cerca de dez vezes menores que a da banda Soret. Essas bandas são denominadas, genericamente, bandas $Q$ e são, na ordem decrescente de energia, $Q y(1,0), Q y(0,0)$, $Q \times(1,0), Q \times(0,0)$.

As cinco bandas têm origem na transição $\pi^{*} \leftarrow \pi$ e devem-se à simetria das bases livres $\left(D_{2 h}\right)^{21,36}$. As metaloporfirinas e porfirinas diprotonadas possuem uma maior simetria $\left(D_{4 h}\right)$, e um número menor de bandas $Q$ : $Q(1,0)$ e $Q(0,0)$, na ordem decrescente de energia.

O modelo dos quatro orbitais de fronteira de Gouterman ${ }^{35,37}$ atribui à banda Soret a transição do orbital molecular ocupado de alta energia (HOMO), $a_{1 u}$, para o orbital molecular desocupado de menor energia (LUMO), $e_{g}$, enquanto que as bandas $Q$ para a simetria $D_{4 h}$ são atribuídos às transições do orbital $a_{2 u}$ para os níveis vibracionais 0 e 1 do orbital excitado $e_{g}$, resultando em duas bandas $Q$ (ver figura 5). Com a perda de simetria observada nas bases livres, passando para $D_{2 h}$, há 0 desdobramento da transição $e_{g} \leftarrow a_{2 u}$, formando as transições $b_{3 g} \leftarrow b_{1 u}$, referente ao eixo y e $b_{2 g} \leftarrow b_{1 u}$ referente ao eixo $x$. 


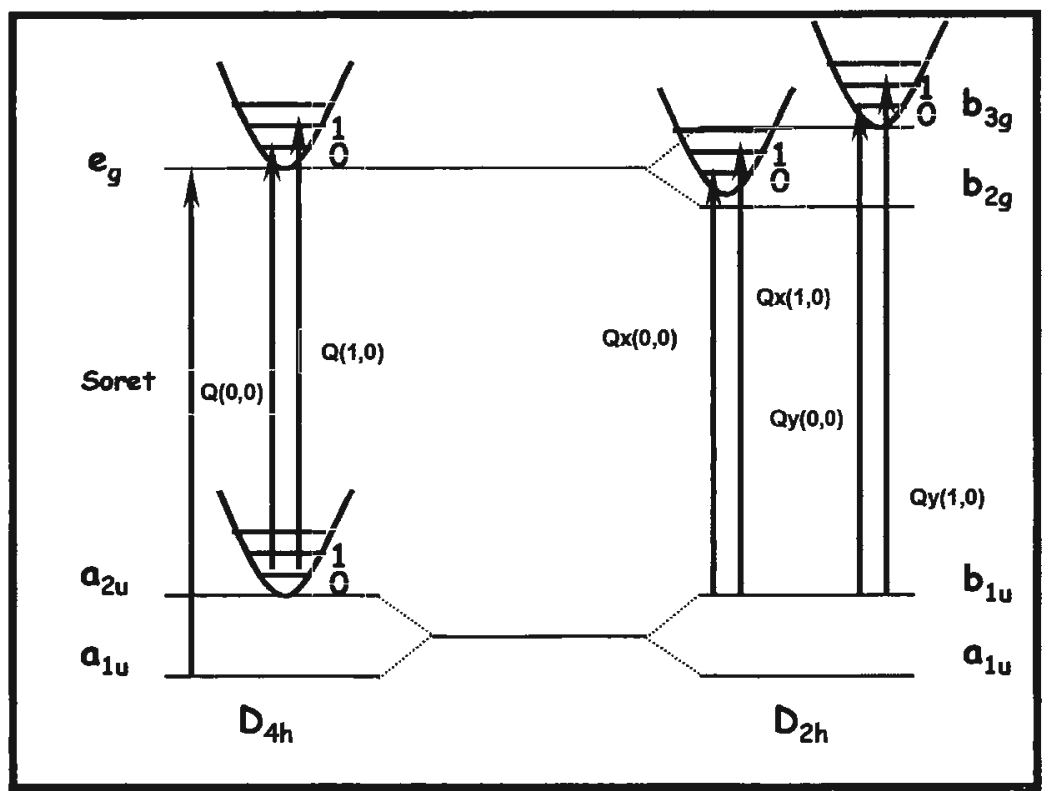

figura 5: Representação esquemática das transiçōes entre os diferentes níveis eletrônicos e vibracionais de porfirinas $\left(D_{2 h}\right)$ e metaloporfirinas $\left(D_{4 h}\right)^{21}$.

Analisando as densidades eletrônicas dos orbitais HOMO, $a_{1 u}$ e $a_{2 u}$, e do orbital LUMO, $e_{g}$, nota-se que as transições LUMO $\leftarrow$ HOMO resultam no deslocamento da densidade eletrônica do centro para a periferia do anel, ou seja mudanças estruturais que representem uma expansão do sistema $\pi$ devem resultar em deslocamentos das bandas para a região do vermelho. A inserção de ions metálicos pouco eletronegativos, como o zinco(II), por exemplo, também vão resultar em deslocamentos batocrômicos da banda Soret (ver figura 7).

As porfininas meso substituídas $\mathrm{H}_{2}$ TPP e $\mathrm{H}_{2}$ TPyP apresentam espectro do tipo etio $^{36}$, em que as intensidades relativas das bandas $Q$ seguem a ordem $Q y(1,0)>Q y(0,0)>Q x(1,0)>Q x(0,0)$. Entretanto, os derivados catiônicos $H_{2} T M A P P$, $\mathrm{H}_{2}$ TMPyP, $\mathrm{H}_{2}$ TBzPyP e $\mathrm{H}_{2}$ TAIPyP apresentam espectro em meio aquoso do tipo phyllo, no qual as interações relativas das bandas $Q$ são: $Q y(1,0)>Q x(1,0)>Q y(0,0)>Q x(0,0)$. A figura 6 apresenta os perfis espectrais encontrados das bandas $Q$ de porfirinas na forma base livre.

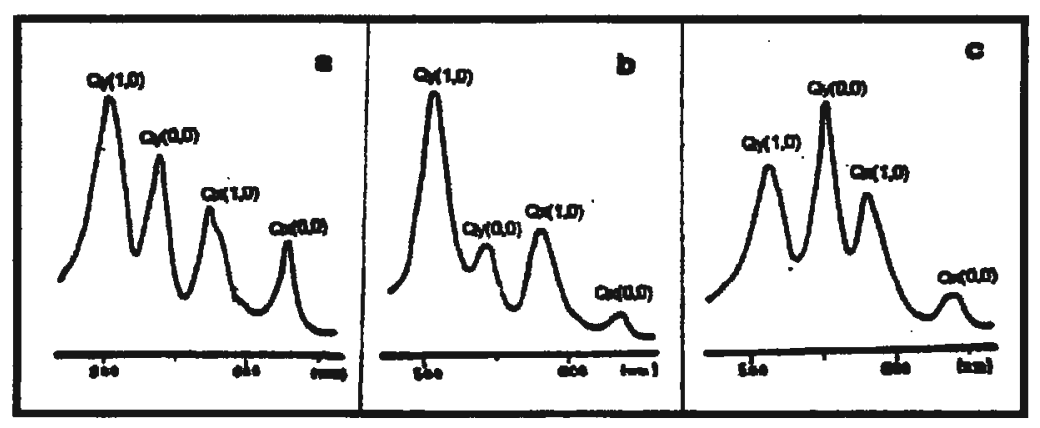

figura 6: Exemplos de espectros tipo: a- etio; b- phyllo; c- rhodo ${ }^{36}$. 


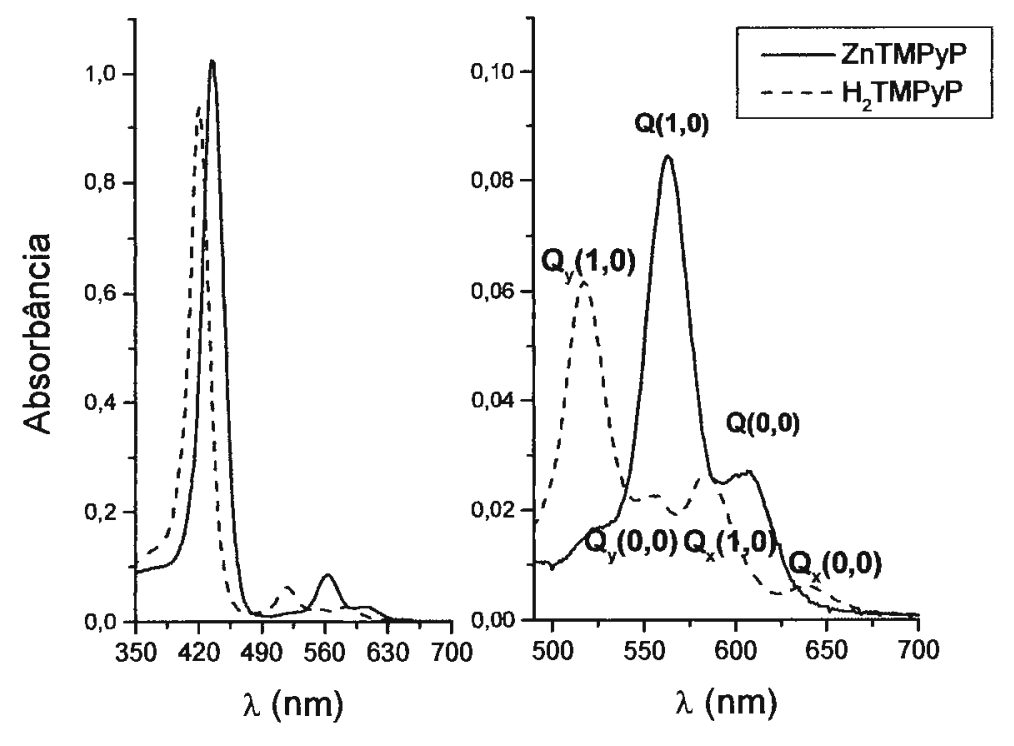

figura 7: Espectros eletrônicos da ZnTMPyP e da $\mathrm{H}_{2}$ TMPyP em água.

As porfirinas piridínio substituidas $\mathrm{H}_{2} \mathrm{TMPyP}^{39}, \mathrm{H}_{2}, \mathrm{H}_{2}$ TBzPyP e $\mathrm{H}_{2}$ TAIPyP $^{21}$ apresentam significativa mudança do perfil do espectro de absorção em solução aquosa na região das bandas $Q$ quando dissolvidas em solventes orgânicos polares como metanol, DMF e DMSO ou mistura desses solventes com água. $A$ intensidade relativa das bandas $Q_{y}(0,0)$ e $Q_{x}(1,0)$ modifica-se, apresentando o perfil etio, além disso há uma maior separação entre bandas $Q_{y}$ e $Q_{x}$. $A$ adição de surfactantes aniônicos como o SDS em concentrações acima da $\mathrm{cmc}$ também apresenta essa variação das bandas de absorção.

\subsubsection{Espectros Eletrônicos de Emissão}

Após a absorção de luz por uma molécula, o estado excitado formado pode ser desativado por diversos caminhos, retornando ao estado fundamental, mais estável e de menor energia. Os processos de decaimento energético podem ser classificados em radioativos, com emissão de luz, e não radioativos, havendo apenas liberação de calor $^{41,42}$

À temperatura ambiente os elétrons estão preferencialmente no estado vibracional mais baixo do estado fundamental singlete $\left(S_{0}\right)$. Com a absorção de energia ocorrem transições para niveis vibracionais mais altos $(1,2, \ldots, n)$ dos estados excitados singlete $\left(S_{1}, S_{2}, \ldots, S_{n}\right)$. Em seguida, a energia térmica é dissipada, atingindose o nível vibracional mais baixo do estado excitado $S_{1}$, em um processo chamado de conversão interna.

Nesse momento, várias etapas podem ocorrer simultaneamente. A desativação do estado excitado acontece em duas vias: uma transição térmica (não radioativa) 
$S_{1} \rightarrow S_{0}$ (conversão interna) e uma transição radioativa com emissão de luz $S_{1} \rightarrow S_{0}$, chamada fluorescência. Essa transição pode ocorrer para um nível vibracional do estado fundamental diferente de zero, originando diferentes bandas no espectro de emissão.

Há ainda a possibilidade de ocorrer uma transição proibida, uma transição entre estados de multiplicidade diferentes, ou seja uma transição singlete-triplete, geralmente $S_{1} \rightarrow T_{1}$. Essa etapa é denominada de cruzamento inter sistemas. O estado $T_{1}$ também pode ser depopulado pela via não radioativa (conversão interna) ou ainda em um processo com emissão de luz, chamado fosforescência. Todo esse processo é ilustrado pelo diagrama de Jablonski simplificado apresentado na figura 8 .

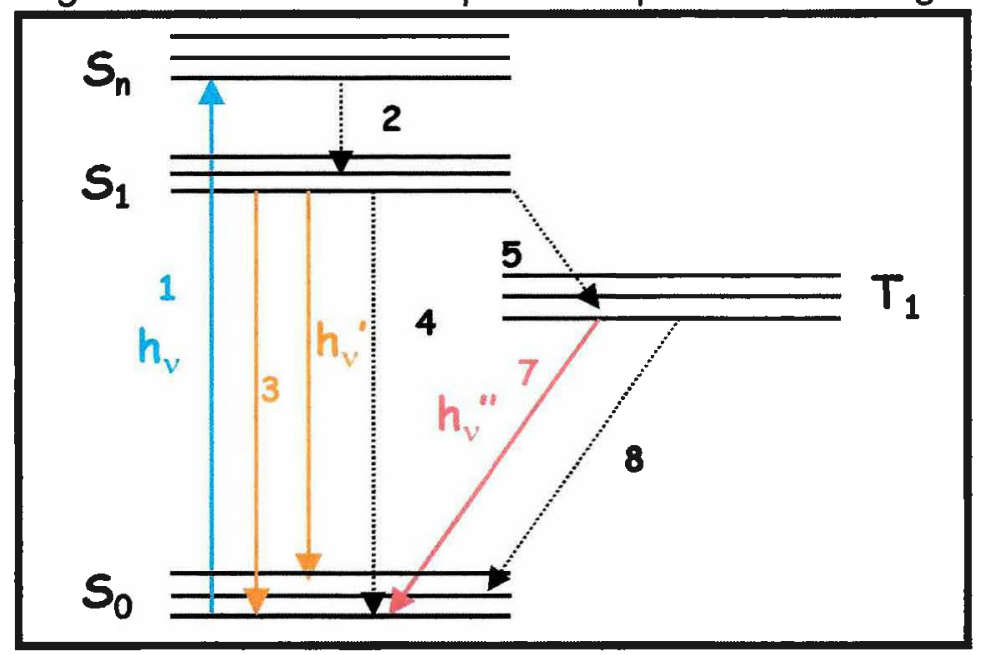

figura 8: Representação esquemática das possíveis transições eletrônicas após excitação por $h v(1)$ : decaimento não radiativo $S_{n} \rightarrow S_{1}(2)$; emissão de fluorescência $S_{1} \rightarrow S_{0}(3)$; decaimento não radiativo $S_{1} \rightarrow S_{0}(4)$ e $T_{1} \rightarrow S_{0}(8)$; cruzamento intersistemas $S_{1} \rightarrow T_{1}(5)$; e emissão de fosforescência $T_{1} \rightarrow S_{0}(7)$.

A caracterização desses processos se dá pela determinação das constantes de velocidade dos processos radioativos e não radioativos ${ }^{43}$ e dos rendimentos quânticos de fluorescência $\left(\Phi_{F}\right)$, de fosforescência $\left(\Phi_{P}\right)$ e de formação do estado triplete $\left(\Phi_{T}\right)$, ou seja, a razão entre os fótons emitidos em cada um desses processos pelos fótons absorvidos na excitação da espécie.

As porfirinas meso substituidas na forma base livre são luminescentes, assim como boa parte de seus metalo derivados ${ }^{21}$. As porfirinas bases livres e metaloporfirinas com metais de camada cheia são fluorescentes, ou seja apresentam rendimentos quânticos de fluorescência entre 0,2 e 0,02 para as porfirinas derivadas da $\mathrm{H}_{2}$ TPP e $\mathrm{H}_{2}$ TPyP. A fluorescência desses derivados é observada à temperatura ambiente, enquanto que a fosforescência só é verificada a baixas temperaturas "11 $\mathrm{e}$ em meio congelado, diminuindo-se a conversão interna $T_{1} \rightarrow S_{0}$. 
As porfirinas meso substituídas aquossolúveis na forma base livre apresentam duas bandas de fluorescência na região entre 600 e $800 \mathrm{~nm}$, atribuídas à transição do nível vibracional de menor energia do estado $S_{1}$ para os niveis vibracionais 1 e 0 do estado fundamental $S_{0}$. Essas bandas são designadas $Q(0,1)$ e $Q(0,0)$, em ordem crescente de energia. Entretanto, as porfirinas piridinio substituidas $\mathrm{H}_{2} \mathrm{TMPyP}{ }^{39}{ }_{4}^{40,4}$, $\mathrm{H}_{2}$ TBzPyP e $\mathrm{H}_{2}$ TAIPyP $^{21}$ apresentam espectro de emissão em solução aquosa em que as duas bandas de fluorescência estão sobrepostas, mal definidas, resultando em uma banda larga e disforme. As bandas $Q(0,1)$ e $Q(0,0)$ aparecem bem resolvidas em espectros obtidos a partir de soluções em solventes orgânicos polares (metanol, etanol, DMSO e DMF), misturas desses solventes com água ou em solução aquosa de SDS em condições micelares.

Em meio congelado a $77 \mathrm{~K}$ (geralmente, mistura glicerinalágua $2: 1)^{1,11,21}$, essas porfirinas apresentam banda de fosforescência relativamente intensa em comprimentos de onda superiores a $700 \mathrm{~nm}$. O máximo de emissão dessa banda permite o cálculo da energia do estado triplete $\left(E_{T}\right)$, parâmetro importante na determinação dos potenciais redox do estado excitado ${ }^{11}$, bem como a utilização como fotossensibilizadores.

Metaloporfirinas de elementos de transição não apresentam fluorescência devido à formação de novos estados gerados pelos orbitais d, permitindo novas vias de decaimento não radioativo.

Metaloporfirinas contendo íons metálicos diamagnéticos com a camada d semi preenchida são preferencialmente fosforescentes, sendo que os complexos de Pd(II) e $\mathrm{Pt}$ (II) apresentam alto rendimento quântico de fosforescência mesmo em temperatura ambiente, mas na ausência de $\mathrm{O}_{2}{ }^{9,37}$.

Já os complexos de metais paramagnéticos são geralmente não luminescentes, as exceções apresentam baixo rendimento quântico de emissão, sendo que a luminescência não pode ser caracterizada como fluorescência ou fosforescência uma vez que os estados moleculares não são classificados como singletes ou tripletes, devido a interação entre estados de transferência de carga e o sistema $\pi$ do macrociclo ${ }^{45}$.

Os parâmetros de emissão das porfirinas $\mathrm{H}_{2}$ TMPyP, $\mathrm{H}_{2}$ TPPS, $\mathrm{H}_{2}$ TMAPP e seus metalo derivados foram exaustivamente estudados na década de 80 como parte da caracterização de promissores agentes fotossensibilizadores em sistemas de conversão de energia. A tabela abaixo apresenta alguns desses parâmetros.

As metaloporfirinas de $\mathrm{Pd}(\mathrm{II}), \mathrm{Sn}(\mathrm{II})$ e $\mathrm{Zn}(\mathrm{II})$ dos derivados meso substituídos aquossolúveis apresentam longos tempo de vida do estado triplete $\left(\tau_{T}\right)$ e alto 
rendimento quântico de formação do estado triplete $\left(\Phi_{T}\right)$, sendo propriedades importantes para aplicação como fotossensibilizadores em processos de transferência de energia e/ou elétrons. complexos

tabela 1: Parâmetros fotofísicos de porfirinas meso substituídas e seus metalo

\begin{tabular}{|c|c|c|c|c|c|}
\hline Porfirinas & $\Phi_{\mathrm{F}}$ & $\tau_{S}(n S)$ & $\Phi_{T}$ & $\tau_{s}(\mathrm{~ms})$ & ${ }_{\text {ET }}\left(\mathrm{kJ} \mathrm{mol}^{3-1}\right.$ \\
\hline $\mathrm{H}_{2}$ TPPS $^{1}$ & 0,08 & 10,4 & 0,78 & 0,42 & -- \\
\hline $\mathrm{H}_{2}$ TMAPP $^{1}$ & 0,07 & 9,3 & 0,80 & 0,54 & - \\
\hline $\mathrm{H}_{2} \mathrm{TMPyP} \mathrm{P}^{2}$ & 0,047 & 6,0 & 0,95 & 0,17 & - \\
\hline $\mathrm{ZnTPPS}^{3}$ & 0,042 & 1,7 & 0,85 & 1,40 & 156 \\
\hline ZnTMAPP ${ }^{2}$ & - & 1,75 & 0,82 & 1,2 & - \\
\hline PdTPPS $^{3}$ & $\cong 10^{-4}$ & $<0,5$ & 1,00 & 0,38 & 172 \\
\hline SnTPPS & 0,036 & - & 0,95 & 1,0 & 158 \\
\hline ZnTMPyP ${ }^{3}$ & $0,035(0,025)^{2}$ & 1,5 & 0,90 & 1,22 & 157 \\
\hline PdTMPyP & $\cong 10^{-4}$ & $<0,5$ & 1,00 & 0,17 & 174 \\
\hline SnTMPyP ${ }^{3}$ & 0,027 & -- & 0,95 & 0,9 & 164 \\
\hline
\end{tabular}

${ }^{1}$ ref. ${ }^{11} ;{ }^{2}$ ref. ${ }^{1} ;{ }^{3}$ ref. ${ }^{9} . \Phi_{F}$ - rendimento quântico de fluorescência;

$\tau_{s}$ - tempo de vida do estado singlete;

$\Phi_{T}$ - rendimento quântico de formação do estado triplete;

$\tau_{T}$ - tempo de vida do estado triplete; $E_{T}$ - energia do estado triplete.

Embora à temperatura ambiente os processos de desativação térmica do estado triplete devido aos choques entre a porfirina e solvente, não permitam a observação da fosforescência, o estado triplete das porfirinas pode ser caracterizado pela técnica de fotólise por pulso de laser ${ }^{42,46,47}$ (Jaser flash photolysis). Esta técnica consiste na excitação da amostra por um pulso de laser de tempo curto (tipicamente 5 a $20 \mathrm{~ns}$ ), populando estados excitados singletes de alta energia. Através das conversões interna para o estado singlete $S_{1}$ e do cruzamento inter sistemas populase o estado triplete de menor energia $T_{1}$. Perpendicularmente ao laser, um feixe de luz proveniente de uma lâmpada de arco de Xenônio é utilizado para o monitoramento do estado triplete, uma vez que o transiente com estado triplete populado pode absorver fótons provenientes da lâmpada, sendo promovidos a estados tripletes de maior energia $\left(T_{2}, \ldots, T_{n}\right)$. A figura 9 apresenta um esquema típico da aparelhagem descrita acima.

Pode-se então monitorar a variação de densidade ótica em função do tempo devido a absorção de espécies transientes, ou seja, considera-se a absorção do estado fundamental da espécie analisada naquele comprimento de onda como zero e monitora-se a variação da absorbância em função do tempo devido a absorção de luz das espécies no estado triplete. É importante assinalar que essa técnica não permite o monitoramento do estado singlete uma vez que o seu decaimento ocorre em tempos 
semelhantes que o pulso do laser (da ordem de ns). Já o estado triplete apresenta tempos de vida significativamente maiores devido à transição proibida $T_{1} \rightarrow S_{0}$.

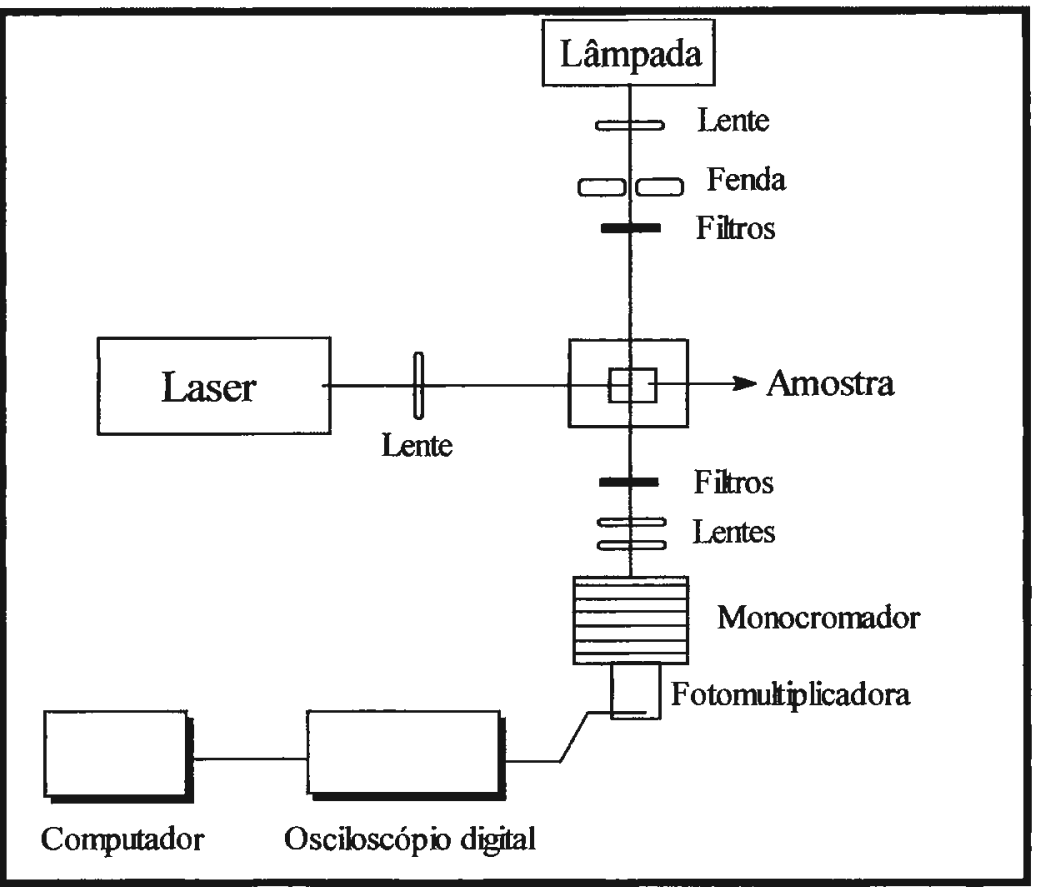

figura 9: Esquema da aparelhagem de um laser flash photolysis ${ }^{46}$.

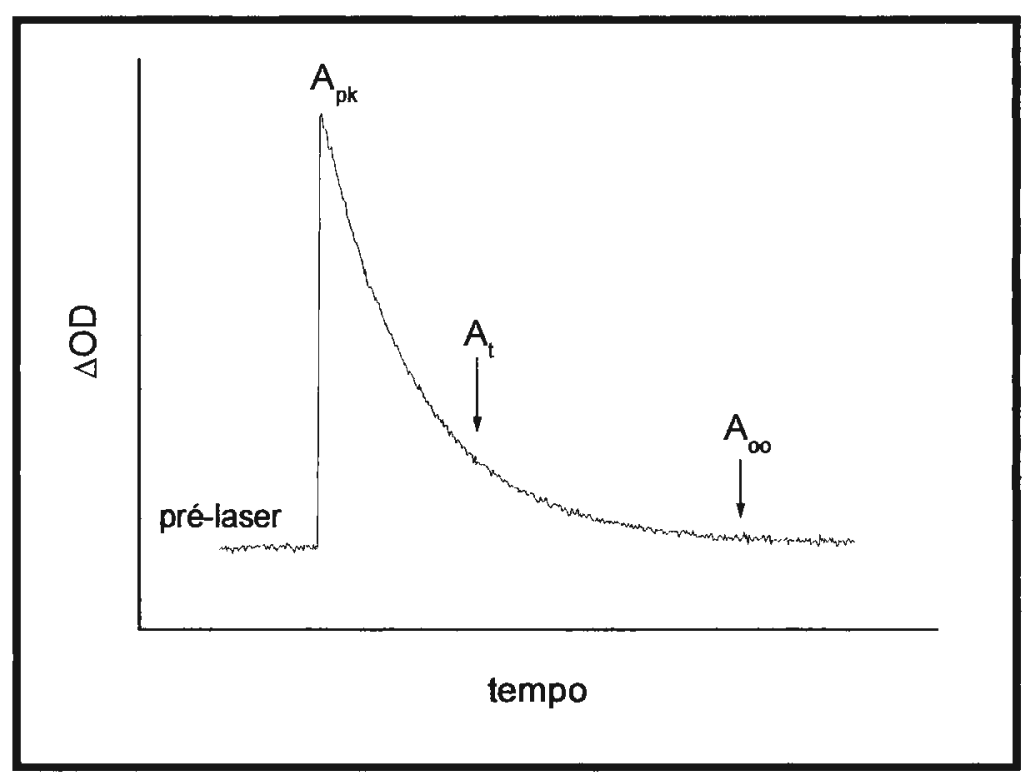

figura 10: Decaimento transiente com parâmetros relevantes para cálculos. A densidade ótica da espécie transiente no máximo de concentração é definidio como $A_{p k}$; a um tempo $t$ após a excitação como $A_{t}$; e após um tempo infinito para o decaimento do transiente como $\mathbf{A}_{6}{ }^{46}$.

A figura 10 apresenta um típico decaimento de uma espécie transiente em função do tempo. É importante lembrar que a absorbância medida é sempre em relação a absorção da espécie no estado fundamental naquele comprimento de onda, representada na figura na região pré-laser. Com essa consideração nota-se que é 
possivel detectar uma absorção negativa, que representaria a diminuição de intensidade (bleaching) de uma banda do espectro de absorção fundamental em um comprimento de onda que o transiente não absorva tanto. É também possível que a densidade ótica em $A_{\infty}$ seja diferente da absorção no pré-laser, indicando a formação de novas espécies ou ainda a presença de transientes de tempo de vida mais longos $^{46}$.

O tratamento cinético da curva obtido permite a determinação do tempo de vida do estado triplete $\left(\tau_{\mathrm{T}}\right)$ e o valor de $\mathrm{A}_{\mathrm{pk}}$ determinados em vários comprimentos de onda de absorção permite a construção do espectro de absorção T-T do transiente ${ }^{42,46}$.

Essa técnica também permite o acompanhar o efeito da concentração de aceptores de elétrons na supressão do estado triplete da porfirina fotoexcitada através de um processo de transferência eletrônica. O mecanismo dessas reações pode ser acompanhado a partir do espectro das espécies intermediárias formadas, assim como uma estimativa da taxa de transferência de elétrons com a determinação da constante de supressão do estado excitado triplete.

Um dos processos de desativação do estado triplete mais relevantes é a supressão pelo oxigênio do ar, ocorrendo tranferência de energia do estado excitado triplete do sensibilizador para o estado fundamental triplete do oxigênio molecular, com geração da espécie reativa oxigênio singlete $\left({ }^{1} \mathrm{O}_{2}\right)$.

Existem duas formas excitadas de oxigênios singlete ${ }^{48},{ }^{1} \Sigma_{g}{ }^{+} e^{1} \Delta_{g}$, sendo a primeira mais energética, mas com um tempo de vida em solução ou em fase gasosa muito curto, não sendo relevante para os processos conhecidos até hoje. Por tanto, o uso genérico do termo oxigêrio singlete $\left({ }^{1} \mathrm{O}_{2}\right)$ está relacionado ao estado ${ }^{1} \Delta_{\mathrm{g}}$. $\mathrm{A}$ transição e ${ }^{1} \Delta_{g} \leftarrow{ }^{3} \Sigma_{g}{ }^{-}$apresenta $94 \mathrm{~kJ} \mathrm{~mol}^{-1}$ de energia ou comprimento de onda correspondente a $1269 \mathrm{~nm}$.

A supressão do estado excitado triplete de porfirinas e formação do ${ }^{1} \mathrm{O}_{2}$ é importante uma vez que esta espécie atua como agente oxidante em processos de terapia fotodinâmica ${ }^{49}$ ou inativação de virus e bactérias.

Nas últimas duas décadas, vários autores têm se dedicado a determinar o rendimento quântico de formação de oxigênio singlete $\left(\Phi_{\Delta}\right)$ para as porfirinas meso substituídas $2, \%$. Dois métodos têm sido geralmente empregados, o método direto, medindo-se a intensidade da emissão fosforescente do decaimento ${ }^{1} \Delta_{g} \leftarrow{ }^{3} \Sigma_{g}{ }^{-}$em $1270 \mathrm{~nm}$ e o método indireto em que se monitora espectroscopicamente o desaparecimento de um substrato supressor da espécie ${ }^{1} \mathrm{O}_{2}$. Para melhor entendimento das considerações cinéticas de cada método e suas respectivas simplificações consulte a referência ${ }^{48}$. 


\subsubsection{Formação de Homoagregados em Solução Aquosa}

O estado de agregação dos derivados porfirinicos em solução aquosa influenciam as suas propriedades fotofísicas, os processos de transferência de elétrons e a sua capacidade de formar agregados com biomoléculas, como proteínas e ácidos nucleicos. É, portanto, etapa fundamental do processo de caracterização das porfininas meso substituídas o estudo do estado de agregação em solução aquosa e em condições de força iônica controlada, uma vez que muitas de suas aplicações se estabelecem nesses meios.

A formação de agregados em solução aquosa das porfininas aquossolúveis fenil substituídas, $\mathrm{H}_{2}$ TPPS, $\mathrm{H}_{2}$ TPPC $^{12,51,52}$ e $\mathrm{H}_{2}$ TMAPP $^{44,53}$ e alguns dos seus metalo complexos é conhecida desde a década de 70 , com vários trabalhos demonstrando a influência da força iônica na formação dos agregados, tendo sido determinadas as constantes de associação em diversas condições experimentais.

Essa agregação ocorre numa primeira etapa com a formação de dímeros e com o aumento da concentração da porfirina e/ou o aumento da força iônica pode-se obter agregados maiores. A formação dos agregados e a determinação de suas constantes de associação foram estudadas pelas mudanças apresentadas nos espectros eletrônicos de absorção e emissão, assim como a variação dos deslocamentos químicos dos prótons nos espectros de $\mathrm{RMN}^{1} \mathrm{H}$ em função da concentração da porfirina elou da concentração do sal.

De modo geral, a formação desses agregados se deve às interações de van der Waals devido ao extenso sistema $\pi$ dos macrociclos, essas interações suplantam, em certas condições, a repulsão eletrostática causada pelas cargas dos substituintes periféricos. O aumento da força iônica favorece a formação dos agregados, diminuindo a repulsão eletrostática devido a presença dos contra-ions na esfera de solvatação das porfirinas.

Já a caracterização do estado de agregação da $\mathrm{H}_{2}$ TMPyP em solução aquosa foi tema de uma longa série de controvérsias que durou mais de uma década (aproximadamente entre 1983 e 1997).

Alguns autores defendiam a tese de que a $\mathrm{H}_{2}$ TMPyP apresenta-se na forma monomérica ${ }^{12,54,55}$ tanto em água pura como em soluções concentradas de sais como $\mathrm{NaCl}$ e $\mathrm{NaNO}_{3}$. Pasternack e colaboradores ${ }^{12}$ demonstraram a obediência à lei de Beer das bandas dos máximos de absorção da $\mathrm{H}_{2}$ TMPyP na faixa de $10^{-7}$ a $10^{-4} \mathrm{~mol}$ $\mathrm{dm}^{-3}$. Foster ${ }^{55}$ demonstrou que a vaniação dos deslocamentos químicos observada para os prótons da $\mathrm{H}_{2}$ TMPyP em $\mathrm{D}_{2} \mathrm{O}$ em função da sua concentração é melhor explicada pela formação dos pares iônicos porfirina/tosilato e não pela formação de 
dímeros. Posteriormente, Pasternack e colaboradores ${ }^{54}$ voltaram a refutar o modelo da dimerização argumentando que o valor teónico da constante de dimenização atribuído a $\mathrm{H}_{2}$ TMPyP seria muito elevado. Esse valor não seria coerente com a alta repulsão eletrostática entre os macrociclos, com a não variação do perfil do espectro eletrônico à medida que se aumenta a força iônica do meio, e nem com as constantes de associação determinados para os agregados porfirina/ mononucleotídeos.

Por outro lado, um grupo de autores defendia a tese de que a $\mathrm{H}_{2}$ TMPyP encontra-se na forma dimérica ${ }^{39,40,44,56}$ em solução aquosa em concentrações inferiores a $10^{-7} \mathrm{~mol} \mathrm{dm}^{-3}$, sendo o dímero o principal componente de soluções na qual se observa a obediência à lei de Beer. Essa tese era suportada pelos perfis dos espectros eletrônicos de absorção e de emissão da $\mathrm{H}_{2}$ TMPyP em água e em solventes orgânicos, bem como o alargamento do sinal do próton pirrólico nos espectros de RMN- ${ }^{1} \mathrm{H}$ em $\mathrm{D}_{2} \mathrm{O}$.

Kano e colaboradores ${ }^{39,40,44}$ numa série de artigos propôs que os comportamentos espectrais da $\mathrm{H}_{2}$ TMPyP em solução aquosa poderiam ser explicados por um dimero de estrutura cofacial(figura 12). O espectro de absorção da $\mathrm{H}_{2}$ TMPyP em água apresenta perfil phyllo, entretanto a adição de solventes polares como metanol modifica o perfil espectral, com melhor separação e definição das bandas $Q_{y} e$ $Q_{x}$, além de mudança nas intensidades relativas das bandas, resultando em um espectro etio (figura 11).

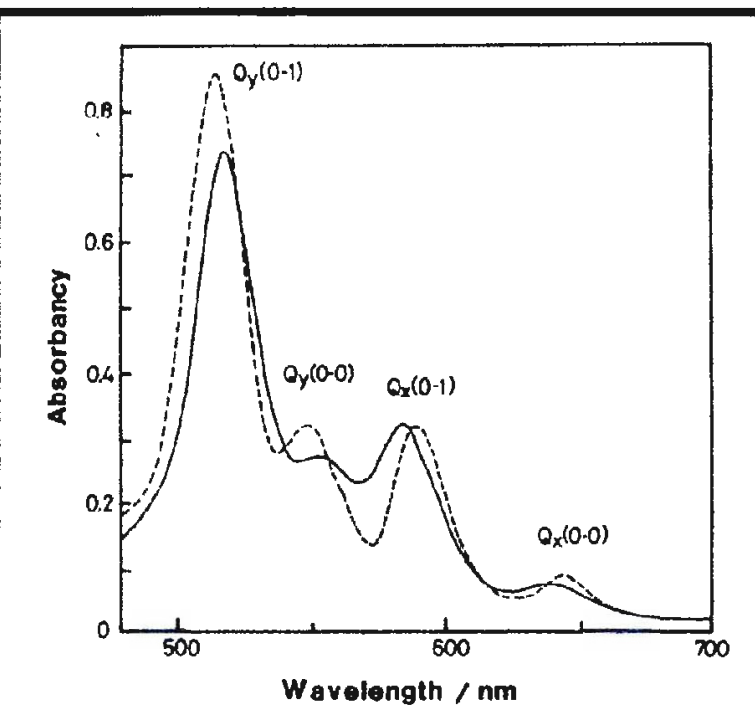

figura 11: Espectro de absorção da $\mathrm{H}_{2} \mathrm{TMPyP}\left(5 \times 10^{-5} \mathrm{~mol} \mathrm{dm}^{-3}\right) \mathrm{em}$ água (linha contínua) e em metanol (tracejado) 40 .

$\mathrm{O}$ espectro de emissão em solução aquosa da $\mathrm{H}_{2}$ TMPyP é pouco usual, apresentando as duas bandas $Q$ mal resolvidas, entretanto Kano e colaboradores obtiveram espectros de emissão com as duas bandas $Q$ definidas com a adição de 
metanol ou nitrobenzeno. A adição de SDS em concentrações acima da cmc também definem o espectro de emissão. Além disso, soluções de $\mathrm{H}_{2}$ TMPyP em água tridestilada com concentrações da ordem de $10 \mathrm{nmol} \mathrm{dm}^{-3}$ apresentam boa definição das bandas $Q(0,0)$ e $Q(0,1)$. A definição das bandas de emissão também ocorre com o aumento da temperatura, sendo mais um fator que corrobora com a hipótese da formação de agregados. Segundo Kano e colaboradores o valor do tempo de vida do estado singlete $\left(\tau_{s}\right)$ da $\mathrm{H}_{2}$ TMPyP é baixo quando comparado com outras porfirinas, mais um argumento favorável à forma dimérica.

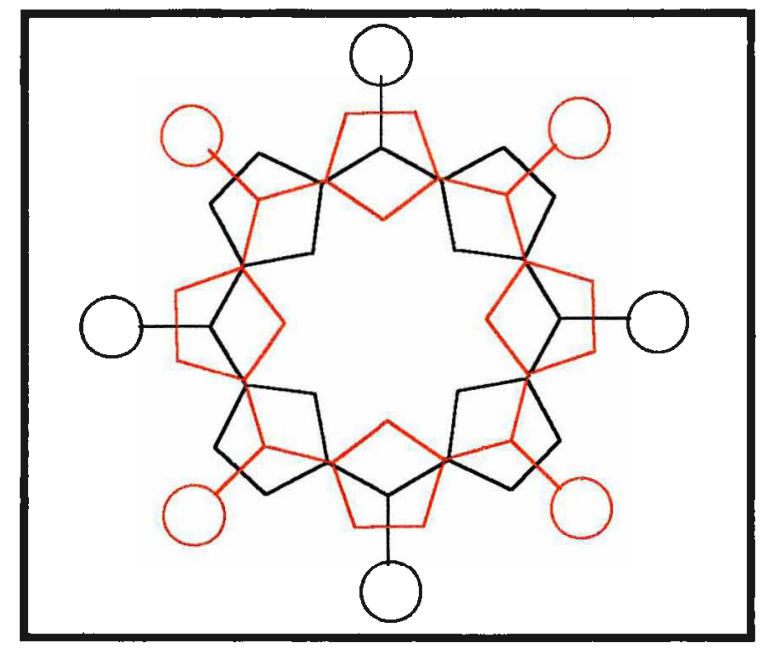

figura 12: Estrutura representando o modelo proposto para a formação de um dímero da $\mathrm{H}_{2} \mathrm{TMPyP}^{40}$.

Kano argumenta que a insensibilidade dos parâmetros espectrais em relação a concentração de $\mathrm{NaCl}$ é devida a presença do dímero já em concentrações muito baixas, não havendo a formação de agregados maiores.

Os espectros de $\mathrm{RMN}-{ }^{1} \mathrm{H}$ da $\mathrm{H}_{2}$ TMPyP em $\mathrm{D}_{2} \mathrm{O}$ apresentam um sinal alargado referente ao próton pirrólico, sendo essa observação explicada pelo modelo dimérico cofacial. A banda torna-se mais fina com o aumento de temperatura ou a utilização de solventes orgânicos, aparecendo um singlete bem definido.

Kano e colaboradores sintetizaram outros dois derivados piridínio substituídos, butil e octil, que são grupos alifáticos mais volumosos, obtendo a $\mathrm{H}_{2}$ TBuPyP e $\mathrm{H}_{2} \mathrm{TOcPyP}$, respectivamente. Esses derivados apresentaram comportamento espectroscópico e sinal de $\mathrm{RMN}-{ }^{1} \mathrm{H}$ semelhante ao observado para a $\mathrm{H}_{2} \mathrm{TMPyP}$, entretanto, esses derivados apresentam sensibilidade quanto à adição de $\mathrm{NaCl}$ em solução, mostrando dependência da formação de agregado com a força iônica. Essa evidência foi interpretada como a formação de agregados maiores para essas duas porfirinas, sendo possivel graças ao maior caráter hidrofóbico dos grupos periféricos aumentando as interações de van der Waals entre as espécies. 
Harriman e colaboradores ${ }^{56}$ reforçaram a proposta de Kano apresentando os espectros de emissão corrigidos de soluçōes de $\mathrm{H}_{2}$ TMPyP e demonstrando a dependência do perfil espectral com a concentração de porfirina (figura 13). Foram determinados os rendimentos quânticos de fluorescência $\left(\Phi_{F}\right)$ para a forma monomérica e dimérica, 0,048 e 0,056 , bem como o tempo de vida do estado singlete $\left(\tau_{\mathrm{s}}\right)$, sendo 3,7 ns para o monômero e 6,1 ns para o dímero. Além disso, esse artigo põe em dúvida a linearidade da lei de Beer para a banda Soret em concentraçōes entre $10^{-7}$ e $10^{-6} \mathrm{~mol} \mathrm{dm}^{-3}$.

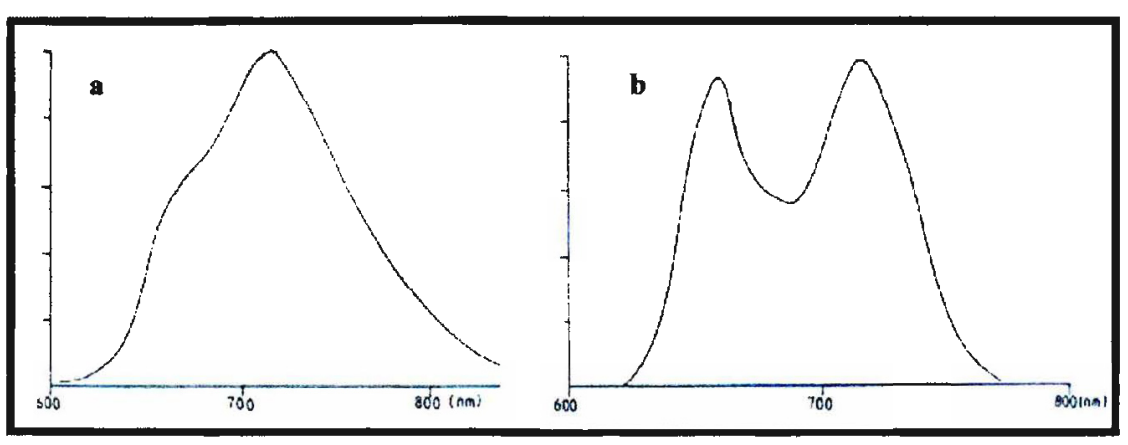

figura 13: Espectros de emissão da $\mathrm{H}_{2}$ TMPyP; a- $10^{-6} \mathrm{~mol} \mathrm{dm} \mathrm{m}^{-3} ; \mathrm{b}-10^{-8} \mathrm{~mol} \mathrm{dm}^{-3^{56}}$.

As porfirinas $\mathrm{H}_{2}$ TAIPyP e $\mathrm{H}_{2}$ TBzPyP $^{21}$ apresentam comportamento espectroscópico condizente com o observado por Kano e Harriman para a $\mathrm{H}_{2} T M P y P$, indicando que os perfis dos espectros de absorção e de emissão são característicos das porfirinas piridínio substituídas, e estão relacionados ao grupo piridínio e aos efeitos da sua carga positiva na estrutura eletrônica do macrociclo.

É importante lembrar que apesar de ambos os grupos defenderem com convicção suas propostas, todos deixavam claro não terem provas conclusivas que comprovasse a existência da forma dimérica em soluções aquosas da $\mathrm{H}_{2} T M P y P$, nem a presença única da forma monomérica. Cada um dos grupos tinha argumentos para os quais não havia contra argumentação.

A forma monomérica era suportada por não ser observada nenhuma alteração espectral em solução aquosa de $\mathrm{H}_{2}$ TMPyP com concentrações superiores a $10^{-6}$ mol $\mathrm{dm}^{-3}$, nem mesmo em solução saturada de $\mathrm{NaCl}$. O que implica que se houver a formação de dímero esse possui constante de associação elevadíssima, incoerente com a presença de quatro cargas positivas na porfirina, com os valores de constante de dimerização determinados para outras porfirinas e com as constantes de associação da $\mathrm{H}_{2}$ TMPyP com outras espécies.

Por outro lado, a mudança no perfil do espectro de emissão em concentrações inferiores a $10^{-7} \mathrm{~mol} \mathrm{dm}^{-3}$, passando a um perfil semelhante ao observado em solventes orgánicos onde a forma monomérica deve estar presente, bem como a 
dependência do perfil espectral com a temperatura é um forte argumento em favor da existência de dímeros das porfirinas piridínio substituídas em solução aquosa.

Vergeldt e colaboradores ${ }^{57}$, entretanto, apresentaram resultados experimentais e um modelo eletrônico para a $\mathrm{H}_{2}$ TMPyP que explicam os dados espectroscópicos obtidos e sustentam a presença apenas da forma monomérica do derivado porfirínico em solução aquosa. Os autores afirmam que a resolução das bandas $Q$ do espectro de emissão da $\mathrm{H}_{2}$ TMPyP em concentrações abaixo de $10^{-7} \mathrm{~mol} \mathrm{dm}^{-3}$ se deve à presença de particulados em solução, sendo que tomando-se algumas medidas de precaução obtém-se o espectro mal resolvido característico das porfirinas piridínio substituídas em solução aquosa mesmo nessas concentrações.

Esse perfil espectral e sua dependência com a temperatura é explicado por um modelo baseado em cálculos computacionais da posição dos anéis piridínicos em relação ao macrociclo e dos parâmetros espectroscópicos do estado singlete $S_{1}$ determinados para os três isômeros da $\mathrm{H}_{2}$ TMPyP, com a piridina ligada na posição meso em orto, meta e para, respectivamente $\mathrm{H}_{2} \mathrm{TMPyP}(2), \mathrm{H}_{2} \mathrm{TMPyP}(3)$ e $\mathrm{H}_{2} \operatorname{TMPyP}(4)$ (figura 14).

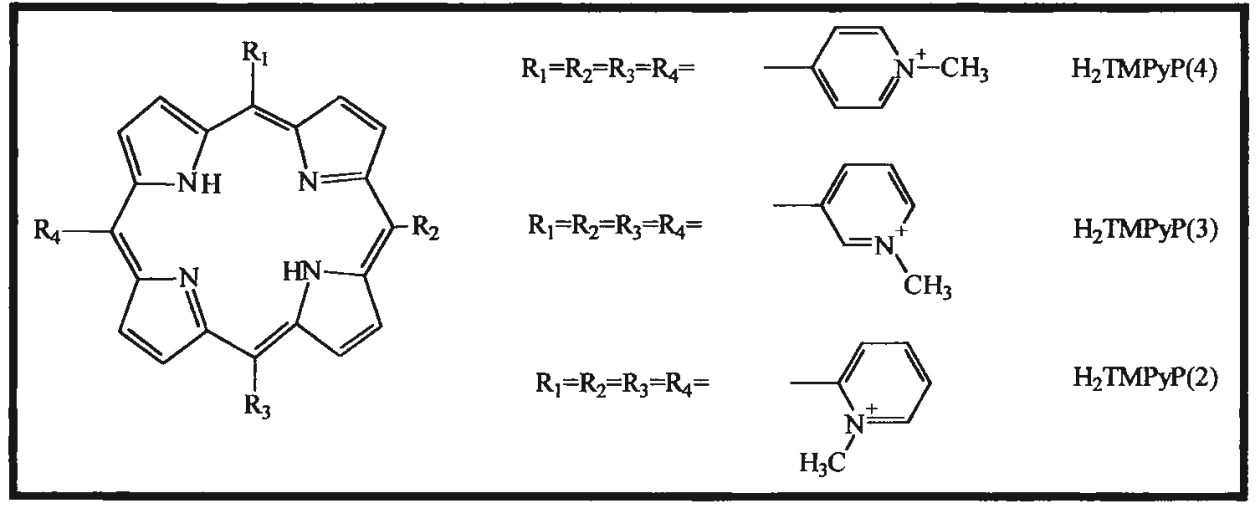

figura 14: Estruturas dos isômeros da $\mathrm{H}_{2}$ TMPyP

Vergeldt e colaboradores propõem um estado eletrônico de transferência de carga intramolecular de energia muito próxima a energia do estado excitado $S_{1}$, havendo um acoplamento vibracional desses dois estados, aumentando a via de decaimento não radioativo. Esse modelo explica para a $\mathrm{H}_{2} \mathrm{TMPyP}(4)$ o espectro mal resolvido e os baixos tempo de vida do estado singlete. Esse efeito é menor na $\mathrm{H}_{2}$ TMPyP(3) pois a posição meta não apresenta um efeito mesomérico do anel piridínico em relação ao macrociclo, restando somente o indutivo. Esse efeito é menos pronunciado para a $\mathrm{H}_{2} \mathrm{TMPyP}(2)$, apesar do efeito mesomérico ser forte para substituintes em posição orto, uma vez que o impedimento estérico entre o grupo metil e os hidrogênios pirrólicos do macrociclo impede a coplanaridade dos anéis piridínicos em relação ao anel porfirínico, não havendo uma boa interação entre as nuvens $\pi$ (figura 15). 


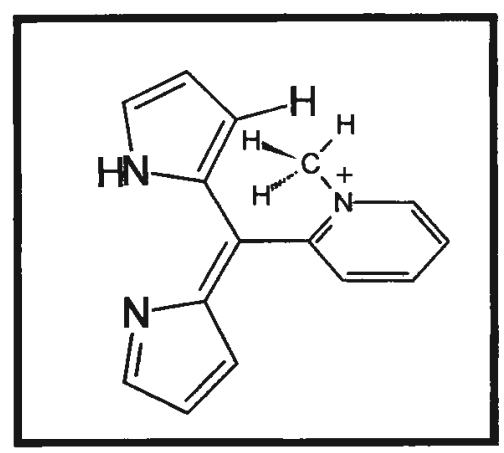

figura 15: Estrutura representando o impedimento estérico entre 0 anel piridínico e o porfirínico na $\mathrm{H}_{2} \mathrm{TMPyP(2)}$.

Posteriormente, losif e colaboradores ${ }^{52}$, em estudo sobre a agregação entre a $\mathrm{H}_{2}$ TMPyP e a $\mathrm{H}_{2}$ TPPS, confirmam os resultados apresentados por Vergeldt e o modelo de estrutura eletrônica proposto. Dixon e coautores ${ }^{53}$ elaboram um modelo matemático baseado na teoria de Debye-Hückel para prever a ocorrência de agregação de porfirinas iônicas em função da força iônica do meio. Nesse trabalho eles comprovam a não formação de agregados para a $\mathrm{H}_{2}$ TMPyP em soluções de $\mathrm{NaCl}$ com concentrações de até $3 \mathrm{~mol} \mathrm{dm}^{-3}$. Entretanto, os autores apresentam evidências de agregação em solução de $\mathrm{NaCl}$ das porfirinas piridínio substituídas TBuPyP e TOcPyP, que apresentam substituintes mais hidrofóbicos.

Porfirinas piridínio substituidas contendo grupos alquilicos mais volumosos agregam em solução aquosa contendo sais inorgânicos. Shachter e co-autores ${ }^{58}$ publicaram um estudo com uma dezena de derivados porfirínicos com diferentes substituintes piridínicos e todos apresentaram algum tipo de agregação em solução aquosa contendo $\mathrm{NaNO}_{3} 0,1 \mathrm{~mol} \mathrm{dm}^{-3}$.

\subsubsection{Interação com Surfactantes}

Moléculas anfifilicas são caracterizadas por conter regiões polares e apolares numa mesma estrutura. Estas geralmente apresentam um grupo iônico ou ainda um grupo altamente polar numa das extremidades e uma longa cadeia carbônica apolar, resultando numa estrutura que apresenta numa extremidade um caráter altamente hidrofílico e no restante da molécula um caráter hidrofóbico ${ }^{59,60}$.

Dentre os tipos de moléculas anfifílicas mais comuns podemos citar as aniônicas como o sabão (carboxilatos de sódio ou potássio) e os sulfatos alquílicos como o dodecil sulfato de sódio (SDS); as catiônicas, derivadas de sais quaternários de amônio geralmente, como o brometo de hexadeciltrimetilamônio (CTAB); e os não iônicos, usualmente com a região polar formada por cadeias de polioxietileno, como nos detergentes Triton $\times 100$ (éter iso-octilfenilpolioxietileno(10)). A figura 16 aporesenta a estruturas desses surfactantes. 


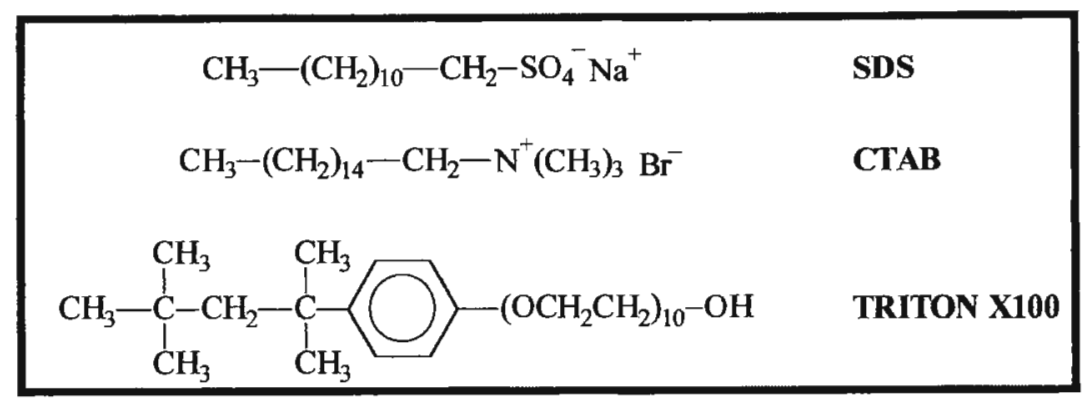

figura 16: Estrutura de surfactantes iônicos e não iônicos comuns.

Devido a ambigüidade de suas interações com solventes polares e apolares essas moléculas apresentam um comportamento característico em solução e têm papel fundamental na formação de estruturas de interesse biológico, como membranas e vesículas, por exemplo.

As substâncias anfifílicas quando dissolvidas na água alteram as propriedades da superfície do solvente, uma vez que a parte hidrofilica è solvatada pela água, enquanto que a região hidrofóbica localiza-se na interface entre a água e o ar ou outra fase apolar imiscível com a água. Dessa influência na superfície dos solventes característica dessas estruturas deriva o nome surfactantes.

Com o aumento da concentração dessas substâncias formam-se aglomerados coloidais nos quais as cadeias hidrofóbicas unem-se no interior da estrutura e a superfície do colóide é formada pela parte iônica ou hidrofílica. Esse aglomerado é denominado micela e a concentração a partir da qual verifica-se a formação desse agregado é denominada concentração micelar crítica $(\mathrm{cmc})$.

As micelas são estruturas dinâmicas havendo um equilíbrio entre a formação $e$ desintegração desses agregados em solução. O interior da micela é um ambiente bastante hidrofóbico, geralmente caracterizado como um hidrocarboneto líquido, e percorrendo a micela em direção à superfície há uma região mista, com características hidrofóbicas e hidrofilicas, até chegar a superfície altamente hidrofílica. Essa superfície pode apresentar interações ion-dipolo no caso dos surfactantes iônicos e interações de ligação de hidrogênio no caso de surfactantes não iônicos. Esses diferentes ambientes existentes na micela permitem a solubilização de uma série de substâncias inicialmente insolúveis na água e a modificação da sua reatividade e das propriedades espectroscópicas devido à mudança do ambiente de solvatação e à diferente interação dos substratos com o agregado micelar. Devido a essas propriedades de solubilização surfactantes têm sido extensamente utilizados em fármacos, controlando a difusão, a solubilidade e a ação de princípios ativos no organismo ${ }^{59}$.

Os agregados formados pelas porfirinas iônicas meso substituídas e por surfactantes catiônicas, iônicas e não iônicas têm sido caracterizados na última década por suas propriedades espectroscópicas. Essa caracterização é importante 
devida a aplicação dessas porfirinas como agentes em terapia fotodinâmica, sendo a utilização de surfactantes uma das estratégias utilizadas para uma difusão controlada de drogas pelo organismo, permitindo uma maior especificidade do fármaco.

Kadish e colaboradores ${ }^{61}$ estudaram a interação dos derivados $\mathrm{H}_{2}$ TPPS, ZnTPPS, CuTPPS e VOTPPS e os surfactantes CTAB, SDS e Triton X100 utilizando espectro eletrônico de absorção, $\mathrm{RMN}^{-1} \mathrm{H}$ e ressonância de spin eletrônico (ESR). Os resultados apresentados apontam para uma não interação entre as porfirinas aniônicas e o surfactantes SDS, devido a repulsão coulômbica entre as espécies. $O$ espectro de absorção indica que o SDS age como promotor da agregação do $\mathrm{H}_{2}$ TPPS em solução aquosa, havendo a formação do dímero em concentração inferior a observada em água pura. Neste caso, o efeito do SDS é semelhante ao da adição de sais inorgânicos, aumentando a força iônica do meio e diminuindo a repulsão eletrostática entre as moléculas de porfirina.

Já os surfactantes CTAB e Triton $\times 100$ formam agregados micelares com a TPPS, e todas evidências espectroscópicas indicam a presença de monômeros da porfirina na micela. $A$ interação entre os derivados porfirínicos e o CTAB deve ser predominantemente eletrostática, e o modelo proposto por Kadish indica a porfirina localizada na superfície catiônica da micela. $O$ deslocamento dos sinais dos prótons do CTAB em função da concentração de porfirina mostra uma maior influência sobre os prótons próximos ao nitrogênio quaternário. Entretanto, os autores também consideram que a porfirina está associada à região polar do Triton $\times 100$, apesar das maiores variações dos sinais dos prótons ocorrerem na região apolar e não para os prótons do polioxietileno.

Posteriormente, Kadish e colaboradores ${ }^{62}$ fizeram um estudo similar envolvendo a $\mathrm{H}_{2}$ TMPyP, seus metalo derivados ZnTMPyP, CuTMPyP e VOTMPyP e os mesmos surfactantes. Os dados de RMN- ${ }^{-1}$, ESR e os espectros de absorção evidenciam não ocorrer interação entre os derivados porfirínicos catiônicos e os surfactantes CTAB e Triton X100. Devido a presença da mesma carga, ocorrendo uma repulsão coulômbica já era esperado a não formação de agregados entre a $\mathrm{H}_{2} \mathrm{TMPyP}$ e o CTAB.

A não interação entre a $\mathrm{H}_{2}$ TMPyP e o surfactante não iônico Triton X100 mostra que a atração hidrofóbica entre essas espécies é menor do que a observada para o par $\mathrm{H}_{2}$ TPPS/Triton $\times 100$. Como a quantidade de cargas nas duas classes de porfirinas é a mesma (quatro substituintes periféricos iônicos) e não há diferença apreciável no tamanho dessas moléculas, o fator associado a essa diferença de comportamento é a maior delocalização da carga positiva no derivado piridínio substituído. Como já discutido, os baixos valores de potencial de redução da $\mathrm{H}_{2}$ TMPyP 
e sua baixa constante de protonação dos nitrogênios pirrólicos mostram a ocorrência de uma ressonância entre a carga do anel piridínico e o macrociclo porfirínico, essa delocalização diminui o caráter hidrofóbico do macrociclo em relação às porfirinas fenil substituídas em que a carga fica mais localizadas no substituinte periférico.

A interação das $\mathrm{H}_{2}$ TMPyP e MTMPyP com o SDS em concentrações acima da cmc foram caracterizadas pelas três técnicas utilizadas. Os resultados foram interpretados indicando a presença dos denvados porfirínicos na forma monomérica associados às micelas. Essa interação deve ocorrer na superfície carregada da micela, correspondendo a um forte caráter coulômbico como responsável pela interação. É importante ressaltar que os modelos de interação proposto por Kadish e colaboradores levam em consideração a presença de dímeros da $\mathrm{H}_{2}$ TMPyP em solução aquosa, seguindo a proposta de Kano e outros autores.

Baku e colaboradores ${ }^{63}$ investigaram as propriedades espectroscópicas do agregado formado pela $\mathrm{H}_{2}$ TPPS e as micelas de Triton $\times 100$. Os deslocamentos dos máximos de emissão e de absorção e suas intensidades relativas da $\mathrm{H}_{2}$ TPPS em solução aquosa e em solução contendo Triton X100 em concentrações acima, próximo e abaixo da cmc são interpretados em função do modelo dos quatro orbitais de fronteira proposto por Gouterman. A partir de comparações com dados espectroscópicos da $\mathrm{H}_{2}$ TPPS em vários solventes orgânicos Os autores concluem que a interação entre a porfirina e a micela deve ocorrer na região polar desta, ou seja na região dos polioxietilenos ${ }^{63}$. O aumento da intensidade de fluorescência do derivado porfirínico com o aumento da concentração de Triton $X 100$ verificado é atribuído à microviscosidade da região de solvatação da porfirina. O meio em que a porfirina se encontra na micela (região polar) inibe o decaimento não radioativo devido ao aumento na rigidez da molécula, causando a intensificação da fluorescência.

Um estudo utilizando surfactantes catiônicos derivados de sais quaternários de amônio com diferentes extensões da cadeia hidrofóbica determinou as faixas de concentração da $\mathrm{H}_{2}$ TPPS e do surfactante em que há a formação de um agregado insolúvel $^{64}$. A solubilização desse agregado ocorre em concentrações abaixo da cmc, indicando a formação de um agregado pré micelar.

Hinoue e colaboradores ${ }^{65}$ comunicaram o estudo da interação entre CTAB e $\mathrm{H}_{2}$ TPPS, variando-se a concentração do surfactante. $\mathrm{O}$ acompanhamento espectrofotométrico e sua posterior análise fatorial possibilitou a determinação do cálculo das constantes de formação dos agregados, bem como a determinação da relação estequiométrica porfirina/surfactante nos complexos formados em concentrações inferiores a cmc. Segundo a comunicação, o complexo TPPS(CTAB $)_{4}$ é 
a espécie insolúvel referida por Tominaga e co-autores. A ausência de fluorescência do precipitado e o perfil anormal do espectro de absorção em relação ao observado para $\mathrm{H}_{2}$ TPPS em água pura ou em meio micelar indica uma interação eletrônica entre os anéis porfirínicos no precipitado.

As interações das porfirinas meso substituidas $\mathrm{H}_{2}$ TMPyP, $\mathrm{H}_{2}$ TPPS e $\mathrm{H}_{2}$ TPPC e suas respectivas formas diácidas foram estudadas com os surfactantes CTAB, SDS e Triton X100 em função da concentração do surfactante ${ }^{66}$. Uma atenção especial foi dada à formação de agregados pré micelares que foram caracterizados por espectroscopia de absorção e de emissão. Maiti e colaboradores confirmam a não ocorrência de agregados entre porfirinas e surfactantes de mesma carga, assim como da $\mathrm{H}_{2}$ TMPyP com Triton $\times 100$.

A $\mathrm{H}_{2}$ TMPyP forma um agregado pré micelar com SDS, esse agregado apresenta absortividade por mol da banda Soret e intensidade de fluorescência menores do que a porfirina em água pura ou em solução micelar de SDS. Já a porfirina dissolvida em solução aquosa contendo SDS em concentração acima da cmc apresenta deslocamento batocrômico das bandas de absorção, maior rendimento quântico de fluorescência $\left(\Phi_{\mathrm{F}}\right)$ e maior tempo de vida do estado excitado singlete $\left(\tau_{\mathrm{S}}\right)$ do que a porfirina em solução aquosa.

A interação das porfirinas aniônicas com Triton X100 não apresenta formação de agregados pré micelares. A determinação de apenas um ponto isosbéstico durante a adição de surfactante evidencia a presença de duas espécies em equilíbrio, a porfirina em solução aquosa e a porfirina em meio micelar. Experimentos realizados em soluções ácidas, em que a porfirina em solução se encontra na forma totalmente protonada mostram que ocorre desprotonação da porfirina durante a incorporação na micela, pois o espectro de absorção passa de duas bandas $Q$ (simetria $D_{4 h}$ ) para quatro bandas $Q$ (simetria $D_{2 h}$ ) característica da forma base livre.

As porfirinas $\mathrm{H}_{2}$ TPPS e $\mathrm{H}_{2}$ TPPC formam agregados em soluções contendo CTAB em concentrações abaixo da cmc que apresentam deslocamento hipsocrômico da banda Soret. Esses agregados foram identificados como $\mathrm{H}$-agregados, ou seja um agregado em que os monômeros possuem alto acoplamento eletrônico e os momentos de transição dos monômeros estão perpendiculares ao eixo do agregado. Esses agregados apresentam geometria cofacial.

Agregados com um arranjo espacial bem definido apresentam propriedades eletrônicas e espectroscópicas de muito interesse na construção de molecular devices $^{67}$. Além dos $\mathrm{H}$-agregados identificados para a interação $\mathrm{H}_{2}$ TPPS e CTAB, podem ocorrer os agregados do tipo $\mathrm{J}$, em que os monômeros estão agrupados lado a 
lado, sendo que os momentos de transição dos monômeros estão paralelos entre si (figura 17).

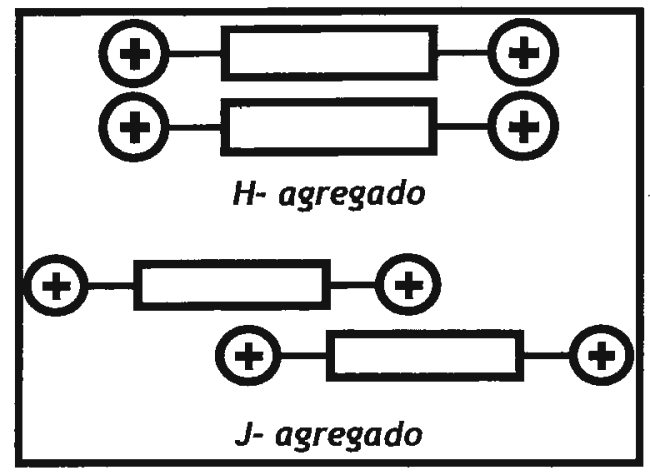

figura 17: Esquema representando os agregados tipo $\mathrm{J}$ e $\mathrm{H}$

\subsection{Terapia Fotodinâmica}

O uso da luz visivel aplicada à medicina é conhecida por fototerapia. A fototerapia é classificada em duas categonas: direta, na qual moléculas endógenas, como proteínas e ácidos nucléicos, aborvem a luz, ocorrendo alterações na sua estrutura ou processo metabólico; ou, indireta, na qual o efeito é promovido por um fotossensibilizador administrado, atuando como absorvedor efetivo da luz.

A fototerapia indireta aplicada ao tratamento de tumores é chamada de terapia fotodinâmica. A terapia fotodinâmica (PDT) é uma das aplicações com maiores possibilidades para as porfirinas meso substituídas. Essas porfirinas têm se destacado quanto às suas propriedades fotofísicas, sua baixa toxicidade e alguma especificidade às células tumorais.

Em linhas gerais, a terapia fotodinâmica consiste na aplicação de um fármaco, denominado sensibilizador, na incidência de luz e a interação da espécie excitada formada com o oxigênio $\left(\mathrm{O}_{2}\right)^{3,68}$. Após a aplicação da droga deve-se esperar 0 momento em que a sua distribuição é máxima nos tecidos tumorais e mínima nos tecidos sadios. O tecido é então irradiado com luz visivel, excitando o sensibilizador. Em seguida, ocorre a transferência de energia do estado triplete do fotossensibilizador para $\circ \mathrm{O}_{2}$ presente na célula, formando a espécie reativa ${ }^{1} \mathrm{O}_{2}$, responsável por uma série de danos celulares, podendo levar à necrose ou apoptose da célula ${ }^{69}$. Esse processo está esquematizado na figura abaixo, sendo conhecido processo fotodinâmico Tipo II, sendo considerado o principal mecanismo de dano em PDT $^{3}$. As reações entre o ${ }^{1} \mathrm{O}_{2}$ e as biomoléculas como lipídios insaturados, colesterol, triptofano, metionina e guanina são descritas na literatura e estudadas in vivo e in vitro ${ }^{3}$. 


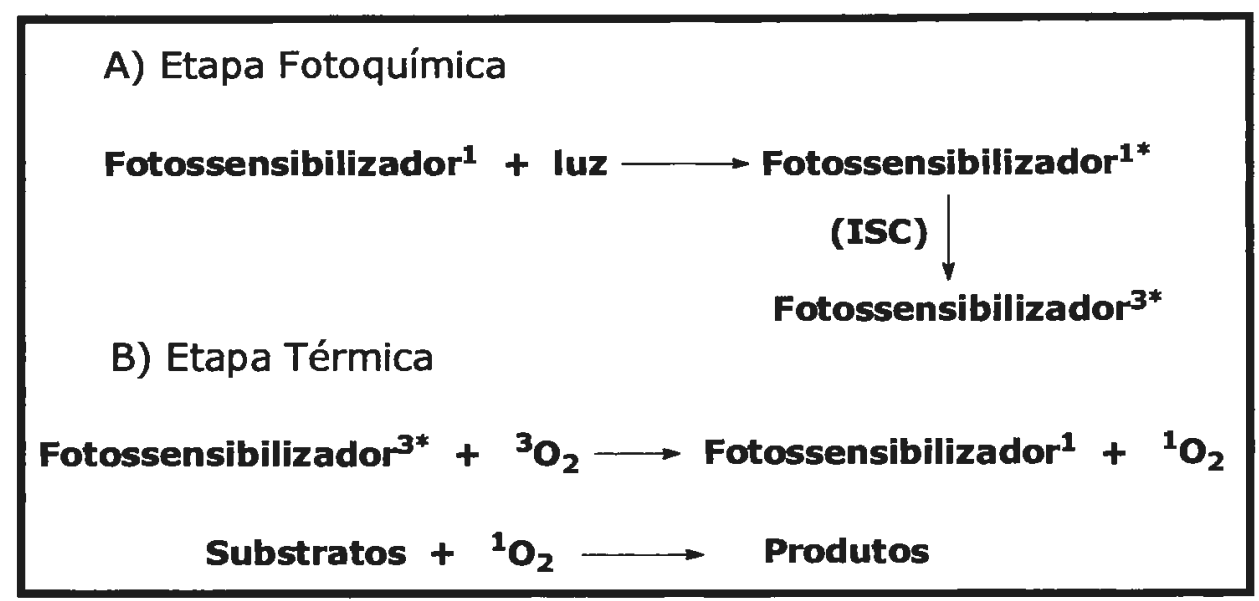

figura 18: Esquema das etapas do processo Tipo I de PDT.

Outro processo possivel na terapia fotodinâmica, relevante em condições de baixa concentração de oxigênio molecular, é o processo fotodinâmico Tipo I, que envolve a transferência de elétrons do estado excitado triplete do sensibilizador diretamente para uma biomolécula, gerando um ânion radical que pode em seguida reagir com uma espécie oxigenada para formar um radical reativo como por exemplo, $\mathrm{HO}^{*}, \mathrm{O}_{2}^{-}, \mathrm{H}_{2} \mathrm{O}_{2}{ }^{70}$.

O fotossensibilizador ideal deve apresentar alto teor de pureza e deve possuir bandas de absorção intensas na região no visível, preferencialmente na região de menor energia, que apresentam maior penetração nos tecidos. Idealmente, o fármaco deve apresentar citotoxicidade desprezível no escuro nas doses aplicadas, além de alta especificidade às células tumorais. A droga deve ser estável cinética e termodinamicamente, deve ter curto tempo de permanência no organismo, não sendo acumulado em nenhum tecido específico, diminuindo os efeitos tóxicos. Em termos fotofísicos o sensibilizador deve ser um eficiente gerador de espécies citotóxicas a partir da transferência de energia e/ou elétrons do estado excitado.

Os primeiros derivados porfirínicos utilizados como agentes em terapia fotodinâmica são derivados da hematoporfirina e são considerados sensibilizadores de primeira geração, não sendo muito seletivos, apresentando baixo teor de pureza e sensibilidade na pele por algumas semanas. ${ }^{3}$. Alguns desses derivados são conhecidos comercialmente como Photofrin, Photogem e Photocarcinorim.

As porfirinas meso substituidas que apresentam cargas nos substituintes periféricos e seus metaloderivados são potenciais agentes fotossensibilizadores de segunda geração. Esses derivados porfirínicos apresentam alto grau de pureza, alto rendimento quântico de formação do estado triplete e tempo de vida do estado triplete longo, sendo muito eficientes na formação de oxigênio singlete ou de outras espécies reativas de oxigênio $\left(\mathrm{O}_{2}^{-} ; \mathrm{OH}^{\circ}, \mathrm{H}_{2} \mathrm{O}_{2}\right)$. Além disso, apresentam baixa toxicidade no 
escuro e uma considerável seletividade para tecidos tumorais ${ }^{3}$. Outros derivados utilizados são as ftalocianinas ${ }^{71,72}$, e derivados reduzidos das porfirinas como as clorinas e as bacterioclorinas ${ }^{73}$.

Além da utilização da terapia fotodinâmica em tratamentos de câncer, outras aplicaçōes vem surgindo recentemente pois a $\mathrm{H}_{2}$ TMPyP e seus metalo derivados apresentam atividade contra o vírus $\mathrm{HIV}^{74,75}$ e alta eficiência na inativação de bactérias $\operatorname{gram}(+)$ e $\operatorname{gram}(-)^{76,77,78}$, a partir da excitação luminosa.

\subsubsection{Sistemas Carregadores de Drogas (Drug Delivery Systems)}

A associação dos fotossensibilizadores com macromoléculas, micelas ou lisossomos é uma possibilidade de aumentar a especificidade dessas drogas a tecidos tumorais ou outros alvos para a terapia fotodinâmica ${ }^{79,80}$, além de facilitar a permeação da droga pela membrana plasmática da célula alvo. Essa estratégia pode fornecer drogas específicas para cada tipo de tumor ou tecido atingido, melhorando em muito a eficiência da terapia. Esses sistemas são chamados de carregadores de drogas (drugs delivery) e têm representado um dos principais ramos de desenvolvimento da indústria farmacêutica nos últimos anos, sendo associados a vários tipos de drogas e tratamentos.

Os carregadores mais comuns utilizados são lipossomos ${ }^{81}$, soroalbuminas, lipoproteínas e anticorpos.

Associaçōes entre porfirinas meso substituídas e sistemas carregadores de drogas em potencial têm sido estudado, procurando-se determinar as alterações espectroscópicas e fotofísicas das porfirinas decorrente dessas interações.

Recentemente, foram investigadas as propriedades fotofísicas e físicoquímicas da $\mathrm{H}_{2}$ TMPyP e de derivados catiônicos mistos meso substituídos contendo o grupo fenil e o grupo metilpiridínio, derivando porfirinas com três, duas e uma carga positiva em lisossomos de diferentes tamanhos ${ }^{76}$. Dicelio e colaboradores concluem que todos os derivados apresentam-se na forma monomérica nos lisossomos e possuem alta constante de associação. Dependendo do grau de hidrofobicidade do substituinte periférico, com o derivado monocatiônico situando-se no centro hidrofóbico e a $\mathrm{H}_{2}$ TMPyP na interface membrana-água, entretanto todas apresentam alto rendimento quântico de formação de ${ }^{1} \mathrm{O}_{2}$.

A interação das porfirinas $\mathrm{H}_{2}$ TMPyP, $\mathrm{H}_{2}$ TPPS e $\mathrm{H}_{2}$ TPPC com a soroalbumina bovina (BSA) $)^{8,82,83}$ e humana (HSA) ${ }^{84}$ foi estudada em termos de suas propriedades fotofísicas e determinação de suas constantes de associação. 
Enquanto a $\mathrm{H}_{2}$ TMPyP não apresenta evidência de interação com a HSA a porfirina aniônica $\mathrm{H}_{2}$ TPPC e seu Co(III) derivado mostram alta associação com essa macromolécula, indicando a importância do substituinte aniônico e o papel do metal central na interação com a proteína, que age como transportadora do grupo Heme no organismo $^{84}$.

Analisando a interação porfirina-BSA a partir de dados de espectroscopia eletrônica ${ }^{82}$, ressonância de espalhamento de luz $^{83}$ e experimentos de fotólise por pulso de laser ${ }^{8}$, Borissevitch e colaboradores concluíram que tanto a $\mathrm{H}_{2}$ TMPyP, quanto a $\mathrm{H}_{2}$ TPPS se associam com o BSA.

As constantes de associação entre a porfirina aniônica e a soroalbumina são maiores e dependente do $\mathrm{pH}$ do meio, comprovando o caráter eletrostático da interação. Além disso, em certas condições são observados agregados de $\mathrm{H}_{2}$ TPPS associados à proteína, implicando em mudança significativa das propriedades fotofísicas do anel porfirínico. Já a $\mathrm{H}_{2}$ TMPyP, apesar de apresentar constantes de associação menores com o BSA, apresenta-se na forma monomérica quando associada à proteína, ocorrendo variações menos drásticas nas suas propriedades fotofísicas.

Outros carregadores têm sido avaliados, como os calixarenos tetrasulfonados e as ciclodextrinas ${ }^{85}$. Lang e coautores investigaram as propriedades fotofísicas e as transferência de elétrons fotoinduzidas de complexos da $\mathrm{H}_{2}$ TMPyP e ciclodextrinas ou calixarenos de diferentes tamanhos de cavidade.

Os calixarenos sulfonados apresentam alta interação eletrostática com a porfirina catiônica formando complexos muito estáveis. Observa-se considerável decréscimo dos rendimentos quânticos de fluorescência $\left(\Phi_{F}\right)$ e de formação do estado triplete $\left(\Phi_{\mathrm{T}}\right)$, atribuído a uma transferência de elétrons intramolecular. Esse complexo pode ser um ótimo modelo para o estudo de transferência de elétrons fotoinduzida em sistemas não covalentemente ligados, entretanto não apresenta interesse como carreador de drogas uma vez que impede a formação de espécies reativas de oxigênio, não sendo um fotosensibilizador adequado para a PDT. Já as ciclodextrinas não modificam as propriedades fotofísicas da $\mathrm{H}_{2}$ TMPyP em relação às observadas em solução, indicando ser ter uma possivel aplicação como carregador desse sensibilizador.

O estudo da interação das porfirinas meso substituídas com surfactantes catiônicos, aniônicos e não iônicos mimetizam as diferentes condições hidrofóbicas e hidrofílicas encontradas nas interações com biomoléculas ou lisossomos, sendo importantes modelos de carregadores de drogas $59,64,70$. 


\subsubsection{Interação com Ácidos Nucleicos}

Nas últimas duas décadas a interação de porfirinas piridínio substituídas, principalmente a $\mathrm{H}_{2}$ TMPyP com ácidos nucleicos (RNA e DNA) tem sido largamente estudada com dois objetivos principais ${ }^{86}$ :

- a obtenção de informações sobre a estrutura e dinâmica dos ácidos nucleicos, permitindo um entendimento mais detalhado das bases moleculares de uma grande variedade de processos genéticos e dos fenômenos envolvendo a interação destes ácidos com moléculas de interesse farmacológico. Isto torna-se possivel, visto que os compostos porfirínicos apresentam um amplo e versátil conjunto de propriedades, tais como fluorescência, intensa absorção na região do visivel e paramagnetismo, que podem ser moduladas em função da estrutura do ligante e/ou do metal coordenado, e que também são influenciadas pelo meio;

- o potencial uso terapêutico no tratamento de câncer, uma vez que os compostos porfirínicos têm grande afinidade pelos tecidos tumorais e, sob determinadas condições, provocam a clivagem química/fotoquímica dos ácidos nucleicos.

Os estudos realizados até o momento procuram caracterizar a interação das porfirinas catiônicas e seus metalo derivados com cadeias de DNA ou poli nucleotídeos com repetição de bases fixas (poli $(G-C)_{n}$ ou poli( $\left.(A-T)_{n}\right)$, através de técnicas e parâmetros diversos: dicroismo circular e linear ${ }^{6,87}$, espectroscopia UV$V_{i s}{ }^{6,74,88}, R M N-{ }^{1} H^{74,88,89}, R^{2}{ }^{31}{ }^{375}$, viscosimetria ${ }^{90}$, fluorescência ${ }^{6}$, ressonância Raman, cinética stopped-flow ${ }^{91}$, fotólise por pulso de laser e formação de oxigênio singlete ${ }^{2}$.

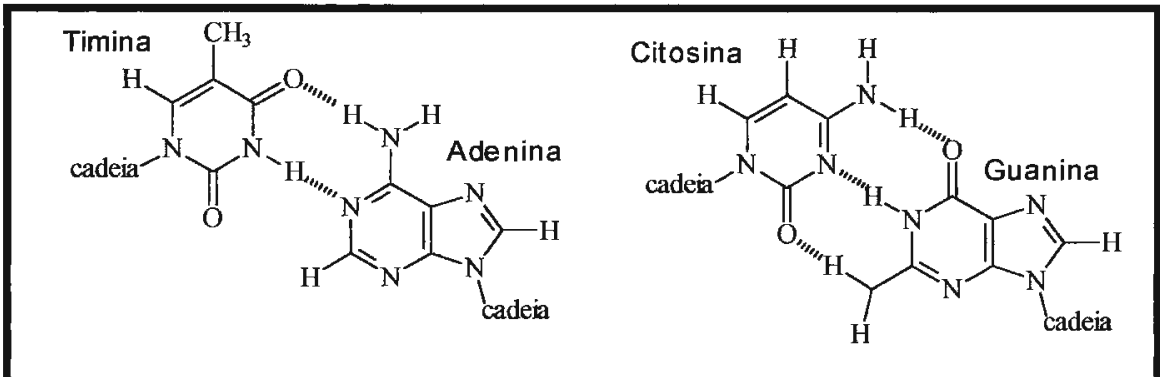

figura 19: Estrutura dos pares de bases do DNA

Genericamente dois tipos de interação são verificados, a porfirina intercalando em posição perpendicular a dupla hélice ou ocorrendo uma ligação externa da porfirina na dupla hélice. 
As porfirinas que intercalam com o DNA são as bases livres ou os derivados metálicos que não apresentam ligantes axiais, formando complexos quadrado planares, como os íons metálicos $\mathrm{Cu}(\mathrm{II}), \mathrm{Ni}(\mathrm{II})$ e $\mathrm{Pd}(\mathrm{II})$. Porfirinas com substituintes periféricos muito grandes como a TOcPyP ou que apresentem impedimento estérico evitando a coplanaridade entre o macrociclo central e os anéis piridínicos $\left(\mathrm{H}_{2} T M P y P-2\right.$, por exemplo), não apresentam intercalação. O sítio específico para intercalação ocorre em regiões ricas em pares de bases $G-C^{26,92}$.

O mecanismo proposto ${ }^{6}$ para a intercalação com DNA envolve a quebra das ligações de hidrogênio e outras interações entre as bases de DNA G-C, além da energia necessária para manter os substituintes meso coplanares ao anel porfirínico. Essa perda de energia seria compensada pelas interações eletrostáticas entre as cargas dos anéis piridínicos e os grupos fosfato das bases do DNA, as interações de van der Waals entre o macrociclo e os anéis pirimidina e purina das bases e a retirada do anel porfirínico do meio aquoso.

Complexos porfirínicos de Zn(II), que apresentam um ligante axial, e de $\mathrm{Fe}$ (III), $\mathrm{Mn}$ (III) e Co(III), que apresentam dois ligantes axiais, não intercalam com o DNA, ligando-se externamente à regiões nicas em bases $A T^{88,92}$. O mesmo acontece com as porfirinas que possuem substituintes periféricos muito grandes ou que impedem a rotação do anel piridínico. Dois tipos de associação externa foram caracterizados, um em que a porfirina está na forma monomérica e um segundo em que ocorre agregação da porfirina associada ao DNA.

Os tipos de interação verificados entre as porfirinas meso piridínio substituídas e os polímeros de ácidos nucleicos são dependentes da força iônica do meio ${ }^{88,93}$.

A clivagem do DNA na presença de compostos porfirínicos pode ocorrer através de um processo químico ou fotoquímico. Na clivagem química, os responsáveis pela quebra são os oxo-complexos de alta valência ${ }^{675}$, que têm sua formação induzida por agentes oxidantes, como $\mathrm{KHSO}_{5}$, ou ion superóxido. A clivagem pode ocorrer em uma ou nas duas fitas da dupla hélice do DNA, sendo estas características de clivagem dependentes do tipo de DNA, assim como do composto porfirínico utilizado.

No processo fotoquímico, o agente responsável pela clivagem é o oxigênio singlete ${ }^{2.94}$, formado pela transferência de energia entre o estado excitado da porfirina/metaloporfirina e o oxigênio molecular. Para que a quebra seja efetiva a formação da espécie ${ }^{1} \mathrm{O}_{2}$ deve ocorrer próximo de resíduos de guanina, uma vez que 
essa base apresenta reatividade cerca de 50 vezes maior do que a citosina e mais de cem vezes maior em relação às outras bases nitrogenadas $2,95$.

Kruk e colaboradores ${ }^{2}$ determinaram os parâmetros fotofísicos de formação do estado triplete e formação de ${ }^{1} \mathrm{O}_{2}$ da $\mathrm{H}_{2}$ TMPyP ligada a dupla fita de DNA ou ainda de

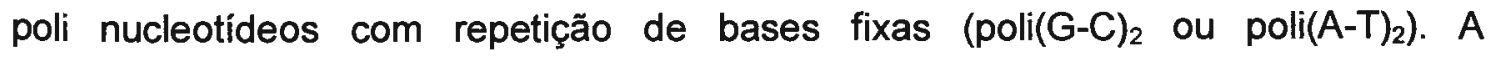
intercalação da porfirina com regiões ricas em pares G-C ocasiona uma diminuição do rendimento quântico do estado triplete para 0,44. O aumento do tempo de vida do estado triplete devido a dificuldade de acesso do oxigênio molecular à porfirina corrobora com o modelo de intercalação proposto. A eficiência de formação do ${ }^{1} \mathrm{O}_{2}$ é de aproximadamente 1,0 , mostrando que esse é um bom modelo em aplicação de PDT. A $\mathrm{H}_{2}$ TMPyP ligada externamente ao DNA, em sítios ricos em bases A-T, apresenta rendimento quântico de formação de ${ }^{1} \mathrm{O}_{2}$ de 0,78 , um valor bastante elevado. Entretanto, a sua relevância para aplicações em PDT depende da presença de resíduos de guanina próximos, para que haja quebra do $\mathrm{DNA}^{2,96}$.

Um novo campo de aplicação anti tumoral têm sido estudado nos últimos anos para a $\mathrm{H}_{2} \mathrm{TMPyP}^{97}$ e seus metalo derivados, uma vez que essas porfirinas têm se mostrado um eficiente inibidor da enzima telomerase, envolvida no processo de duplicação celular ${ }^{97,98}$. Fedoroff e colaboradores ${ }^{89}$ demonstraram recentemente que a interação da $\mathrm{H}_{2}$ TMPyP com a região telomérica de fitas de DNA, também conhecida como i-Motif DNA, ocasiona a formação de estruturas não usuais nessa região, sendo esse o mecanismo provável de inibição da telomerase.

\subsection{Pares lônicos entre Complexos Porfirínicos}

Dímeros de macrociclos tetrapirrólicos apresentam um papel fundamental como modelos do special pair do sistema fotossintético, formando sistemas com efetiva separação de cargas após fotoexcitação ${ }^{10,99}$. Esses sistemas supramoleculares podem ser sintetizados a partir de ligações covalentes, ou via complexação dos metais internos, ou ainda através da interação eletrostática entre dois anéis porfirínicos contendo substituintes periféricos de carga oposta.

Nos últimos anos têm se desenvolvido a química de sistemas envolvendo pares iônicos formados por porfirinas ou ftalocianinas ${ }^{10,100}$. Além da atração eletrostática, as forças de van der Waals provenientes das interações entre os macrociclos $^{101}$ são responsáveis pelas associação dessas moléculas, formando dímeros ou trímeros de acordo com as moléculas em questão e o solvente utilizado. $\mathrm{A}$ geometria planar desses compostos permite uma disposição cofacial dos macrociclos constituintes resultando em uma forte interação orbital. 
A magnitude das interações entre os macrociclos são dependentes ${ }^{100}$ do íon metálico coordenado aos macrociclos, pois se há coordenação axial com o solvente ocorre distorção na planandade do anel, diminuindo a interação entre as nuvens $\pi$; dos substituintes periféricos que podem dificultar a formação do dímero devido a impedimento estérico ou ainda auxiliar a interação criando novas regiões de interações de van der Waals; e dos solventes que alteram a esfera de solvatação e as forças de atração de van der Waals e coulômbica.

As propriedades espectroscópicas e fotofísicas desses sistemas têm sido estudadas e um resumo dos resultados é apresentado por Tran-Thi ${ }^{10}$. Alguns autores têm proposto modelos de agregação para os diferentes pares iônicos obtidos, enquanto Hofstra ${ }^{99}$ e colaboradores propõem para o heterodímero ZnTMPyP/ZnTPPC um agregado cofacial com deslocamento dos macrociclos a partir da análise dos espectros e RMN-1'H em solução, Tran-Thi propõe uma disposição totalmente cofacial para o heterodímero entre a ZnTMPyP e a tetrasulfonato cobre(II)ftalocianina (CuPcTS.).

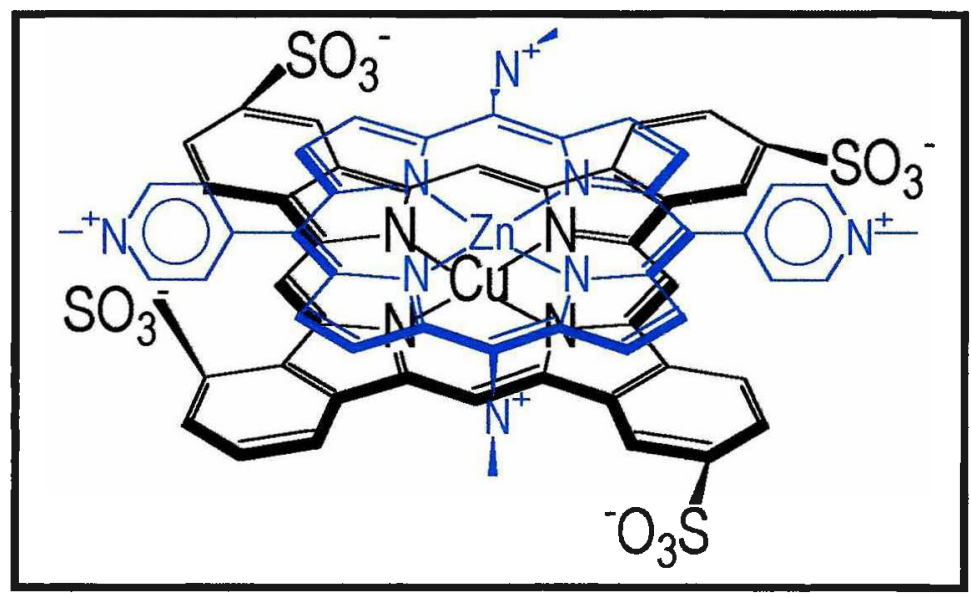

figura 20: Estrutura do Heterodímero formado ZnTMPyPICuPcTS. 


\subsection{Objetivos}

Nos últimos anos a $\mathrm{H}_{2}$ TMPyP e seus derivados metalados têm se destacado em aplicações de terapia fotodinâmica, sobretudo na interação com DNA e na ação anti-tumoral. Essa porfirina apresenta comportamentos fotofísicos, eletroquímicos e de associação em solução aquosa únicos, devido a delocalização da carga dos nitrogênios piridínicos no anel do macrociclo.

O objetivo desse trabalho é a sintese e a caracterização espectroscópica, eletroquímica e da interação com surfactantes de uma nova série de porfirinas piridínio substituidas e seus respectivos $\mathrm{Zn}$ (II) e $\mathrm{Cu}$ (II) complexos, cujo substituinte periférico contém anéis fenílicos, conferindo a molécula um maior caráter hidrofóbico.

O estudo espectroscópico de absorção e emissão procura correlacionar o efeito eletrônico dos substituintes periféricos com as transições eletrônicas dos estados fundamental e excitado. A caracterização do estado triplete, através da técnica de fotólise por pulso de laser, tem como objetivo veificar as alterações causadas pelos substituintes benzílicos na cinética do estado excitado triplete. A determinação das constantes de supressão com reconhecidos aceptores de elétrons iônicos, metilviologênio (MV), benzilviologênio (BV), antraquinona-2-sulfonato de sódio (AQS) e pentamincloro cobalto(III) $\left(\mathrm{CoA}_{5} \mathrm{Cl}^{2+}\right)$ fornece informações da reatividade do estado triplete frente ao oxigênio molecular e outros supressores presentes em solução. Os resultados são comparados com os apresentados pela a $\mathrm{H}_{2}$ TMPyP, pois suas propriedades do estado triplete são adequadas para aplicações em terapia fotodinâmica. Adicionalmente, a determinação dos rendimentos quânticos de formação de ${ }^{1} \mathrm{O}_{2}$, serve para demonstrar a eficiếncia desta classe de compostos em futuras aplicaçōes de terapia fotodinâmica.

O estudo eletroquímico, através dos voltamogramas cíclicos e da espectroeletroquímica, tem como intuito a caracterização dos processos redox das porfirinas piridínio substituídas até então limitadas pela $\mathrm{H}_{2}$ TMPyP e seus metalo derivados.

Para uma efetiva utilização dessas porfirinas em sistemas biológicos é necessário conhecer o seu comportamento em solução aquosa com força iônica controlada, procurando-se determinar a sua tendência de formação de agregados, uma vez que a formação de homoagregados é relatada para derivados análogos, modificando substancialmente as propriedades fotofísicas em relação aos monômeros em soluçäo.

A caracterização da interação com surfactantes busca correlacionar o papel do substituinte periférico, que apresenta maior caráter hidrofóbico, nas interações com 
micelas e monômeros dos detergentes catiônicos, aniônicos e não iônicos, comparando com o comportamento conhecido das porfirinas $\mathrm{H}_{2}$ TMPyP e $\mathrm{H}_{2}$ TPPS. Essa maior contribuição hidrofóbica pode auxiliar na formação de agregados com biomoléculas utilizadas como carreadores de corantes, obtendo-se maior especificidade nos processos de terapia fotodinâmica.

A caracterização das porfirinas obtidas por $\mathrm{RMN}-{ }^{1} \mathrm{H}$, infravermelho e raman ressonante permite inferências sobre a sua estrutura e os efeitos eletrônicos dos substituintes periféricos sobre o macrociclo.

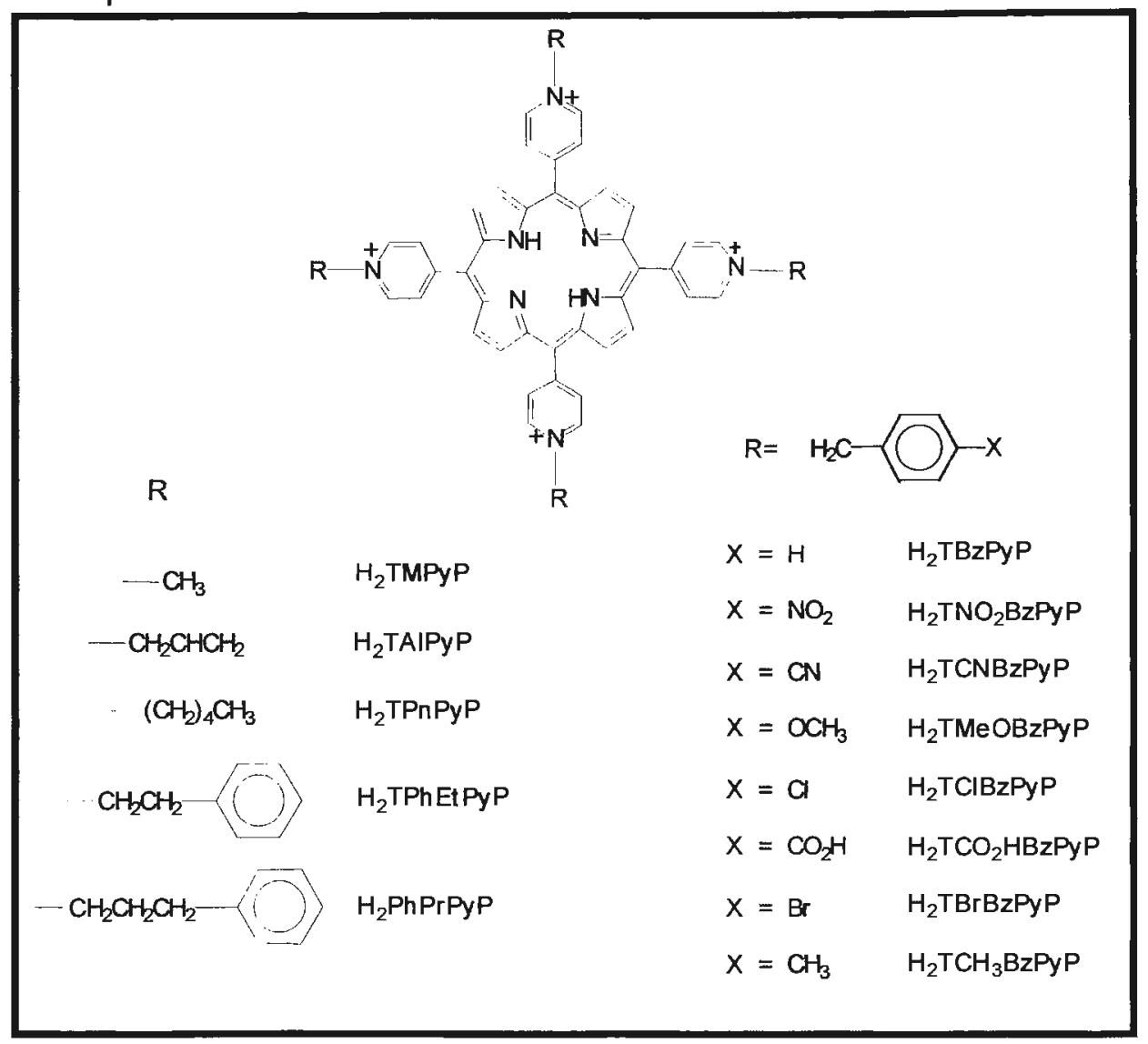

figura 21: Estrutura e abreviatura das porfirinas envolvidas nesse trabalho. 


\section{Materiais e Métodos}

\subsection{Reagentes}

Os reagentes e solventes obtidos comercialmente são de grau analítico e foram empregados nas sínteses sem purificação prévia, exceto quando indicado.

\begin{tabular}{|c|c|c|}
\hline Sub & Fórm & Procedência \\
\hline 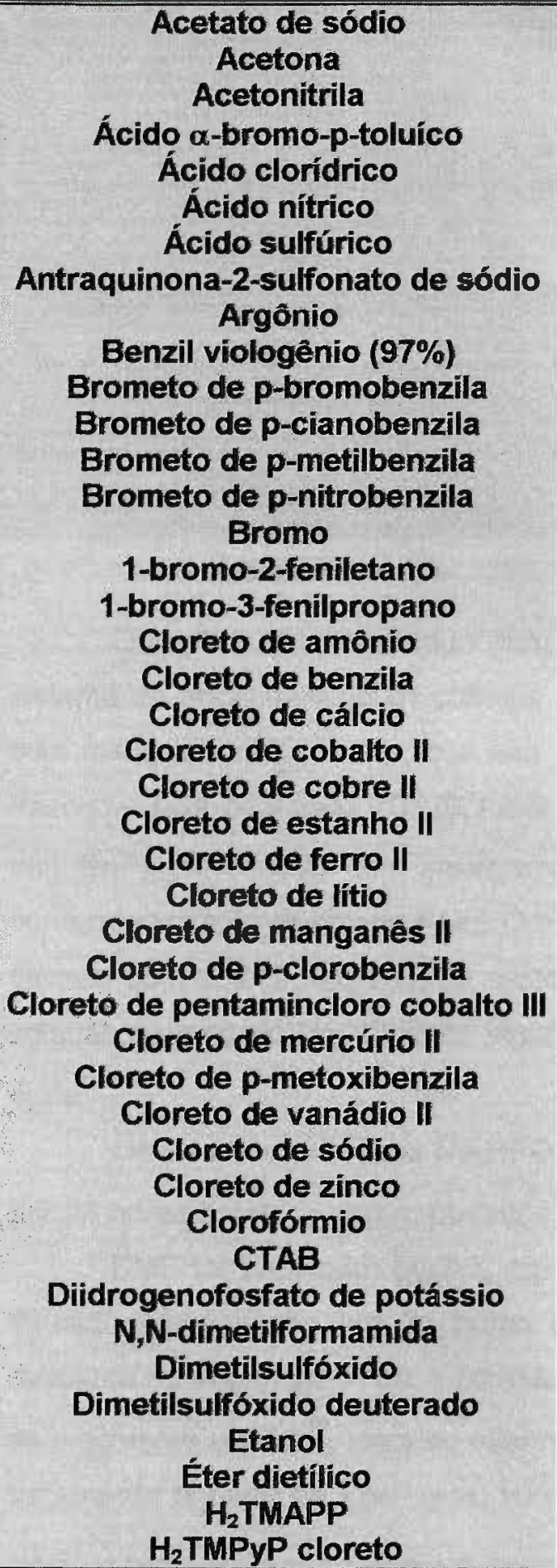 & 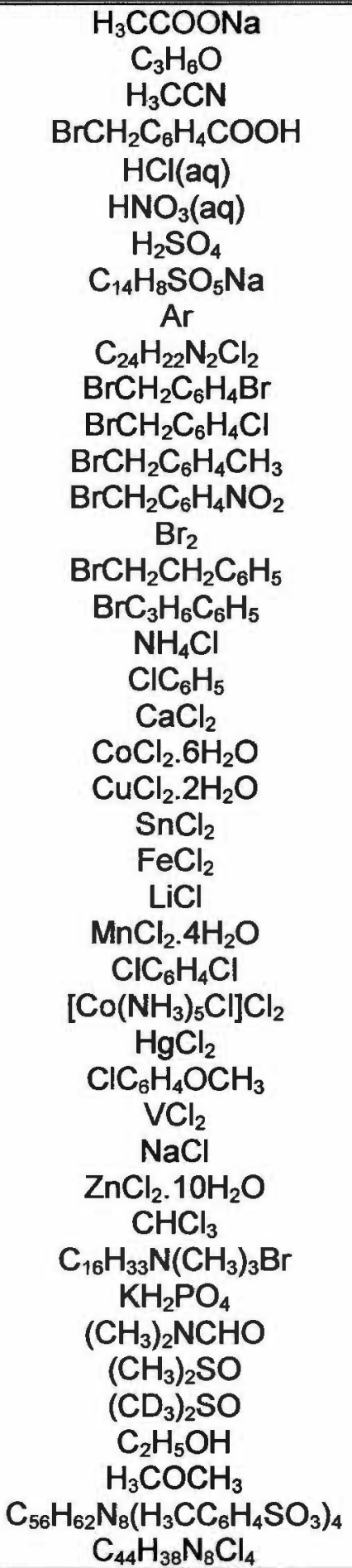 & $\begin{array}{c}\text { Merck } \\
\text { Merck } \\
\text { Sigma } \\
\text { Aldrich } \\
\text { Merck } \\
\text { Merck } \\
\text { Merck } \\
\text { Aldrich } \\
\text { White Martins } \\
\text { Aldrich } \\
\text { Aldrich } \\
\text { Aldrich } \\
\text { Aldrich } \\
\text { Aldrich, sintetizado* } \\
\text { Losco } \\
\text { Aldrich } \\
\text { Aldrich } \\
\text { Merck } \\
\text { Aldrich } \\
\text { Cinética } \\
\text { Aldrich } \\
\text { Reagen } \\
\text { Merck } \\
\text { Synth } \\
\text { Mallinckodt } \\
\text { Merck } \\
\text { Sato, Aldrich } \\
\text { Sintetizado* } \\
\text { Merck } \\
\text { Aldrich } \\
\text { Aldrich } \\
\text { Merck } \\
\text { Cinética } \\
\text { Merck } \\
\text { Merck } \\
\text { Carlo Erba } \\
\text { Merck, Sigma } \\
\text { Aldrich } \\
\text { Merck, Aldrich } \\
\text { Merck } \\
\text { QM, Synth } \\
\text { Aldrich } \\
\text { Midcentury } \\
\text { Miden }\end{array}$ \\
\hline
\end{tabular}




\begin{tabular}{|c|c|c|}
\hline $\begin{array}{c}\mathrm{H}_{2} \text { TMPyP tosilato } \\
\mathrm{H}_{2} \text { TPPS } \\
\mathrm{H}_{2} \text { TPyP (97\%) } \\
\text { Hidrogenofosfato de sódio } \\
\text { Hidróxido de amónio } \\
\text { Hidróxido de sódio } \\
\text { 1-iodopentano } \\
\text { Metanol } \\
\text { Metanol deuterado } \\
\text { Metil viologênio } \\
\text { Nitrato de sódio } \\
\text { Nitrogênio } \\
\text { Nitrotolueno } \\
\text { Óxido de deutério } \\
\text { Pentóxido de fósforo } \\
\text { Perclorato de sódio } \\
\text { Perclorato de tetraetilamônio } \\
\text { Peróxido de hidrogênio } 30 \% \\
\text { PTE } \\
\text { p-toluenosulfonato de metila } \\
\text { SDS } \\
\text { Sulfato de cobre II pentaidratad } \\
\text { Sulfato de magnésio } \\
\text { Sulfato de sódio } \\
\text { Triton-X100 } \\
\text { Zinco }\end{array}$ & $\begin{array}{c}\mathrm{C}_{44} \mathrm{H}_{38} \mathrm{~N}_{8}\left(\mathrm{H}_{3} \mathrm{CC}_{6} \mathrm{H}_{4} \mathrm{SO}_{3}\right)_{4} \\
\mathrm{C}_{44} \mathrm{H}_{26} \mathrm{~N}_{4} \mathrm{O}_{12} \mathrm{~S}_{4} \mathrm{Na}_{4} \\
\mathrm{C}_{40} \mathrm{H}_{26} \mathrm{~N}_{8} \\
\mathrm{Na}_{2} \mathrm{HPO}_{4} \\
\mathrm{NH}_{4} \mathrm{OH}(\mathrm{aq}) \\
\mathrm{NaOH} \mathrm{OH} \\
\mathrm{C}_{5} \mathrm{H}_{11} \mathrm{I} \\
\mathrm{CH}_{3} \mathrm{OH} \\
\mathrm{CD}_{3} \mathrm{OD} \\
\mathrm{C}_{12} \mathrm{H}_{14} \mathrm{~N}_{2} \mathrm{Cl}_{2} \\
\mathrm{NaNO}_{3} \\
\mathrm{~N}_{2} \\
\mathrm{H}_{3} \mathrm{CC}_{6} \mathrm{H}_{4} \mathrm{NO}_{2} \\
\mathrm{D}_{2} \mathrm{O} \\
\mathrm{P}_{2} \mathrm{O}_{5} \\
\mathrm{NaClO}_{4} \\
\left(\mathrm{C}_{2} \mathrm{H}_{5}\right)_{4} \mathrm{NClO}_{4} \\
\mathrm{H}_{2} \mathrm{O}_{2}(\mathrm{aq}) \\
\mathrm{C}_{13} \mathrm{H}_{27}\left(\mathrm{OCH}_{2} \mathrm{CH}_{2}\right)_{10} \mathrm{OH} \\
\mathrm{H}_{3} \mathrm{CC}_{6} \mathrm{H}_{4} \mathrm{SO}_{3} \mathrm{CH}_{3} \\
\mathrm{C}_{12} \mathrm{H}_{25} \mathrm{OSO}_{3} \mathrm{Na} \\
\mathrm{CuSO}_{4} .5 \mathrm{H}_{2} \mathrm{O} \\
\mathrm{MgSO}_{4} \\
\mathrm{Na}_{2} \mathrm{SO}_{4} \\
\mathrm{Ca}_{8} \mathrm{H}_{17} \mathrm{C}_{6} \mathrm{H}_{4}\left(\mathrm{OCH}_{2} \mathrm{CH}_{2}\right)_{10} \mathrm{OH} \\
\mathrm{Zn}\end{array}$ & $\begin{array}{c}\text { Aldrich, sintetizado* } \\
\text { Midcentury } \\
\text { Aldrich } \\
\text { Carlo Erba } \\
\text { Merck } \\
\text { Merck } \\
\text { Aldrich } \\
\text { Merck } \\
\text { Aldrich } \\
\text { Aldrich } \\
\text { Carlo Erba } \\
\text { White Martins } \\
\text { Merck } \\
\text { Merck } \\
\text { Riedel de Haen } \\
\text { Aldrich } \\
\text { Sintetizado* } \\
\text { Merck } \\
\text { Sigma } \\
\text { Aldrich } \\
\text { Sigma } \\
\text { Synth } \\
\text { Synth } \\
\text { Cinética } \\
\text { Sigma } \\
\text { Aldrich }\end{array}$ \\
\hline
\end{tabular}

* síntese descrita abaixo

$\mathrm{O}$ argônio (Ar) foi tratado para a eliminação de traços de $\mathrm{O}_{2}$. Foi montado um sistema de encanamento de cobre e de vidro reduzindo-se ao máximo as conexōes com mangueira de silicone, que são permeáveis ao $\mathrm{O}_{2}$. $\mathrm{O} \mathrm{Ar}$ foi borbulhado em um frasco lavador contendo $\mathrm{VCl}_{2}\left(0,1 \mathrm{~mol} \mathrm{dm}^{-3}\right)$ em solução aquosa de ácido clorídrico (3 $\mathrm{mol} \mathrm{dm}^{-3}$ ) em contato com amálgama de $\mathrm{Zn}$, passando em seguida em um frasco contendo solução diluída de $\mathrm{KOH}$. O amálgama foi preparado a partir de Zn granulado, ativado com solução aquosa de ácido clorídrico $\left(2 \mathrm{~mol} \mathrm{dm}^{-3}\right)$, seguido de banho em solução aquosa de $\mathrm{HgCl}_{2}$. Após alguns minutos o amálgama é filtrado e lavado com água $^{102}$.

Os padrões primários $\mathrm{Na}_{2} \mathrm{HPO}_{4}$ e $\mathrm{KH}_{2} \mathrm{PO}_{4}$ foram deixados em estufa a $110^{\circ} \mathrm{C}$ por 24 horas antes de serem pesados ${ }^{103}$.

DMF foi seco com $\mathrm{MgSO}_{4}$ anidro por 24 horas. Após filtração, o solvente foi deixado em agitação por 24 horas com $\mathrm{CuSO}_{4}$ anidro. A mistura esverdeada foi destilada na ausência de luz a pressão de $6 \mathrm{mmHg}$ sob atmosfera de $\mathrm{N}_{2}$, recolhendose o solvente a $43^{\circ} \mathrm{C}^{34}$. Para os experimentos de eletroquímica foi realizado o mesmo tratamento a partir de DMF grau HPLC (Sigma). O solvente foi recolhido em frasco 
escuro com peneira molecular (4 A) e mantido em atmosfera de argônio, sendo utilizado em menos de 48 horas.

Éter dietílico foi tratado com soluçăo de $\mathrm{SnCl}_{2}$ em $\mathrm{H}_{2} \mathrm{SO}_{4} 6 \%$, para eliminar peróxidos $^{104}$. O solvente foi, posteriormente, seco com $\mathrm{CaCl}_{2}$ e destilado, sendo armazenado em geladeira.

Cloreto de benzila e o brometo de alila foram secos em $\mathrm{MgSO}_{4}$ anidro e destilados a pressão reduzida.

O p-toluenosulfonato de metila foi destilado a $4 \mathrm{mmHg}$, sendo recolhido a $143^{\circ} \mathrm{C}$.

Brometo de p-nitrobenzila foi obtido a partir da adiçăo lenta de $\mathrm{Br}_{2}$ ao p-nitrotolueno ${ }^{105}$ a $150^{\circ} \mathrm{C}$. O sólido obtido após recristalização em éter de petróleo apresenta ponto de fusão de $99^{\circ} \mathrm{C}$.

Cloreto de pentamincloro cobalto foi obtido repetindo-se o procedimento descrito por Pass ${ }^{106}$, utilizando-se cloreto de cobalto(II) ao invés de carbonato de cobalto(II). Os valores de absortividade molar são condizentes com a literatura ${ }^{107}$.

O perclorato de tetraetilamônio (TEAP), gentilmente cedido pelo prof. Henrique E. Toma, foi preparado a partir da reação entre o hidróxido de tetraetilamônio e ácido perclónico, sendo purificado por recristalizaçāo ${ }^{108}$.

\subsection{Sintese das porfirinas e metaloporfirinas}

As condições de sintese empregadas nesse trabalho foram desenvolvidas pelo laboratório em estudos anteriores ${ }^{21,22}$ sendo que algumas modificaçōes foram inseridas de acordo com as particularidades de cada síntese. As condiçōes descritas referem-se às concentraçōes dos reagentes e não às quantidades empregadas, uma vez que algumas sínteses foram repetidas diversas vezes. As condições descritas são as que resultaram em um produto com alto teor de pureza e um rendimento adequado. Reaçōes empregando quantidades superiores a $200 \mathrm{mg}$ de $\mathrm{H}_{2}$ TPyP foram evitadas, pois apresentam uma dificuldade adicional na etapa de separação do produto, uma vez que a grande quantidade de agente alquilante em excesso solubiliza a porfinina tetraalquilada, mesmo adicionando grandes quantidades de clorofórmio ou acetona.

Todas as porfirinas/metaloporfininas isoladas foram secas em pressão reduzida em Abderhalden contendo $\mathrm{P}_{2} \mathrm{O}_{5}$ como dessecante, por cerca de 12 horas, antes de serem enviadas para a determinação da análise elementar. Entretanto, mesmo após esse procedimento foi verificada a presença de água de hidratação nas porfirinas. $O$ número de moléculas de água foi estipulado a partir da porcentagem de carbono encontrada, considerando que qualquer desvio do calculado se deve a moléculas de 
água. A suposição parece razoável uma vez que a proporção $\mathrm{C}: \mathrm{N}$ está de acordo com o valor calculado e a porcentagem de $\mathrm{H}$ se encaixa com a inserção de moléculas de água. O espectro de I.R. mostra a presença de água de hidratação nas porfirinas piridinio substituídas, com as bandas caracteristicas aparecendo com muito mais intensidade do que o observado no espectro da $\mathrm{H}_{2}$ TPyP, que possui nominalmente uma molécula de água de hidratação.

As porfirinas e metaloporfirinas também foram caracterizadas por técnicas espectroscópicas, como espectroscopia vibracional na região do infravermelho (IR), espectroscopia eletrônica na região do visível (UV-Vis) e espectroscopia por ressonância magnética de próton $\left(\mathrm{RMN}^{-1} \mathrm{H}\right)$. Os resultados dessas análises são apresentados e discutidos no capítulo de resultados e discussão.

\subsection{1. $\mathrm{H}_{2}$ TMPyP}

$\mathrm{H}_{2}$ TPyP $\left(2 \mathrm{mmol} \mathrm{dm}^{-3}\right)$ e p-toluenosulfonato de metila $\left(0,4 \mathrm{~mol} \mathrm{dm}^{-3}\right)$ foram dissolvidos em DMF. O sistema foi mantido sob agitação magnética durante três horas a $130^{\circ} \mathrm{C}$.

O solvente foi destilado a pressão reduzida em evaporador rotatório e o excesso de alquilante foi eliminado, lavando-se com clorofórmio. O produto foi posteriormente recristalizado de mistura metanol/éter etilico, obtendo-se um sólido púrpura.

Análise elementar: $\mathrm{C}_{72} \mathrm{H}_{66} \mathrm{~N}_{8} \mathrm{~S}_{4} \mathrm{O}_{12 .} 8 \mathrm{H}_{2} \mathrm{O}, \mathrm{MM}=1507 \mathrm{~g} \mathrm{~mol}^{-1}, \% \mathrm{C} 57,3(57,4$ calculado); \%H 5,49 (5,44); \%N 7,40 (7,43). Rendimento $80 \%$.

\subsection{2. $\mathrm{H}_{2}$ TBzPyP}

$\mathrm{H}_{2}$ TPyP $\left(1 \mathrm{mmol} \mathrm{dm}{ }^{-3}\right)$ e cloreto de benzila $\left(0,24 \mathrm{~mol} \mathrm{dm}^{-3}\right)$ foram dissolvidos em DMF. O sistema foi mantido sob agitação durante três horas a $130^{\circ} \mathrm{C}$.

O solvente foi destilado a pressão reduzida em evaporador rotatório e o excesso de alquilante foi eliminado, lavando-se com clorofórmio. O produto foi posteriormente recristalizado de mistura metanol/éter etílico, obtendo-se um sólido púrpura.

Análise elementar: $\mathrm{C}_{68} \mathrm{H}_{54} \mathrm{~N}_{8} \mathrm{Cl}_{4} .9 \mathrm{H}_{2} \mathrm{O}, \mathrm{MM}=1286 \mathrm{~g} \mathrm{~mol}^{-1}, \% \mathrm{C} 63,5(63,6$ calculado); \%H 5,41 (5,60); \%N 8,83 (8,71). Rendimento $80 \%$.

\subsection{3. $\mathrm{H}_{2}$ TAIPyP}

$\mathrm{H}_{2}$ TPyP $\left(1 \mathrm{mmol} \mathrm{dm}^{-3}\right)$ e brometo de alila $\left(0,30 \mathrm{~mol} \mathrm{dm}^{-3}\right)$ foram dissolvidos em DMF. A reação foi realizada em um frasco de Parr com uma tampa de Teflon, adaptado a uma camisa de ferro fundido. O sistema foi mantido lacrado por 12 horas em estufa a $110^{\circ} \mathrm{C}$. 
O solvente foi destilado à pressão reduzida em evaporador rotatório e o excesso de alquilante foi eliminado, lavando-se com clorofórmio. O produto foi posteriormente recristalizado de mistura metanol/éter etílico, obtendo-se um sólido púrpura.

Análise elementar: $\mathrm{C}_{52} \mathrm{H}_{46} \mathrm{~N}_{8} \mathrm{Br}_{4} \cdot 8 \mathrm{H}_{2} \mathrm{O}, \mathrm{MM}=1246 \mathrm{~g} \mathrm{~mol}^{-1}, \% \mathrm{C} 49,9(50,1$ calculado); \%H 5,06 (4,98); \%N 8,93 (8,99). Rendimento $70 \%$.

\subsection{4. $\mathrm{H}_{2} \mathrm{TNO}_{2} \mathrm{BzPyP}$}

$\mathrm{H}_{2}$ TPyP $\left(1 \mathrm{mmol} \mathrm{dm}{ }^{-3}\right)$ e brometo de p-nitrobenzila $\left(0,20 \mathrm{~mol} \mathrm{dm}^{-3}\right)$ foram dissolvidos em DMF. O sistema foi mantido sob agitação durante três horas a $130^{\circ} \mathrm{C}$.

O solvente foi destilado a pressão reduzida em evaporador rotatório e o excesso de alquilante foi eliminado, lavando-se com clorofórmio. O produto foi posteriormente recristalizado de mistura metanol/éter etílico, obtendo-se um sólido púrpura.

Análise elementar: $\mathrm{C}_{68} \mathrm{H}_{50} \mathrm{~N}_{12} \mathrm{Br}_{4} \mathrm{O}_{8} .7 \mathrm{H}_{2} \mathrm{O}, \mathrm{MM}=1616 \mathrm{~g} \mathrm{~mol}^{-1}, \% \mathrm{C} 50,9$ (50,5 calculado); \%H 3,87 (3,96); \%N 10,2 (10,3). Rendimento $80 \%$.

\subsection{5. $H_{2} T M e O B z P y P$}

$\mathrm{H}_{2}$ TPyP $\left(3 \mathrm{mmol} \mathrm{dm}^{-3}\right)$ e cloreto de p-metoxibenzila $\left(0,6 \mathrm{~mol} \mathrm{dm}^{-3}\right)$ foram dissolvidos em DMF. O sistema foi mantido sob agitação durante duas horas a $130^{\circ} \mathrm{C}$.

O solvente foi destilado a pressão reduzida em evaporador rotatório e o excesso de alquilante foi eliminado, lavando-se com acetona. O produto foi posteriormente recristalizado de mistura metanol/éter etílico, obtendo-se um sólido púrpura.

Análise elementar: $\mathrm{C}_{72} \mathrm{H}_{62} \mathrm{~N}_{8} \mathrm{O}_{4} \mathrm{Cl}_{4}, 10 \mathrm{H}_{2} \mathrm{O}, \mathrm{MM}=1424 \mathrm{~g} \mathrm{~mol}^{-1}, \% \mathrm{C} 60,5(60,7$ calculado); \%H 5,78 (5,76); \%N 7,86 (7,86). Rendimento $60 \%$.

\subsection{6. $\quad \mathrm{H}_{2} \mathrm{TCNBzPyP}$}

$\mathrm{H}_{2} \operatorname{TPyP}\left(1,3 \mathrm{mmol} \mathrm{dm}{ }^{-3}\right)$ e brometo de $\mathrm{p}$-cianobenzila $\left(0,20 \mathrm{~mol} \mathrm{dm}^{-3}\right)$ foram dissolvidos em DMF. O sistema foi mantido sob agitação durante uma hora a $130^{\circ} \mathrm{C}$.

O solvente foi destilado a pressão reduzida em evaporador rotatório e o excesso de alquilante foi eliminado, lavando-se com clorofórmio. O produto foi posteriormente recristalizado de mistura metanol/éter etílico, obtendo-se um sólido púrpura.

Análise elementar: $\mathrm{C}_{72} \mathrm{H}_{50} \mathrm{~N}_{12} \mathrm{Br}_{4} \cdot 9 \mathrm{H}_{2} \mathrm{O}, \mathrm{MM}=1564 \mathrm{~g} \mathrm{~mol}^{-1}, \% \mathrm{C} 55,7$ (55,3 calculado); \%H 4,16 (4,35); \%N 11,0 (10,7). Rendimento $90 \%$. 


\subsection{7. $\mathrm{H}_{2} \mathrm{TCIBzPyP}$}

$\mathrm{H}_{2}$ TPyP $\left(1 \mathrm{mmol} \mathrm{dm}^{-3}\right)$ e cloreto de p-clorobenzila $\left(0,26 \mathrm{~mol} \mathrm{dm}^{-3}\right)$ foram dissolvidos em DMF. O sistema foi mantido sob agitação durante cinco horas a $130^{\circ} \mathrm{C}$.

O solvente foi destilado a pressão reduzida em evaporador rotatório e o excesso de alquilante foi eliminado, lavando-se com acetona. O produto foi posteriormente recristalizado de mistura metanol/éter etílico, obtendo-se um sólido púrpura.

Análise elementar: $\mathrm{C}_{68} \mathrm{H}_{50} \mathrm{~N}_{8} \mathrm{Cl}_{8} .13 \mathrm{H}_{2} \mathrm{O}, \mathrm{MM}=1496 \mathrm{~g} \mathrm{~mol}^{-1}, \% \mathrm{C} 54,2 \quad(54,6$ calculado); \%H 4,87 (5,08); \%N 7,67 (7,49). Rendimento 50\%.

\subsection{8. $\quad H_{2}$ TBrBzPyP}

$\mathrm{H}_{2}$ TPyP $\left(2 \mathrm{mmol} \mathrm{dm}^{-3}\right)$ e brometo de p-bromobenzila $\left(0,40 \mathrm{~mol} \mathrm{dm}^{-3}\right)$ foram dissolvidos em DMF. O sistema foi mantido sob agitação durante duas horas a $130^{\circ} \mathrm{C}$.

O solvente foi destilado a pressão reduzida em evaporador rotatório e o excesso de alquilante foi eliminado, lavando-se com clorofórmio. O produto foi posteriormente recristalizado de mistura metanol/éter etílico, obtendo-se um sólido púrpura.

Análise elementar: $\mathrm{C}_{68} \mathrm{H}_{50} \mathrm{~N}_{8} \mathrm{Br}_{8} .8 \mathrm{H}_{2} \mathrm{O}, \mathrm{MM}=1762 \mathrm{~g} \mathrm{~mol}^{-1}, \% \mathrm{C} \mathrm{46,3} \mathrm{(46,3}$ calculado); \%H 3,63 (3,74); \%N 6,12 (6,36). Rendimento $70 \%$.

\subsection{9. $\mathrm{H}_{2} \mathrm{TCH}_{3} \mathrm{BzPyP}$}

Em DMF, foram dissolvidos $\mathrm{H}_{2}$ TPyP $\left(2,5 \mathrm{mmol} \mathrm{dm}^{-3}\right)$ e brometo de $\mathrm{p}$ metilbenzila $\left(0,37 \mathrm{~mol} \mathrm{dm}^{-3}\right)$. O sistema foi mantido sob agitação durante duas horas a $130^{\circ} \mathrm{C}$

O solvente foi destilado a pressão reduzida em evaporador rotatório e o excesso de alquilante foi eliminado, lavando-se com clorofórmio. O produto foi posteriormente recristalizado de mistura metanol/éter etílico, obtendo-se um sólido púrpura.

Análise elementar: $\mathrm{C}_{72} \mathrm{H}_{62} \mathrm{~N}_{8} \mathrm{Br}_{4} .8 \mathrm{H}_{2} \mathrm{O}, \mathrm{MM}=1502 \mathrm{~g} \mathrm{~mol}^{-1} ; \% \mathrm{C} 57,4 \quad(57,6$ calculado); \%H 5,01 (5,19); \%N 7,47 (7,45). Rendimento 80\%.

\subsubsection{0. $\mathrm{H}_{2} \mathrm{TCO}_{2} \mathrm{HBzPyP}$}

Em DMF, foram dissolvidos $\mathrm{H}_{2}$ TPyP $\left(2,0 \mathrm{mmol} \mathrm{dm}^{-3}\right)$ e ácido $\alpha$-bromo-p-toluíco $\left(0,40 \mathrm{~mol} \mathrm{dm}^{-3}\right)$. O sistema foi mantido sob agitação durante uma hora a $130^{\circ} \mathrm{C}$.

O solvente foi destilado a pressão reduzida em evaporador rotatório e o excesso de alquilante foi eliminado, lavando-se com clorofórmio. O produto foi posteriormente recristalizado de mistura metanol/éter etílico, obtendo-se um sólido púrpura. 
Análise elementar: $\mathrm{C}_{72} \mathrm{H}_{54} \mathrm{~N}_{8} \mathrm{Br}_{4} \cdot 8 \mathrm{H}_{2} \mathrm{O}, \mathrm{MM}=1622 \mathrm{~g} \mathrm{~mol}^{-1} ; \% \mathrm{C} 53,2(53,3$ calculado); \%H 4,06 (4,31); \%N 6,32 (6,90). Rendimento 60\%.

\subsubsection{1. $\mathrm{H}_{2}$ TPhPrPyP}

Em DMF, foram dissolvidos $\mathrm{H}_{2}$ TPyP $\left(2 \mathrm{mmol} \mathrm{dm}^{-3}\right)$ e 1-bromo-3-propano (0,50 $\mathrm{mol} \mathrm{dm^{-3 }}$ ). O sistema foi mantido sob agitação durante duas horas a $130^{\circ} \mathrm{C}$.

O solvente foi destilado a pressão reduzida em evaporador rotatório e o excesso de alquilante foi eliminado, lavando-se com clorofórmio. O produto foi posteriormente recristalizado de mistura metanol/éter etílico, obtendo-se um sólido púrpura.

Análise elementar: $\mathrm{C}_{76} \mathrm{H}_{70} \mathrm{~N}_{4} \mathrm{Br}_{4} \cdot 9 \mathrm{H}_{2} \mathrm{O}, \mathrm{MM}=1576 \mathrm{~g} \mathrm{~mol}^{-1}, \% \mathrm{C} 57,7 \quad(57,9$ calculado); \%H 5,04 (5,58); \%N 6,38 (7,11). Rendimento 50\%.

\subsubsection{2. $\mathrm{H}_{2}$ TPhEtPyP}

Em DMF, foram dissolvidos $\mathrm{H}_{2}$ TPyP $\left(2,5 \mathrm{mmol} \mathrm{dm}^{-3}\right)$ e 1-bromo-2-feniletano $\left(0,67 \mathrm{~mol} \mathrm{dm}^{-3}\right)$. O sistema foi mantido sob agitação durante duas horas a $130^{\circ} \mathrm{C}$.

O solvente foi destilado a pressão reduzida em evaporador rotatório e o excesso de alquilante foi eliminado, lavando-se com clorofórmio e acetona. O produto foi posteriormente recristalizado de mistura metanol/éter etílico, obtendo-se um sólido púrpura.

Análise elementar: $\mathrm{C}_{72} \mathrm{H}_{62} \mathrm{~N}_{8} \mathrm{Br}_{4} \cdot 9 \mathrm{H}_{2} \mathrm{O}, \mathrm{MM}=1448 \mathrm{~g} \mathrm{~mol}^{-1}, \% \mathrm{C} 59,77(59,71$ calculado); \%H 4,97 (4,83); \%N 7,83 (7,73). Rendimento $70 \%$.

\subsubsection{3. $\mathrm{H}_{2} T P n P y P$}

Em DMF, foram dissolvidos $\mathrm{H}_{2} \operatorname{TPyP}\left(2,5 \mathrm{mmol} \mathrm{dm}^{-3}\right)$ e 1 -iodopentano $(0,50 \mathrm{~mol}$ $\mathrm{dm}^{-3}$ ). O sistema foi mantido sob agitação durante cinco horas a $115^{\circ} \mathrm{C}$.

O solvente foi destilado a pressão reduzida em evaporador rotatório e o excesso de alquilante foi eliminado, lavando-se com clorofórmio e acetona. O produto foi posteriormente recristalizado de mistura metanol/éter etílico, obtendo-se um sólido púrpura.

Análise elementar: $\mathrm{C}_{60} \mathrm{H}_{70} \mathrm{~N}_{8} \mathrm{Cl}_{4} \cdot 9 \mathrm{H}_{2} \mathrm{O}, \mathrm{MM}=1384 \mathrm{~g} \mathrm{~mol}^{-1}, \% \mathrm{C} 52,0(52,1$ calculado); \%H 6,47 (6,36); \%N 8,03 (8,09). Rendimento 60\%.

\subsubsection{Zincoporfirinas}

Foram obtidos os $\mathrm{Zn}$ derivados de todas as porfirinas piridínio substituídas obtida neste trabalho, exceto as TPhEtPyP, $\mathrm{TCO}_{2} \mathrm{HBzPyP}$ e TCIBzPyP.

$\mathrm{Em}$ água deionizada, foram dissolvidos $\mathrm{ZnCl}_{2}\left(8,0 \mathrm{mmol} \mathrm{dm}{ }^{-3}\right)$ e porfirina na forma base livre correspondente $\left(0,4 \mathrm{mmol} \mathrm{dm}^{-3}\right)$. A reação foi mantida em refluxo por 
uma hora, quando não foram notadas mais mudanças no espectro eletrônico na região do UV-Vis.

A mistura reacional foi resfriada, adicionando-se lentamente solução aquosa de $\mathrm{NaClO}_{4}\left(3 \mathrm{~mol} \mathrm{dm}^{-3}\right)$, ocorrendo a precipitação da porfirina. A zincoporfirina foi filtrada e lavada com água gelada, sendo em seguida redissolvida em quantidade mínima de acetonitrila. Posteriormente, adicionou-se solução saturada de $\mathrm{LiCl}$ em acetonitrila, observando-se a precipitação da metaloporfirina. O sólido foi isolado por filtração a vácuo e lavado com acetona.

Os produtos foram recristalizados de mistura metanol/éter etílico, obtendo-se um sólido verde.

Análise elementar (ZnTMPyP) $\mathrm{ZnC}_{44} \mathrm{H}_{36} \mathrm{~N}_{8} \mathrm{Cl}_{4} \cdot 9 \mathrm{H}_{2} \mathrm{O}, \mathrm{MM}=1046 \mathrm{~g} \mathrm{~mol}^{-1}$, \%C 50,1 (50,5 calculado); \%H 5,33 (5,16); \% N 10,7 (10,7). Rendimento 90\%.

Análise elementar (ZnTAIPyP) $\mathrm{ZnC}_{52} \mathrm{H}_{54} \mathrm{~N}_{8} \mathrm{Cl}_{4} \cdot 9 \mathrm{H}_{2} \mathrm{O}, \mathrm{MM}=1152 \mathrm{~g} \mathrm{~mol}^{-1}$, \%C 54,4 (54,2 calculado); \%H 5,48 (5,56); \% N 9,67 (9,72). Rendimento 90\%.

Análise elementar $\left(\mathrm{ZnTNO}_{2} \mathrm{BzPyP}\right) \mathrm{ZnC}_{68} \mathrm{H}_{48} \mathrm{~N}_{12} \mathrm{O}_{8} \mathrm{Cl}_{4} \cdot 10 \mathrm{H}_{2} \mathrm{O}, \mathrm{MM}=1548 \mathrm{~g}$ $\mathrm{mol}^{-1}$, \%C 52,5 (52,8 calculado); \%H 4,37 (4,39); \%N 10,53 (10,85). Rendimento 90\%. Análise elementar ( $\mathrm{ZnTBzPyP}$ ) $\mathrm{ZnC}_{68} \mathrm{H}_{52} \mathrm{~N}_{8} \mathrm{Cl}_{4} \cdot 12 \mathrm{H}_{2} \mathrm{O}, \mathrm{MM}=1404 \mathrm{~g} \mathrm{~mol}^{-1}$, \%C 58,2 (58,2 calculado); \%H 5,53 (5,41); \% N 7,83 (7,98). Rendimento 80\%.

Análise elementar ( $\mathrm{ZnTMeOBzPyP}$ ) $\mathrm{ZnC}_{72} \mathrm{H}_{60} \mathrm{~N}_{8} \mathrm{O}_{4} \mathrm{Cl}_{4} \cdot 10 \mathrm{H}_{2} \mathrm{O}, \mathrm{MM}=1488 \mathrm{~g}$ $\mathrm{mol}^{-1}, \% \mathrm{C} \mathrm{58,2}$ (58,1 calculado); \%H 5,27 (5,38); \%N 7,32 (7,53). Rendimento 85\%.

Análise elementar ( $\mathrm{ZnTCNBzPyP}$ ) $\mathrm{ZnC}_{72} \mathrm{H}_{48} \mathrm{~N}_{12} \mathrm{Cl}_{4} \cdot 9 \mathrm{H}_{2} \mathrm{O}, \mathrm{MM}=1450 \mathrm{~g} \mathrm{~mol}^{-1}$, \%C 59,5 (59,6 calculado); \%H 4,39 (4,55); \%N 11,4 (11,6). Rendimento 90\%.

Análise elementar $(\mathrm{ZnTCH} 3 \mathrm{BzPyP}) \mathrm{ZnC}_{72} \mathrm{H}_{60} \mathrm{~N}_{8} \mathrm{Cl}_{4} \cdot 10 \mathrm{H}_{2} \mathrm{O}, \mathrm{MM}=1424 \mathrm{~g} \mathrm{~mol}^{-1}$, \%C 60,2 (60,7 calculado); \%H 5,70 (5,62); \%N 7,90 (7,87). Rendimento $90 \%$.

Análise elementar ( $\mathrm{ZnTBrBzPyP}$ ) $\mathrm{ZnC}_{68} \mathrm{H}_{48} \mathrm{~N}_{8} \mathrm{Br}_{4} \mathrm{Cl}_{4} .8 \mathrm{H}_{2} \mathrm{O}, \mathrm{MM}=1647 \mathrm{~g} \mathrm{~mol}^{-1}$, \%C 49,5 (49,6 calculado); \%H 4,05 (3,89); \%N 6,44 (6,80). Rendimento 80\%.

Análise elementar ( $\mathrm{ZnTPhPrBzPyP}$ ) $\mathrm{ZnC}_{76} \mathrm{H}_{68} \mathrm{~N}_{8} \mathrm{Cl}_{4} .8 \mathrm{H}_{2} \mathrm{O}, \mathrm{MM}=1444 \mathrm{~g} \mathrm{~mol}^{-1}$, \%C 63,2 (63,2 calculado); \%H 5,75 (5,82); \%N 7,66 $(7,76)$. Rendimento $80 \%$.

\subsubsection{Cobre(II) Porfirinas}

Foram sintetizados os $\mathrm{Cu}(\mathrm{II})$ derivados das porfirinas benzilpiridínio substituidas CuTBzPyP, $\mathrm{CuTCH}_{3} \mathrm{BzPyP}_{\mathrm{T}}$ CuTMeOBzPyP, CuTNO $\mathrm{O}_{2} \mathrm{BzPyP}$, CuTCNBzPyP e CuTPhPrPyP pelo método de metalação em água, similar ao utilizado para as $\mathrm{Zn}(\mathrm{II})$ porfirinas.

Em água deionizada, foi dissolvida a base livre correspondente para obter uma solução $0,4 \mathrm{mmol} \mathrm{dm}^{-3}$ e $\mathrm{CuCl}_{2}\left(10 \mathrm{mmol} \mathrm{dm}^{-3}\right)$. A reação permaneceu em refluxo por 1 hora, não sendo mais observadas variações no espectro UV-Vis. 
A mistura reacional foi resfriada, adicionando-se lentamente solução aquosa de $\mathrm{NaClO}_{4}\left(3 \mathrm{~mol} \mathrm{dm}^{-3}\right)$, ocorrendo a precipitação da porfirina. A cobre(II) porfirina foi filtrada e lavada com água gelada, sendo em seguida redissolvida em quantidade mínima de acetonitrila. Posteriormente, adicionou-se solução saturada de $\mathrm{LiCl}$ em acetonitrila, observando-se a precipitação da metaloporfirina. O sólido foi isolado por filtração a vácuo e lavado com acetona.

Os produtos foram recristalizados de mistura metanol/éter etílico, obtendo-se um sólido avermelhado.

Análise Elementar CuTBzPyP: $\mathrm{CuC}_{68} \mathrm{H}_{52} \mathrm{~N}_{8} \mathrm{Cl}_{4} \cdot 10 \mathrm{H}_{2} \mathrm{O}, \mathrm{MM}=1366 \mathrm{~g} \mathrm{~mol}^{-1}$, \%C 60,0 (59,8 calculado); \%H 5,24 (5,27); \% N 8,73 (8,22). Rendimento 80\%.

Análise Elementar $\mathrm{CuTCH}_{3} \mathrm{BzPyP}: \mathrm{CuC}_{72} \mathrm{H}_{60} \mathrm{~N}_{8} \mathrm{Cl}_{4} \cdot 10 \mathrm{H}_{2} \mathrm{O}, \mathrm{MM}=1422 \mathrm{~g} \mathrm{~mol}^{-1}$, \%C 61,0 (60,8 calculado); \%H 5,55 (5,62); \% N 8,23 (7,88). Rendimento 90\%.

Análise Elementar CuTNO ${ }_{2} \mathrm{BzPyP}: \mathrm{CuC}_{68} \mathrm{H}_{48} \mathrm{~N}_{12} \mathrm{O}_{8} \mathrm{Cl}_{4} \cdot 14 \mathrm{H}_{2} \mathrm{O}, \mathrm{MM}=1618 \mathrm{~g}$ $\mathrm{mol}^{-1}$, \%C 50,6 (50,5 calculado); \%H 4,54 (4,70); \% N 10,15 (10,38). Rendimento $90 \%$.

Análise Elementar CuTMeOBzPyP: $\mathrm{CuC}_{72} \mathrm{H}_{60} \mathrm{~N}_{8} \mathrm{O}_{4} \mathrm{Cl}_{4} \cdot 10 \mathrm{H}_{2} \mathrm{O}, \mathrm{MM}=1486 \mathrm{~g}$ $\mathrm{mol}^{-1}$, \%C 57,8 (58,2 calculado); \%H 5,53 (5,39); \% N 7,38 (7,54). Rendimento 80\%.

Análise Elementar CuTCNBzPyP: $\mathrm{CuC}_{72} \mathrm{H}_{48} \mathrm{~N}_{12} \mathrm{Cl}_{4} \cdot 11 \mathrm{H} 2 \mathrm{O}, \mathrm{MM}=1484 \mathrm{~g} \mathrm{~mol}^{-1}$, \%C 57,9 (58,3 calculado); \%H 4,40 (4,72); \% N 11,0 (11,3). Rendimento 90\%.

Análise Elementar CuTPhPrPyP: $\mathrm{CuC}_{76} \mathrm{H}_{68} \mathrm{~N}_{8} \mathrm{Cl}_{4} \cdot 14 \mathrm{H}_{2} \mathrm{O}, \mathrm{MM}=1549 \mathrm{~g} \mathrm{~mol}^{-1}$, \%C 58,5 (58,9 calculado); \%H 5,62 (6,20); \% N 7,12 $(7,18)$. Rendimento $90 \%$.

\subsubsection{6. $F e^{\prime \prime \prime} T B z P y P$ e $M n^{\prime \prime \prime} T B z P y P$}

Essas duas metalações foram realizadas em água, a partir de uma solução $1,0 \mathrm{mmol} \mathrm{dm}^{-3}$ de $\mathrm{H}_{2}$ TBzPyP e $15 \mathrm{mmol} \mathrm{dm}^{-3}$ das soluções dos respectivos cloretos $\left(\mathrm{FeCl}_{2}\right.$ e $\left.\mathrm{MnCl}_{2}\right)$. A reação foi deixada sob refluxo até não mais se observarem mudanças no espectro eletrônico na região do UV-Vis (aproximadamente 2 horas).

A mistura reacional foi resfriada, adicionando-se lentamente solução aquosa de $\mathrm{NaClO}_{4}$ (3 mol dm${ }^{-3}$ ), ocorrendo a precipitação da porfirina. A metaloporfirina foi filtrada e lavada com água gelada, sendo em seguida redissolvida em quantidade mínima de acetonitrila. Posteriormente, adicionou-se solução saturada de $\mathrm{LiCl}$ em acetonitrila, observando-se a precipitação da metaloporfirina. O sólido foi isolado por filtração a vácuo e lavado com acetona.

A reação foi realizada sob ar atmosférico, ocasionando a oxidação do $\mathrm{Fe}(\mathrm{II}) \mathrm{e}$ $\mathrm{Mn}(\mathrm{II})$ a $\mathrm{Fe}$ (III) e $\mathrm{Mn}(\mathrm{III})$, após a inserção no anel porfirínico. Os sólidos obtidos apresentam coloração marrom e o contra-ion é cloreto. As Fe(III) e Mn(III) porfirinas foram caracterizadas por análise elementar, infravermelho, UV-Vis. 
Análise Elementar Fe"'TBzPyP: $\mathrm{FeC}_{68} \mathrm{H}_{52} \mathrm{~N}_{8} \mathrm{Cl}_{5} .9 \mathrm{H}_{2} \mathrm{O}$, M.M. $=1376 \mathrm{~g} \mathrm{~mol}^{-1}$, \%C 59,1 (59,1 calculado); \%H 5,15 (5,09); \% N 8,18 (8,14). Rendimento $80 \%$.

Análise Elementar Mn"TBzPyP: $\mathrm{MnC}_{68} \mathrm{H}_{52} \mathrm{~N}_{8} \mathrm{Cl}_{5} .11 \mathrm{H}_{2} \mathrm{O}, \mathrm{M} . \mathrm{M} .=1411 \mathrm{~g} \mathrm{~mol}^{-1}$, \%C 57,9 (57,9 calculado); \%H 5,34 (5,24); \% N 7,95 (7,94). Rendimento 80\%.

\subsection{Equipamentos e Procedimentos}

As análises elementares de $\mathrm{C}, \mathrm{H}$ e $\mathrm{N}$ foram realizadas pela Central Analítica do IQ-USP.

\subsubsection{Espectroscopia Eletrônica}

Os espectros eletrônicos de absorção na região do UV-Vis foram obtidos nos espectrofotômetros Beckman DU70 ou HP8453A diode array. As amostras foram analisadas empregando-se cubetas de quartzo com caminho óptico de $10 \mathrm{~mm} e$ capacidade volumétrica de $3,5 \mathrm{~cm}^{3}$ ou de caminho óptico $2 \mathrm{~mm}$ e capacidade volumétrica $0,6 \mathrm{~cm}^{3}$. As concentrações das porfirinas analisadas variaram entre $10^{-7} \mathrm{e}$ $8 \times 10^{-5} \mathrm{~mol} \mathrm{dm}^{-3}$.

As absortividades por mol $(\varepsilon)$ das porfirinas benzilpiridinio substituídas e seus metalo derivados foram determinadas a partir dos coeficientes angulares dos gráficos de absorção vs. concentração (lei de Beer). As porfirinas foram dissolvidas em tampão $\mathrm{H}_{2} \mathrm{PO}_{4}{ }^{-} / \mathrm{HPO}_{4}{ }^{2-}, 0,025 \mathrm{~mol} \mathrm{dm}^{-3}$ em cada sal ( $\mathrm{pH} 7$ ), resultando numa força iônica $(\mu)$ de $0,1 \mathrm{~mol} \mathrm{dm}^{-3}$, obtendo-se uma solução estoque. As diferentes concentrações de porfirina foram obtidas a partir da adição de uma aliquota da solução estoque à cubeta contendo volume conhecido de solução tampão e posterior homogeneização.

Foram determinadas as absortividades por mol das bases livres em água deionizada e em diferentes eletrólitos suportes, tais como $\mathrm{NaBr}, \mathrm{NaCl}, \mathrm{NaNO}_{3}$, $\mathrm{Na}_{2} \mathrm{SO}_{4}, \mathrm{H}_{3} \mathrm{CCOONa}$, em condições de força iônica igual a $0,1 \mathrm{~mol} \mathrm{dm}^{-3}$.

Para a $\mathrm{H}_{2}$ TCNBzPyP, foram determinados as absortividades por mol nos solventes orgânicos: DMF, DMSO e metanol.

Os espectros eletrônicos de emissão foram obtidos no espectrofluorímetro Spex-Fluorolog FL 212, com geometria de $90^{\circ}$ ou front face. Foram utilizadas cubetas de quartzo de caminho óptico de $10 \mathrm{~mm}$ e capacidade volumétrica de $3,5 \mathrm{~cm}^{3}$. As concentrações das porfirinas variaram entre $10^{-9}$ e $10^{-5} \mathrm{~mol} \mathrm{dm}^{-3}$.

Os rendimentos quânticos relativos foram determinados a partir de soluções com absorbância entre 0,040 a 0,100 nos comprimentos de onda usados para a excitação. A excitação foi feita nos comprimentos de onda dos máximos da banda Soret e da banda $Q$ mais intensa. As áreas dos espectros de emissão foram normalizadas levando-se em conta a diferente intensidade da lâmpada em cada 
comprimento de onda. As condições do aparelho (abertura de fenda, resolução, velocidade de varredura, etc.) foram mantidas constantes, e em todos os dias em que foram realizadas as medidas, repetiram-se as determinações de algumas amostras para se averiguar a reprodutibilidade quantitativa do método e do aparelho. Para cada valor determinado foi feita a média de pelo menos quatro soluções de diferentes absorbâncias.

O espectro de emissão é corrigido em função da resposta da fotomultiplicadora para os diferentes comprimentos de onda por um padrão interno do aparelho.

Para a realização de espectros a $77 \mathrm{~K}$ foram preparadas soluções de porfirinas de concentração $10^{-6} \mathrm{~mol} \mathrm{dm}^{-3} \mathrm{em}$ mistura glicerina/água (2:1) em tubos de quartzo de $5 \mathrm{~mm}$ de diâmetro.

\subsubsection{Espectros vibracionais}

Os espectros vibracionais na região do infravermelho foram obtidos no equipamento Perkin Elmer FTIR 1750, e as amostras preparadas em pastilhas de $\mathrm{KBr}$ na proporção 1:100. As análises foram realizadas pela Central Analítica do IQ-USP.

Os espectros de raman ressonante foram obtidos pela Prof. Dra. Dalva Lucia em um microscópico Raman Renishaw modelo 3000, utilizando laser de excitação de argônio $\left(\mathrm{Ar}^{+}, \lambda=457,9 \mathrm{~nm}\right.$ ) da Ohminochrome refrigerado a ar. A amostra sólida da porfirina pura foi colocada numa lâmina de microscópico, sendo a radiação focalizada em um ponto de $1 \mu \mathrm{m}$ de diâmetro por uma lente de magnificação de 80 vezes. A potência do laser utilizada é da ordem de $10 \mu \mathrm{W}$.

\subsubsection{Espectros de $R M N{ }^{-1} H$}

Os espectros de $\mathrm{RMN}-{ }^{1} \mathrm{H}$ foram obtidos pela Central Analítica do IQ-USP utilizando os equipamentos Bomen AC 200 (200 MHz), Bruker DPX 300 (300 MHz) e Bruker DRX 500 (500 MHz), sempre se utilizando tubos com a especificação adequada para cada aparelho. Os experimentos foram realizados na temperatura ambiente, exceto quando indicado.

Para a determinação dos deslocamentos químicos das porfirinas e metaloporfirinas e sua relação com o parâmetro $\sigma$ de Hammett, foram preparadas soluções $5 \times 10^{-3} \mathrm{~mol} \mathrm{dm}^{-3} \mathrm{em} \mathrm{DMSO-d_{6 }}$.

Para avaliar a influência da concentração, do solvente e da temperatura, foram preparadas amostras em DMSO- $d_{6}, C D_{3} O D$ e $D_{2} O$. Os valores de deslocamento químico foram reportados em função dos sinais dos prótons residuais dos solventes utilizados, ou ainda de um padrão interno de cicloexano, adicionado no $\mathrm{D}_{2} \mathrm{O}$. 


\subsubsection{Eletroquímica}

Os voltamogramas cíclicos foram obtidos em um potenciostato-galvanostato da EG\&G Instruments (Princeton Applied Research) modelo 283 acoplado a um microcomputador $100 \mathrm{MHz}$ (software: Model 270/250 Research Electrochemistry Software 4.30). Foi utilizada uma cela eletroquimica convencional com três eletrodos e arranjo geométrico que permite estudos a partir de pequenos volumes de amostra $\left(1 \mathrm{~cm}^{3}\right)$. Os três eletrodos são: disco de platina (trabalho); fio de prata imerso em solução $0,010 \mathrm{~mol} \mathrm{dm}^{-3}$ de $\mathrm{AgNO}_{3}$ e $0,10 \mathrm{~mol} \mathrm{dm}^{-3}$ de TEAP em acetonitrila (referência); fio de platina em espiral confinado em tubo de vidro (auxiliar). O eletrodo de referência apresenta potencial de $0,503 \mathrm{~V}$ em relação ao eletrodo padrão de hidrogênio $(\mathrm{EPH})^{35}$.

As soluções das porfirinas foram preparadas em solução $0,10 \mathrm{~mol} \mathrm{dm}^{-3} \mathrm{de}$ TEAP (eletrólito suporte) em DMF, em concentrações que variam de 2 a $5 \mathrm{mmol} \mathrm{dm}^{-3}$. As soluções foram purgadas com Ar, evitando-se a presença de $\mathrm{O}_{2}$ em solução. Devido à conhecida decomposição do DMF, produzindo dimetilamina, foi utilizado DMF recém destilado (máximo de 48 horas) e armazenado em atmosfera inerte (ver seção 2.1 Reagentes).

Foram obtidos voltamogramas ciclicos em quatro diferentes velocidades de varredura (v): $20,50,100$ e $200 \mathrm{mV} \mathrm{s}^{-1}$ para cada derivado estudado. Variou-se também a janela de potencial aplicado, obtendo-se os voltamogramas das ondas isoladas.

Os espectros eletrônicos resolvidos no tempo da eletrólise das porfirinas e metaloporfirinas (espectroeletroquímica) foram obtidos em espectrofotômetro Hewlett Packard modelo 8453, utilizando uma cela de caminho óptico 0,25 mm dispondo de um minigrid de ouro como eletrodo de trabalho. Os eletrodos referência e auxiliar são similares aos da voltametria cíclica. Novamente, foram preparadas soluções em solução $0,10 \mathrm{~mol} \mathrm{dm}^{-3}$ de TEAP em DMF, com as concentrações das porfirinas na

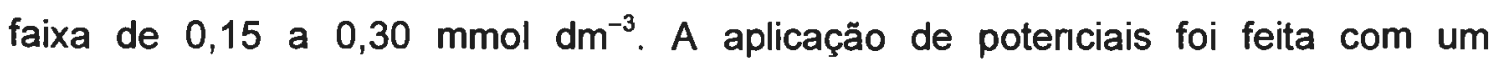
potenciostato-galvanostato de EG\&G Instruments (Princeton Applied Research) modelo 173.

\subsubsection{Fotólise por Pulso de Laser (Flash Photolysis)}

As medidas foram realizadas utilizando-se um sistema de fotólise por pulso de laser LP900 da Edinburgh Analytical Instruments equipado com um laser Surelite I-10 Nd:YAG. A amostra foi excitada no segundo harmônico do laser Nd:YAG, ou seja em $532 \mathrm{~nm}$. O monitoramento da absorção do transiente foi realizado perpendicularmente ao feixe do laser, utilizando uma lâmpada de alta pressão de Xenônio de $450 \mathrm{~W}$ de 
potência, alinhada a um monocromador Czern-Turner e uma fotomultiplicadora Hamamatsu R1527 (185-680 nm). O sinal do transiente da fotomultiplicadora é capturado por um osciloscópio da Tektronix TDS 520 interfaceado a um computador IBM/PC. Os decaimentos dos transientes e os tempos de vida das espécies foram obtidos a partir das rotinas padrões do software do sistema LP900. O espectro de absorção do transiente foi determinado ponto a ponto.

As soluções das zincoporfininas foram preparadas na faixa de concentração entre $1 \times 10^{-5}$ a $2 \times 10^{-5} \mathrm{~mol} \mathrm{dm}^{-3}$, em água deionizada ou em solução de $\mathrm{NaCl}$ com força iônica $0,05 \mathrm{~mol} \mathrm{dm}^{-3}$. Foram determinados os tempos de vida do estado triplete $\mathrm{e}$ os espectros dos transientes T-T em condiçōes de ausência de oxigênio e em equilibrio com o oxigênio atmosférico.

As determinações das constantes de supressão foram realizadas em equilíbrio com ar e em solução aquosa de $\mathrm{NaCl} 0,05 \mathrm{~mol} \mathrm{dm}^{-3}$, mantendo-se a força iônica constante. Foram necessánias concentrações relativamente alta dos supressores, uma vez que a constante de supressão das zincoporfirinas piridínio substituídas com o $\mathrm{O}_{2}$ é da ordem de $10^{9} \mathrm{~L} \mathrm{~mol}^{-1} \mathrm{~s}^{-1}$. A faixa de concentração dos supressores utilizados foi:

- Antraquinona-2-sulfonato de sódio: $7,0 \times 10^{-6}$ a $3 \times 10^{-4} \mathrm{~mol} \mathrm{dm}^{-3}$;

- Pentaminclorocobalto(III): $5 \times 10^{-4}$ a $3 \times 10^{-3} \mathrm{~mol} \mathrm{dm}^{-3}$;

- Metil viologênio: $1 \times 10^{-3}$ a $5 \times 10^{-3} \mathrm{~mol} \mathrm{dm}^{-3}$;

- Benzil viologênio: $5 \times 10^{-4}$ a $3 \times 10^{-3} \mathrm{~mol} \mathrm{dm}^{-3}$.

\subsubsection{Determinação do Rendimento Quântico de Formação de ${ }^{1} \mathrm{O}_{2}$}

As medidas foram realizadas em um fotômetro Edinburgh FLS 920, acoplado a uma fotomultiplicadora Hamamatsu R 5509-20 (200 - $1450 \mathrm{~nm})$, e interfaceado com uma placa de aquisição de alta resolução temporal (10 ns por canal) PCS 900 . Para uma boa relação sinal ruído da fotomultiplicadora na região do infravermelho próximo na qual é realizado o monitoramento do máximo de emissão da fosforescência do ${ }^{1} \mathrm{O}_{2}$ $(1270 \mathrm{~nm})$, a fotomultiplicadora é mantida resfriada $\mathrm{a}-80^{\circ} \mathrm{C}$, passando-se $\mathrm{N}_{2}$ líquido em uma camisa de refrigeração.

As soluçōes de porfirina foram preparadas de modo que a absorbância no comprimento de onda de excitação em $532 \mathrm{~nm}$ fosse de $0,200 \pm 0,005$, estando em equilibrio com o ar.

A excitação da amostra foi realizada no segundo harmônico de um laser de Nd:YAG Surelite 3, contínuo, sendo padronizada uma voltagem de 1,20 kV. Para a determinação do rendimento quântico relativo de formação de ${ }^{1} \mathrm{O}_{2}\left(\Phi_{\Delta}\right)$ foi considerado como padrão uma solução de $\mathrm{H}_{2}$ TMPyP em $\mathrm{D}_{2} \mathrm{O}$, na qual o $\Phi_{\Delta}$ corresponde a $0,74^{48,70}$. 
Entretanto, a alta resolução temporal da placa de aquisição nos permitiu determinar $\circ \Phi_{\Delta}$ em solução aquosa. Não foi encontrada na literatura nenhuma menção a dados referentes à formação de ${ }^{1} \mathrm{O}_{2}$ a partir da fosforescência em $1270 \mathrm{~nm}$ dessa espécie em soluções aquosas de porfirinas. A necessidade da utilização de solventes orgânicos ou água deuterada se dá pelo baixo tempo de vida de fosforescência da espécie ${ }^{1} \mathrm{O}_{2}$ em água, cerca de $4,3 \mu \mathrm{s}^{48}$, enquanto que em $\mathrm{D}_{2} \mathrm{O}$ o tempo é significativamente maior, cerca de $50 \mu \mathrm{s}^{2}$.

A determinação dos valores de $\Phi_{\Delta}$ relativo foi baseada na equação abaixo, proposta por Spiller e colaboradores ${ }^{49}$.

$$
\Phi_{\Delta}=\frac{I}{I_{\text {ref }}} \cdot \Phi_{\Delta r e f} \cdot \frac{\tau_{\Delta r e f}}{\tau_{\Delta}}
$$

Para comparação do rendimento quântico de formação do ${ }^{1} \mathrm{O}_{2}$ as amostras foram excitadas nas mesmas condições de fendas com cinco potências de laser ( $\left.P_{\text {laser }}\right)$ diferentes, variando-se de 0,4 $\mathrm{mJ}$ a $6,5 \mathrm{~mJ}$, obtendo-se a intensidade de fosforescência no tempo zero $\left(I_{0}\right)$ a partir da extrapolação do decaimento do sinal da emissão da espécie ${ }^{1} \mathrm{O}_{2}$ em $1270 \mathrm{~nm}$. A comparação dos coeficientes angulares das reatas obtidas do gráfico $l_{0}$ vs. $P_{\text {laser }}$ permite a determinação do $\Phi_{\Delta}$ relativo ${ }^{48,}{ }^{109}$. Esse método permite identificar se nas condições aplicadas existe algum processo de supressão do estado triplete da porfirina simultâneo ao do $\mathrm{O}_{2}$, como um aniquilamento triplete-triplete, resultante da alta formação da porfirina no estado excitado, por exemplo. Um comportamento linear para as cinco potências utilizadas indicam não haver um processo concorrente nas condições empregadas.

\subsubsection{Interação com Surfactantes}

Foram investigadas as interações das porfirinas catiônicas em meios micelar e pré-micelar de um surfactante catiônico (CTAB), surfactante aniônico (SDS) e de dois surfactantes não iônicos (Triton X-100 e PTE).

A análise dos espectros de absorção UV-Vis e de emissão foi realizada a partir de soluções aquosas contendo uma concentração fixa de porfirina $(6,0$ a $9,0 \mathrm{mmol}$ $\mathrm{dm}^{-3}$ ) e concentrações variáveis de surfactante:

- CTAB: $10^{-4}$ a $10^{-3} \mathrm{~mol} \mathrm{dm}^{-3}$;

- SDS: $8 \times 10^{-6}$ a $0,1 \mathrm{~mol} \mathrm{dm}^{-3}$;

- TRITON X100: $3 \times 10^{-5}$ a $3 \times 10^{-2} \mathrm{~mol} \mathrm{dm}^{-3}$;

- PTE: $3 \times 10^{-4}$ a $3 \times 10^{-2} \mathrm{~mol} \mathrm{dm}^{-3}$.

Os espectros de $\mathrm{RMN}-{ }^{1} \mathrm{H}$ foram obtidos a partir de soluções em $\mathrm{D}_{2} \mathrm{O}$ dos surfactantes $\operatorname{SDS}\left(0,1 \mathrm{~mol} \mathrm{dm}^{-3}\right)$ e TRITON X100 $\left(4 \times 10^{-2} \mathrm{~mol} \mathrm{dm}^{-3}\right)$, contendo 
cicloexano como padrão interno ${ }^{110}$. Para avaliar a posição das porfirinas e dos supressores BV e MV nas micelas foram preparadas soluçöes de surfactante contendo concentrações variáveis da sonda $\left(1,0 \times 10^{-5}\right.$ a $1,2 \times 10^{-4} \mathrm{~mol} \mathrm{dm}^{-3}$ para as porfirinas e $5,0 \times 10^{-4}$ a $8,0 \times 10^{-3} \mathrm{~mol} \mathrm{dm}^{-3}$ para os viologênios), avaliando-se a influência da sonda nos deslocamentos químicos dos prótons do surfactante. A partir de uma solução estoque da sonda em água deionizada retirava-se um volume adequado de solução, que era evaporado em estufa a $50^{\circ} \mathrm{C}$. Em seguida a sonda era redissolvida na solução do surfactante em $\mathrm{D}_{2} \mathrm{O}$. Vale ressaltar que a $\mathrm{ZnTNO}_{2} \mathrm{BzPyP}$ formou um filme nesse processo, não sendo possivel redissolvê-la.

Os experimentos de fotólise por pulso de laser foram realizados em equilibrio com o ar. Foram obtidos os espectros transientes e determinados os tempo de vida das zincoporfirinas em presença dos surfactantes SDS $\left(5 \times 10^{-2} \mathrm{~mol} \mathrm{dm}^{-3}\right)$ e TRITON $X 100\left(2 \times 10^{-2} \mathrm{~mol} \mathrm{dm}^{-3}\right)$ em solução de $\mathrm{NaCl} 0,05 \mathrm{~mol} \mathrm{dm}^{-3}$. Também foram determinadas as constantes de supressão para os supressores indicados na seção 2.3.5. nas soluções de surfactantes descritas.

A determinação do rendimento quântico de formação do ${ }^{1} \mathrm{O}_{2}\left(\Phi_{\Delta}\right)$ das porfirinas e zincoporfirinas foi realizada em meio de SDS (0,1 mol/L) e Triton X-100 (0,02 mol $\mathrm{dm}^{-3}$ ) em água. As soluções foram preparadas de modo que a absorbância em $532 \mathrm{~nm}$ fosse de $0,200 \pm 0,005$. O método utilizado é o mesmo descrito na seção 2.3.6., e o padrão utilizado para comparação é a $\mathrm{H}_{2}$ TMPyP em água.

A determinação da $\mathrm{cmc}$ do SDS na ausência e presença de porfirinas foi realizada pelo método condutométrico. As medidas de condutividade, $\kappa$, foram efetuadas em soluçōes preparadas pela adição, utilizando-se micro-seringas Hamilton, de uma solução $52 \mathrm{mmol} \mathrm{dm}^{-3}$ de SDS (ou SDS + porfirina) em $5,0 \mathrm{~cm}^{3}$ de água (ou água + porfirina), mantendo-se a concentração de porfirina constante. Foram avaliados os efeitos das porfirinas na $\mathrm{cmc}$ do SDS nas condições utilizadas para os espectros eletrônicos $\left(10^{-6} \mathrm{~mol} \mathrm{dm}^{-3}\right)$ e para os experimentos de $\mathrm{RMN}^{-1} \mathrm{H}$ $\left(10^{-4} \mathrm{~mol} \mathrm{dm}^{-3}\right)$. O condutivímetro utilizado foi o modelo $160 \mathrm{da}$ Orion, ligado a uma cela de condutividade de platina de constante igual a 1,061. A temperatura foi mantida a $25^{\circ} \mathrm{C}$ com o auxílio de um banho termostato da Pharmacia, modelo LKB Multitemp II.

Valores de $\mathrm{cmc}$ foram estimados através da interseção de duas retas obtidas

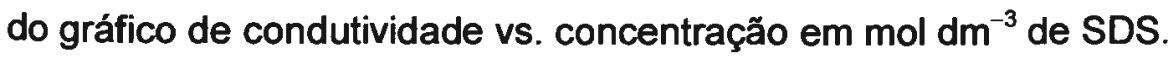

Os valores de $\alpha$ foram obtidos utilizando a equação simplificada de Lianos e Lang $^{111}: \quad \alpha=$ S2/S1

onde S1 e S2 correspondem aos coeficientes angulares das retas obtidas do gráfico, antes e após a cmc. 
Já a determinação da cmc do TRITON X100 na ausência e na presença de porfininas foi realizada por tensão superficial. Pequenos volumes de solução $9,3 \mathrm{mmol}$ $\mathrm{dm}^{-3}$ de Triton $\times 100$ (ou Triton $\times 100+$ porfirina) foram adicionados, com o uso de micro-seringas, a $15 \mathrm{~cm}^{3}$ de água (ou água + porfirina) conhecida em um copo termostatizado a $25^{\circ} \mathrm{C}$. A cada adição a solução foi agitada, e o valor da tensão superficial foi medido em um tensiômetro semi-automático da marca Fisher Scientific (Surface Tensiomat 21), que utiliza o método do destacamento do anel de du Noy. Este método está baseado na medida da força necessária para o destacamento de um anel de platina/irídio da superfície da solução. Os valores de $\mathrm{cmc}$ foram obtidos através da interseção de duas retas obtidas no gráfico de tensão superficial contra o logarítimo da concentração $\mathrm{mol} \mathrm{dm}^{-3}$ de Triton $\times 100$.

\subsubsection{Interação com Antraquinona-2-sulfonato de sódio}

Os espectros de absorção na região do UV-Vis foram obtidos a partir de concentrações fixas das porfirinas catiônicas $\left(6,0\right.$ a $\left.9,0 \mathrm{mmol} \mathrm{dm}^{-3}\right)$, variando-se as concentrações de antraquinona-2-sulfonato de sódio $\left(5 \times 10^{-6}\right.$ a $\left.8 \times 10^{-4} \mathrm{~mol} \mathrm{dm}^{-3}\right)$. Os estudos foram realizados em três meios: água, solução aquosa de SDS $\left(5 \times 10^{-2} \mathrm{~mol}\right.$ $\left.\mathrm{dm}^{-3}\right)$ e solução aquosa de TRITON X100 $\left(2 \times 10^{-2} \mathrm{~mol} \mathrm{dm}^{-3}\right)$. 


\section{Resultados e Discussão}

\subsection{Espectroscopia Eletrônica de Absorção}

Os espectros de absorção na região do UV-Vis fornecem informações relevantes sobre a contribuição dos substituintes alquilicos na estrutura eletrônica do macrociclo das porfirinas piridínio substituidas. São apresentados nessa seção os máximos de absorção $\left(\lambda_{\text {máx }}\right)$ e a absortividade por mol $(\varepsilon)$ das porfirinas e metaloporfirinas obtidas nesse estudo em meio aquoso e meio orgânico.

A caracterização do perfil espectral das porfininas é importante, uma vez que a análise das interações com biomoléculas e outros agentes geralmente é realizada a partir da espectroscopia eletrônica. Uma das questões é inferir a formação de agregados e complexos através da análise dos parâmetros obtidos nos espectros na região do UV-Vis. Uma vez que experimentos com biomoléculas são realizados em condições de força iônica controlada foram investigadas a influência de diferentes eletrólitos na solubilidade e nos espectros de absorção das porfirinas estudadas.

As medidas de absorção obtidas seguem a lei de Beer, o que sugere a existência de apenas uma espécie na faixa de concentração estudada $\left(2 \times 10^{-7}\right.$ a $8 \times 10^{-4} \mathrm{~mol} \mathrm{dm}^{-3}$ ).

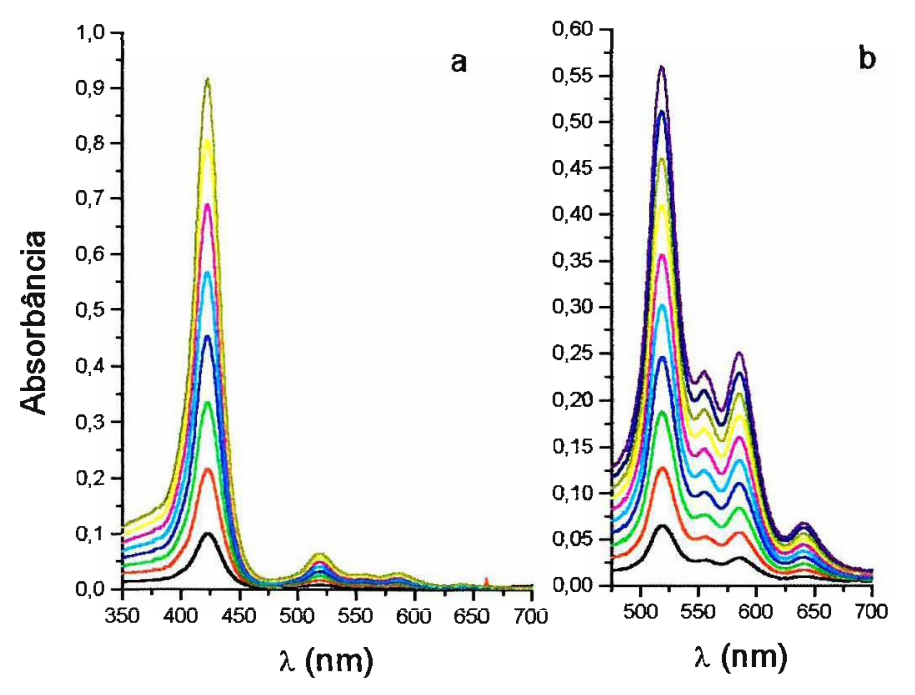

figura 22: Espectros eletrônicos na região do UV-Vis da $\mathrm{H}_{2}$ TPnPyP em tampão fosfato: a - Determinação do $\varepsilon$ da banda Soret; $b$ - Determinação do $\varepsilon$ das bandas $Q$.

Os espectros de absorção das porfirinas piridínio substituídas na forma base livre apresentam, em meio aquoso, uma banda Soret na região entre 420 e $430 \mathrm{~nm}$ e quatro bandas $Q$ na região entre 520 e $650 \mathrm{~nm}$. Como pode ser observado na 
figura 22, a intensidade da banda $Q \times(1,0)$ é maior que a da banda $Q y(0,0)$ para a maioria das bases livres catiônicas em tampão fosfato, caracterizando, portanto, um espectro do tipo phyllo. Os espectros obtidos em água deionizada ou em soluções aquosas com forças iônicas maiores, também apresentam a mesma intensidade relativa das bandas.

Entretanto, o espectro da $\mathrm{H}_{2} \mathrm{TCO}_{2} \mathrm{HBzPyP}$ em tampão fosfato e em água é do tipo etio (figura 23). Devido à baixa solubilidade dessa porfinna em meio aquoso, não foi possivel determinar o valores de $\varepsilon$ das bandas Soret $e$ Q. Essa baixa solubilidade pode ser explicada pela desprotonação, em pH neutro, do substituinte carbóxi, formando o ânion carboxilato. A presença na mesma molécula de cargas positivas (cátion piridínio) e cargas negativas (ânion carboxilato) possibilita a formação de agregados insolúveis. Esse perfil espectral diferenciado para a $\mathrm{H}_{2} \mathrm{TCO}_{2} \mathrm{HBzPyP}$ é um indicativo que deve ocorrer uma auto agregação dessa porfirina em solução.

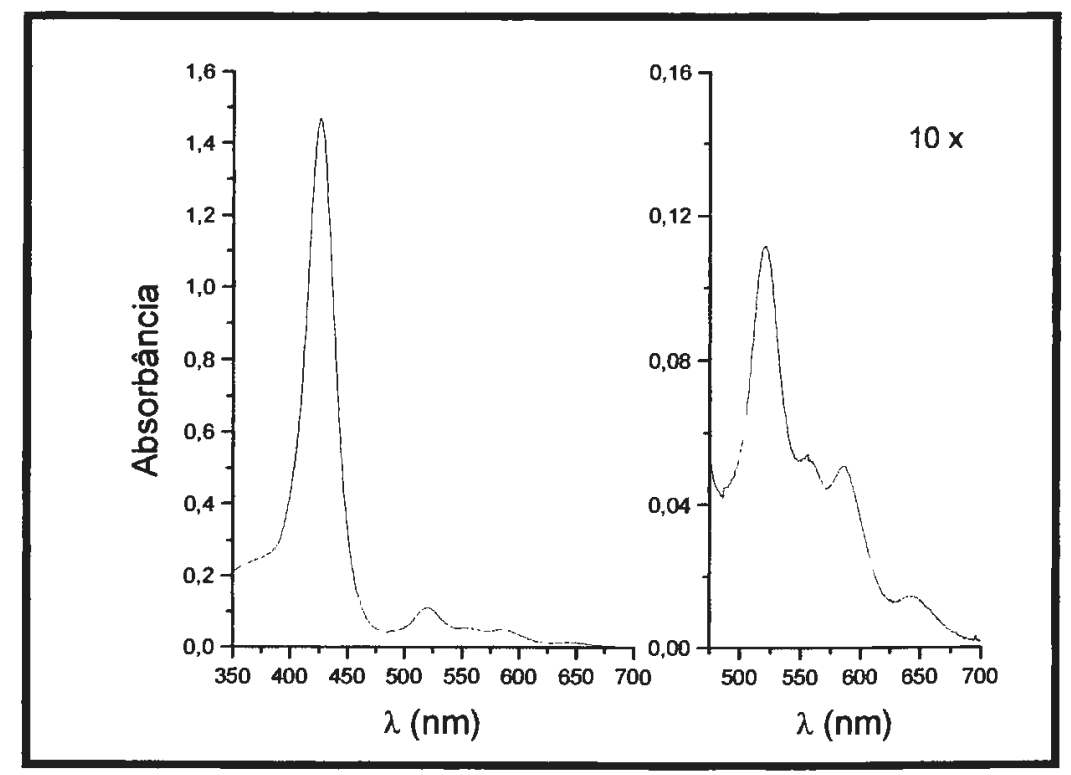

figura 23: Espectro eletrônico da $\mathrm{TCO}_{2} \mathrm{HBzPyP}$ em tampão fosfato. A região das bandas $\mathbf{Q}$ foi ampliada para melhor visualização.

Observa-se, analisando a tabela 2, que as absortividades por mol das bandas Soret das porfirinas que contém substituintes benzílicos doadores de elétrons são maiores do que das porfirinas com substituintes aceptores de elétrons. Essa diferença deve estar relacionada a interação entre a carga do nitrogênio piridínico e a densidade eletrônica do anel benzilico, causando uma maior expansão da nuvem $\pi$ devido a um aumento na estabilização das cargas periféricas.

Em relação aos máximos de absorção, as porfirinas contendo substituintes benzílicos aceptores de elétrons, como o grupo nitro e ciano, apresentam deslocamento batocrômico da banda Soret, de até $4 \mathrm{~nm}$ em relação aos substituintes 
doadores de elétrons, como o grupo metóxi. Esse deslocamento deve significar uma expansão da nuvem $\pi$ do macrociclo porfirínico, estabilizando o estado excitado $\pi^{*}$ (LUMO, eg). Apesar de aparentemente pequeno, o deslocamento da banda Soret para região de menor energia é significativo. Vale ressaltar que a introdução das quatro cargas positivas na $H_{2}$ TMPyP causa um deslocamento de $4 \mathrm{~nm}$ em relação a precursora não carregada $\mathrm{H}_{2}$ TPyP, logo os grupos benzil substituídos dobram o efeito eletrônico ocasionado pela inserção das cargas positivas, pois o $\Delta \lambda_{\operatorname{máx}}$ varia entre 7 e $11 \mathrm{~nm}$, dependendo do substituinte benzílico empregado.

tabela 2: Absortividades molares $(\varepsilon)$ e máximos de absorção $\left(\lambda_{\text {máx. }}\right)$ das bases livres em meio de tampāo fosfato.

\begin{tabular}{|c|c|c|c|c|c|c|}
\hline Porfirina & & $\mathrm{B}(0,0)$ & Qy $(1,0)$ & $Q y(0,0)$ & $Q \times(1,0)$ & $Q \times(0,0)$ \\
\hline \multirow{2}{*}{$\mathrm{H}_{2}$ TMieOBzPyP } & $\lambda(\mathrm{nm})$ & 424 & 520 & 556 & 585 & 640 \\
\hline & $\varepsilon\left(10^{3} \mathrm{~mol}^{-1} \mathrm{~cm}^{-1} \mathrm{dm}^{3}\right)$ & 240 & 17,7 & 8,37 & 8,97 & 2,48 \\
\hline \multirow[t]{2}{*}{$\mathrm{H}_{2} \mathrm{TCH}_{3} \mathrm{Bz} \mathrm{PyP}$} & $\lambda(\mathrm{nm})$ & 425 & 520 & 556 & 585 & 640 \\
\hline & $\varepsilon\left(10^{3} \mathrm{~mol}^{-1} \mathrm{~cm}^{-1} \mathrm{dm}^{3}\right)$ & 204 & 16,3 & 7,54 & 7,68 & 1,83 \\
\hline \multirow[t]{2}{*}{${ }^{*} \mathrm{H}_{2}$ TBzPyP } & $\lambda(\mathrm{nm})$ & 425 & 520 & 556 & 586 & 641 \\
\hline & $\varepsilon\left(10^{3} \mathrm{~mol}^{-1} \mathrm{~cm}^{-1} \mathrm{dm}^{3}\right)$ & 191 & 13,1 & 5,55 & 6,02 & 1,32 \\
\hline \multirow[t]{2}{*}{${ }^{*} \mathrm{H}_{2} \mathrm{TCIBz} P y P$} & $\lambda(\mathrm{nm})$ & 425 & 520 & 556 & 585 & 640 \\
\hline & $\varepsilon\left(10^{3} \mathrm{~mol}^{-1} \mathrm{~cm}^{-1} \mathrm{dm}^{3}\right)$ & 165 & 12,6 & 6,11 & 6,24 & 1,99 \\
\hline \multirow[t]{2}{*}{$\mathrm{H}_{2}$ TBrBzPyP } & $\lambda(\mathrm{nm})$ & 426 & 520 & 556 & 586 & 642 \\
\hline & $\varepsilon\left(10^{3} \mathrm{~mol}^{-1} \mathrm{~cm}^{-1} \mathrm{dm}^{3}\right)$ & 173 & 15,2 & 7,39 & 7,52 & 2,26 \\
\hline \multirow[t]{2}{*}{$\mathrm{H}_{2} \mathrm{TCO}_{2} \mathrm{HBzPyP}$} & $\lambda(\mathrm{nm})$ & 426 & 520 & 555 & 585 & 642 \\
\hline & $\varepsilon\left(10^{3} \mathrm{~mol}^{-1} \mathrm{~cm}^{-1} \mathrm{dm}^{3}\right)$ & - & - & - & - & - \\
\hline \multirow[t]{2}{*}{$\mathrm{H}_{2} \mathrm{TCNBzPyP}$} & $\lambda(\mathrm{nm})$ & 427 & 522 & 558 & 587 & 641 \\
\hline & $\varepsilon\left(10^{3} \mathrm{~mol}^{-1} \mathrm{~cm}^{-1} \mathrm{dm}^{3}\right)$ & 183 & 14,4 & 7,20 & 7,41 & 2,17 \\
\hline \multirow[t]{2}{*}{${ }^{*} \mathrm{H}_{2} \mathrm{TNO}_{2} \mathrm{Bz} \mathrm{PyP}$} & $\lambda(\mathrm{nm})$ & 428 & 522 & 559 & 586 & 642 \\
\hline & $\varepsilon\left(10^{3} \mathrm{~mol}^{-1} \mathrm{~cm}^{-1} \mathrm{dm}^{3}\right)$ & 176 & 13,5 & 5,80 & 6,00 & 1,00 \\
\hline \multirow[t]{2}{*}{$\mathrm{H}_{2}$ TPhEtPyP } & $\lambda(\mathrm{nm})$ & 425 & 519 & 552 & 585 & 642 \\
\hline & $\varepsilon\left(10^{3} \mathrm{~mol}^{-1} \mathrm{~cm}^{-1} \mathrm{dm}^{3}\right)$ & 200 & 14,6 & 6,14 & 6,68 & 1,80 \\
\hline \multirow[t]{2}{*}{$\mathrm{H}_{2}$ TPhPrPyP } & $\lambda(\mathrm{nm})$ & 425 & 520 & 555 & 586 & 641 \\
\hline & $\varepsilon\left(10^{3} \mathrm{~mol}^{-1} \mathrm{~cm}^{-1} \mathrm{dm}^{3}\right)$ & 216 & 16,2 & 7,20 & 7,53 & 1,99 \\
\hline \multirow[t]{2}{*}{$\mathrm{H}_{2}$ TMPyP } & $\lambda(\mathrm{nm})$ & 421 & 517 & 555 & 583 & 641 \\
\hline & $\varepsilon\left(10^{3} \mathrm{~mol}^{-1} \mathrm{~cm}^{-1} \mathrm{dm}^{3}\right)$ & 241 & 16,1 & 5,90 & 6,96 & 1,60 \\
\hline \multirow[t]{2}{*}{$\mathrm{H}_{2}$ TPnPyP } & $\lambda(\mathrm{nm})$ & 423 & 519 & 555 & 585 & 640 \\
\hline & $\varepsilon\left(10^{3} \mathrm{~mol}^{-1} \mathrm{~cm}^{-1} \mathrm{dm}^{3}\right)$ & 160 & 11,0 & 4,54 & 4,93 & 1,32 \\
\hline \multirow[t]{2}{*}{$\mathrm{H}_{2}$ TAIPyP } & $\lambda(\mathrm{nm})$ & 423 & 519 & 557 & 584 & 640 \\
\hline & $\varepsilon\left(10^{3} \mathrm{~mol}^{-1} \mathrm{~cm}^{-1} \mathrm{dm}^{3}\right)$ & 190 & 14,7 & 7,13 & 7,42 & 2,77 \\
\hline
\end{tabular}

$t=25^{\circ} \mathrm{C}$. * dados da referência ${ }^{22}$;

soluções preparadas em tampão $\mathrm{H}_{2} \mathrm{PO}_{4}^{-} / \mathrm{HPO}_{4}{ }^{2-}, \mathrm{pH}=7 \mu=0,1 \mathrm{~mol} \mathrm{dm}^{-3}$;

Outra análise interessante é quanto aos valores de $\varepsilon$ da banda Soret para as porfirinas $\mathrm{H}_{2}$ TBzPyP, $\mathrm{H}_{2}$ TPhEtPyP e $\mathrm{H}_{2}$ TPhPrPyP, pois nesta série aumenta-se em um carbono saturado a distância entre o nitrogênio positivamente carregado do anel piridínio e $\mathrm{o}$ anel fenílico do substituinte. As absortividades das bandas da $\mathrm{H}_{2}$ TBzPyP são sensivelmente menores que as da $\mathrm{H}_{2}$ TPhEtPyP, que são menores que da 
$\mathrm{H}_{2}$ TPhPrPyP. Ou seja, quanto maior o grupo alquila que separa o anel piridínio do anel fenílico, maior os valores das absortividades por mol, provavelmente devido a menor expansão do sistema $\pi$.

Quando se utiliza solventes orgânicos na preparação de soluções destas bases livres, observa-se perfil espectral do tipo etio, sendo que a figura 24 e a tabela 3 ilustram este comportamento para a $\mathrm{H}_{2}$ TCNBzPyP em DMF, metanol e água. $\mathrm{O}$ espectro de $\mathrm{H}_{2}$ TCNBzPyP em DMF apresenta a maior separação das barıdas $Q$.

tabela 3: Absortividades por mol $(\varepsilon)$ e máximos de absorção $\left(\lambda_{\text {máx. }}\right)$ da $\mathrm{H}_{2}$ TCNBzPyP em diversos solventes

\begin{tabular}{cccccccc}
\hline Solvente & & $\mathrm{B}(0,0)$ & $\mathrm{Qy}(1,0)$ & $\mathrm{Qy}(0,0)$ & $\mathrm{Qx}(1,0)$ & $\mathrm{Qx}(0,0)$ \\
\hline Tampão Fosfato & $\lambda(\mathrm{nm})$ & 427 & 522 & 558 & 587 & 641 \\
& $\varepsilon\left(10^{3} \mathrm{~mol}^{-1} \mathrm{~cm}^{-1} \mathrm{~L}\right)$ & 183 & 14,4 & 7,20 & 7,41 & 2,17 \\
DMSO & $\lambda(\mathrm{nm})$ & 430 & 518 & 552 & 589 & 645 \\
& $\varepsilon\left(10^{3} \mathrm{~mol}^{-1} \mathrm{~cm}^{-1} \mathrm{~L}\right)$ & 224 & 18,5 & 7,39 & 7,36 & 2,43 \\
\multirow{2}{*}{ DWF } & $\lambda(\mathrm{nm})$ & 429 & 518 & 553 & 591 & 646 \\
& $\varepsilon\left(10^{3} \mathrm{~mol}^{-1} \mathrm{~cm}^{-1} \mathrm{~L}\right)$ & 253 & 18,8 & 7,74 & 7,34 & 2,45 \\
Metanol & $\lambda(\mathrm{nm})$ & 429 & 518 & 554 & 592 & 648 \\
& $\varepsilon\left(10^{3} \mathrm{~mol}^{-1} \mathrm{~cm}^{-1} \mathrm{~L}\right)$ & 179 & 18,1 & 8,66 & 7,25 & 2,44 \\
\hline
\end{tabular}

$t=25^{\circ} \mathrm{C}$; caminho ótico $=1 \mathrm{~cm}$.

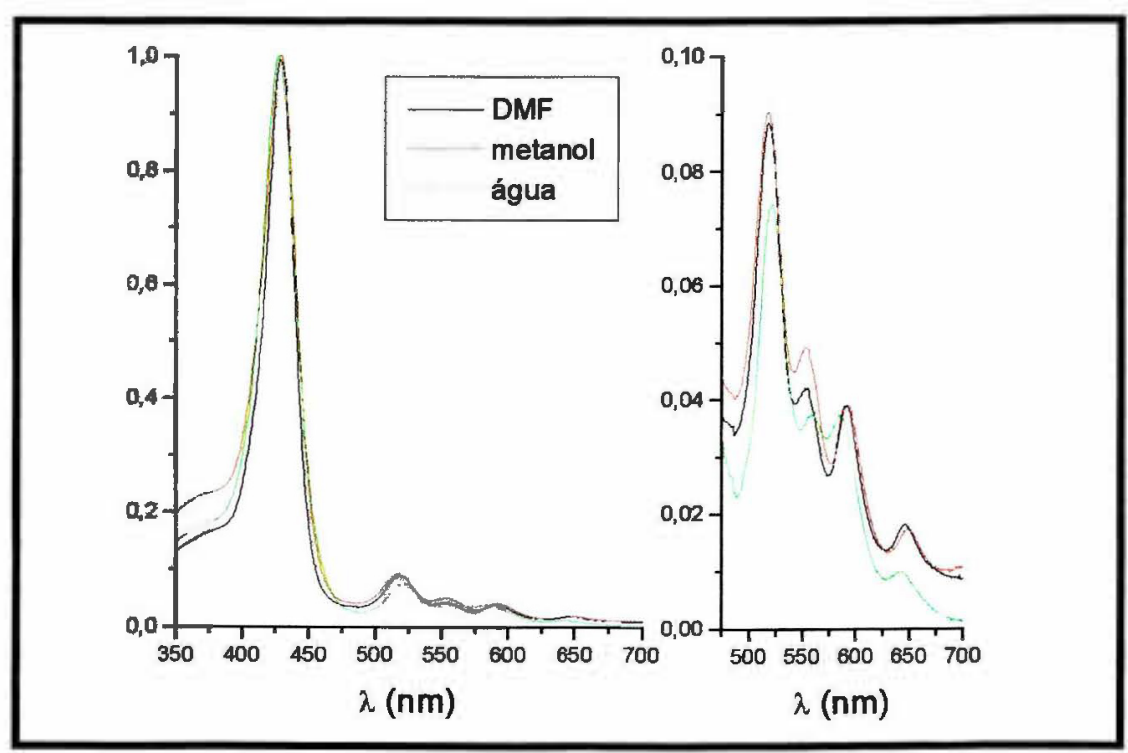

figura 24: Espectros eletrônicos da $\mathrm{H}_{2}$ TCNBzPyP em diferentes solventes. A região das bandas $Q$ foi ampliada para melhor visualização.

Os espectros da $\mathrm{H}_{2}$ TCNBzPyP nos três solventes orgânicos empregados apresentam diferenças significativas nas absortividades por mol da banda Soret e na intensidade relativa das bandas $Q y(0,0)$ e $Q x(1,0)$, evidenciando as transições mais sensiveis ao efeito de solvatação. Em metanol, por exemplo, encontramos o menor 
valor de $\varepsilon$ para a banda Soret e a maior diferença de intensidade entre as bandas $Q y(0,0)$ e $Q x(1,0)$.

A tabela 4 apresenta os valores dos máximos de absorção para as metaloporfirinas obtidas nesse estudo. Devido à maior simetria do anel em relação a base livre, pois a presença do metal altera a simetria de $D_{2 h}$ para $D_{4 h}$, os espectros das metaloporfirinas apresentam apenas duas bandas $Q$, designadas $Q(1,0)$ e $Q(0,0)$, em ordem decrescente de energia.

tabela 4: Máximos de absorção $\left(\lambda_{\text {máx. }}\right)$ das metaloporfirinas em tampão fosfato.

\begin{tabular}{|c|c|c|c|c|}
\hline Porfirina & & $\mathrm{B}(0,0)$ & $Q(1,0)$ & $Q(0,0)$ \\
\hline ZnTMPyP & $\lambda(\mathrm{nm})$ & 436 & 563 & 607 \\
\hline ZnTMeOBzPyP & $\lambda(\mathrm{nm})$ & 440 & 566 & 609 \\
\hline $\mathrm{ZnTCH} \mathrm{CBzPyP}_{3}$ & $\lambda(\mathrm{nm})$ & 441 & 566 & 608 \\
\hline ZnTBzPyP & $\lambda(\mathrm{nm})$ & 440 & 565 & 607 \\
\hline ZnTBrBzPyP & $\lambda(\mathrm{nm})$ & 441 & 565 & 608 \\
\hline ZnTCNBzPyP & $\lambda(\mathrm{nm})$ & 445 & 568 & 610 \\
\hline $\mathrm{ZnTNO}{ }_{2} \mathrm{BzPyP}$ & $\lambda(\mathrm{nm}$ & 444 & 567 & 610 \\
\hline ZnTPhPrPyP & $\lambda(\mathrm{nm})$ & 439 & 566 & 608 \\
\hline CuTMLOBzPyP & $\lambda(\mathrm{nm})$ & 428 & 549 & 584(sh) \\
\hline $\mathrm{CuTCH}_{3} \mathrm{BzPyP}$ & $\lambda(\mathrm{nm})$ & 428 & 550 & $585(\mathrm{sh})$ \\
\hline CuTBzPyP & $\lambda(\mathrm{nm})$ & 428 & 550 & 585(sh) \\
\hline CuTCNBzPyP & $\lambda(\mathrm{nm})$ & 431 & 551 & 586(sh) \\
\hline $\mathrm{CuTNO}_{2} \mathrm{BzPyP}$ & $\lambda(\mathrm{nm})$ & 431 & 552 & $587(\mathrm{sh})$ \\
\hline CuTPhPrPyP & $\lambda(\mathrm{nm})$ & 428 & 550 & $583(\mathrm{sh})$ \\
\hline MnTBzPyP & $\lambda(\mathrm{nm})$ & 462 & 561 & 595(sh) \\
\hline FeTBzPyP & $\lambda(\mathrm{nm})$ & 425 & 600 & 639 \\
\hline
\end{tabular}

As zincoporfirinas apresentam deslocamento médio de $16 \mathrm{~nm}$ da banda Soret para a região do vermelho em relação às respectivas bases livres (tabela 2). Essa menor energia de transição pode ser atribuído ao baixo caráter eletronegativo do íon metálico $\mathrm{Zn}(\mathrm{II})$, ocorrendo uma menor atração sobre os elétrons $\pi$ do macrociclo, o que permite uma maior expansão do anel ${ }^{112}$. Esse deslocamento batocrômico também é observado para os derivados catiônicos ZnTMAPP e ZnTPPS, entretanto com bem menor intensidade, 7 e $9 \mathrm{~nm}$, respectivamente ${ }^{11}$.

A cor das soluções das zincoporfirinas piridínio substituidas é verde, contrariando a classificação proposta por Buchler ${ }^{112}$, em que metais de configuração $d^{10}$ formam metaloporfirinas que apresentam soluções vermelhas, como o observado para a ZnTPyP e a ZnTPP, por exemplo.

As cobreporfirinas apresentam ligeiro deslocamento batocrômico, cerca de 3 $\mathrm{nm}$, para a Soret em relação às respectivas bases livres (figura 25). Esse comportamento já era esperado, pois os metais de camada não preenchida $d^{6}-d^{9}$ geralmente ocasionam deslocamentos hipsocrômicos ou até nenhum deslocamento. 
As bandas $Q(0,0)$ aparecem como ombros, dificultando a atribuição dos seus respectivos máximos.

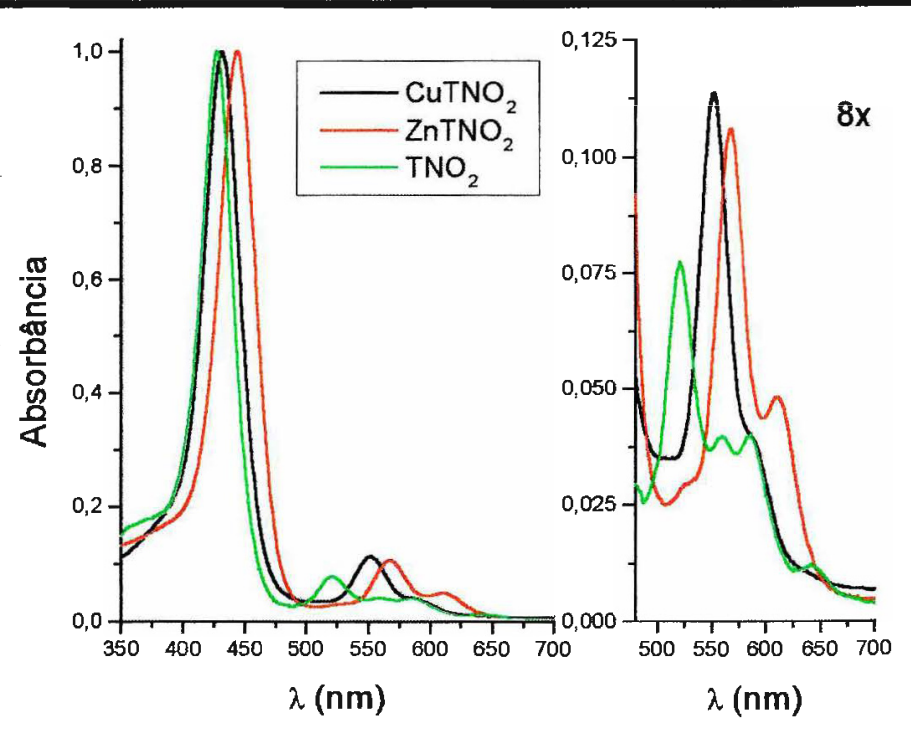

figura 25: Espectros eletrônicos de absorção da $\mathrm{H}_{2} \mathrm{TNO}_{2} \mathrm{BzPyP}$ e seus respectivos Zn(II) e Cu(II) derivados em tampão fosfato. A região das bandas $Q$ foi ampliada para melhor visualização.

A Mn'TBzPyP apresenta espectro muito diferente das demais metaloporfirinas estudadas. Além das bandas Soret, $Q(1,0)$ e $Q(0,0)$ são observadas duas bandas na região de 350 a $400 \mathrm{~nm}$ designadas $\mathrm{M} \mathrm{e} \mathrm{N}$, assim como duas pequenas bandas, uma em $500 \mathrm{~nm}$ e outra entre 650 e $700 \mathrm{~nm}$. Esse perfil espectral, entretanto, é característico de $\mathrm{Mn}$ "'porfirina, existindo inclusive uma nomenclatura diferenciada para essa classe de porfirinas (numeração de I a VI em ordem crescente de energia) ${ }^{35,37}$.

O perfil espectral relatado da Mn"'TMPyP em tampão fosfato ${ }^{93}$ é muito semelhante ao verificado para a Mn"'TBzPyP (figura 26) e a porfirina deve estar na forma monomérica nessas condições.

Já a Fe'llTMPyP têm um comportamento complexo em solução aquosa, havendo uma mistura de monômero e do dímero $\mu$-oxo em soluções neutras ${ }^{93,113}$. Essas espécies apresentam máximo de absorção próximos e o resultado é um espectro com bandas largas que resultam da soma dos dois espectros. A Fe ${ }^{\text {Ill TBzPyP }}$ segue o mesmo padrão e provavelmente o espectro apresentado é resultante dos espectros da forma monomérica e do dímero $\mu$-oxo. 


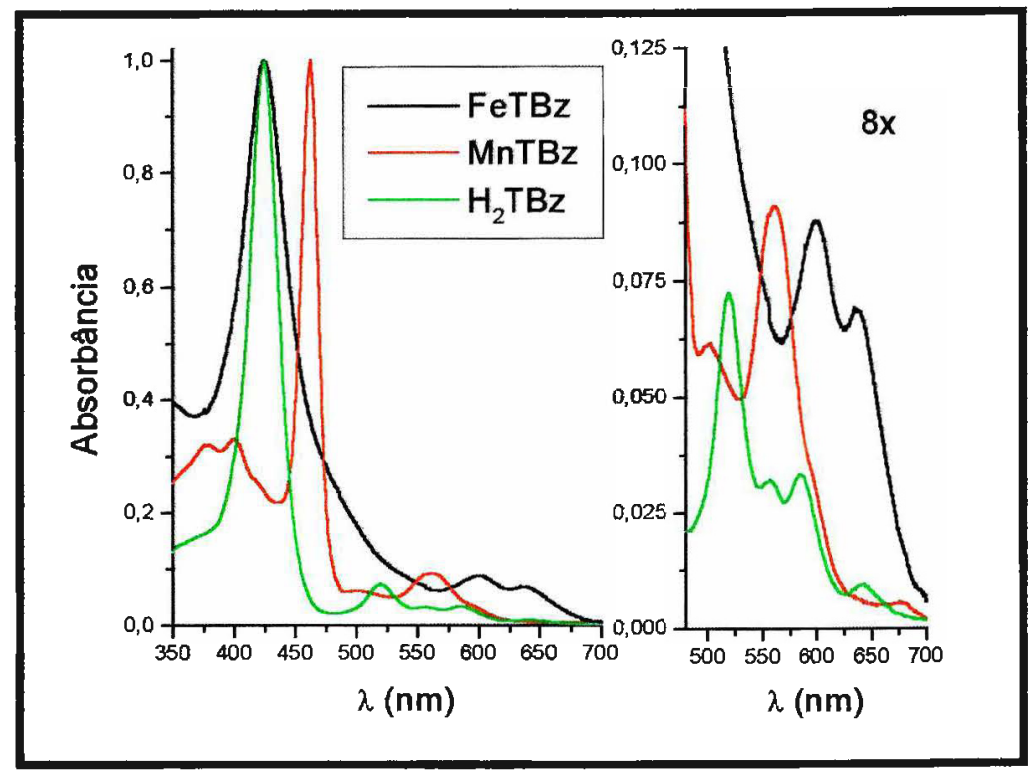

figura 26: Espectros eletrônicos de absorção da $\mathrm{H}_{2}$ TBzPyP e seus respectivos $\mathrm{Mn}(\mathrm{III})$ e $\mathrm{Fe}$ (III) derivados em tampão fosfato. A região das bandas $Q$ foi ampliada para melhor visualização.

\subsubsection{Comportamento Dependente dos Ânions Presentes em Solução}

As porfirinas benzilpiridínio substituídas apresentam solubilidade muito diversa dependendo do solvente e do substituinte benzílico. Ao contrário da $\mathrm{H}_{2}$ TMPyP que é muito solúvel em água e em solução aquosa contendo ânions pequenos $\left(\mathrm{Cl}^{-}, \mathrm{NO}_{3}{ }^{-}\right)$, essas porfirinas precipitam ${ }^{22}$ em solução aquosa de $\mathrm{NaCl} 0,5 \mathrm{~mol} \mathrm{dm}^{-3}$. Essa propriedade possibilita a recuperação das metaloporfirinas sintetizadas sem a adição

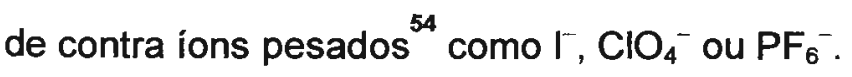

Foram estudados o comportamento de seis porfirinas na forma base livre, $\mathrm{H}_{2}$ TMPyP, $\mathrm{H}_{2}$ TAIPyP, $\mathrm{H}_{2}$ TBzPyP, $\mathrm{H}_{2}$ TCNBzPyP, $\mathrm{H}_{2}$ TMeOBzPyP e $\mathrm{H}_{2} \mathrm{TNO}_{2}$ BzPyP em água deionizada, solução aquosa de $\mathrm{NaNO}_{3}$, solução aquosa de $\mathrm{NaCl}$, solução aquosa de $\mathrm{NaBr}$, solução aquosa de $\mathrm{H}_{3} \mathrm{CCOONa}$, solução aquosa de $\mathrm{Na}_{2} \mathrm{SO}_{4}$ e solução aquosa tampão $\mathrm{HPO}_{4}{ }^{2-} / \mathrm{H}_{2} \mathrm{PO}_{4}^{-}$, todos com força iônica $0,1 \mathrm{~mol} \mathrm{dm}^{-3}$. A concentração de porfirina variou entre 0,5 e $80 \mu \mathrm{mol} \mathrm{dm}^{-3}$.

Foram determinadas as absortividades por mol $(\varepsilon)$ da banda Soret para as bases livres citadas. Os resultados para água, tampão fosfato, $\mathrm{NaCl}$ e $\mathrm{NaNO}_{3}$ são apresentados na tabela 5 . Os eletrólitos $\mathrm{Na}_{2} \mathrm{SO}_{4}$ e $\mathrm{H}_{3} \mathrm{CCOONa}$ não ocasionam variações significativas nos espectros das porfirinas estudadas em relação ao $\mathrm{NaCl}$, portanto não foram colocados na tabela.

Os máximos de absorção da banda Soret da $\mathrm{H}_{2}$ TMPyP seguem a lei de Beer independentemente do ânion do eletrólito suporte. Esse comportamento já era esperado, uma vez que essa porfirina apresenta alta solubilidade mesmo em solução 
saturada de $\mathrm{NaCl}^{53}$. Entretanto, observa-se uma significativa alteração dos valores de absortividade por mol $(\varepsilon)$ da Soret em função do eletrólito suporte utilizado (ver tabela 5). Supōe-se que a alteração na solvatação da $H_{2}$ TMPyP em função do eletrólito presente em solução ocasione algumas distorçōes na estrutura eletrônica da molécula.

As porfirinas $\mathrm{H}_{2}$ TAIPyP e $\mathrm{H}_{2}$ TBzPyP apresentam comportamento semelhante entre si, o máximo de absorção da banda Soret obedece a lei de Beer para todos os eletrólitos. Observa-se uma variação nos valores de $\varepsilon$, dependendo do eletrólito utilizado, entretanto numa intensidade muito menor do que a observada para a $\mathrm{H}_{2}$ TMPyP.

Nota-se que em solução contendo $\mathrm{NaNO}_{3}$ há um deslocamento de $1 \mathrm{~nm}$ da banda Soret para a regiăo do vermelho, tanto para a $\mathrm{H}_{2}$ TAIPyP quanto para a $\mathrm{H}_{2}$ TBzPyP. Deslocamentos dessa ordem de grandeza foram considerados evidência de formação de agregados por Shachter e colaboradores para a $\mathrm{H}_{2}$ TAIPyP e outras porfirinas piridínio substituídas ${ }^{58}$. Entretanto, a pequena variação dos valores de $\varepsilon$ em relação a outros eletrólitos, além da aplicação da lei de Beer em toda a faixa de concentração estudada contraria a hipótese de formação de agregados, indicando apenas a modificação na interação entre o solvente e os níveis eletrônicos da porfirina.

tabela 5: Absortividades por mol ${ }^{a}(\varepsilon)$ e máximos de absorção $\left(\lambda_{\text {máx. }}\right)$ da Soret das porfirinas estudadas.

\begin{tabular}{ccccccc}
\hline Porfirina & & Água & Fosfato & $\mathrm{NaCl}$ & $\mathrm{NaBr}$ & $\mathrm{NaNO}_{3}$ \\
\hline H $_{2}$ TMeOBzPyP & $\lambda(\mathrm{nm})$ & 424 & 424 & 424 & 426 & 426 \\
& $\varepsilon\left(10^{3} \mathrm{~mol}^{-1} \mathrm{~cm}^{-1} \mathrm{dm}^{3}\right)$ & 259 & 242 & 255 & 165 & $113^{*}$ \\
H $_{2}$ TBzPyP & $\lambda(\mathrm{nm})$ & 425 & 425 & 425 & 426 & 426 \\
& $\varepsilon\left(10^{3} \mathrm{mo}^{-1} \mathrm{~cm}^{-1} \mathrm{dm}^{3}\right)$ & 206 & 183 & 205 & 195 & 184 \\
$\mathrm{H}_{2}$ TCNBzPyP & $\lambda(\mathrm{nm})$ & 427 & 427 & 427 & 428 & 429 \\
& $\varepsilon\left(10^{3} \mathrm{~mol}^{-1} \mathrm{~cm}^{-1} \mathrm{dm}^{3}\right)$ & 191 & 184 & 188 & 192 & $105^{*}$ \\
$\mathrm{H}_{2}$ TNO $_{2}$ BzPyP & $\lambda(\mathrm{nm})$ & 428 & 428 & 429 & $431-442$ & $431-448$ \\
& $\varepsilon\left(10^{3} \mathrm{~mol}^{-1} \mathrm{~cm}^{-1} \mathrm{dm}^{3}\right)$ & 182 & 176 & 177 & $61^{*}$ & $65^{*}$ \\
$\mathrm{H}_{2}$ TMPyP & $\lambda\left(\mathrm{nm}^{*}\right)$ & 421 & 421 & 421 & 421 & 421 \\
& $\varepsilon\left(10^{3} \mathrm{~mol}^{-1} \mathrm{~cm}^{-1} \mathrm{dm}^{3}\right)$ & 240 & 208 & 224 & 243 & 270 \\
H $_{2}$ TAIPyP & $\lambda(\mathrm{nm})$ & 423 & 423 & 423 & 424 & 424 \\
& $\varepsilon\left(10^{3} \mathrm{~mol}^{-1} \mathrm{~cm}^{-1} \mathrm{dm}^{3}\right)$ & 194 & 181 & 195 & 211 & 188 \\
\hline
\end{tabular}

a- concentrações: 0,8 a $8,0 \mu \mathrm{mol} \mathrm{dm}^{-3}$; " não segue a lei de Beer nessas condições.

As porfininas $\mathrm{H}_{2}$ TCNBzPyP e $\mathrm{H}_{2}$ TMeOBzPyP são muito mais sensiveis à solução $0,1 \mathrm{~mol} \mathrm{dm}^{-3}$ de $\mathrm{NaNO}_{3}$. Novamente em água pura e nos demais eletrólitos estudados verifica-se uma pequena variação nos valores de $\varepsilon$ determinados. Entretanto em solução de $\mathrm{NaNO}_{3}$ percebe-se rapidamente a precipitação da porfirina, com o aumento da linha base dos espectros UV-Vis, além da diminuição da absorção da solução de porfirina. Há também um deslocamento batocrômico de $2 \mathrm{~nm}$ da banda 
Soret. Em solução de $\mathrm{NaBr}$ também se observa deslocamento da banda Soret e precipitação dessas porfirinas, entretanto, somente em concentrações mais elevadas de porfirina, ou seja, a partir de $20 \mu \mathrm{mol} \mathrm{dm}^{-3}$.

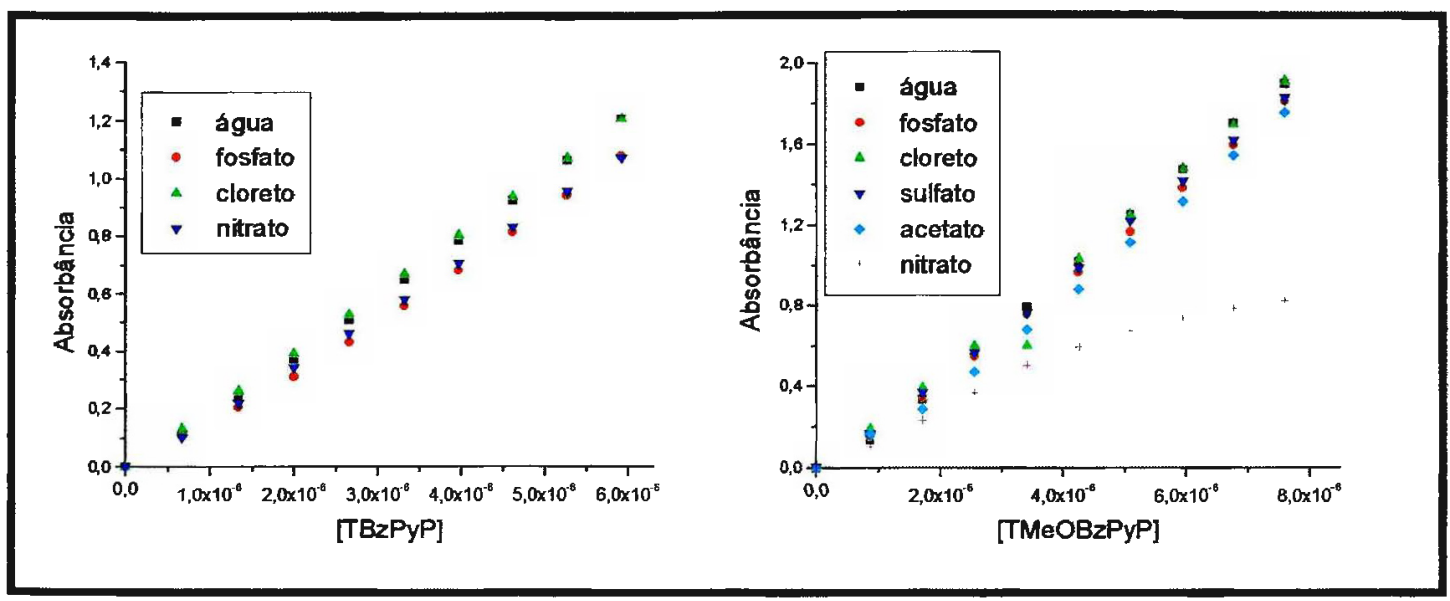

figura 27: Lei de Beer da $\mathrm{H}_{2}$ TBzPyP e $\mathrm{H}_{2}$ TMeOBzPyP em soluções aquosas contendo diversos eletrólitos com força iônica $0,1 \mathrm{~mol} \mathrm{dm}^{-3}$.

A $\mathrm{H}_{2} \mathrm{TNO}_{2}$ BzPyP apresentou comportamento diferenciado das demais porfirinas, com precipitação da porfirina em soluções de $\mathrm{NaNO}_{3}$ e $\mathrm{NaBr} 0,1 \mathrm{~mol} \mathrm{dm}^{-3}$, mesmo em concentrações baixas de porfirina. Além disso, a banda Soret apresenta um alargamento anômalo para essas condições, com grande desvio do máximo de absorção dependente da concentração de porfirina, como apresenta a figura 28. O máximo da banda Soret desloca-se durante a adição da porfirina de $431 \mathrm{~nm}$ a $448 \mathrm{~nm}$.

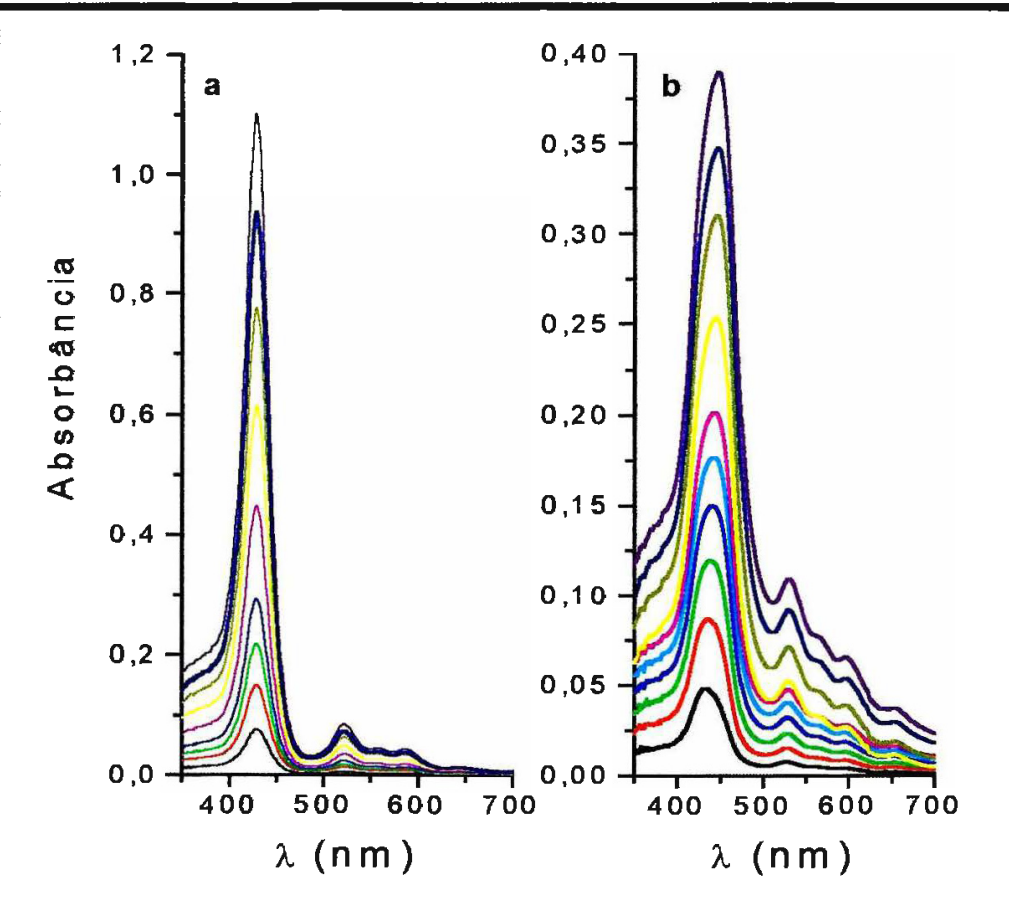

figura 28: Espectros de absorção de diferentes concentrações da $\mathrm{H}_{2} \mathrm{TNO}_{2} \mathrm{BzPyP}$ $\left(0,5\right.$ a $\left.6,5 \mu \mathrm{mol} \mathrm{dm}^{-3}\right)$. a - solução aquosa de $\mathrm{NaCl} 0,1 \mathrm{~mol} \mathrm{dm}^{-3}$; b - solução aquosa de $\mathrm{NaNO}_{3} 0,1 \mathrm{~mol} \mathrm{dm}^{-3}$. 
Para evidenciar a formação de agregados ou de precipitação, preparou-se soluções das porfirinas em água, tampão fosfato e $\mathrm{NaNO}_{3}$, acompanhando-se a variação dos espectros de absorção em função do tempo. Neste ponto pode-se notar uma maior sensibilidade da $\mathrm{H}_{2}$ TBzPyP em relação a solução aquosa de $\mathrm{NaNO}_{3}$, enquanto que a $\mathrm{H}_{2}$ TAIPyP apresenta o mesmo comportamento para as três soluções.

Os espectros das $\mathrm{H}_{2} \mathrm{TNO}_{2}$ BzPyP, $\mathrm{H}_{2}$ TCNBzPyP e $\mathrm{H}_{2}$ TMeOBzPyP variam significativamente em função do tempo para a solução aquosa contendo $0,1 \mathrm{~mol} \mathrm{dm}^{-3}$ de $\mathrm{NaNO}_{3}$, indicando a precipitação dessas porfirinas nessas condições.
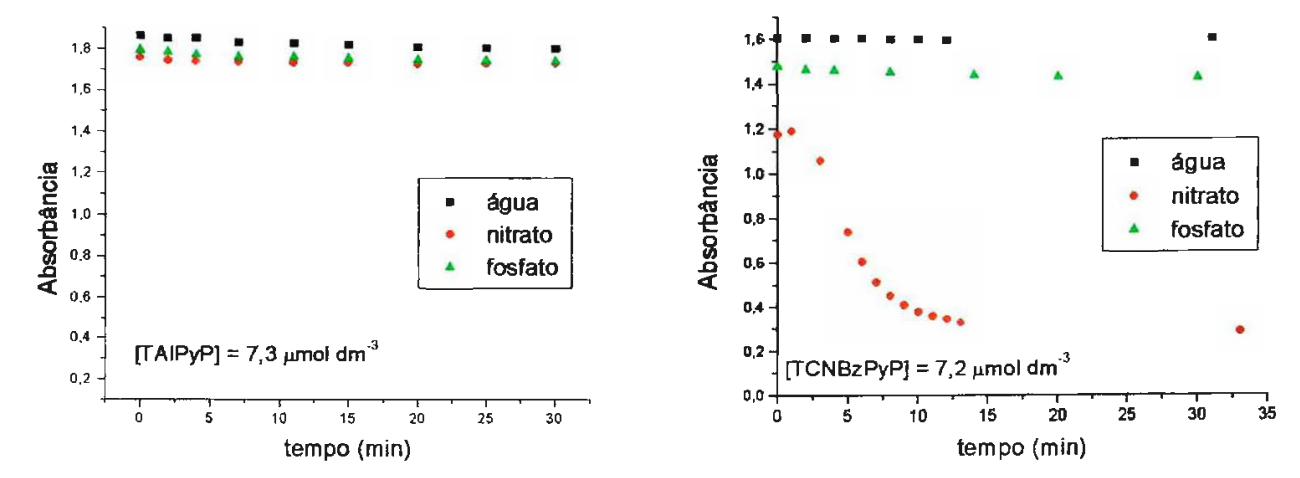

figura 29: Variação da absorbância da Banda Soret em função do tempo das soluções das porfirinas $\mathrm{H}_{2}$ TAIPyP e $\mathrm{H}_{2} \mathrm{TCNBzPyP}$ em água, tampão fosfato e $\mathrm{NaNO}_{3}$.

A solubilidade das porfirinas piridínio substituídas em solução aquosa está diretamente associada com o grau de hidrofobicidade do substituinte alquil, levando-se em conta principalmente o tamanho do grupo ligado ao nitrogênio piridínico. Daí uma menor solubilidade das porfirinas $\mathrm{H}_{2} \mathrm{TNO}_{2} B z P y P, \mathrm{H}_{2}$ TMeOBzPyP e $\mathrm{H}_{2} \mathrm{TCNBzPyP}$ em relação a $\mathrm{H}_{2}$ TBzPyP e $\mathrm{H}_{2}$ TAIPyP, sendo a $\mathrm{H}_{2}$ TMPyP muito mais solúvel que os demais derivados. A força iônica do meio também influencia a solubilidade, visto que todas as porfirinas apresentam-se solúveis em $\mathrm{NaCl} 0,1 \mathrm{~mol} \mathrm{dm}^{-3}$, enquanto que as porfirinas $\mathrm{H}_{2}$ TCNBzPyP, $\mathrm{H}_{2}$ TMeOBzPyP e $\mathrm{H}_{2} \mathrm{TNO}_{2}$ BzPyP já não são solúveis em $\mathrm{NaCl}$ $0,5 \mathrm{~mol} \mathrm{dm}^{-3}$, sendo necessário $\mathrm{NaCl} 1,0 \mathrm{~mol} \mathrm{dm}^{-3}$ para precipitar a $\mathrm{H}_{2}$ TBzPyP.

Entretanto, é preciso considerar o ânion do eletrólito suporte presente na solução. Os resultados apresentados nesse estudo e os relatos da baixa solubilidade das porfirinas piridínio substituídas em presença dos ânions $\mathrm{I}^{-}{\mathrm{e} \mathrm{ClO}_{4}}^{-}$, mostram que a solubilidade corresponde a série liotrópica, também chamada de série de Hofmeister. Essa série correlaciona o efeito como contra ion de uma série de ânions em diversos sistemas como precipitação de proteínas ${ }^{114}$, a cmc e o número de monômeros que participam de agregados de surfactantes catiônicos ${ }^{115}$, obtendo-se uma relação linear da atividade relativa dos ânions (N) para cada sistema. $\mathrm{O}$ valor de $\mathrm{N}$ para cada ânion 
foi determinado a partir das concentrações de cada ânion necessária para a precipitação de gelatina e de ágar-ágar, atribuindo-se valores arbitrários para o ânion $\mathrm{SO}_{4}{ }^{2-}(\mathrm{N}=2,00)$ e para o ânion $\mathrm{Cl}^{-}(\mathrm{N}=10,00)$.

Qualitativamente, a série liotrópica apresenta a seguinte ordem para os ânions empregados no estudo com as porfirinas ${ }^{114},{ }^{115}: \mathrm{SO}_{4}{ }^{2-}<\mathrm{H}_{2} \mathrm{PO}_{4}{ }^{-}<\mathrm{CH}_{3} \mathrm{COO}^{-}<\mathrm{Cl}^{-}<\mathrm{Br}^{-}<$ $\mathrm{NO}_{3}{ }^{-}<\mathrm{ClO}_{4}{ }^{-}<\mathrm{I}^{-}$. Quanto maior o valor na série liotrópica menor a concentração do ânion necessária para precipitar uma proteína nas mesmas condições, por exemplo. $\mathrm{A}$ solubilidade das porfirinas benzilpiridínio substituídas está relacionada à série liotrópica, apresentando boa solubilidade em acetato, fosfato, ocorrendo a precipitação em concentrações apreciáveis de cloreto e mais facilmente na presença de nitrato e brometo.

\subsection{Espectroscopia Eletrônica de Emissão}

Os espectros de emissão podem fomecer uma série de informações relevantes sobre a contribuição dos substituintes alquílicos na estrutura eletrônica do macrociclo das porfirinas piridínio substituídas. Sob esse aspecto, são apresentados nessa seção os espectros de emissão das porfirinas e zincoporfirinas obtidas nesse estudo em meio aquoso e meio orgânico, sempre procurando comparações com os dados conhecidos da $\mathrm{H}_{2}$ TMPyP e seus metalo derivados.

Essa seção, também se propõe a contribuir em dois aspectos controversos da caracterização das porfirinas piridínio substituídas. O primeiro é referente aos valores de rendimento quântico de fluorescência $\left(\Phi_{F}\right)$ para a $H_{2} T M P y P$, uma vez que a literatura apresenta valores bastante discrepantes dos valores obtidos nesse trabalho.

Outro ponto refere-se à dramática mudança no perfil espectral das bases livres em meio aquoso em soluções com concentrações da ordem de $10 \mathrm{nmol} \mathrm{dm}^{-3}$. Durante muitos anos, o fato de que soluções aquosas contendo baixas concentrações de $\mathrm{H}_{2}$ TMPyP apresentam bandas de emissão bem definidas, semelhantes aos espectros em meio orgânico, significou que o espectro mal resolvido em solução aquosa seria devido a formação de agregados diméricos ${ }^{39,40}$ em concentrações superiores a 50 $\mathrm{nmol} \mathrm{dm}^{-3}$. Foram realizados alguns experimentos para corroborar com a proposta de Vergeldt e colaboradores que refutam o modelo da dimerização ${ }^{57}$. Os resultados obtidos permitem afirmar que não ocorre agregação das porfirinas em meio aquoso em concentrações abaixo de $10^{-4} \mathrm{~mol} \mathrm{dm}^{-3}$.

A obtenção de espectros de emissão das zincoporfininas em soluções glicerinalágua congeladas $(77 \mathrm{~K})$, propicia a observação da fosforescência desses metalo derivados, possibilitando a determinação da energia do estado excitado 
triplete $^{21}$. Esse valor está diretamente relacionado aos potenciais redox do estado excitado, podendo-se fazer uma avaliação da reatividade fotoquímica dos derivados benzilpiridínio substituídos sintetizados nesse trabalho.

Todos os espectros apresentados nessa seção foram corrigidos em função da resposta da fotomultiplicadora ${ }^{56}$, uma vez que sua sensibilidade diminui muito em comprimentos de onda superiores a $600 \mathrm{~nm}$. Os espectros corrigidos apresentam perfis compatíveis aos espectros publicados na literatura recente ${ }^{56,57}$. Entretanto, os espectros anteriormente publicados,${ }^{1,39}$ apresentam perfis espectrais mais próximos aos espectros sem correção.

As figuras 30 e 31 apresentam, respectivamente, espectros da $\mathrm{H}_{2} \mathrm{TBzPyP}$ e da ZnTBzPyP em meio aquoso com e sem correção da resposta da fotomultiplicadora. $O$ perfil espectral de todas as porfirinas piridínio alquil substituídas é semelhante em solução aquosa. Os espectros estão normalizados para facilitar a comparação.

A figura 32 apresenta a representação gráfica da função utilizada para corrigir a resposta da fotomultiplicadora. O inverso dessa curva representaria a sensibilidade da fotomultiplicadora.

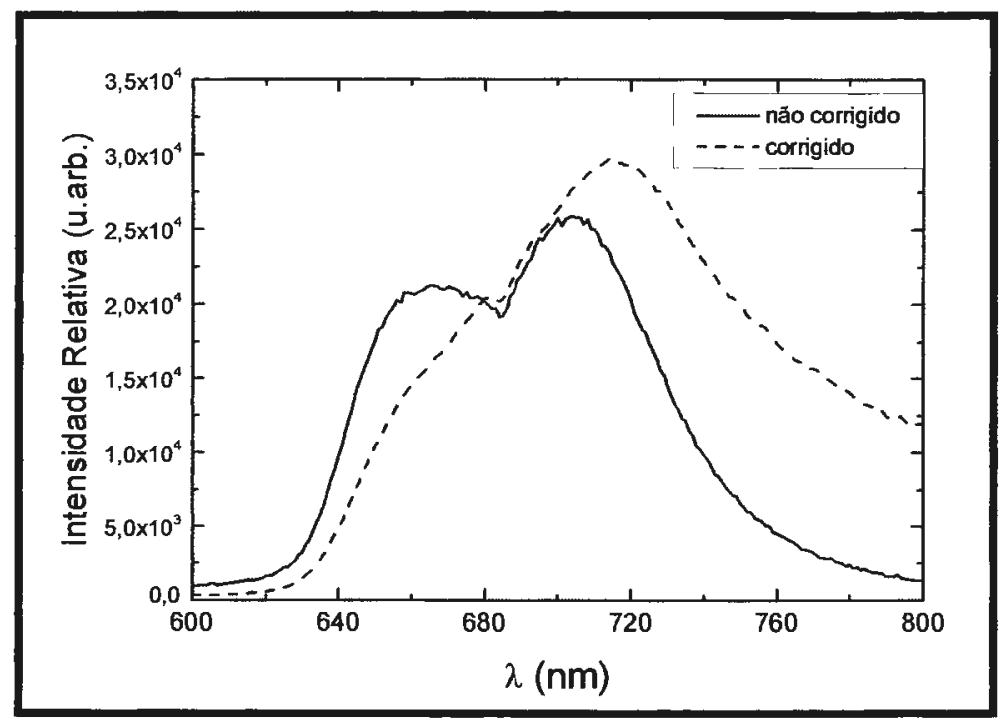

figura 30: Espectros de emissão da $\mathrm{H}_{2} \mathrm{TBzPyP}\left(380 \mathrm{nmol} \mathrm{dm}^{-3}\right)$ em água. 


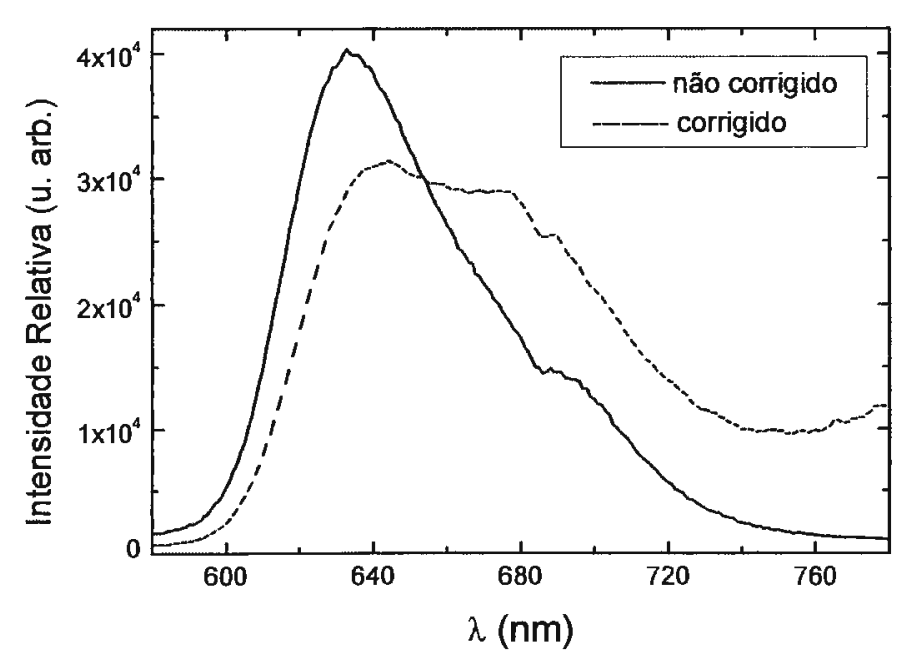

figura 31: Espectros de emissão da ZnTBzPyP $\left(350 \mathrm{nmol} \mathrm{dm}^{-3}\right)$ em água.

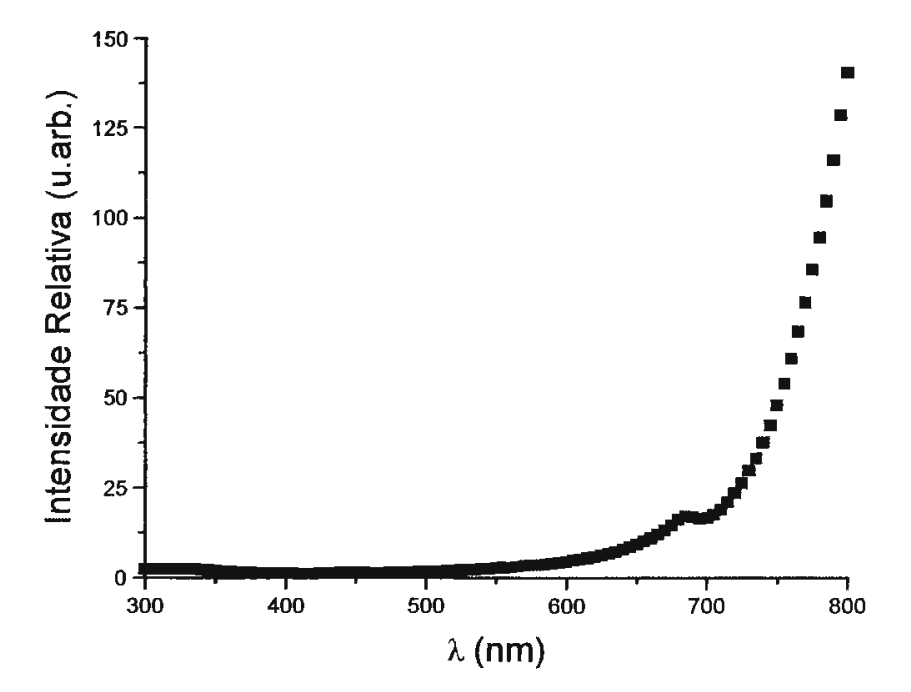

figura 32: Curva utilizada para a correção dos espectros de emissão no espectrofluorímetro Spex-Fluorolog FL 212. Essa correção visa compensar as diferentes respostas da fotomultiplicadora em função do comprimento de onda.

\subsubsection{Emissão das Bases Livres em Solventes Orgânicos}

Diferentemente dos espectros obtidos em solução aquosa, os espectros em solvente orgânico das porfirinas piridínio substituídas apresentam duas bandas muito bem definidas designadas $Q(0,0)$ (maior energia) e $Q(0,1)$ (menor energia) ${ }^{21,37}$. Essas bandas correspondem ao decaimento eletrônico radioativo do nível vibracional zero do estado excitado singlete, para o nível vibracional zero e um, respectivamente, do estado fundamental. O perfil dos espectros em solvente orgânico é semelhante ao observado para as porfirinas fenil substituídas ( $\mathrm{H}_{2}$ TPPS e $\mathrm{H}_{2}$ TMAPP) em qualquer 
solvente e para as porfirinas não iônicas $\mathrm{H}_{2}$ TPyP e $\mathrm{H}_{2}$ TPP em solventes apolares (figura 33).

Foram obtidos os espectros de emissão das base livres em metanol, em pelo menos duas concentrações: 4,0 a $8,0 \mathrm{nmol} \mathrm{dm}^{-3}$ e 400 a $800 \mathrm{nmol} \mathrm{dm}^{-3}$, excitando-se as soluções no comprimento de onda do máximo de absorção da banda Soret de cada porfirina. Essas concentrações foram utilizadas pois é nessa faixa que observam-se variações nos perfis do espectro de emissão em solução aquosa.

Não são percebidos deslocamentos significativos dos máximos de emissão das duas bandas com a variação da concentração da porfirina, indicando a presença de apenas uma espécie em solução nessa faixa de concentração. Em concentrações mais elevadas (até $10 \mu \mathrm{mol} / \mathrm{L}$ ) o perfil espectral é mantido.

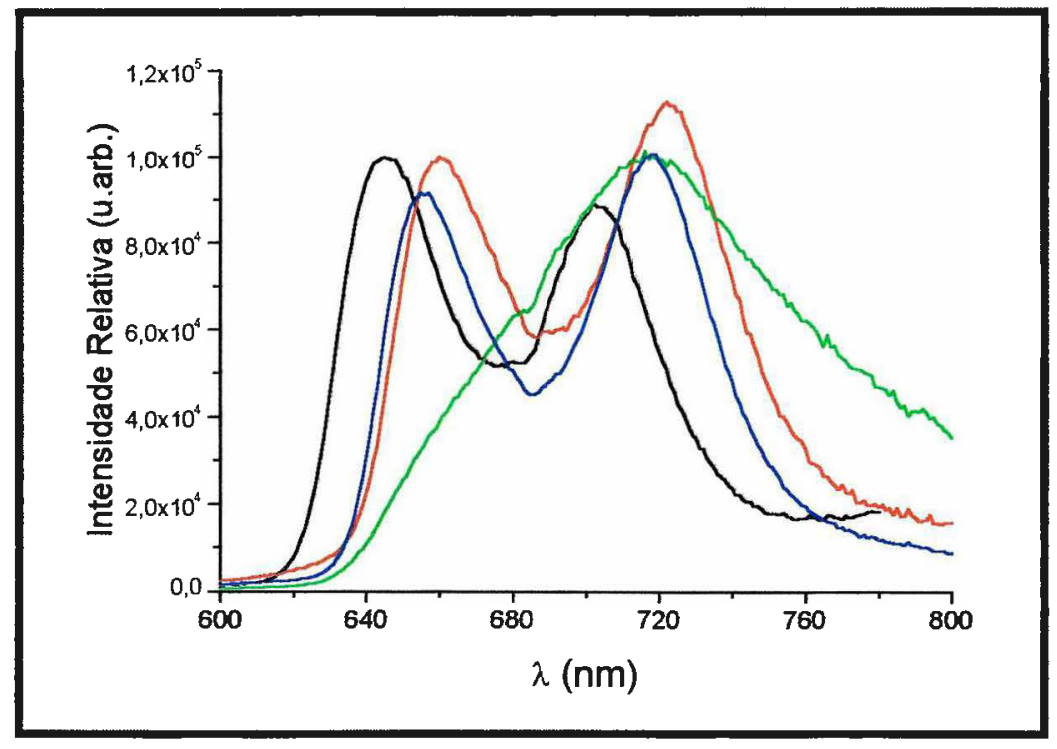

figura 33: Espectros de emissão da $\mathrm{H}_{2}$ TMAPP em água, $\mathrm{H}_{2}$ TCNBzPyP em metanol, $\mathrm{H}_{2}$ TCNBzPyP em água, $\mathrm{H}_{2}$ TCNBzPyP em DMSO. Os espectros foram normalizados para melhor comparação.

Como pode ser observado na figura 34 a banda $Q(0,0)$ apresenta uma diminuição da intensidade em relação à banda $Q(0,1)$ com o aumento da concentração de $\mathrm{H}_{2}$ TMeOBzPyP. Essa diferença de intensidade das bandas deve ser decorrente da auto absorção da solução pois a banda $Q x(0,0)$ apresenta máximo de absorção na região eritre 640-650 nm, apesar da sua intensidade nas concentrações utilizadas ser relativamente baixa (menor que 0,1 ). O filtro interno não deve ser a causa dessa variação, pois este deveria ocasionar diminuição eqüitativa das duas bandas, uma vez que o comprimento de onda de excitação da fonte é absorvido pela solução de porfirina em soluções mais concentradas. 


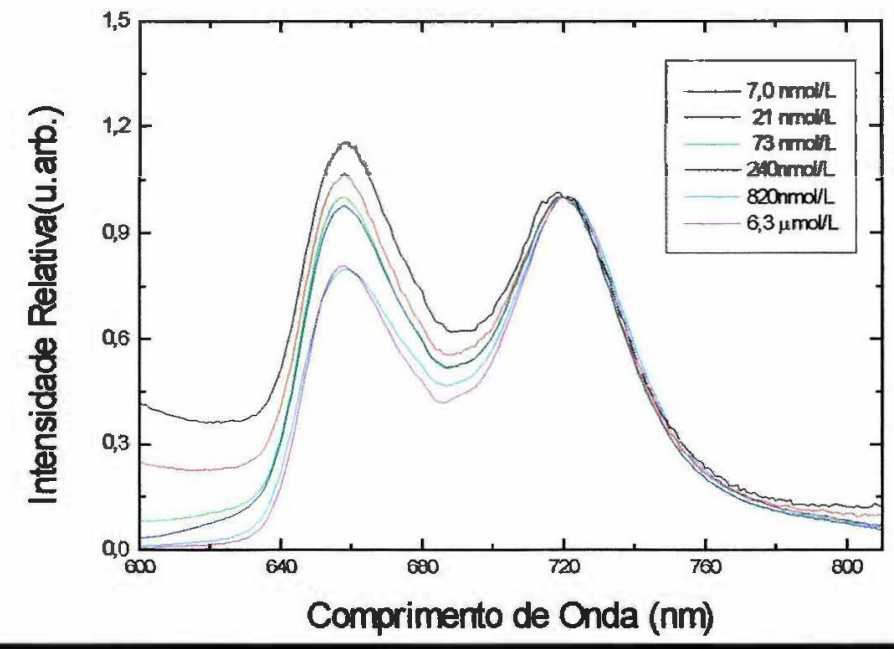

figura 34: Espectros de emissão da $\mathrm{H}_{2} \mathrm{TMeOBzPyP}$ em diferentes concentrações em metanol, normalizado para o máximo de emissão da banda $Q(0,1)$.

A tabela 6 apresenta os comprimentos de onda dos máximos de emissão dos espectros das porfirinas analisadas. Observa-se um deslocamento para o vermelho (batocrômico) da banda $Q(0,0)$ na série das porfirinas benzilpiridínio substituídas, em relação a $\mathrm{H}_{2}$ TMPyP seguindo comportamento observado nos espectros de absorção. A banda $Q(0,1)$ é menos sensivel a esse deslocamento do que a banda $Q(0,0)$. Os máximos de deslocamento citados por Kano e colaboradores ${ }^{39}$ para a $\mathrm{H}_{2}$ TMPyP em metanol ( $654 \mathrm{~nm}$ e $715 \mathrm{~nm}$ ) estão em ligeiro desacordo com o indicado na tabela 6 .

tabela 6: Máximos de emissão das porfirinas piridínio substituídas em solventes orgânicos .

\begin{tabular}{|c|c|c|c|c|}
\hline Porfininas & Solvente & & $\mathrm{Q}(0,0)$ & $Q(0,1)$ \\
\hline $\mathrm{H}_{2}$ TMPyP & Metanol & $\lambda(\mathrm{nm})$ & 656 & 719 \\
\hline $\mathrm{H}_{2}$ TAIPyP & Metanol & $\lambda(\mathrm{nm})$ & 658 & 721 \\
\hline $\mathrm{H}_{2}$ TMeOBzPyP & Metanol & $\lambda(\mathrm{nm})$ & 658 & 721 \\
\hline $\mathrm{H}_{2} \mathrm{TCH}_{3}$ BzPyP & Metanol & $\lambda(\mathrm{nm})$ & 658 & 722 \\
\hline $\mathrm{H}_{2}$ TBzPyP & Metanol & $\lambda(\mathrm{nm})$ & 659 & 722 \\
\hline $\mathrm{H}_{2}$ TBrBzPyP & Metanol & $\lambda(\mathrm{nm})$ & 659 & 722 \\
\hline $\mathrm{H}_{2} \mathrm{TCO}_{2} \mathrm{HBz}_{\mathrm{PyP}}$ & Metanol & $\lambda(\mathrm{nm})$ & 660 & 722 \\
\hline $\mathrm{H}_{2} \mathrm{TCNBzPyP}$ & Metanol & $\lambda(\mathrm{nm})$ & 659 & 721 \\
\hline $\mathrm{H}_{2} \mathrm{TNO}_{2} \mathrm{BzPyP}$ & Metanol & $\lambda(\mathrm{nm})$ & 661 & 721 \\
\hline $\mathrm{H}_{2} \mathrm{TCNBzPyP}$ & DMSO & $\lambda(\mathrm{nm})$ & 655 & 717 \\
\hline $\mathrm{H}_{2} \mathrm{TCNBzPyP}$ & DMF & $\lambda(\mathrm{nm})$ & 656 & 719 \\
\hline $\mathrm{H}_{2} \mathrm{TCH}_{3} \mathrm{BzPyP}$ & DMSO & $\lambda(\mathrm{nm})$ & 655 & 717 \\
\hline $\mathrm{H}_{2} \mathrm{TCH}_{3}$ BzPyP & DMF & $\lambda(\mathrm{nm})$ & 655 & 719 \\
\hline $\mathrm{H}_{2} \mathrm{TCH}_{3} \mathrm{BzPyP}$ & acetona & $\lambda(\mathrm{nm})$ & 655 & 718 \\
\hline
\end{tabular}

${ }^{a}$ Concentrações 0,4 a $0,8 \mu \mathrm{mol} \mathrm{dm}{ }^{-3}$. 
Os espectros obtidos em outros solventes polares como DMSO, DMF e acetona não apresentam mudança significativa em relação aos obtidos em metanol. Novamente se observa uma diminuição da intensidade da banda $Q(0,0)$ em relação à banda $Q(0,1)$ com o aumento da concentração.

Em DMSO, DMF e acetona ocorre um deslocamento das bandas para o azul (hipsocrômico) em relação ao metanol, devido à mudança de polaridade do meio. A menor polaridade do solvente deve aumentar a energia do estado excitado singlete, estabilizando-o menos.

\subsubsection{Emissão das Zincoporfirinas}

Os espectros de emissão das zinco benzilpiridínio porfirinas possuem uma menor definição das duas bandas $Q(0,0)$ e $Q(0,1)$ quando comparados com o espectro de emissão da ZnTMPyP. Os espectros foram obtidos em uma ampla faixa de concentração em água e tampão fosfato (10 nmol dm a $10 \mu \mathrm{mol} \mathrm{dm} \mathrm{dm}^{-3}$ ), não verificando-se alterações significativas nos perfis espectrais. A menor definição das bandas $Q(0,0)$ e $Q(0,1)$ deve estar relacionada a interações entre os niveis vibracionais do estado fundamental das zincoporfirinas em questão.

No caso das zincoporfirinas, a utilização de um solvente orgânico não leva a uma melhor definição das bandas, obtendo-se um espectro muito semelhante ao obtido em meio aquoso. Podemos afirmar que a sobreposição de bandas é característica da espécie, independentemente da sua interação com o solvente. A figura 35 apresenta o espectros da ZnTCNBzPyP em metanol e em água.

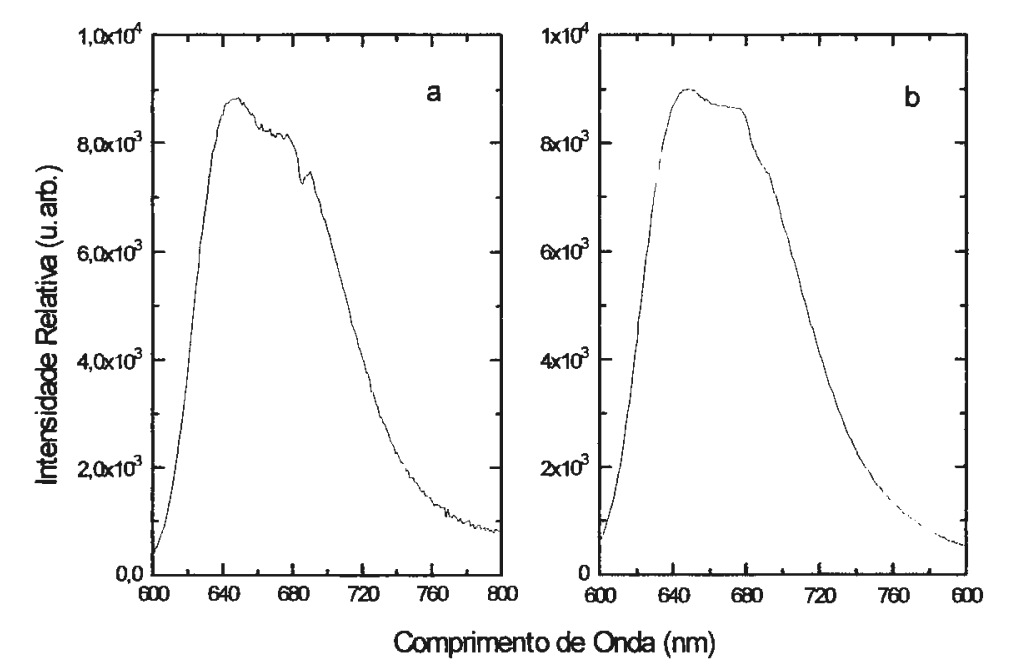

figura 35: Espectros de emissão da ZnTCNBzPyP:

a- água, [ZnTCNBzPyP] $=390 \mathrm{nmol} \mathrm{dm}^{-3}$;

b- metanol, [ZnTCNBzPyP] $=400 \mathrm{nmol} \mathrm{dm}^{-3}$ 
Os espectros foram obtidos excitando-se a solução nos máximos de absorção da banda Soret ou da banda $Q(1,0)$, sem se observar diferenças quanto ao perfil do espectro. As figuras apresentadas e os valores tabelados nessa seção referem-se aos espectros obtidos com a excitação da banda Soret dos zinco derivados.

Encontrou-se dificuldade para determinar os máximos de emissão das bandas $Q(0,0)$ e $Q(0,1)$ para as zincoporfirinas benzilpiridínio substituídas. Foi utilizado um artifício matemático para fazer a deconvolução das bandas, considerando que a curva observada provém da soma de duas curvas lorentzianas. A adoção de curvas lorentzianas ao invés de curvas gaussianas é justificada pois a soma das duas curvas lorentzianas resultam em uma função muito próxima dos espectros obtidos, o mesmo não ocorrendo em relação às curvas gaussianas. A aproximação por duas curvas lorentzianas também apresentou máximos mais próximos aos relatados para a ZnTMPyP do que a aproximação gaussiana. A figura 36 apresenta os espectros originais da ZnTMPyP e da ZnTMeOBzPyP e os resultados obtidos no cálculo de deconvolução lorentziana das curvas. A tabela 7 lista os valores de máximos obtidos por esse método. Os cálculos foram realizados utilizando-se o software Origin 5.0.

tabela 7: Máximos de emissão das zincoporfirinas estudadas em solução aquosa.

\begin{tabular}{|cccc|}
\hline Porfirinas & & $\mathrm{Q}(0,0)$ & $\mathrm{Q}(0,1)$ \\
\hline ZnTMPyP $^{a}$ & $\lambda(\mathrm{nm})$ & 626 & 660 \\
ZnTMPyP $^{b}$ & $\lambda(\mathrm{nm})$ & 630 & 664 \\
ZnTMPyP $^{c}$ & $\lambda(\mathrm{nm})$ & 634 & 673 \\
ZnTMeOBzPyP $^{c}$ & $\lambda(\mathrm{nm})$ & 640 & 679 \\
ZnTBzPyP $^{c}$ & $\lambda(\mathrm{nm})$ & 642 & 679 \\
ZnTCNBzPyP $^{c}$ & $\lambda(\mathrm{nm})$ & 644 & 680 \\
ZnTNO $_{2}$ BzPyP $^{c}$ & $\lambda(\mathrm{nm})$ & 646 & 680 \\
\hline
\end{tabular}

$\mathbf{a}$ - ref. ${ }^{1} ; \mathbf{b}-$ ref. $^{24} ; \mathbf{c}$ - calculados pela deconvolução do espectro obtido;

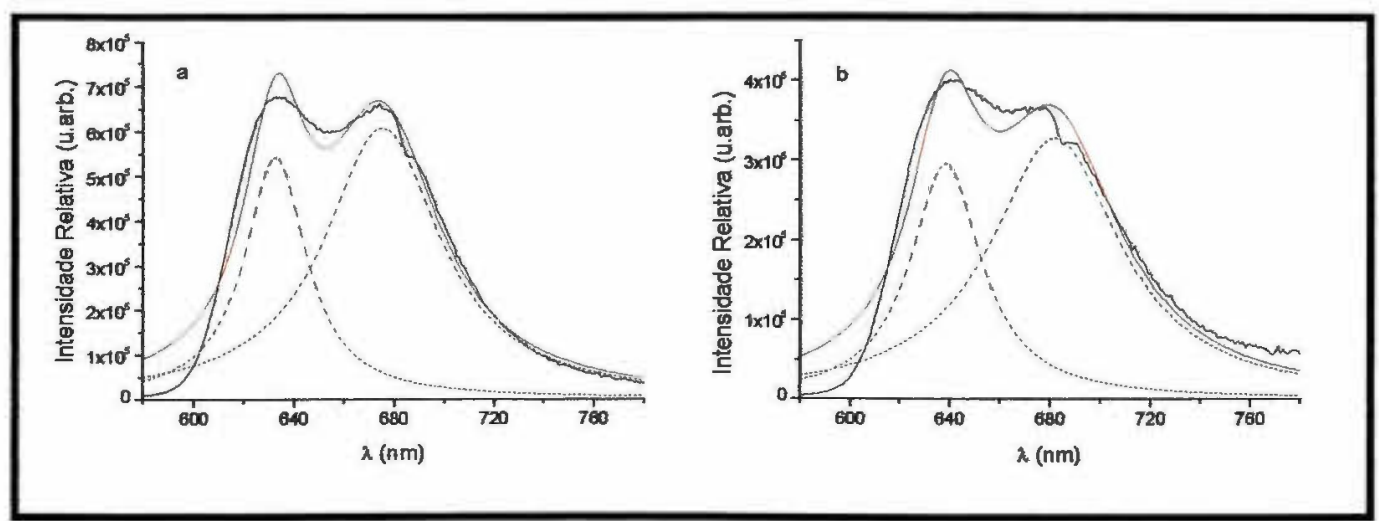

figura 36: Espectro de emissão de fluorescência da (a) ZnTMPyP (560 nmol dm ${ }^{-3}$ ) e (b) ZnTMeOBzPyP $\left(600 \mathrm{nmol} \mathrm{dm}^{-3}\right)$ em água. Em azul, as duas curvas lorentzianas provenientes da deconvolução do espectro. Em vermelho, a curva resultante da soma das duas curvas lorentzianas. 
3.2.3. Determinação do Rendimento Quântico de Fluorescência Relativo $\left(\Phi_{F}\right)$

O rendimento quântico de fluorescência ${ }^{21,42,41}$ é a medida da eficiência da emissão de luz no processo de decaimento do estado excitado singlete para o estado fundamental de mesma multiplicidade (decaimento radiativo singlete-singlete). $\dot{E}$ definido pela razão dos números de fótons emitidos pelo número de fótons absorvidos pelo sistema. Usualmente, é suficiente determinar o rendimento quântico relativo ${ }^{116}$ de um sistema, ou seja, comparar a eficiência da emissão fluorescente do sistema estudado com a de um sistema padrão, determinado e aceito por outros autores. A equação que permite a comparação de rendimentos quânticos de fluorescência está descrita abaixo:

$$
\frac{\Phi_{\mathrm{F} 1}}{\Phi_{\mathrm{F} 2}}=\frac{A_{2} \times \Delta_{1} \times \eta_{2}{ }^{2}}{A_{1} \times \Delta_{2} \times \eta_{1}{ }^{2}}
$$

onde $\Phi_{F}$ é o rendimento quântico de fluorescência relativo, A é a absorbância da solução no comprimento de onda de excitação, $\Delta$ é a área das curvas do espectro de fluorescência e $\eta$ é o índice de refração do solvente.

Para a determinação dos rendimentos quânticos de fluorescência relativo foi utilizado o optical method dilute ${ }^{41,117,118}$, com as absorbâncias das soluções das porfirinas no comprimento de onda de excitação variando entre 0,04 e 0,10, visando minimizar eventuais desvios nos valores dos rendimentos devido a fenômenos de auto absorção ou de filtro interno. Foi considerado como padrão o rendimento quântico da ZnTMPyP em água, $\Phi_{\mathrm{F}}=0,025^{1,21}$. Foram determinados os rendimentos quânticos das porfirinas analisadas excitando-se no máximo de emissão da banda Soret e da banda Qy $(1,0)$ ou $Q(1,0)$.

Entretanto, ao excitar-se em comprimentos de onda diferentes, não se pode esquecer que a intensidade da lâmpada de $\mathrm{Xe}$ pode ser diferente para cada comprimento de onda. Ao não se considerar esse fato, os valores de rendimento quântico obtidos a partir da excitação na banda Soret serão discrepantes em relação ao obtido com excitação da banda $Q y(1,0)$. Vale lembrar que a Soret nas zincoporfirinas estudadas apresenta máximo de absorção na região de $440 \mathrm{~nm}$, enquanto que as bases livres apresentam o máximo da banda Soret na região de 425 $\mathrm{nm}$. Na banda $Q$, a diferença é ainda maior, pois para as zincoporfirinas o máximo se encontra em $565 \mathrm{~nm}$, enquanto que para as bases livres o máximo está em $520 \mathrm{~nm}$.

A fórmula para a determinação do rendimento quântico relativo apresentada (1) parte da premissa que ambas as amostras recebem a mesma quantidade de fótons 
(intensidade de luz) ${ }^{41}$, logo se a lâmpada apresenta variação significativa na intensidade de luz emitida em função do comprimento de onda, o rendimento quântico deve ser determinado excitando as duas amostras no mesmo comprimento de onda, ou deve-se corrigir eventuais diferenças de intensidade de excitação.

A figura 37 apresenta o espectro de emissão da lâmpada de Xe utilizada como fonte de excitação nos experimentos de emissão. A intensidade da lâmpada em 563 $\mathrm{nm}$ (máximo de absorção da banda $Q(1,0)$ da ZnTMPyP) é cerca de $70 \%$ da intensidade da lâmpada em $518 \mathrm{~nm}$ (máximo de absorção da banda $Q y(1,0)$ da $\mathrm{H}_{2}$ TMPyP). A diferença na banda Soret é menor, a intensidade da lâmpada em $440 \mathrm{~nm}$ (máximo de absorção da banda Soret da ZnTMPyP) é cerca de 90\% da intensidade da lâmpada em $421 \mathrm{~nm}$ (máximo de absorção da banda Soret da $\mathrm{H}_{2} \mathrm{TMPyP}$ ).

Como a excitação foi feita sempre nos máximos de absorção das bandas Soret, $Q y(1,0)$ ou $Q(1,0)$ foi necessário normalizar a intensidade luminosa da fonte. Dois métodos foram utilizados, o primeiro foi comparar a intensidade da lâmpada de Xe em cada comprimento de onda a partir da área do espectro da ZnTMPyP, obtido com excitação nos diversos comprimentos de onda utilizados para as demais porfirinas. Outro método é avaliar a intensidade da lâmpada a partir do seu espectro (figura 37). Os dois métodos apresentam resultados semelhantes. Para efeito de comparação são apresentados na tabela 8 os valores considerando-se ou não a correção da intensidade da lâmpada para cada comprimento de onda de excitação utilizado.

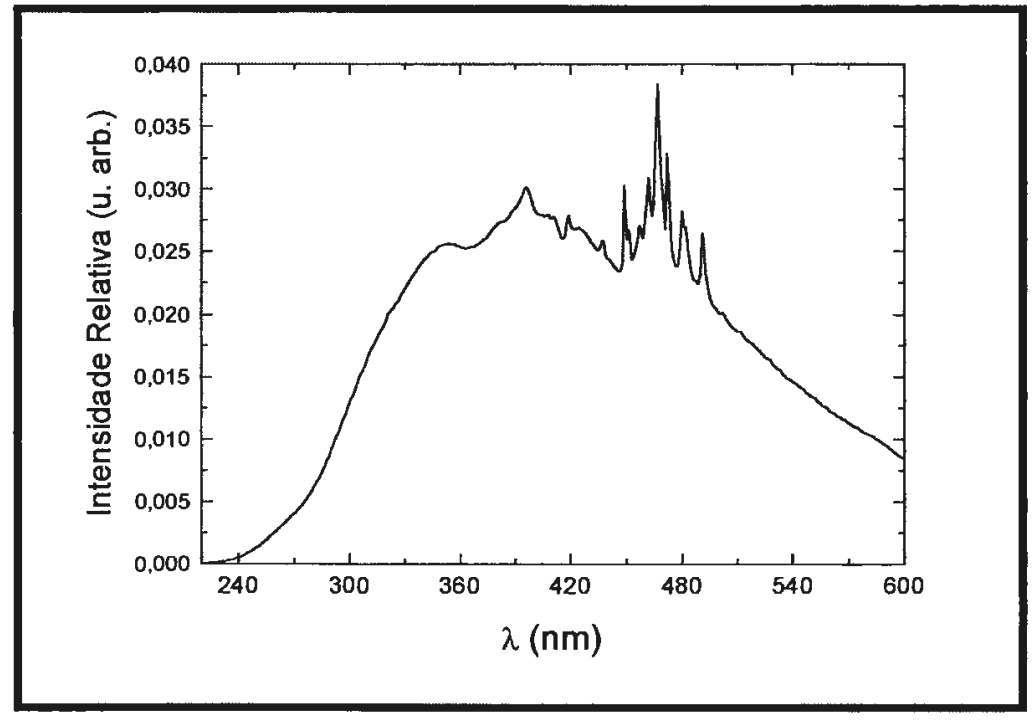

figura 37: Espectro de emissão da lâmpada de $X e$, fonte utilizada nos experimentos de emissão.

Após a normalização dos espectros de emissão em função da intensidade da lâmpada de $\mathrm{Xe}$, observa-se na tabela 8 que os valores dos rendimentos quânticos são semelhantes, independentemente do comprimento de onda escolhido para emissão, 
como seria de se esperar. Ao que tudo indica essa correção basta, não sendo necessário obter todos espectros excitando num mesmo comprimento de onda.

Outra observação imediata é que a normalização afeta em maior grau os rendimentos quânticos obtidos na excitação da banda $Q$. Esse fato é justificado pelas diferenças de intensidade no espectro da lâmpada de Xe nos diferentes comprimentos de ondas de excitação empregados na excitação das amostras e pode ser constatado analisando-se o espectro da lâmpada de Xe.

tabela 8: Rendimentos quânticos de fluorescência $\left(\Phi_{F}\right)$ relativos das porfirinas piridínio substituidas.

\begin{tabular}{|c|c|c|c|c|}
\hline Porfirinas & Qy $(1,0)^{a}$ & Soret $^{2}$ & $\mathrm{Qy}(1,0)^{\mathrm{D}}$ & Soret $^{b}$ \\
\hline ZnTMPyP & 0,025 & 0,025 & 0,025 & 0,025 \\
\hline ZnTCNBzPyP & 0,025 & 0,021 & 0,026 & 0,023 \\
\hline ZnTMeOBzPyP & 0,025 & 0,022 & 0,026 & 0,024 \\
\hline ZnTBzPyP & 0,025 & - & 0,024 & - \\
\hline $\mathrm{ZnTNO} \mathrm{Bz}_{2} \mathrm{PyP}$ & 0,021 & 0,019 & 0,021 & 0,021 \\
\hline $\mathrm{H}_{2}$ TMPyP & 0,047 & 0,033 & 0,033 & 0,030 \\
\hline $\mathrm{H}_{2}$ TAIPYP & 0,046 & 0,034 & 0,031 & 0,032 \\
\hline $\mathrm{H}_{2}$ TPnPyP & 0,054 & 0,037 & 0,037 & 0,035 \\
\hline $\mathrm{H}_{2} \mathrm{TBz} P y P$ & 0,044 & 0,033 & 0,030 & 0,031 \\
\hline $\mathrm{H}_{2} \mathrm{TBrBzPyP}$ & 0,046 & 0,030 & 0,032 & 0,028 \\
\hline $\mathrm{H}_{2} \mathrm{TCIBzPyP}$ & -- & 0,033 & - & 0,031 \\
\hline $\mathrm{H}_{2}$ TCNBzPyP & 0,040 & 0,027 & 0,027 & 0,025 \\
\hline $\mathrm{H}_{2} \mathrm{TCO}_{2} \mathrm{HBzPyP}$ & 0,029 & 0,034 & 0,020 & 0,032 \\
\hline $\mathrm{H}_{2} \mathrm{TCH}_{3} \mathrm{BzPyP}$ & 0,046 & 0,033 & 0,030 & 0,031 \\
\hline $\mathrm{H}_{2}$ TMeOBzPyP & 0,046 & 0,031 & 0,031 & 0,029 \\
\hline $\mathrm{H}_{2}$ TPhPrPyP & 0,043 & 0,029 & 0,030 & 0,027 \\
\hline $\mathrm{H}_{2}$ TPhEtPyP & 0,044 & 0,031 & 0,031 & 0,029 \\
\hline $\mathrm{H}_{2} \mathrm{TNO}_{2} \mathrm{BzPyP}$ & 0,039 & 0,028 & 0,027 & 0,026 \\
\hline $\mathrm{H}_{2}$ TAMPP & 0,102 & --- & 0,066 & --- \\
\hline $\mathrm{H}_{2}$ TPPS & 0,150 & -- & 0,097 & $-\cdots$ \\
\hline ZnTMPyP & 0,025 & 0,025 & 0,025 & 0,025 \\
\hline $\mathrm{H}_{2}$ TBzPyP & 0,040 & 0,037 & 0,029 & 0,033 \\
\hline $\mathrm{H}_{2}$ TMeOBzPyP & 0,044 & 0,034 & 0,030 & 0,031 \\
\hline $\mathrm{H}_{2}$ TMPyP & 0,047 & 0,039 & 0,031 & 0,035 \\
\hline $\mathrm{H}_{2}$ TCNBzPyP & - & 0,022 & - & 0,020 \\
\hline $\mathrm{H}_{2}$ TMeOBzPyP & -- & 0,026 & -- & 0,024 \\
\hline $\mathrm{H}_{2}$ TCNBzPyP & -- & 0,018 & -- & 0,017 \\
\hline $\mathrm{H}_{2}$ TMeOBzPyP & -- & 0,022 & -- & 0,020 \\
\hline
\end{tabular}

Solventes: água; tampão fosfato; DMSO; metanol. $\Phi_{\mathrm{F}} \pm 10 \%$ a - valores obtidos sem a correção da intensidade da lâmpada;

b - valores obtidos após cálculo para normalização da intensidade da lâmpada.

Um dado interessante é que a literatura recomenda a determinação do rendimento quântico relativo das porfirinas a partir da excitação nas bandas $Q(1,0)$ ou Qy $(1,0)$ e em nenhum momento fica claro a preocupação com a diferença de intensidade luminosa na excitação, o que acarreta em um grande erro nos valores 
obtidos. A comparação dos valores de $\Phi_{\mathrm{F}}$ das três porfirinas que possuem dados relatados na literatura mostra algumas discrepâncias.

$O$ rendimento quântico obtido na excitação da banda $Q y(1,0)$ da $H_{2} T M P y P$ (sem a normalização da intensidade da lâmpada) é de $\Phi_{F}=0,047$, coerente com outros valores já descritos $\left(0,047^{1,21} ; 0,048^{56}\right)$. Com a normalização, o valor encontrado tanto para a banda Soret quanto para a banda $Q$ é da ordem de 0,030 .

Para o caso das porfirinas fenil substituídas $\mathrm{H}_{2}$ TMAPP e $\mathrm{H}_{2}$ TPPS, utilizadas como padrão de referência para posterior comparação com a literatura, a normalização dos espectros produz valores mais próximos aos publicados ${ }^{11}$. Para a $\mathrm{H}_{2}$ TMAPP o valor encontrado na literatura é 0,070 , próximo ao valor de 0,066 . Para a $\mathrm{H}_{2}$ TPPS o valor publicado é de 0,080 , bem mais próximo do valor normalizado $(0,097)$ do que sem considerar a intensidade da lâmpada $(0,150)$. É interessante ressaltar que o padrão utilizado como referência para as porfirinas fenil substituídas é o espectro da $\mathrm{H}_{2}$ TPP em clorofórmio ${ }^{11}$.

Outra decorrência da normalização dos espectros é que os rendimentos quânticos das bases livres deixam de ser significativamente maiores que dos respectivos zinco derivados, sendo outro ponto discordante com outros resultados relatados para as porfirinas piridínio alquil substituídas ${ }^{21}$.

Os valores obtidos em tampão fosfato excitando-se na banda $Q y(1,0)$ são equivalentes aos obtidos em solução aquosa.

Comparando os diferentes solventes água, DMSO e metanol utilizados para a determinação de $\Phi_{\mathrm{F}}$ da $\mathrm{H}_{2}$ TCNBzPyP e $\mathrm{H}_{2}$ TMeOBzPyP a tabela 8 mostra que $\Phi_{\mathrm{F}}$ está relacionado à solvatação da porfirina, sendo que os solventes DMSO e metanol devem favorecer os decaimentos não radioativos $S_{1} \rightarrow S_{0}$.

\subsubsection{Perfil espectral de soluções diluídas em solução aquosa}

Desde a década de 80 , alguns autores ${ }^{40,56}$ defendem a hipótese do equilíbrio monômero-dímero da $\mathrm{H}_{2}$ TMPyP em soluções aquosas muito diluídas $\left(10 \mathrm{nmol} \mathrm{dm}{ }^{-3}\right.$ ). Em soluções mais concentradas, a porfirina se apresentaria predominantemente na forma do dímero, o que explicaria a correspondência à lei de Beer observada na faixa

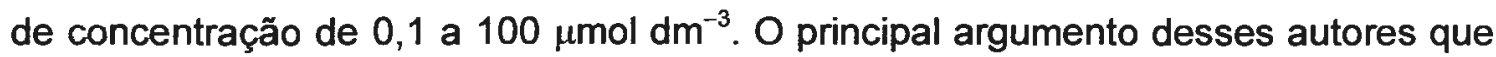
não era refutado pelos que não acreditavam na dimerização da $\mathrm{H}_{2} \mathrm{TMPyP}^{54}$ em concentrações tão baixas era a definição das duas bandas do espectro de emissão da $\mathrm{H}_{2}$ TMPyP em concentrações abaixo de $10 \mathrm{nmol} \mathrm{dm}^{-3}$, atribuída ao monômero. O espectro mal definido seria atribuído ao dímero, o que explicaria ser a $\mathrm{H}_{2} \mathrm{TMPyP}$ a única das porfirinas meso substituídas a não apresentar duas bandas bem definidas 
$(Q(0,0)$ e $Q(0,1))$ no espectro de emissão. Contribuía em favor dessa hipótese o fato que em solventes orgânicos o espectro da $\mathrm{H}_{2}$ TMPyP possui duas bandas bem definidas.

Entretanto, dois artigos mais recentes ${ }^{57},{ }^{52}$ propõem uma nova explicação para os diferentes perfis espectrais observados. Vergeldt e coautores ${ }^{57}$ negam a dimerização da $\mathrm{H}_{2}$ TMPyP em meio aquoso a partir de experimentos de absorção (UVVis), $\mathrm{RMN}^{-1} \mathrm{H}$ e emissão fluorescente. $\mathrm{O}$ dado mais espantoso relatado no artigo é a não definição em duas bandas do espectro de emissão da $\mathrm{H}_{2}$ TMPyP em água em concentrações de até $1 \mathrm{nmol} \mathrm{dm^{-3 }}$. Segundo o artigo, só se verifica a presença de duas bandas no espectro de emissão quando a água utilizada não possui um alto grau de pureza, ou passa por processos que aumentem a concentração de particulados (filtração em papel de filtro, algodão ou resina de troca iônica). Os espectros bem resolvidos relatados por diversos autores nas décadas de 80 e 90 são explicados pela presença de particulados em suspensão na solução estudada. $A \mathrm{H}_{2} \mathrm{TMPyP}$ tem alta afinidade a superficies sólidas (vidro, por exemplo), e o espectro de emissão da porfirina adsorvida apresenta duas bandas bem definidas. O espectro da solução de $\mathrm{H}_{2}$ TMPyP que contém partículas suspensas é na verdade a soma dos espectros da porfirina em solução aquosa e adsorvida, e em baixas concentrações a fração correspondente ao espectro da porfirina adsorvida tem uma contribuição maior, definindo o espectro observado. Segundo Vergeldt e coautores o modelo em que há uma variação na concentração da porfirina e uma concentração constante de particulado explica o perfil espectral observado, enquanto que o suposto equilíbrio dímero-monômero não.

Os espectros de emissão das porfirinas piridínio substituídas em concentrações inferiores a $500 \mathrm{nmol} \mathrm{dm}^{-3}$ foram registrados em três condições:

a - evitando-se a presença de particulado nas soluções preparadas;

b - permitindo-se o contato das soluções preparadas com os particulados presentes no ar;

c - produzindo-se uma solução contendo particulados de lã de vidro.

Foi utilizada água Nanopure ${ }^{\circledR}$ para a preparação de todas as soluções. Para minimizar a presença de particulados toda vidraria envolvida na preparação das soluções foi exaustivamente lavada com água Nanopure ${ }^{\circledR}$ e a solução foi preparada e medida imediatamente. Quando o intuito era promover a presença de particulado em suspensão, a água e a solução tampão utilizada para diluir a solução estoque de porfirina foram deixadas por várias horas em recipientes abertos. Para as soluções preparadas com particulado os cuidados para evitar a poeira do ar foram os mesmos, 
entretanto, foi empregada uma suspensão de lã de vidro em água Nanopure ${ }^{\circledR}$. Essa suspensão foi preparada colocando-se cerca de $3,0 \mathrm{~g}$ de lã de vidro em um balão volumétrico contendo $300 \mathrm{~mL}$ de água Nanopure ${ }^{\circledast m}$ um banho de ultra som por alguns minutos. Após a decantação da lã de vidro, foi utilizado a fração superior da suspensão para o preparo da solução, não sendo observado a olho nu a presença de partículas na água.

Foram obtidos espectros de emissão da água pura e da suspensão da lã de vidro e não foram observadas diferenças significativas.

As bases livres estudadas apresentam mudança de perfil espectral, com a definição das duas bandas nas soluções contendo suspensão de lã de vidro (figura 38). Observa-se uma menor intensidade de emissão nos espectros com as bandas definidas, indicando que as porfirina adsorvida apresenta um rendimento quântico menor que a porfirina livre em solução. Com uma concentração muito baixa de porfinina em solução aparece o espectro de emissão da porfirina adsorvida na lã de vidro, que apresenta uma boa separação das bandas $Q$. Infelizmente, não foi possível filtrar as soluções (com e sem lã de vidro) e obter um novo espectro de emissão, pois a porfirina é toda adsorvida no filtro e ambos os filtrados não apresentam espectro de emissão detectável pelo aparelho.

A $\mathrm{H}_{2}$ TMPyP só apresenta as bandas definidas em concentrações inferiores a $10 \mathrm{nmol} \mathrm{dm}{ }^{-3}$ enquanto as demais porfirinas benzil piridínio substituídas chegam a apresentar bandas definidas em alguns casos em concentração superiores a $100 \mathrm{nmol}$ $\mathrm{dm}^{-3}$. Para as porfirinas com grupos substituintes mais volumosos $\mathrm{H}_{2} \mathrm{TMeOBzPyP}$, $\mathrm{H}_{2}$ TCNBzPyP, $\mathrm{H}_{2} \mathrm{TNO}_{2}$ BzPyP foi necessário elevar a concentração até $300 \mathrm{nmol} \mathrm{dm}^{-3}$ na solução em suspensão de lã de vidro para se obter um espectro com perfil semelhante ao da solução em água pura.

Uma vez que a concentração de impurezas deve ser praticamente constante e os valores de $\Phi_{\mathrm{F}}$ para as bases livres em solução são da mesma ordem de grandeza, essas observações evidenciam que a capacidade de adsorção das porfirinas benzil piridínio substituidas é muito maior que das $\mathrm{H}_{2}$ TAIPyP e $\mathrm{H}_{2}$ TMPyP, e que o grau de adsorção dessas porfirinas dependem do caráter hidrofóbico e do volume dos substituintes periféricos. 


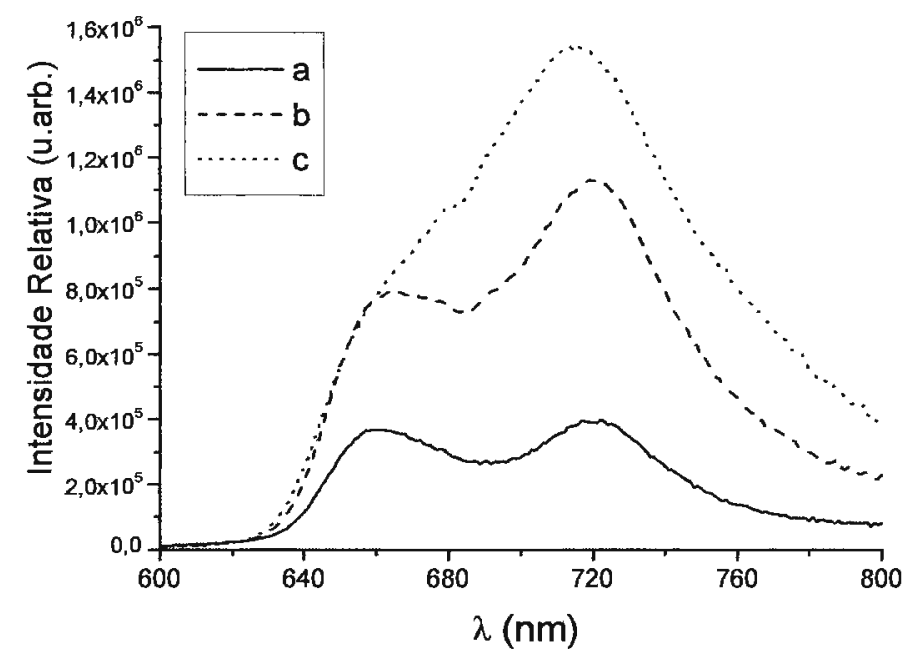

figura 38: Espectro de Emissão da $\mathrm{H}_{2} \mathrm{TMeOBzPyP}$; Excitação: $\lambda=425 \mathrm{~nm}$; de vidro;

a- $\left[\mathrm{H}_{2} \mathrm{TMeOBzPyP}\right]=43 \mathrm{nmol} \mathrm{dm}{ }^{-3} \mathrm{em}$ água Nanopure ${ }^{\circledast}$ contendo suspensão de lã

b- $\left[\mathrm{H}_{2} \mathrm{TMeOBzPyP}\right]=32 \mathrm{nmol} \mathrm{dm}{ }^{-3}$ em água Nanopure ${ }^{\circledR}$ contendo "poeira";

c- $\left[\mathrm{H}_{2} \mathrm{TMeOBzPyP}\right]=32 \mathrm{nmol} \mathrm{dm}{ }^{-3}$ em água Nanopure ${ }^{\circledR}$.

Em condições não controladas de particulado (particulado devido a poeira) 0 perfil espectral sem definição das bandas foi atingido em concentrações menores, indicando que o fenômeno também depende da quantidade de particulado presente na solução.

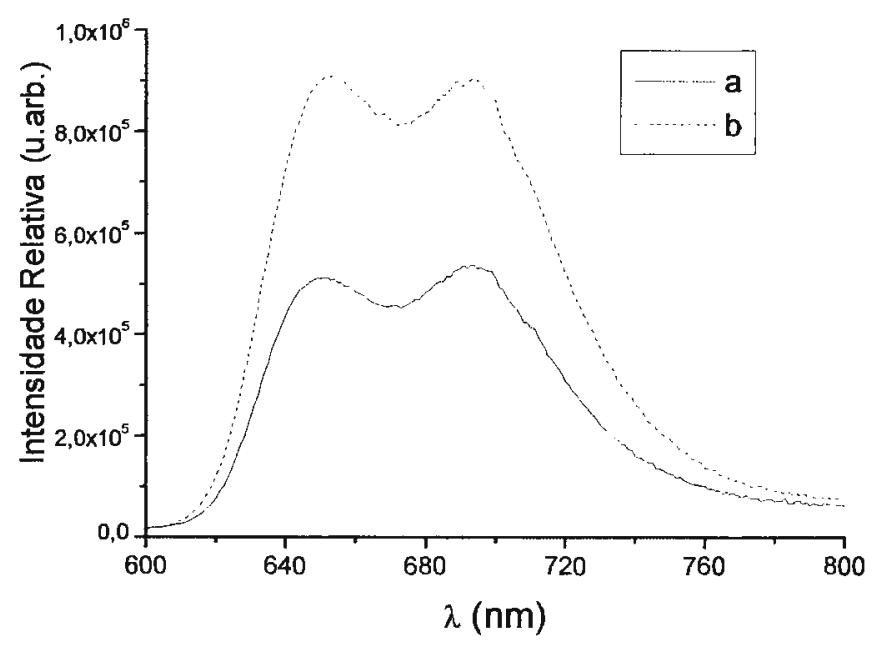

figura 39: Espectro de Emissão da ZnTBzPyP; Excitação: $\lambda=441$ nm;

a - [ZnTBzPyP] $=45 \mathrm{nmol} \mathrm{dm}^{-3}$ em água Nanopure ${ }^{\circledast}$ contendo suspensão de lã de vidro; b - $[\mathrm{ZnTBzPyP}]=34 \mathrm{nmol} \mathrm{dm}^{-3}$ em água Nanopure ${ }^{\circledR}$.

As zincoporfirinas não apresentam diferenciação no perfil espectral, apesar de se observar uma diminuição significativa da intensidade do espectro (figura 39). Essa observação evidencia que as zincoporfirinas adsorvem na lã de vidro, porém o 
espectro da metaloporfirina adsorvida não apresenta perfil espectral diferenciado da solução aquosa, ou ainda a metaloporfirina adsorvida possui uma emissão negligenciável.

\subsubsection{Emissão em soluções congeladas}

Os espectros dos derivados ZnTMPyP, ZnTBzPyP, ZnTMeOBzPyP, ZnTCNBzPyP e $\mathrm{ZnTNO}_{2}$ BzPyP foram obtidos em mistura glicerina:água (2:1), tanto à temperatura ambiente, quanto em nitrogênio líquido $(77 \mathrm{~K})$.

O espectro obtido à temperatura ambiente apresenta as duas bandas $Q$ sobrepostas e mal resolvidas, entretanto ao congelarmos a solução em nitrogênio líquido as duas bandas se resolvem e uma terceira banda em comprimento de onda menor aparece (figura 40). A melhor resolução do espectro se deve ao abaixamento da temperatura e congelamento da amostra, resultando em um menor grau de vibração e diminuindo os choques entre as moléculas de porfinina e do solvente, e portanto definindo melhor os niveis vibracionais da molécula. A terceira banda é atribuída a transição proibida do estado triplete para a o estado fundamental (singlete), chamada fosforescência. Apesar do alto rendimento quântico de fosforescência das zincoporfirinas piridínio substituidas, essa fosforescência não é observada à temperatura ambiente, pois os processos de desativação triplete-singlete são não radioativos e são causados principalmente pelos choques entre a molécula de porfirina e as moléculas do solvente.

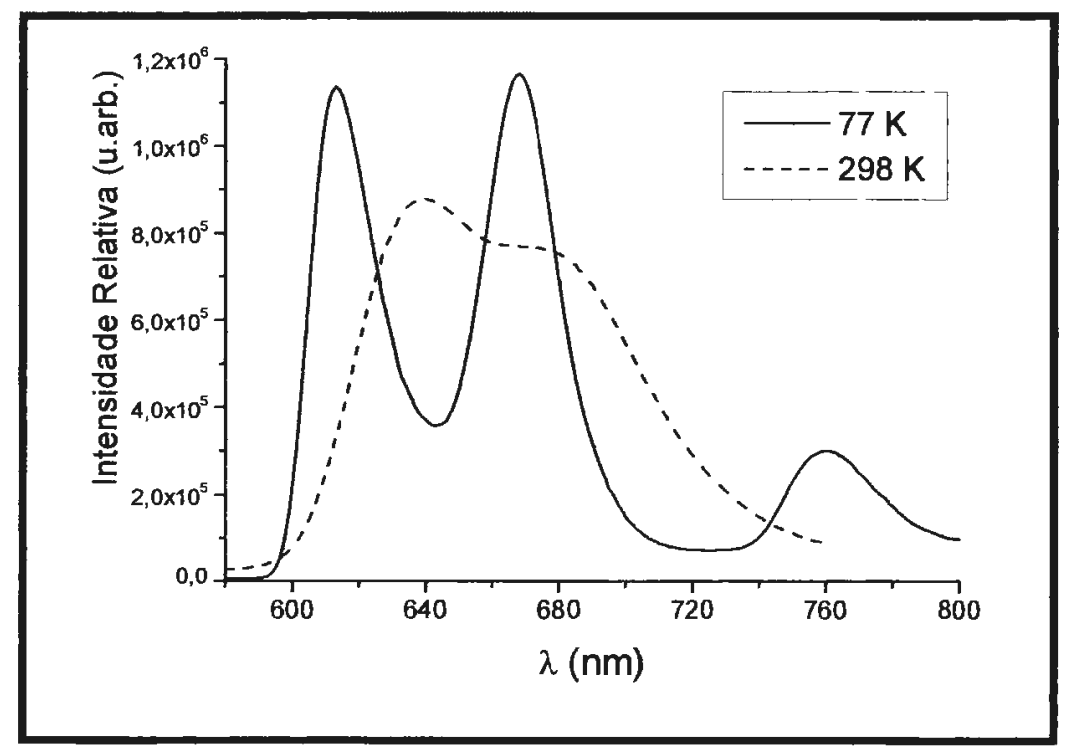

figura 40: Espectros de emissão da $\mathrm{ZnTNO}_{2} \mathrm{BzPyP}_{\mathrm{P}}$ em glicerina/água.

A tabela 9 apresenta os máximos de emissão das zincoporfirinas em solução glicerina/água, os valores em temperatura ambiente foram obtidos através da 
econvolução lorentziana também aplicada para os demais espectros das incoporfirinas (ver seção 3.2.2).

tabela 9: Máximos de emissão das zincoporfirinas em solução glicerinalágua.

\begin{tabular}{ccccc}
\hline Porfirinas & Temperatura & $Q(0,0)$ & $Q(0,1)$ & $T(0,0)$ \\
\hline ZnTMPyP & $298 \mathrm{~K}^{\mathrm{a}}$ & 632 & 670 & \\
& $77 \mathrm{~K}^{\mathrm{a}}$ & 607 & 662 & 757 \\
ZnTMeOBzPyP & $298 \mathrm{~K}^{\mathrm{a}}$ & 635 & 673 & \\
& $77 \mathrm{~K}$ & 610 & 665 & 758 \\
ZnTBzPyP & $298 \mathrm{~K}^{\mathrm{a}}$ & 635 & 674 & \\
& $77 \mathrm{~K}$ & 610 & 665 & 758 \\
ZnTCNBzPyP & $298 \mathrm{~K}^{\mathrm{a}}$ & 639 & 676 & \\
& $77 \mathrm{~K}$ & 613 & 668 & 760 \\
ZnTNO 2 BzPyP & $298 \mathrm{~K}^{\mathrm{a}}$ & 638 & 676 & \\
& $77 \mathrm{~K}$ & 613 & 668 & 760 \\
\hline
\end{tabular}

a - calculados pela deconvolução lorentziana do espectro.

A comparação dos máximos de emissão da ZnTMPyP e das zincoporfirinas enzil piridínio substituídas seguem o mesmo comportamento observado para os spectros de absorção e emissão em outros solventes. O grupo benzil induz um eslocamento das bandas de emissão para o vermelho e esse deslocamento é centuado para as porfirinas substituintes benzílicos aceptores de elétrons, como os rupos ciano e nitro. A variação observada para a banda atribuída a fosforescência é e no máximo $3 \mathrm{~nm}$, indicando que a energia do estado triplete é muito semelhante ara essa série de zincoporfirinas.

Em relação aos espectros obtidos à temperatura ambiente, a comparação com s máximos de emissão em solução aquosa mostra um deslocamento para o azul das andas do espectro realizado em solução glicerina/água, indicando que nesse meio há $\mathrm{m}$ maior distanciamento entre os níveis de energia do estado fundamental e excitado. ssa diferença se deve a uma menor estabilização da nuvem $\pi$ do macrociclo em um leio de menor constante dielétrica, além de menor possibilidade de rearranjo da strutura eletrônica devido a maior viscosidade do meio.

\subsection{Fotólise por Pulso de Laser}

A determinação dos tempos de vida do estado triplete $\left(\tau_{T}\right)$ das zincoporfirinas e obtenção dos espectros de absorção dos transientes complementa a caracterização a estrutura eletrônica das porfirinas benzilpiridínio substituídas já discutida em função os espectros eletrônicos de absorção e emissão. Esses dados são importantes em ıturas aplicações dessas porfirinas como fotossensibilizadores em reações nvolvendo a fotorredução de um substrato de interesse. 
Outro parâmetro estudado a partir da técnica de fotólise por pulso de laser foi a determinação dos rendimentos quânticos de supressão do estado triplete em relação a aceptores de elétrons catiônicos e aniônicos, visando maiores informações sobre o processo de transferência de elétrons a partir do estado triplete das zincoporfirinas benzilpiridínio substituídas.

Foram determinados os tempos de vida das zincoporfirinas ZnTMPyP, ZnTBzPyP, ZnTNO ${ }_{2}$ BzPyP, ZnTMeOBzPyP e ZnTCNBzPyP em água na ausência de $\mathrm{O}_{2}$ ou em situação de equilíbrio com o ar atmosférico. Além disso, foram determinados os tempos de vida dessas espécies em solução aquosa de $\mathrm{NaCl} 0,05 \mathrm{~mol} \mathrm{dm}^{-3} \mathrm{em}$ equilíbrio com o ar. As concentrações das porfirinas nas diversas medidas foram

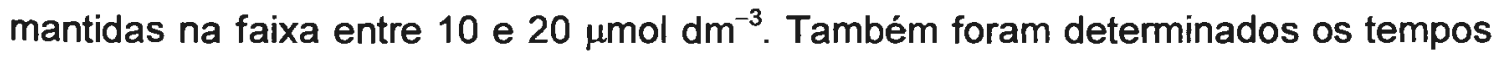
de vida, para efeito de comparação, das respectivas bases livres em solução em equilibrio com o ar.

Para a eliminação do $\mathrm{O}_{2}$ dissolvido nas soluções das zincoporfirinas foi borbulhado argônio fivre de traços de $\mathrm{O}_{2}$ (ver parte experimental, seção 2.1) durante 90 minutos em uma cubeta de quartzo adaptada com torneiras para alto vácuo. $O$ sistema mostrou-se reprodutivel e estável, não ocorrendo entrada de ar durante o período de algumas horas, pois não se observou modificação nos tempos de vida obtido em um intervalo de seis horas. Entretanto, alguns experimentos apresentaram tempos de vida consideravelmente menores, mostrando que a deaeração não havia sido eficiente. Os resultados apresentados correspondem aos tempos de vida mais longos obtidos em pelo menos três experimentos independentes.

Devido aos valores muito longos dos tempos de vida na ausência de $\mathrm{O}_{2}$ foi necessário monitorar o espectro de absorção com um feixe contínuo da lâmpada de $\mathrm{Xe}$, uma vez que o pulso do modo pulsado tem duração inferior a $1 \mathrm{~ms}$. As soluções das zincoporfirinas se mostraram bastante estáveis na faixa de potência utilizada, mesmo após um grande número de flashes do laser. Mesmo após a obtenção do espectro transiente que é obtido ponto a ponto, as soluções apresentaram diminuição da absorção inicial de no máximo $5 \%$.

Todos os decaimentos analisados são de primeira ordem e apresentam os tempos de vida da mesma magnitude, independentemente do comprimento de onda de monitoramento do transiente. Decaimentos de segunda ordem só foram observados em soluções muito concentradas (acima de $20 \mu \mathrm{mol} \mathrm{dm}{ }^{-3}$ ) e com a utilização de potência muito elevada do laser. Essa cinética de segunda ordem do decaimento do estado triplete é atribuída ao aniquilamento triplete-triplete, que ocorre com a alta concentração de espécies excitadas. 
Os espectros dos transientes provenientes da excitação das zincoporfirinas analisadas possuem o mesmo perfil (figura 41), com duas regiões positivas, uma entre $330-370 \mathrm{~nm}$ e outra entre $470-540 \mathrm{~nm}$, com deslocamentos dos máximos de absorção seguindo a mesma tendência observada para os espectros eletrônicos na região do UV-Vis. Na região da banda Soret há uma redução apreciável de absorção (bleaching), que também foi monitorado.
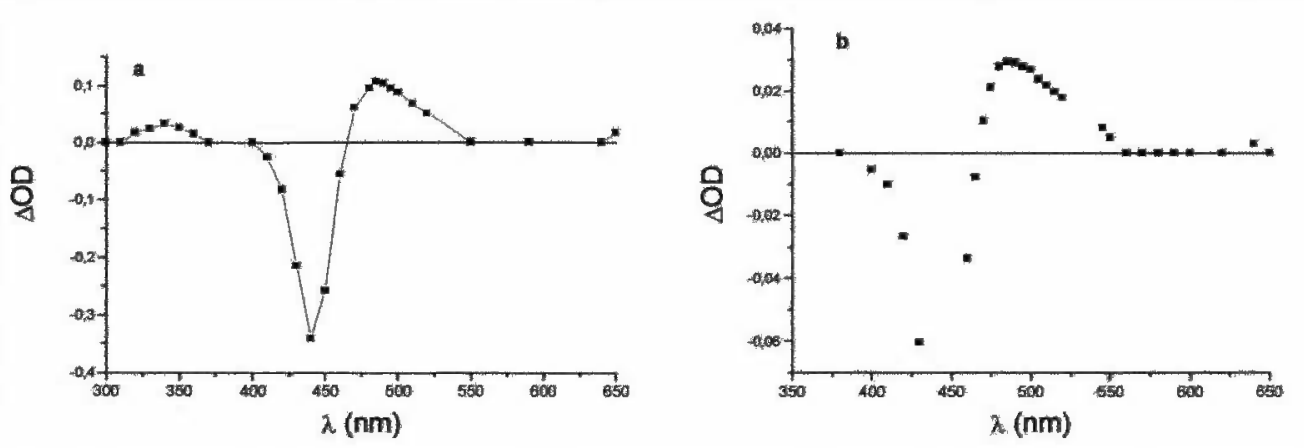

figura 41: Espectros transientes: a- ZnTMeOBzPyP em equilíbrio com ar; b- ZnTCNBzPyP na ausência de $\mathrm{O}_{2}$.

tabela 10: Tempo de vida do estado triplete $\left(\tau_{\tau}\right)$ das zincoporfirinas.

\begin{tabular}{|c|c|c|c|}
\hline Porfirinas & $\begin{array}{l}\text { Solução aquosa } \\
\text { ausência de } \mathrm{O}_{2}\end{array}$ & $\begin{array}{l}\text { Solução aquosa } \\
\text { equilíbrio } \mathrm{cl} \text { ar }\end{array}$ & $\begin{array}{c}\mathrm{NaCl}(\mathrm{aq}) \\
\text { equilibrio } \mathrm{cl} \text { ar }\end{array}$ \\
\hline ZnTMPyP & $2,5 \mathrm{~ms}$ & $2,9 \mu \mathrm{s}$ & $3,2 \mu \mathrm{s}$ \\
\hline ZnTMeOBzPyP & $1,9 \mathrm{~ms}$ & $3,0 \mu \mathrm{s}$ & $3,2 \mu \mathrm{s}$ \\
\hline ZnTBzPyP & $2,6 \mathrm{~ms}$ & $3,0 \mu \mathrm{s}$ & $3,2 \mu \mathrm{s}$ \\
\hline ZnTCNBzPyP & $2,1 \mathrm{~ms}$ & $3,1 \mu \mathrm{s}$ & $3,3 \mu \mathrm{s}$ \\
\hline $\mathrm{ZnTNO}{ }_{2} \mathrm{Bz} \mathrm{PyP}$ & $68 \mu \mathrm{s}$ & $3,0 \mu \mathrm{s}$ & $2,9 \mu \mathrm{s}$ \\
\hline $\mathrm{H}_{2}$ TMPyP & - & $2,2 \mu \mathrm{s}$ & $2,3 \mu \mathrm{s}$ \\
\hline $\mathrm{H}_{2} \mathrm{TMeOBz}$ PyP & - & $2,4 \mu \mathrm{s}$ & $2,3 \mu \mathrm{s}$ \\
\hline $\mathrm{H}_{2}$ TBzPyP & - & $2,4 \mu \mathrm{s}$ & $2,4 \mu \mathrm{s}$ \\
\hline $\mathrm{H}_{2}$ TCNBzPyP & - & $2,4 \mu s$ & $2,5 \mu \mathrm{s}$ \\
\hline $\mathrm{H}_{2} \mathrm{TNO}_{2} \mathrm{BzPyP}$ & - & $2,4 \mu \mathrm{s}$ & $2,4 \mu \mathrm{s}$ \\
\hline
\end{tabular}

Nas soluções aquosas das zincoporfirinas em equilíbrio com o ar atmosférico verifica-se uma considerável diminuição nos valores de $\tau_{\mathrm{T}}$ (da ordem de $2 \mathrm{~ms}$ para 3 $\mu$ s) devido a supressão do estado triplete causada pelo $\mathrm{O}_{2}$ (tabela 10). Não se observa variação apreciável nos tempos de vida e nas cinéticas de decaimento entre a soluções em água deionizada e solução de $\mathrm{NaCl} 0,05 \mathrm{~mol} \mathrm{dm}^{-3}$. Resultados publicados anteriormente ${ }^{119}$ demonstram a dependência do $\tau_{\mathrm{T}}$ da ZnTMPyP com a força iônica do meio em solução aquosa, entretanto, esses estudos foram realizados 
na ausência de $\mathrm{O}_{2}$. Com o aumento da força iônica aumenta a constante de associação entre as espécies excitadas, aumentando a ocorrência de aniquilação triplete-triplete. Essa atribuição é confirmada com a diminuição do $\tau_{\mathrm{T}}$ com o aumento da força iônica do meio, além do decaimento passar a ser de segunda ordem.

Aparentemente, a constante de supressão entre $\mathrm{o}_{2}$ e as zincoporfirinas é muito mais alta do que a constante de supressão devido ao aniquilamento tripletetriplete, tornando desprezivel a força iônica de $0,05 \mathrm{~mol} \mathrm{dm}^{-3}$ nos valores de $\tau_{\top}$ obtidos. Baseando-se apenas em duas medidas, na ausência e em equilibrio com o ar, é possivel estimar a constante de supressão $\left(k_{Q}\right)$ do estado triplete das zincoporfirinas pelo $\mathrm{O}_{2}$. Esses valores são calculados a partir da equação de Stern-Volmer ${ }^{2}$ :

$k_{Q}=\left(1 / \tau_{T}-1 / \tau_{T}{ }^{\circ}\right) /\left(\left[O_{2}\right] \alpha\right.$

onde $\tau_{\top}$ e $\tau_{\top}{ }^{\circ}$ são o tempo de vida do estado triplete em equilibrio com ar e na ausência de $\mathrm{O}_{2}$, respectivamente, $\left[\mathrm{O}_{2}\right]$ é a concentração de $\mathrm{O}_{2}$ em solução aquosa sob pressão de 1 bar e $\alpha$ é a razão entre a pressão atmosférica no local do experimento pela pressão de 1 bar.

Os valores da constante de supressão do estado triplete das zincoporfirinas pelo $\mathrm{O}_{2}$ são todos da ordem de $1,3 \times 10^{9} \mathrm{~mol} \mathrm{dm}^{-3} \mathrm{~s}^{-1}$.

A $\mathrm{ZnTNO}{ }_{2} \mathrm{BzPyP}$ apresenta $\tau_{\mathrm{T}}$ muito menor do que das demais zincoporfirinas piridínio substituídas na ausência de $\mathrm{O}_{2}$ ( $68 \mu \mathrm{s}$ para $2 \mathrm{~ms}$ ), entretanto em contato com o ar o tempo de vida é da mesma ordem de grandeza que as demais zincoporfirinas (todas com $\tau_{\mathrm{T}}$ da ordem de $3 \mu \mathrm{s}$ ). Apesar desse valor de $\tau_{\top}$ a constante de supressão do estado triplete da $\mathrm{ZnTNO}_{2} \mathrm{BzPyP}$ em relação ao $\mathrm{O}_{2}$ não é diferente das observadas para as demais zincoporfininas piridínio substituídas, sendo da ordem de $1,2 \times 10^{9} \mathrm{~mol} \mathrm{dm}^{-3} \mathrm{~s}^{-1}$. Esse tempo de vida baixo na ausência do $\mathrm{O}_{2}$ pode ser atribuída ao caráter aceptor de elétrons do grupo nitro. O grupo nitro acentua o caráter aceptor de elétrons do anel piridínio, propiciando uma transferência intramolecular que o anel piridínio recebe elétrons do estado triplete do macrociclo. Entretanto, essa reação deve ser mais lenta e menos eficiente que a transferência de energia para $\mathrm{O}_{2}$, apesar deste ser um processo intermolecular. Desse modo, a supressão pelos grupos nitrobenzil piridínio só é significativa na ausência de $\mathrm{O}_{2}$, havendo um tempo de vida do estado triplete longo o suficiente para que ocorra a transferência. A eficiente supressão do estado excitado da zincoporfirina pelo $\mathrm{O}_{2}$ não permite transferência eletrônica para os grupos nitrobenzil piridínio. Esse resultado mostra que todas as cinco zincoporfirinas piridínio substituídas têm propriedades do estado triplete muito semelhantes, e o $\tau_{\mathrm{T}}$ anômalo da $\mathrm{ZnTNO}_{2} \mathrm{BzPyP}$ se deve a um mecanismo de supressão intramolecular. 
As bases livres apresentam tempo de vida do estado triplete cerca de $20 \%$ mais curto que seus respectivos zinco complexos, os decaimentos observados também foram de primeira ordem, entretanto, não foram realizados experimentos na ausência de $\mathrm{O}_{2}$, condição em que a cinética de decaimento das bases livres é mais complexa devido à protonação e deprotonação dos nitrogênios pirrólicos no estado excitado, causando decaimentos que não são de primeira ordem. Esse resultado já era esperado uma vez que a presença do zinco aumenta o cruzamento inter sistema, aumentando a população do triplete, e amaior rigidez do anel diminui a velocidade de decaimento do estado triplete.

Foram realizados experimentos de supressão do estado triplete em força iônica controlada por solução aquosa de $\mathrm{NaCl} 0,05 \mathrm{~mol} \mathrm{dm}^{-3}$, para 3 supressores catiônicos, metilviologênio (MV), benzilviologênio (BV) e pentamincloro cobalto (III) $\left(\mathrm{CoA}_{5} \mathrm{Cl}\right)$ e para um supressor aniônico antraquinona-2-sulfonato de sódio (AQS). As constantes de supressão foram obtidas pelo método de Stern-Volmer e são apresentadas na tabela 11. As medidas foram realizadas em equilibrio com $\mathrm{O}_{2}$, diferentemente dos dados apresentados na literatura para a supressão da ZnTMPyP utilizando MV e $\mathrm{CoA}_{5} \mathrm{Cl}$ como supressores ${ }^{9}$, cujo valores foram obtidos em soluções isentas de $\mathrm{O}_{2}$. As medidas foram realizadas com as soluções em contato com atmosfera pois desse modo sabemos que a concentração de $\mathrm{O}_{2}$ será igual para todas as medidas. Medidas realizadas na ausência de $\mathrm{O}_{2}$ poderiam aumentar os erros na determinação da constante, uma vez que uma pequena variação da quantidade de $\mathrm{O}_{2}$ presente em solução afeta muito os valores de $\tau_{\top}$ devido ao alto valor da constante de supressão para $\circ \mathrm{O}_{2}$. $\mathrm{O}$ inconveniente de se trabalhar na presença de $\mathrm{O}_{2}$ é a necessidade de se utilizar concentrações maiores de supressor de modo a se ter variações mensuráveis nos valores de $\tau_{\mathrm{T}}$, lembrando que a imprecisão da medida é da ordem de $10 \%$. As concentrações de supressores utilizadas nos experimentos estão na seção 2.3.5.

O método adotado mostrou-se conveniente uma vez que as constantes de supressão do estado triplete da ZnTMPyP com os supressores $\mathrm{MV}$ e $\mathrm{CoA}_{5} \mathrm{Cl}$ obtidos estão de acordo com os valores relatados na literatura ${ }^{9}$.

As constantes obtidas para as porfirinas benzil pindínio substituídas são da mesma ordem de grandeza que as verificadas para a ZnTMPyP, entretanto os derivados $\mathrm{ZnTCNBzPyP}$ e $\mathrm{ZnTNO}_{2} \mathrm{BzPyP}$ aparentam ter uma menor interação com os supressores catiônicos quando comparados às demais zincoporfirinas estudadas. Os substituintes nitro e ciano são aceptores de elétrons, diminuindo a densidade de carga dos anéis benzílicos em relação a ZnTBzPyP e ZnTMeOBzPyP, dificultando a interação entre os supressores catiônicos com o centro porfirínico. 
tabela 11: Constantes de supressão $\left(k_{Q}\right)$ do estado triplete excitado das zincoporfirinas piridínio substituídas.

\begin{tabular}{ccccc}
\hline Porfirinas & $\begin{array}{c}\mathrm{MV} \\
\mathrm{k}_{\mathrm{Q}}\left(\mathrm{dm}^{3} \mathrm{~mol}^{-1} \mathrm{~s}^{-1}\right)\end{array}$ & $\begin{array}{c}\mathrm{BV} \\
\mathrm{k}_{Q}\left(\mathrm{dm}^{3} \mathrm{~mol}^{-1} \mathrm{~s}^{-1}\right)\end{array}$ & $\begin{array}{c}\mathrm{CoA}_{5} \mathrm{Cl} \\
\mathrm{k}_{Q}\left(\mathrm{dm}^{3} \mathrm{~mol}^{-1} \mathrm{~s}^{-1}\right)\end{array}$ & $\begin{array}{c}\text { AQS } \\
\mathrm{k}_{\mathrm{Q}}\left(\mathrm{dm}^{3} \mathrm{~mol}^{-1} \mathrm{~s}^{-1}\right)\end{array}$ \\
\hline ZnTMPyPa & $1,8 \times 10^{7}$ & --- & $1,5 \times 10^{8}$ & -- \\
ZnTMPyP & $1,5 \times 10^{7}$ & $1,0 \times 10^{8}$ & $1,4 \times 10^{8}$ & $2,6 \times 10^{9}$ \\
ZnTMeOBzPyP & $1,0 \times 10^{7}$ & $1,2 \times 10^{8}$ & $1,3 \times 10^{8}$ & $3,7 \times 10^{9}$ \\
ZnTBzPyP & $9,1 \times 10^{6}$ & $9,5 \times 10^{7}$ & $1,2 \times 10^{8}$ & $3,2 \times 10^{9}$ \\
ZnTCNBzPyP & $4,1 \times 10^{6}$ & $4,2 \times 10^{7}$ & $5,9 \times 10^{7}$ & $7,0 \times 10^{9}$ \\
ZnTNO $_{2}$ BzPyP & $3,5 \times 10^{6}$ & $4,4 \times 10^{7}$ & $5,9 \times 10^{7}$ & $2,8 \times 10^{9}$ \\
\hline
\end{tabular}

$k_{Q} \pm 10 \%$. a- dados obtidos na ausência de $\mathrm{O}_{2}{ }^{9}$.

As constantes de supressão do estado triplete das zincoporfirinas pelo AQS são muito altas devido à interação eletrostática entre as espécies. A maior constante de supressão é verificada para a ZnTCNBzPyP, ainda seguindo o raciocínio proposto para os supressores catiônicos, o grupo ciano retira cargas do anel benzílico e o anel deficiente em elétrons deve ter maior interação com o ânion AQS. Entretanto, a $\mathrm{ZnTNO}_{2} \mathrm{BzPyP}$ apresenta constante de supressão similar às demais zincoporfirinas, enquanto esperava-se que $\circ$ valor determinado acompanhasse o obtido para a ZnTCNBzPyP.

Também foram obtidos os espectros de absorção dos transientes das zincoporfirinas estudadas na presença dos supressores catiônicos $\mathrm{MV}, \mathrm{BV}$ e $\mathrm{CoA}_{5} \mathrm{Cl}$, com o intuito de identificar bandas referentes ao cátion $\pi$-radical $\left(\mathrm{ZnP}^{+\bullet}\right)$ formado na transferência de um elétron do estado excitado triplete para o aceptor. $O$ aceptor $\mathrm{CoA}_{5} \mathrm{Cl}$ não forma com a zincoporfirina um par redox reversivel, uma vez que o complexo pentaminclorocobalto(III) sofre rapidamente hidrólise formando o aqua complexo ${ }^{9}$, como mostra a equação abaixo:

$$
\left[\mathrm{Co}\left(\mathrm{NH}_{3}\right)_{5} \mathrm{Cl}\right]^{2+}+\mathrm{e}^{-}+5 \mathrm{H}^{+} \rightarrow \mathrm{Co}^{2+}+5 \mathrm{NH}_{4}^{+}+\mathrm{Cl}^{-}
$$

Entretanto, a faixa de resposta da fotomultiplicadora do aparelho não atinge a região do infravermelho próximo, entre 700 e $900 \mathrm{~nm}$, região em que são geralmente observadas bandas atribuídas a espécies oxidadas dos derivados porfirínicos ${ }^{9 / 120}$. $\mathrm{Na}$ região espectral monitorada $(300-680 \mathrm{~nm})$ não foi possivel a identificação de bandas referentes ao cátion $\pi$-radical ou às espécies oxidadas, como por exemplo as isoporfirinas, decorrentes da transferência de elétron do estado excitado das zincoporfirinas. $O$ único caso em que foi possível identificar a formação de uma nova espécie foi no sistema ZnTMPyP/BV. 


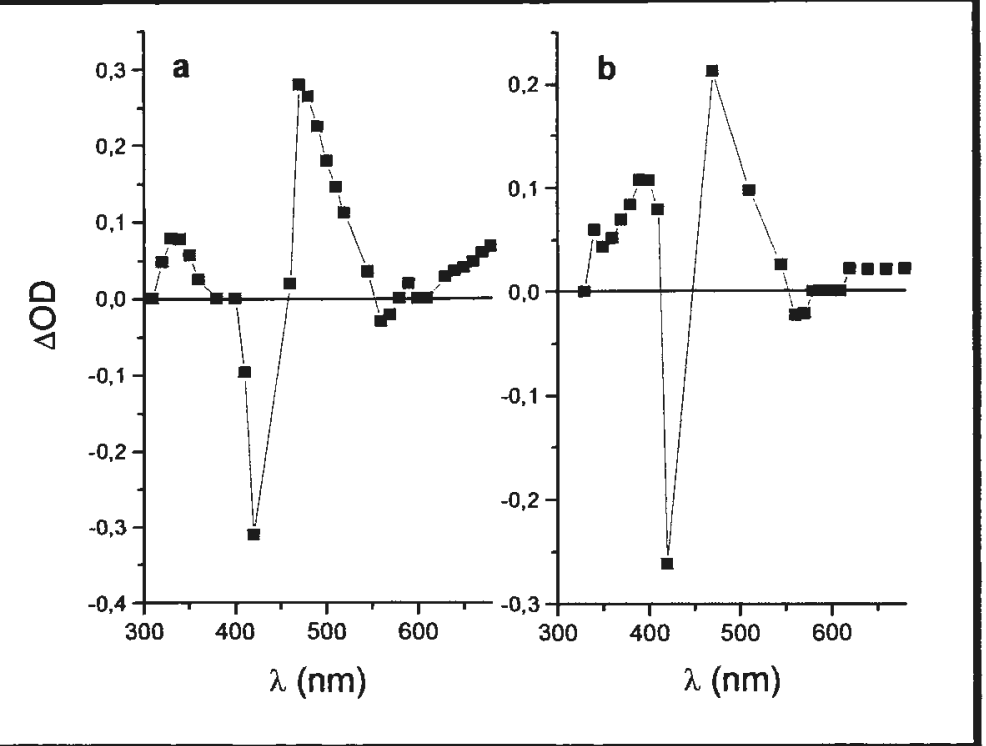

figura 42: Espectros eletrônicos de absorção dos transientes: a - ZnTMPyP em solução de $\mathrm{NaCl}\left(0,05 \mathrm{~mol} \mathrm{dm}^{-3}\right) ; b-\mathrm{ZnTMPyP}$ com BV $\left(1,5 \mathrm{mmol}^{-3}\right)$ em solução aquosa de $\mathrm{NaCl}\left(0,05 \mathrm{~mol} \mathrm{dm}^{-3}\right)$.

O espectro do transiente da ZnTMPyP apresenta máximos em relação ao espectro de absorção do estado fundamental em $350 \mathrm{~nm}$ e $470 \mathrm{~nm}$ (figura 42). Em todas essas regiões, entretanto, bem como nas regiões onde há diminuição da absorbância (430 nm), os tempos de vida são da mesma ordem, cerca de $3 \mu \mathrm{s}$. Com a presença do supressor catiônico BV, nota-se uma mudança no perfil espectral, com aparecimento de um novo máximo entre $370-400 \mathrm{~nm}$. Essa banda se refere a outra espécie e não ao estado triplete da ZnTMPyP, uma vez que os tempos de vida monitorados nesses comprimentos de onda são bastante distintos do tempo de vida do estado triplete da ZnTMPyP nessa concentração de BV, cerca de $2 \mu \mathrm{s}$. O tempo de vida da espécie que absorve na região de $360-400 \mathrm{~nm}$ é da ordem de $24 \mu \mathrm{s}$.

\subsubsection{Determinação do Rendimento Quântico de Formação de ${ }^{1} \mathrm{O}_{2}$}

O rendimento quântico de formação de oxigênio singlete $\left(\Phi_{\Lambda}\right)$ é um parâmetro fundamental que viabiliza a aplicação de um cromóforo em terapia fotodinâmica (PDT), uma vez que a produção de espécies reativas de oxigênio in situ é que devem ocasionar a morte das células tumorais. Portanto, a utilização dessa nova classe de porfirinas catiônicas em PDT está diretamente relacionada com valores de $\Phi_{\Delta} \mathrm{em}$ solução aquosa, que devem ser compativeis com o $\Phi_{\Delta}$ das $\mathrm{H}_{2}$ TMPyP e ZnTMPyP, que correspondem a 0,74 e $0,88^{48,70}$,respectivamente.

O estudo realizado nesse trabalho ainda traz a novidade de ser uma determinação direta, a partir da emissão fosforescente da espécie ${ }^{1} \mathrm{O}_{2}$, em água, enquanto que os dados da literatura remetem-se a água deuterada, solventes 
orgânicos, ou a métodos indiretos, monitorando produtos formados após a reação com - ${ }^{1} \mathrm{O}_{2}$ formado, sendo a p-nitroso dimetilanilina (RNO) o reagente mais utilizado em solução aquosa". Essa inovação só foi possivel graças a resolução temporal da aparelhagem utilizada que permite uma detecção precisa do decaimento de emissão do ${ }^{1} \mathrm{O}_{2}$ em água, que apresenta tempo de vida de $4,3 \mu \mathrm{s}$.

Como padrão para determinação do $\Phi_{\Delta}$ relativo foi utilizado uma solução de $\mathrm{H}_{2}$ TMPyP em $\mathrm{D}_{2} \mathrm{O}$, com absorbância de $0,200 \pm 0,005$, condição aplicada às soluções aquosas de todas as porfirinas e seus zinco derivados analisados.

A comparação dos rendimentos quânticos de formação de ${ }^{1} \mathrm{O}_{2}\left(\Phi_{\Delta}\right)$ foi feita a partir da extrapolação para o tempo zero da intensidade de emissão de fosforescência da espécie ${ }^{1} \mathrm{O}_{2}$ formada $\left(\mathrm{I}_{0}\right)$, a partir do acompanhamento cinético do decaimento dessa emissão. Cada solução foi monitorada em cinco diferentes potências de excitação (laser, $\lambda=532 \mathrm{~nm}$ ), obtendo-se uma reta a partir da correlação entre osvalores de $\mathrm{I}_{0}$ determinados $\mathrm{e}$ as respectivas potências $\left(\mathrm{P}_{0}\right)$ aplicadas. $\mathrm{O}$ comportamento linear verificado para as potências aplicadas (figura 43) demonstra não haver outro processo concorrente à formação do ${ }^{1} \mathrm{O}_{2}$, como o aniquilamento triplete-triplete, nas condições empregadas. Desse modo, os coeficientes lineares dos gráficos $I_{0}$ vs. $P_{o}$ obtidos são diretamente proporcionais ao $\Phi_{\Delta}$.

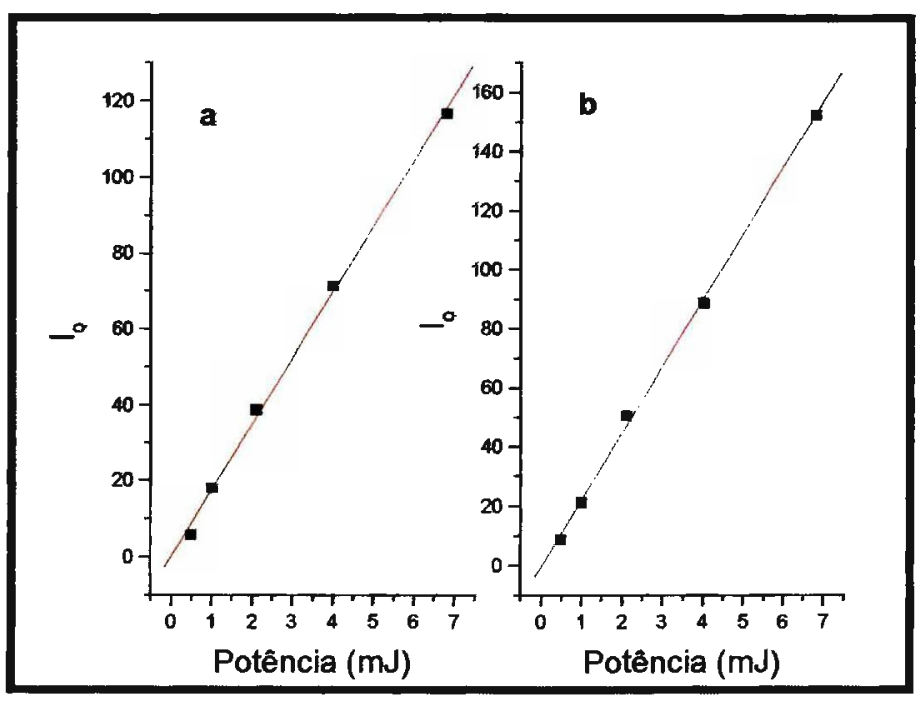

figura 43: Correlação da intensidade de emissão do ${ }^{1} \mathrm{O}_{2}$ no tempo zero $\left(\mathrm{I}_{0}\right)$ pela potência de excitação do laser em $532 \mathrm{~nm}\left(P_{0}\right)$;

a - $\mathrm{H}_{2} \mathrm{TMeOBzPyP}$ em $\mathrm{H}_{2} \mathrm{O} ;$ b - ZnTMPyP em $\mathrm{H}_{2} \mathrm{O}$.

O $\Phi_{\Delta}$ apresentado pela $\mathrm{H}_{2}$ TMPyP foi o mesmo, seja em solução aquosa ou em $\mathrm{D}_{2} \mathrm{O}$, variando apenas o tempo de vida do ${ }^{1} \mathrm{O}_{2}$, muito menor em água. Os valores de tempo de vida obtidos estão compatíveis com dados da literatura ${ }^{48,270}$, assim como 0 
$\Phi_{\Delta}$ da ZnTMPyP e da $\mathrm{H}_{2}$ TPPS em água ${ }^{48,4}$. A figura 44 ilustra o decaimento de emissão do ${ }^{1} \mathrm{O}_{2}$ em solução de $\mathrm{H}_{2}$ TMPyP em $\mathrm{H}_{2} \mathrm{O}$ e em $\mathrm{D}_{2} \mathrm{O}$.

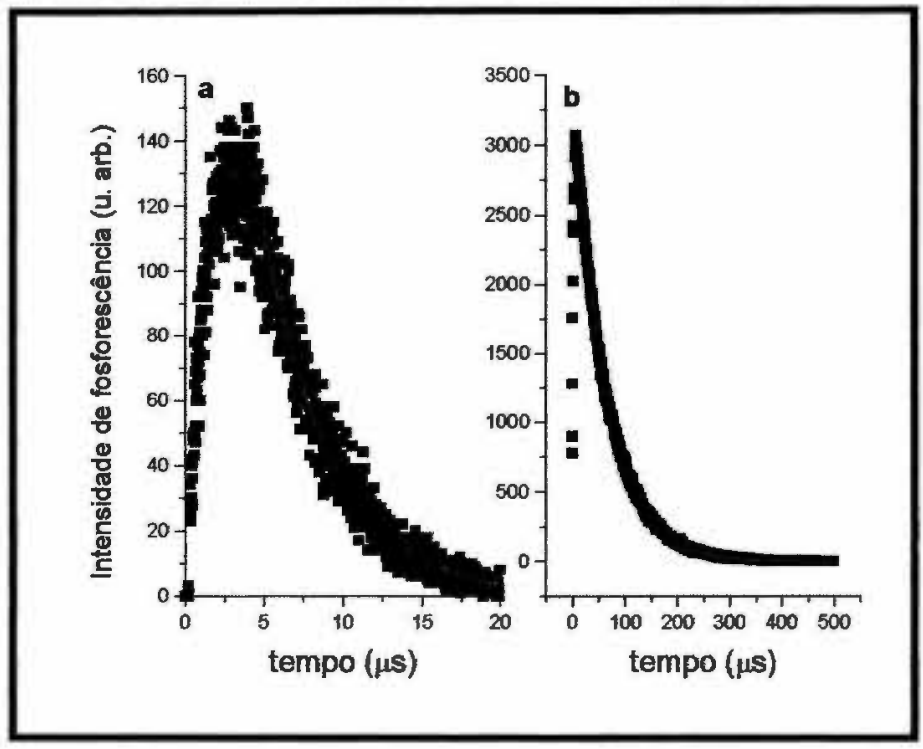

figura 44: Decaimento de emissão de fosforescência do ${ }^{1} \mathrm{O}_{2} \mathrm{em} 1270 \mathrm{~nm}$. a- $\mathrm{H}_{2}$ TMPyP em $\mathrm{H}_{2} \mathrm{O}$; b - $\mathrm{H}_{2}$ TMPyP em $\mathrm{D}_{2} \mathrm{O}$.

tabela 12: Rendimentos quântico relativo ${ }^{a}$ de formação de ${ }^{1} \mathrm{O}_{2}\left(\Phi_{\Delta}\right)$ e tempo de vida de ${ }^{1} \mathrm{O}_{2}\left(\tau_{\Lambda}\right)$.

\begin{tabular}{cccc}
\hline Porfirina & solvente & $\Phi$, & $\tau_{1}(\mu \mathrm{s})$ \\
\hline $\mathrm{H}_{2}$ TMPyP & $\mathrm{D}_{2} \mathrm{O}$ & 0,74 & 60 \\
$\mathrm{H}_{2}$ TMPyP & $\mathrm{H}_{2} \mathrm{O}$ & 0,74 & 4,4 \\
$\mathrm{H}_{2}$ TPPS & $\mathrm{H}_{2} \mathrm{O}$ & 0,66 & 4,2 \\
$\mathrm{H}_{2}$ TMeOBzPyP & $\mathrm{H}_{2} \mathrm{O}$ & 0,67 & 4,3 \\
$\mathrm{H}_{2}$ TBzPyP & $\mathrm{H}_{2} \mathrm{O}$ & 0,64 & 4,5 \\
$\mathrm{H}_{2}$ TCNBzPyP & $\mathrm{H}_{2} \mathrm{O}$ & 0,61 & 4,3 \\
$\mathrm{H}_{2} \mathrm{TNO}_{2}$ BzPyP & $\mathrm{H}_{2} \mathrm{O}$ & 0,66 & 4,4 \\
$\mathrm{H}_{2}$ TAIPyP & $\mathrm{H}_{2} \mathrm{O}$ & 0,76 & 4,4 \\
$\mathrm{H}_{2}$ TPnPyP & $\mathrm{H}_{2} \mathrm{O}$ & 0,90 & 4,4 \\
ZnTMPyP & $\mathrm{H}_{2} \mathrm{O}$ & 0,87 & 4,5 \\
ZnTMeOBzPyP & $\mathrm{H}_{2} \mathrm{O}$ & 0,75 & 4,3 \\
ZnTBzPyP & $\mathrm{H}_{2} \mathrm{O}$ & 0,73 & 4,4 \\
\hline ZnTCNBzPyP & $\mathrm{H}_{2} \mathrm{O}$ & 0,78 & 4,3 \\
ZnTNO ${ }_{2}$ BzPyP & $\mathrm{H}_{2} \mathrm{O}$ & 0,51 & 4,4 \\
\hline
\end{tabular}

a - $\Phi_{\Delta}$ da $\mathrm{H}_{2}$ TMPyP em $\mathrm{D}_{2} \mathrm{O}=0,74^{70}$ e $\Phi_{\Delta}$ da $\mathrm{H}_{2}$ TMPyP em $\mathrm{H}_{2} \mathrm{O}=0,74^{48}$; valores de $\Phi_{\Delta}$ e $\tau_{\Delta} \pm 10 \%$.

Analisando os dados da tabela 12 constata-se a validade para o método proposto para a determinação do $\Phi_{\Delta}$, uma vez que os valores para a $\mathrm{H}_{2}$ TMPyP em 
$\mathrm{H}_{2} \mathrm{O}$ e $D_{2} \mathrm{O}$ são da mesma ordem, bem como os valores obtidos para a $\mathrm{H}_{2}$ TPPS e ZnTMPyP em $\mathrm{H}_{2} \mathrm{O}$ são coerentes para os relatados na literatura por métodos indiretos, 0,64 e 0,88 , respectivamente ${ }^{48}$. Por outro lado, o valor relatado por Kruk e colaboradores ${ }^{2}$ para o $\Phi_{\Delta}$ da $\mathrm{H}_{2}$ TMPyP em $\mathrm{D}_{2} \mathrm{O}(0,90)$ foi considerado exagerado, e significaria rendimentos quânticos de formação de ${ }^{1} \mathrm{O}_{2}$ acima de 1,0 para a ZnTMPyP e $\mathrm{H}_{2}$ TPnPyP.

Os valores de $\Phi_{\Delta}$ para as porfirinas benzilpiridínio substituídas em solução aquosa são de $10 \%$ a $15 \%$ menores que os valores apresentados para a $\mathrm{H}_{2}$ TMPyP, o mesmo ocorrendo em relação aos zinco derivados, sendo esses sempre superiores aos $\Phi_{\Delta}$ das respectivas bases livres. As exceçôes acontecem em relação a $\mathrm{ZnTNO}_{2} \mathrm{BzPyP}$ que possui um $\Phi_{\Delta}$ menor do que a respectiva base livre e a ZnTCNBzPyP que apresenta $\circ \Phi_{\Delta}$ da mesma magnitude que a ZnTMPyP.

Já as porfirinas $\mathrm{H}_{2}$ TAIPyP e $\mathrm{H}_{2}$ TPnPyP apresentam $\Phi_{\Delta}$ superior a $\mathrm{H}_{2}$ TMPyP, indicando uma provável participação dos substituintes benzílicos no processo de transferência de energia do estado triplete da porfirina para $\circ \mathrm{O}_{2}$, reduzindo a eficiência de formação do estado singlete excitado.

\subsection{Eletroquímica}

A técnica de voltametria cíclica permite uma ampla caracterização do comportamento redox de espécies eletroativas. Essa técnica em conjunto com a espectroeletroquímica têm sido largamente utilizada no estudo redox de metaloporfirinas em diversos meios ${ }^{17,121,122}$.

As porfirinas derivadas da $\mathrm{H}_{2}$ TMPyP apresentam algumas características peculiares quando comparadas às demais porfirinas (aquossolúveis ou não). A redução do macrociclo porfirínico na $\mathrm{H}_{2}$ TMPyP ocorre em apenas um passo com dois elétrons envolvidos ${ }^{17,20}$, geralmente a redução do anel central ocorre em dois passos de apenas um elétron cada. Esse comportamento é justificado pela delocalização do primeiro elétron entre o anel porfirínico e o piridírico, formando uma espécie que é facilmente reduzida, ocasionando a entrada do segundo elétron simultaneamente. Além disso, o potencial de redução para a $\mathrm{H}_{2}$ TMPyP é mais baixo, devido a presença das cargas positivas nos anéis pidínicos, que estão em ressonância com o macrociclo $^{20}$.

Em experimentos realizados com metalo derivados da $\mathrm{H}_{2}$ TMPyP em DMF foi possivel caracterizar uma redução envolvendo seis elétrons em três etapas de dois elétrons cada ${ }^{17,121,123}$. Essas etapas se referem à redução do anel porfirínico e à 
posterior redução dos anéis piridínicos, formando as espécies $\mathrm{MP}^{2+}$, MP e $\mathrm{MP}^{2-}$, respectivamente.

O estudo eletroquímico das porfirinas benzilpiridínio substituídas foi realizado com o intuito de contribuir para a compreensão dos processos redox das porfirinas piridinio substituídas, avaliando a influência dos substituintes alquílicos nos potenciais de redução do macrociclo e do anel piridínico. Outra informação adicional a ser analisada é a extensão da conjugação entre o anel porfirínico e o anel piridínico e a transmissão eletrônica entre o substituinte periférico e o macrociclo.

Para o tratamento dos dados obtidos na voltametria ciclica foram utilizados os parâmetros e as técnicas já descritos na literatura ${ }^{35,124,125,126,127,128}$. Um par redox é considerado eletroquimicamente reversivel quando ambas as espécies trocam elétrons rapidamente com o eletrodo de trabalho. Esse processo é controlado por difusão e não ocorrem reações paralelas significativas, não havendo formação de outros produtos a partir da espécie reduzida ou oxidada.

Dois critérios de reversibilidade devem ser observados nos voltamogramas de pares redox reversiveis.

$$
\Delta E_{p}=E_{p a}-E_{p c} \approx 0,059 / n \quad(1)
$$

$E_{p c}$ é o potencial de pico catódico; $E_{p a}$ é o potencial de pico anódico; $n$ é o número de elétrons transferidos.

Os valores da corrente anódica ( $i_{\mathrm{pa}}$ ) e a corrente catódica $\left(\mathrm{i}_{\mathrm{pc}}\right)$ devem ser diretamente proporcionais com a raiz quadrada da velocidade de varredura $\left(v^{1 / 2}\right)$. Em um sistema reversível sem complicações cinéticas:

$$
\mathrm{i}_{\mathrm{pa}} / \mathrm{i}_{\mathrm{pc}} \approx 1
$$

Para um par redox reversível a média entre o potencial anódico e o catódico é o potencial formal do eletrodo $\left(E^{\circ}\right)$.

$$
E^{0^{\prime}}=\left(E_{p a}+E_{p c}\right) / 2
$$

Para a estimativa do $E_{1 / 2}$ catódico utilizou-se a relação proposta por Nicholson ${ }^{129,},{ }^{130}$ para processos reversiveis:

$$
\mathrm{i}_{\mathrm{E} 1 / 2}=0,8517 \mathrm{i}_{\mathrm{Ep}}
$$

Segundo Kadish ${ }^{17}$ os três processos de redução da ZnTMPyP e CuTMPyP à temperatura ambiente são reversiveis, controlados por difusão e obedecem os criténios (1) e (2). $O$ artigo apresenta os valores de $E_{1 / 2}$ obtidos por polarografia e as espécies resultantes de cada redução são analisadas por UV-Vis, após eletrólise.

Inicialmente, foram repetidos os voltamogramas obtidos por Kadish para a ZnTMPyP em DMF. O sistema utilizado apresenta algumas diferenças em relação ao 
da literatura. O eletrodo de trabalho é de platina, assim como o eletrodo auxiliar, entretanto o eletrodo referência é $\mathrm{Ag} / \mathrm{AgCl}$ em acetonitrila, que possui potencial de $0,503 \mathrm{~V}$ em relação ao eletrodo padrão de hidrogênio (EPH). Kadish utilizou um eletrodo saturado de calomelano como referência. O eletrólito suporte utilizado não foi - TBAP e sim o TEAP, o que pode influenciar nos valores de potenciais obtidos, mas não deve modificar os processos redox. Os valores desse estudo foram corrigidos para o eletrodo padrão de hidrogênio, somando-se $0,503 \mathrm{~V}$ aos valores obtidos para o eletrodo de $\mathrm{Ag} / \mathrm{AgCl}$ em acetonitrila ${ }^{35}$.

Para a ZnTMPyP obteve-se um voltamograma muito similar ao relatado na literatura $^{17}$, com três ondas bem definidas. Entretanto, não se observa as condições de completa reversibilidade nos pares redox. Os valores de $\Delta E_{p}$ são maiores que os 30 $\mathrm{mV}$ esperados e variam com a velocidade de varredura. A relação entre a corrente catódica e a anódica é próxima de um levando em consideração a linha base de cada voltamograma ${ }^{129,130}$. Foram feitos diversos arranjos na geometria da cela utilizada sem melhoria significativa do sistema. Foi verificado a influência do contra-íon da porfirina na voltametria, utilizando-se $\mathrm{Cl}^{-}$ou $\mathrm{ClO}_{4}^{-}$, porém não verificou-se diferenças no comportamento eletroquímico da espécie. A tabela 13 apresenta os valores dos potenciais polarográficos de meia onda obtidos por Kadish ${ }^{17}$ e os obtidos nesse estudo a partir da equação (4).

tabela 13: Potenciais de meia-onda da ZnTMPyP: $E_{122}(\triangle E p)$.

\begin{tabular}{|ccccc|}
\hline Eletrodo referencia & $v(\mathrm{mV} / \mathrm{s})$ & $1^{\mathrm{a}}$ onda $(\mathrm{V})$ & $2^{\mathrm{a}}$ onda $(\mathrm{V})$ & $3^{\mathrm{a}}$ onda $(\mathrm{V})$ \\
\hline $\mathrm{SCE}$ & 100 & $-0,41(0,040)$ & $-0,79(0,035)$ & $-0,90(0,035)$ \\
$\mathrm{Ag} / \mathrm{AgCl}$ em $\mathrm{CH}_{3} \mathrm{CN}$ & 100 & $-0,59(0,110)$ & $-0,92(0,087)$ & $-1,06(0,077)$ \\
$\mathrm{Ag} / \mathrm{AgCl}$ em $\mathrm{CH}_{3} \mathrm{CN}$ & 20 & $-0,58(0,077)$ & $-0,94(0,065)$ & $-1,01(0,054)$ \\
\hline
\end{tabular}

$E$ (V) vs EPH ;a-dados da literatura ${ }^{17}$.

As diferenças nos valores dos potenciais obtidos nos dois estudos pode estar relacionado aos potenciais de junção que não foram considerados nas correções. Vale lembrar que nos dois casos o eletrodo referência possui solvente diferente da solução analisada (DMF), água no caso do SCE e acetonitrila para o eletrodo $\mathrm{Ag} / \mathrm{AgCl}$. Existe também diferença no método empregado, sendo a polarografia um método mais preciso na determinação dos potenciais de redução.

Apesar da não reversibilidade total dos pares redox, contrariando o relatado na literatura, o sistema se mostrou reprodutivo (figura 45). O mesmo sistema foi utilizado para o estudo eletroquímico dos demais derivados porfirínicos. 

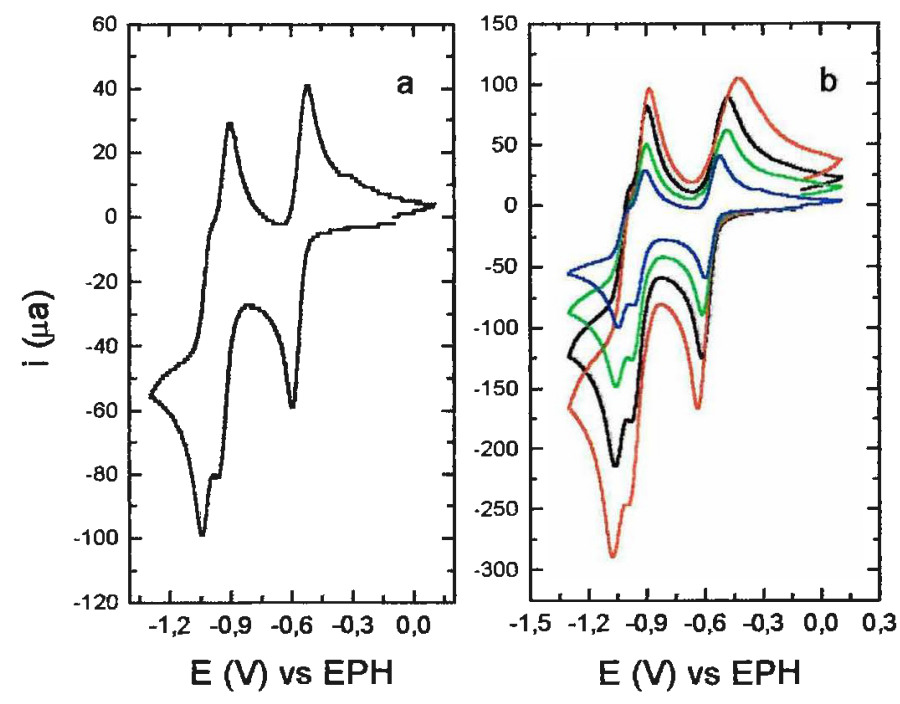

figura 45: Voltamogramas cíclicos da ZnTMPyP em DMF (TEAP 0,1 mol $\mathrm{dm}^{-3}$ ); a $-v=20 \mathrm{mV} / \mathrm{s} ; \mathbf{b}-v=200 \mathrm{mV} / \mathrm{s}, v=100 \mathrm{mV} / \mathrm{s}, v=50 \mathrm{mV} / \mathrm{s}$ e $v=20 \mathrm{mV} / \mathrm{s}$.

\subsubsection{Eletroquímica das Zincoporfirinas}

Foi estudado o comportamento eletroquímico de seis zincoporfirinas piridínio substituídas: ZnTMeOBzPyP, ZnTCH ${ }_{3}$ BzPyP, ZnTBzPyP, ZnTCNBzPyP, ZnTPhPrPyP e $\mathrm{ZnTNO}_{2} \mathrm{BzPyP}$. Aparentemente, os voltamogramas cíclicos apresentam uma redução de seis elétrons em três passos como o verificado para a ZnTMPyP. As duas ondas referentes à redução dos anéis piridínio, entretanto, não são bem definidas em nenhum dos derivados analisados, aparecendo sobrepostas. No sentido da oxidação, verifica-se apenas uma onda para os grupos piridínios. A oxidação do anel porfirínico apresenta uma onda larga, e dependente da velocidade de varredura e em determinadas situações, uma nova onda de oxidação é observada em potenciais mais positivos (na região de $-0,30 \mathrm{~V}$ ).

A figura 46 mostra os voltamogramas cíclicos obtidos para a ZnTBzPyP e $\mathrm{ZnTCH}_{3}$ BzPyP, que evidenciam as observações relatadas acima. Esses voltamogramas permitem notar que o aparecimento da inesperada onda de oxidação depende do substituinte benzílico e da velocidade de varredura empregada. Enquanto que para a $\mathrm{ZnTCH}_{3}$ BzPyP já é possível verificar a onda com varredura de $100 \mathrm{mV} / \mathrm{s}$, para a ZnTBzPyP essa onda não é tão nítida, ficando evidente apenas a $20 \mathrm{mV} / \mathrm{s}$. 


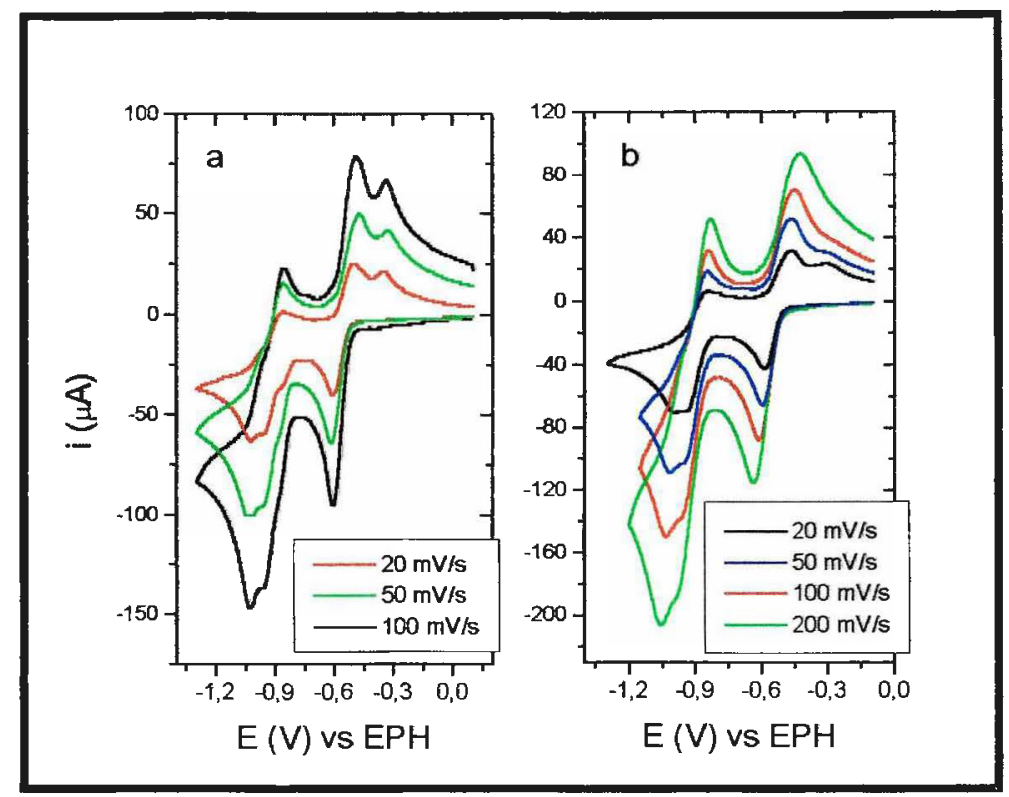

figura 46: Voltamogramas cíclicos em diferentes velocidades de varredura em DMF (TEAP 0,1 mol $\mathrm{dm}^{-3}$ ); a - $\mathrm{ZnTCH}_{3}$ BzPyP; b - ZnTBzPyP

Observando atentamente a figura 45 é possivel identificar uma pequena onda de oxidação para a ZnTMPyP em $20 \mathrm{mV} / \mathrm{s}$, indicando que o mesmo processo deve ocorrer para essa metaloporfirina, entretanto com menor intensidade.

A tabela 14 apresenta alguns valores para os potenciais de pico catódico das zincoporfirinas. Os valores de $E_{1 / 2}$ foram calculados para a redução do anel porfirínico ( $1^{a}$ redução), utilizando a equação (4), apesar da onda ser quase reversível.

A tabela evidencia que nenhuma das zincoporfirinas estudadas apresenta comportamento totalmente reversível dos pares redox nas três reduções observadas. Os valores de $\Delta \mathrm{E}_{\mathrm{p}}$ ficam bastante distantes das condições de reversibilidade (30 $\mathrm{mV}$ para um processo que envolve dois elétrons). Entretanto as intensidades de pico catódicos $\left(i_{p c}\right)$ apresentam uma boa relação entre si, indicando que cada processo envolve o mesmo número de elétrons, reforçando a proposta de Kadish de que seriam dois elétrons por etapa.

Os voltamogramas modificam-se com a velocidade de varredura $(v)$, ocorrendo aproximação dos picos e o aparecimento da onda de oxidação após a oxidação do macrociclo com a diminuição de $v$. Essa dependência com $v$ indica um processo químico concorrendo com a oxidação da espécie formada.

Para identificar qual a espécie responsável pelo aparecimento dessa nova onda foram obtidos voltamogramas de cada uma das ondas separadamente. A figura 47 apresenta três voltamogramas da $\mathrm{ZnTCH}_{3} \mathrm{BzPyP}$ com $v$ de $50 \mathrm{mV} / \mathrm{s}$. A onda de oxidação em $-0,30 \mathrm{~V}$ desaparece quando só a primeira onda é varrida, demonstrando que a primeira não se refere ao processo de redução do macrocicio. Varrendo-se até a 
segunda onda (redução dos grupos piridínios) a onda de oxidação volta a aparecer. A figura $47 \mathrm{c}$ apresenta o voltamograma obtido após várias varreduras até $1,0 \mathrm{~V}$ (relativo ao EPH), fica evidente a formação de novo par redox, com a respectiva redução do produto oxidado em $-0,30 \mathrm{~V}$.

tabela 14: $E_{p c}, E_{p a} \in E_{1 / 2}$ para as zincoporfirinas $(v=100 \mathrm{mV} / \mathrm{s})$

\begin{tabular}{|ccccc}
\hline Porfirinas & & $E_{p c}(V)$ & $E_{p a}(V)$ & $E_{1 / 2}(V)$ \\
\hline ZnTMPyP & $1^{a}$ onda & $-0,614$ & $-0,480$ & $-0,59$ \\
& $2^{\mathrm{a}}$ onda & $-0,981$ & $-0,894$ & $-0,98$ \\
& $3^{\mathrm{a}}$ onda & $-1,060$ & $\approx-0,98$ & $-1,03$ \\
\hline ZnTBzPyP & $1^{\mathrm{a}}$ onda & $-0,613$ & $-0,451$ & $-0,59$ \\
& $2^{\mathrm{a}}$ onda & $\approx-0,96$ & $-0,839$ & \\
& $3^{\mathrm{a}}$ onda & $-1,030$ & $\approx-0,97$ & \\
\hline ZnTMeOBzPyP & $1^{\mathrm{a}}$ onda & $-0,634$ & $-0,436$ & $-0,61$ \\
& $2^{\mathrm{a}}$ onda & $-0,972$ & $\approx-0,84$ & \\
& $3^{\mathrm{a}}$ onda & $-1,004$ & - & \\
\hline ZnTCH ${ }_{3}$ BzPyP & $1^{\mathrm{a}}$ onda & $-0,604$ & $-0,487$ & $-0,59$ \\
& $2^{\mathrm{a}}$ onda & $-0,955$ & $-0,855$ & \\
& $3^{\mathrm{a}}$ onda & $-1,028$ & $\approx-0,96$ & \\
\hline ZnTCNBzPyP & $1^{\mathrm{a}}$ onda & $-0,590$ & $-0,409$ & $-0,57$ \\
& $2^{\mathrm{a}}$ onda & $-0,921$ & $-0,805$ & \\
& $3^{\mathrm{a}}$ onda & $-0,969$ & - & \\
\hline ZnTPhPrPyP & $1^{\mathrm{a}}$ onda & $-0,685$ & $\approx-0,29$ & $-0,65$ \\
& $2^{\mathrm{a}}$ onda & $-1,021$ & $-0,857$ & \\
\hline $3^{\mathrm{a}}$ onda & $-1,086$ & - & \\
\hline ZnTNO ${ }_{2}$ BzPyP & $1^{\mathrm{a}}$ onda & $-0,573$ & $-0,463$ & $-0,55$ \\
\hline
\end{tabular}

Pode-se concluir que o produto de redução do anel piridínio (MP ou $\mathrm{MP}^{2-}$ ) reage formando um novo produto que é oxidado em $-0,30 \mathrm{~V}$. Há, portanto, uma competição entre a oxidação do piridínio reduzido (MP ou $\mathrm{MP}^{2-}$ ) e a formação desse novo produto. Em velocidades altas de varredura não há tempo para a formação significativa do novo produto, não aparecendo a onda em $-0,30 \mathrm{~V}$. A formação desse produto também depende do substituinte benzílico, pois é mais evidente para a $\mathrm{ZnTCH}_{3}$ BzPyP e ZnTCNBzPyP, enquanto só aparece em $v$ de $20 \mathrm{mV} / \mathrm{s}$ para a ZnTBzPyP, ZnTMeOBzPyP e ZnTPhPrPyP. Já para a ZnTMPyP esse processo é muito menos favorecido, pois mesmo em $v$ de $20 \mathrm{mV} / \mathrm{s}$ a onda de oxidação em $-0,30 \mathrm{~V}$ é pouco perceptivel. 


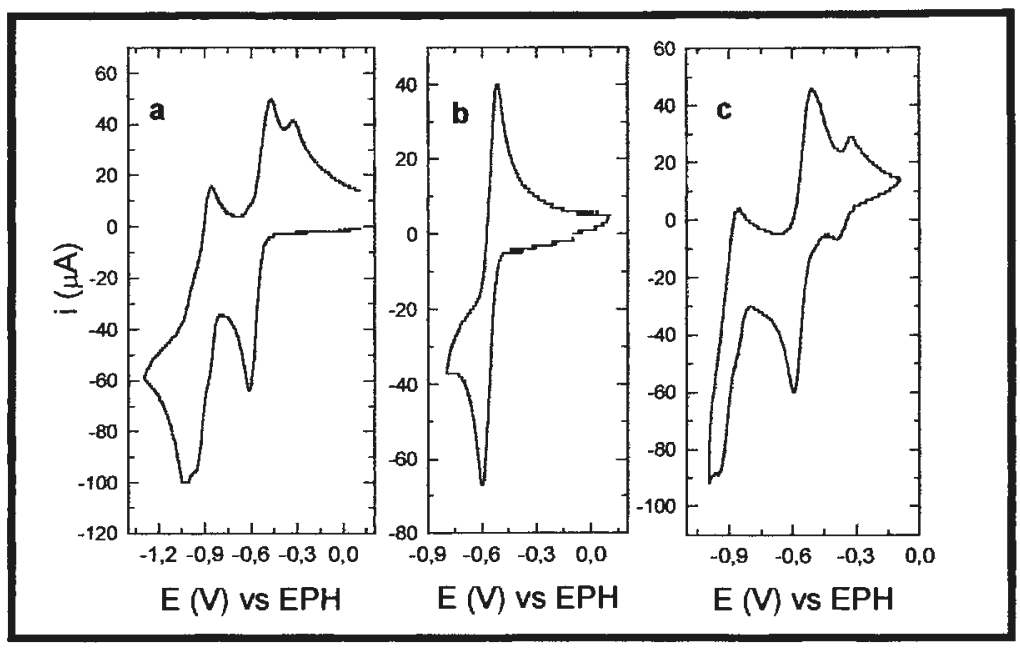

figura 47: Voltamogramas cíclicos da $\mathrm{ZnTCH}_{3}$ BzPyP em DMF (TEAP $0,1 \mathrm{~mol} \mathrm{dm}^{-3}$ ) com $v=50 \mathrm{mV} / \mathrm{s}$. a- $0,10 \mathrm{~V}$ a $-1,3 \mathrm{~V} ; \mathrm{b}-0,10 \mathrm{~V}$ a $-0,8 \mathrm{~V} ; \mathrm{c}-0,10 \mathrm{~V}$ a $-1,0 \mathrm{~V}$ (após vários ciclos).

A $\mathrm{ZnTNO}_{2} \mathrm{BzPyP}$ apresenta um comportamento atipico, os processos de redução vão se tornando totalmente irreversíveis após alguns ciclos, ocorrendo uma deformação nas ondas de redução. Ao varrer apenas a primeira onda observa-se um par redox muito semelhante ao das demais zincoporfirinas. As ondas de redução e de oxidação do macrociclo $\left(\mathrm{MP}^{4+} / \mathrm{MP}^{2+}\right)$ mantém-se após vários ciclos.

Esses dados evidenciam a formação de um processo químico irreversivel a partir do produto da redução dos piridínios da $\mathrm{ZnTNO}_{2} \mathrm{BzPyP}$. O grupo nitro também é eletroativo e sua redução deve ocorrer em potencial próximo às reduções dos anéis piridínio, podendo este processo estar envolvido na formação da espécie inerte na superfície do eletrodo. Após a medida o eletrodo de trabalho deve ser lixado para voltar a responder com a mesma eficiência, indicando a formação de um filme sobre 0 eletrodo.

A figura 48 apresenta os voltamogramas da $\mathrm{ZnTNO}_{2} \mathrm{BzPyP}$ com velocidade de varredura de $50 \mathrm{mV} / \mathrm{s}$, evidenciando a independência da redução do anel porfirínico com a formação do produto eletroinerte.

Foi realizado um estudo de espectroeletroquímica para identificar os produtos da redução dos compostos porfirínicos estudados. Em uma cubeta contendo um minigrid de ouro foi realizada a eletrólise em potencial fixo, acompanhada por espectroscopia eletrônica na região do UV-Vis. Os potenciais utilizados para a eletrólise estão situados após as ondas de redução.

Apesar de não ser possivel determinar os potenciais em que ocorrem as duas reduções dos anéis piridínio, pode-se identificar as mesmas espécies relatadas por Kadish $^{17}$ na redução da ZnTMPyP. 

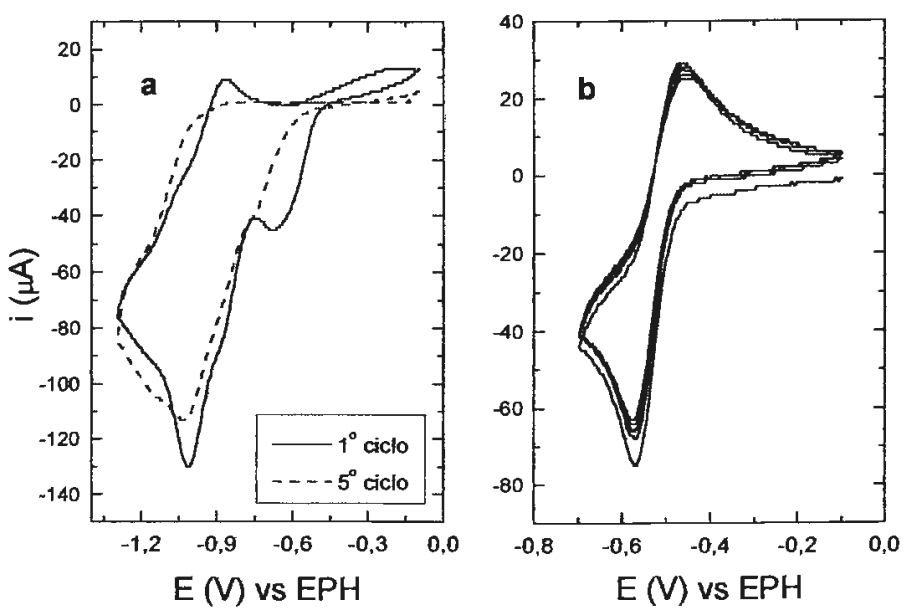

figura 48: Voltamogramas cíclicos da ZnTNO ${ }_{2}$ BzPyP em DMF (TEAP 0,1 $\mathrm{mol} \mathrm{dm}^{-3}$ ) com $v=50 \mathrm{mV} / \mathrm{s}$. a- $0,10 \mathrm{~V}$ a $-1,3 \mathrm{~V}\left(1^{\circ}\right.$ e $5^{\circ}$ ciclos); b- $0,10 \mathrm{~V}$ a $-0,8 \mathrm{~V}$ (vários ciclos).

A figura 49 apresenta os espectros eletrônicos de absorção para os produtos de redução da $\mathrm{ZnTBzPyP}$. A primeira redução (-650 mV, epH) forma o $\mathrm{ZnTBzPyP}{ }^{2+}$, com diminuição drástica da banda Soret e aparecimento de uma banda deslocada para o vermelho. Nota-se o aparecimento de uma nova banda intensa na região do vermelho, característica de produto de redução do anel porfirinico. As próximas duas reduções ocorrem com a elevação do potencial a $-1100 \mathrm{mV}$, ficando difícil a identificação das duas espécies reduzidas (MP e $\mathrm{MP}^{2-}$ ). Nota-se o desaparecimento das bandas em $475 \mathrm{~nm}$ e $777 \mathrm{~nm}$, características da espécie $\mathrm{MP}^{2+}$ e a formação de nova banda intensa em $426 \mathrm{~nm}$, concordando com o observado por Kadish ${ }^{17}$ para a terceira redução. A espécie MP, fruto da primeira redução dos anéis piridínio deve apresentar banda na região de $550 \mathrm{~nm}$, característica da redução de 1 elétron de viologênios substituídos ${ }^{17,131}$. Na eletrólise em $-1100 \mathrm{mv}$ da ZnTBzPyP é possivel observar a presença de um ombro nos espectros intermediários em $532 \mathrm{~nm}$, mas não se pode confirmar a atribuição apresentada por Kadish. 

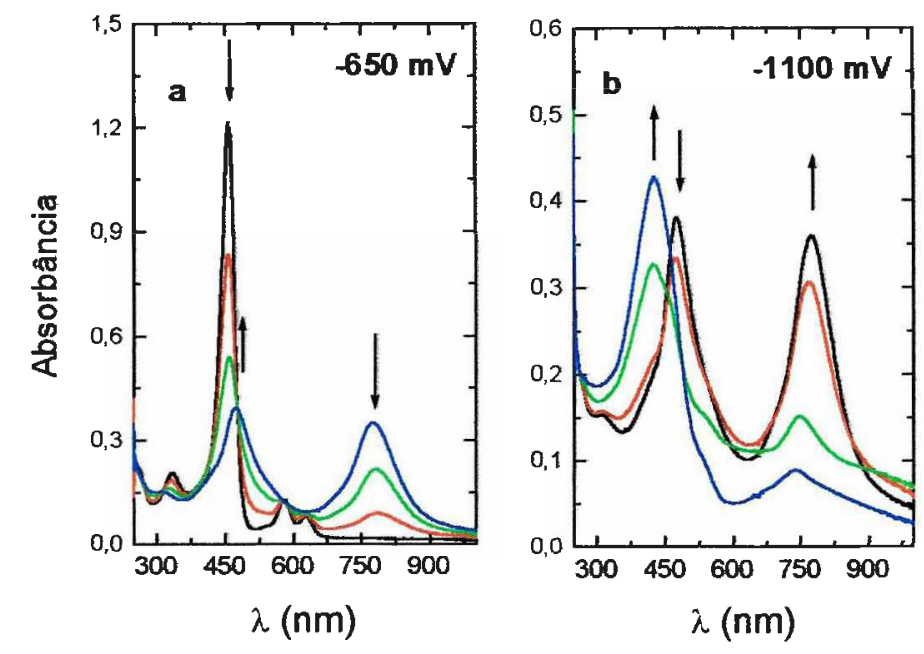

figura 49: Espectro eletrônico (UV-Vis) das espécies reduzidas da ZnTBzPyP (0,2 mmol dm ${ }^{-3}$ ) em DMF $\left(0,1 \mathrm{~mol} \mathrm{dm}^{-3}\right.$ de TEAP). a- eletrólise em $-650 \mathrm{mV}$; b- eletrólise em $-1100 \mathrm{mV}$.

\subsubsection{Eletroquímica das Cobreporfirinas}

As cobre(II) porfirinas benzilpiridínio substituídas apresentaram comportamento eletroquímico diverso ao observado para as respectivas zincoporfirinas. As três ondas de redução e oxidação apresentam-se bem definidas nos voltamogramas cíclicos e não se nota a formação de produtos que não participam dos pares redox em cada processo. De qualquer modo, não foram verificadas as condições de um processo reversível controlado por difusão (equaçōes (1) e (2)), diferindo dos dados da literatura para a CuTMPyP.

A intensidade de corrente catódica continua superior à corrente nos processos de oxidação e a diferença entre os picos das ondas é bem superior aos $30 \mathrm{mV}$ esperados. Além disso, a velocidade de varredura modifica os potenciais dos picos de onda $\left(E_{p}\right)$ e os valores de $E_{1 / 2}$.

A voltametria cíclica da $\mathrm{CuTNO}_{2} \mathrm{BzPyP}$ (figura 50c) apresenta quatro ondas de redução no intervalo de $0,0 \mathrm{~V}$ a $-1,2 \mathrm{~V}$. Os três primeiros processos referem-se a redução do anel porfirinico e dos anéis piridínio, já o quarto processo deve estar relacionado à redução dos grupos nitro. A correrite na quarta onda é bem maior, indicando um processo que envolve a inserção de quatro elétrons. $E$ interessante notar que a $\mathrm{CuTNO}_{2} \mathrm{BzPyP}$ apresenta os três primeiros processos de redução em potenciais mais baixos do que a $\mathrm{ZnTNO} \mathrm{TN}_{2} \mathrm{BzPyP}$, não ocorrendo a redução dos grupos nitro sobreposto à redução do anel piridínio. Aparentemente, a separação dos processos em potenciais bem definidos evita a formação do subproduto eletroinerte observado na voltametria da $\mathrm{ZnTNO}_{2} \mathrm{BzPyP}$. 

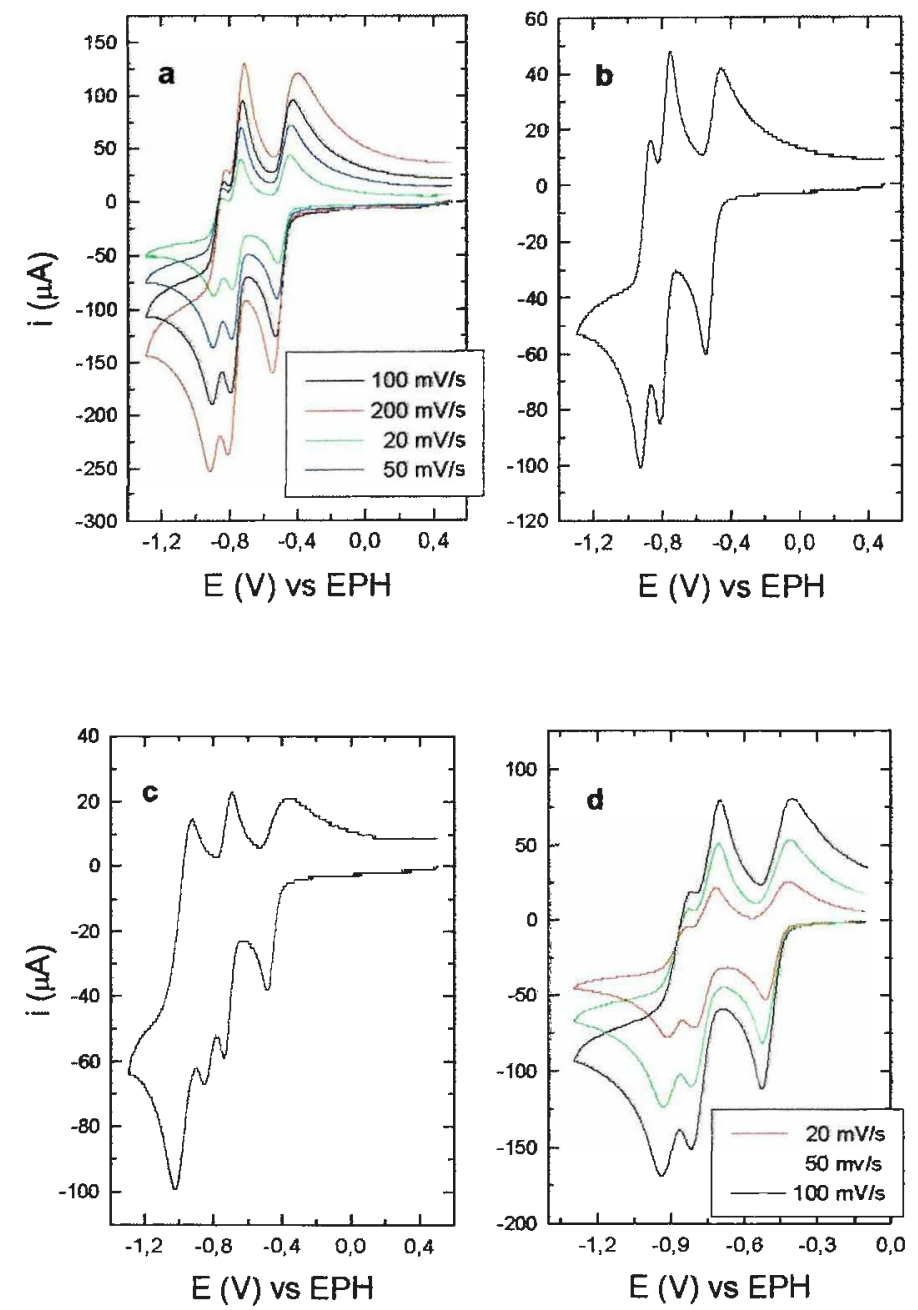

figura 50: Voltamogramas ciclicos em DMF (TEAP 0,1 $\mathrm{mol} \mathrm{dm}^{-3}$ ):

a- CuTMeOBzPyP, várias velocidades; b-CuTPhPrPyP, v $=50 \mathrm{mV} / \mathrm{s}$;

c- CuTNO ${ }_{2} B z P y P, v=50 \mathrm{mV} / \mathrm{s} ; \mathrm{d}-\mathrm{CuTCH}_{3}$ BzPyP, várias velocidades.

A figura 50d mostra que mesmo em velocidades de varredura baixas não se verifica a onda de oxidação em $-0,3 \mathrm{~V}$ para a $\mathrm{CuTCH}_{3} \mathrm{BzPyP}$, indicando que a presença dessa onda nos voltamogramas dos derivados $\mathrm{Zn}(\mathrm{II})$ porfirínicos é uma característica das porfirinas benzilpiridínio substituídos que depende do metal coordenado.

A análise dos valores de $E_{p c}$ e $E_{1 / 2}$ das tabelas 14 e 15 evidencia o efeito do metal nos processos de redução do macrociclo e dos anéis periféricos. A relação entre o potencial de redução da metaloporfirina e a eletronegatividade do metal já haviam sido relatadas na literatura ${ }^{17},{ }^{132}$, portanto, já era de se esperar que as cobre(II) porfirinas apresentassem potenciais de redução mais altos que os zinco derivados. 
tabela 15: $E_{p c}, E_{p a} \in E_{1 / 2}$ para as cobreporfirinas $(v=100 \mathrm{mV} / \mathrm{s})$

\begin{tabular}{|c|c|c|c|c|}
\hline \multicolumn{2}{|l|}{ Porfirinas } & $E_{p c}(V)$ & $E_{p a}(V)$ & $E_{1 / 2}(V)$ \\
\hline CuTBzPyP & $\begin{array}{l}1^{a} \text { onda } \\
2^{a} \text { onda } \\
3^{a} \text { onda }\end{array}$ & $\begin{array}{l}-0,519 \\
-0,787 \\
-0,884\end{array}$ & $\begin{array}{l}-0,427 \\
-0,721 \\
-0,825\end{array}$ & $\begin{array}{l}-0,49 \\
-0,77 \\
-0,86\end{array}$ \\
\hline CuTMeOBzPyP & $\begin{array}{l}1^{a} \text { onda } \\
2^{a} \text { onda } \\
3^{a} \text { onda }\end{array}$ & $\begin{array}{l}-0,535 \\
-0,800 \\
-0,909\end{array}$ & $\begin{array}{l}-0,429 \\
-0,727 \\
-0,836\end{array}$ & $\begin{array}{l}-0,51 \\
-0,78 \\
-0,88\end{array}$ \\
\hline $\mathrm{CuTCH}_{3} \mathrm{BzPyP}$ & $1^{a}$ onda & $-0,529$ & $-0,407$ & $-0,51$ \\
\hline & $\begin{array}{l}2^{a} \text { onda } \\
3^{a} \text { onda }\end{array}$ & $\begin{array}{l}-0,821 \\
-0,939\end{array}$ & $\begin{array}{l}-0,703 \\
-0,821\end{array}$ & $\begin{array}{l}-0,80 \\
-0,91\end{array}$ \\
\hline CuTCNBzPyP & $\begin{array}{l}1^{\mathrm{a}} \text { onda } \\
2^{\mathrm{a}} \text { onda } \\
3^{\mathrm{a}} \text { onda }\end{array}$ & $\begin{array}{l}-0,513 \\
-0,763 \\
-0,870\end{array}$ & $\begin{array}{l}-0,360 \\
-0,676 \\
-0,787\end{array}$ & $\begin{array}{l}-0,48 \\
-0,74 \\
-0,84\end{array}$ \\
\hline CuTPrфPyP & $\begin{array}{l}1^{a} \text { onda } \\
2^{a} \text { onda } \\
3^{a} \text { onda }\end{array}$ & $\begin{array}{l}-0,559 \\
-0,826 \\
-0,941\end{array}$ & $\begin{array}{l}-0,449 \\
-0,747 \\
-0,864\end{array}$ & $\begin{array}{l}-0,54 \\
-0,81 \\
-0,92\end{array}$ \\
\hline $\mathrm{CuTNO}_{2} \mathrm{BzPyP}$ & $1^{2}$ onda & $-0,484$ & $-0,393$ & $-0,47$ \\
\hline & $\begin{array}{l}2^{a} \text { onda } \\
3^{a} \text { onda } \\
4^{a} \text { onda }\end{array}$ & $\begin{array}{l}-0,752 \\
-0,871 \\
-1,050\end{array}$ & $\begin{array}{l}-0,687 \\
\approx-0,81 \\
-0,921\end{array}$ & $\begin{array}{l}-0,73 \\
-0,84 \\
-1,00\end{array}$ \\
\hline
\end{tabular}

O dado mais relevante, entretanto, é o efeito do substituinte benzílico nos potenciais dos três processos de redução. Para os $\mathrm{Cu}$ (II) e $\mathrm{Zn}$ (II) derivados verificouse que os substituintes aceptores de elétrons facilitam a redução, tanto do macrociclo, quanto dos anéis piridínio. Já os grupos doadores de elétrons dificultam a entrada de elétrons nos macrociclos. Esses dados estão de acordo com o esperado, pois se o anel está mais deficiente de elétrons mais fácil deve ser a sua redução. Nota-se que a segunda e a terceira reduções sofrem um efeito maior do substituinte benzílico do que a primeira, esse dado concorda com a proposta de Kadish de que esses processos referem-se à redução do anel piridínio. Dados da eletroquímica de viologênios ${ }^{133}$ substituídos por grupos benzil e p-nitrobenzil mostram que a redução do anel piridínio ocorre em potenciais mais positivos (mais fácil) para o p-nitrobenzilviologênio, concordando com os dados do nosso estudo.

A espectroeletroquímica para as $\mathrm{CuTCH}_{3}$ BzPyP (figura 52) segue o relatado por Kadish para a CuTMPyP e o observado para a ZnTMPyP, entretanto os espectros eletrônicos dos produtos de redução da $\mathrm{CuTNO}_{2} \mathrm{BzPyP}$ são bastante diferentes (figura 51). A banda na região de $800 \mathrm{~nm}$, que indica a redução do anel porfirínico não desaparece durante a segunda redução, sofrendo um deslocamento hipsocrômico de $20 \mathrm{~nm}$ e aumentando de intensidade (15\%). Na terceira redução ocorre alargamento dessa banda e a formação de uma banda larga na região de $550 \mathrm{~nm}$. Durante a última redução, finalmente desaparece a banda na região de $800 \mathrm{~nm}$, e verifica-se um 
aumento de intensidade da banda larga em $550 \mathrm{~nm}$. Apenas o espectro eletrônico não é suficiente para atribuir os produtos formados a partir da segunda onda de redução, entretanto é possivel presumir que os processos para a $\mathrm{CuTNO}_{2} \mathrm{BzPyP}$ são diferentes do que para as demais porfirinas.

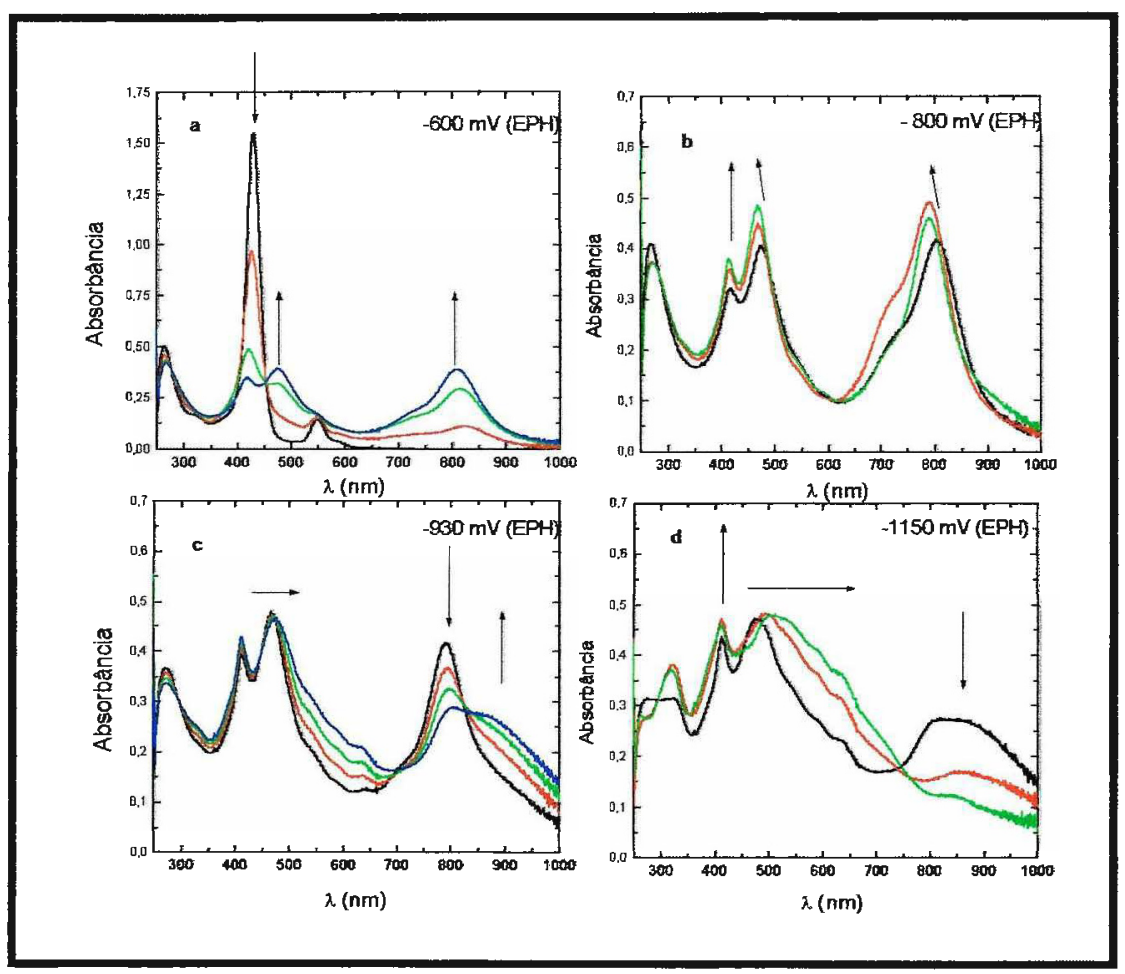

figura 51: Espectros Eletrônicos resolvidos no tempo da eletrólise da CuTNO ${ }_{2} \mathrm{BzPyP}\left(0,3 \mathrm{mmol} \mathrm{dm}^{-3}\right)$ em DMF/TEAP $0,1 \mathrm{~mol} \mathrm{dm}^{-3}$.
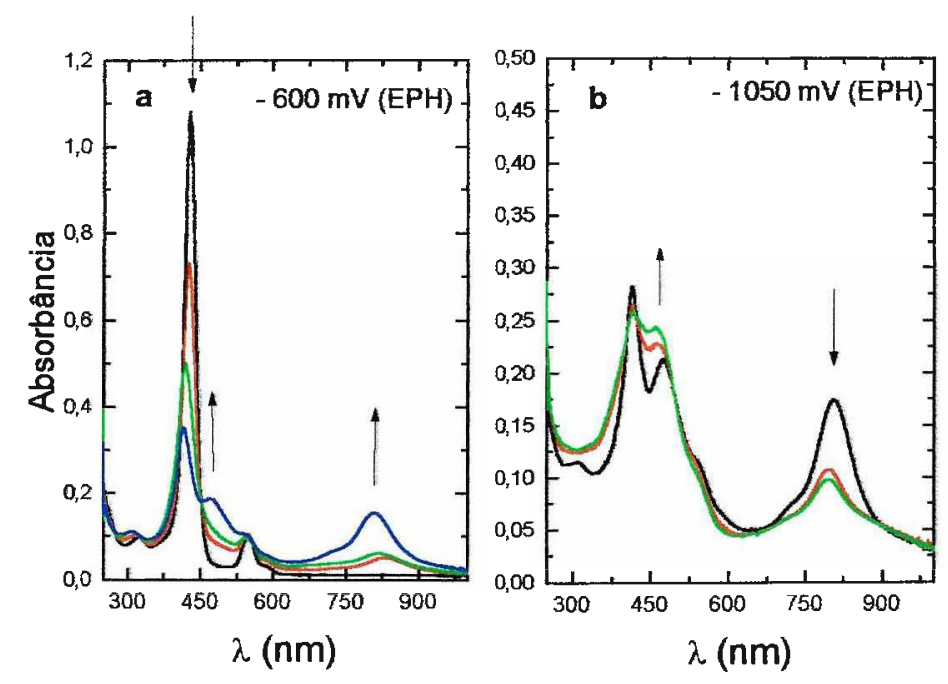

figura 52: Espectros Eletrônicos resolvidos no tempo da eletrólise da $\mathrm{CuTCH}_{3} \operatorname{BzPyP}\left(0,2 \mathrm{mmol} \mathrm{dm}^{-3}\right)$ em DMF/TEAP $0,1 \mathrm{~mol} \mathrm{dm}^{-3}$. 


\subsubsection{Eletroquímica das Bases Livres}

Os voltamogramas cíclicos das bases livres em DMF são complexos e não seguem o mesmo padrão apresentado dos respectivos metaloderivados. As figuras 48 e 49 mostram a diversidade qualitativa dos voltamogramas cíclicos da $\mathrm{H}_{2}$ TBzPyP, $\mathrm{H}_{2} \mathrm{TMeOBzPyP}$ e $\mathrm{H}_{2} \mathrm{TNO}_{2}$ BzPyP em DMF. Nota-se que nenhuma das porfirinas apresenta uma onda bem definida para a primeira redução. Em água, esse processo é irreversivel para a $\mathrm{H}_{2} \mathrm{TMPyP}$, devido a formação de hidroporfirina ${ }^{122}$. A quantidade de água no DMF utilizado não deve ser suficiente para a protonação da espécie reduzida, porém deve ser formado uma nova espécie, pois a onda de oxidação é bastante deformada.

Novamente, a $\mathrm{H}_{2} \mathrm{TNO}_{2} \mathrm{BzPyP}$ apresenta comportamento distinto das demais. Verificou-se a presença de mais três processos de redução. Os dois primeiros não apresentam nenhuma onda correspondente no sentido anódico. A última redução (em $-1,0$ V) apresenta um processo de oxidação correspondente, com alta intensidade de corrente, tanto no sentido anódico quanto no catódico. Esse processo é atribuído à redução do grupo nitro. A segunda onda de oxidação deve estar relacionada aos produtos formados nas três primeiras reduções. Varrendo apenas a primeira onda $(-0,6 \mathrm{~V})$ nota-se um par redox $\left(\mathrm{P}^{4+} / \mathrm{P}^{2+}\right)$ quase reversivel, indicando que a segunda e a terceira redução devem ser responsáveis pela formação de novos produtos com potencial de oxidação próximo ao par $\mathrm{P}^{4+} / \mathrm{P}^{2+}$ (ver figura 53).
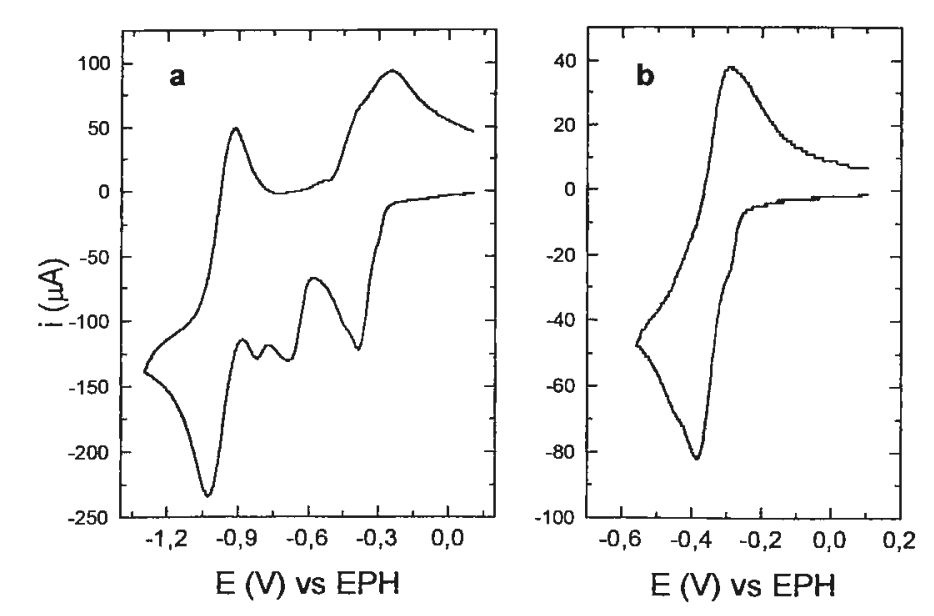

figura 53: Voltamogramas cíclicos da $\mathrm{H}_{2} \mathrm{TNO}_{2} \mathrm{BzPyP}$ em DMF (TEAP 0,1 $\mathrm{mol} \mathrm{dm}^{-3}$ ). a- $0,10 \mathrm{Va}-1,3 \mathrm{~V}(\mathrm{v}=100 \mathrm{mV} / \mathrm{s}) ;$ b- $0,10 \mathrm{~V}$ a $-0,6 \mathrm{~V}(\mathrm{v}=50 \mathrm{mV} / \mathrm{s})$.

A $\mathrm{H}_{2}$ TBzPyP e a $\mathrm{H}_{2}$ TMeOBzPyP apresentam formato das ondas bastante distintos, entretanto pode-se identificar dois processos de redução não reversíveis em cada voltamograma (ver figura 54). A onda de oxidação na $\mathrm{H}_{2} \mathrm{TBzPyP}$ deve se referir aos produtos das duas reduções. Não foram obtidos dados suficientes para atribuições 
dos processos eletroquímicos das bases livres, além de uma sensível lacuna na literatura para sistemas similares em solventes orgânicos. Entretanto, foi possivel perceber que os processos envolvidos são mais complexos que das respectivas metaloporfirinas e novos experimentos devem ser realizados para melhor elucidar os dados obtidos até o momento.

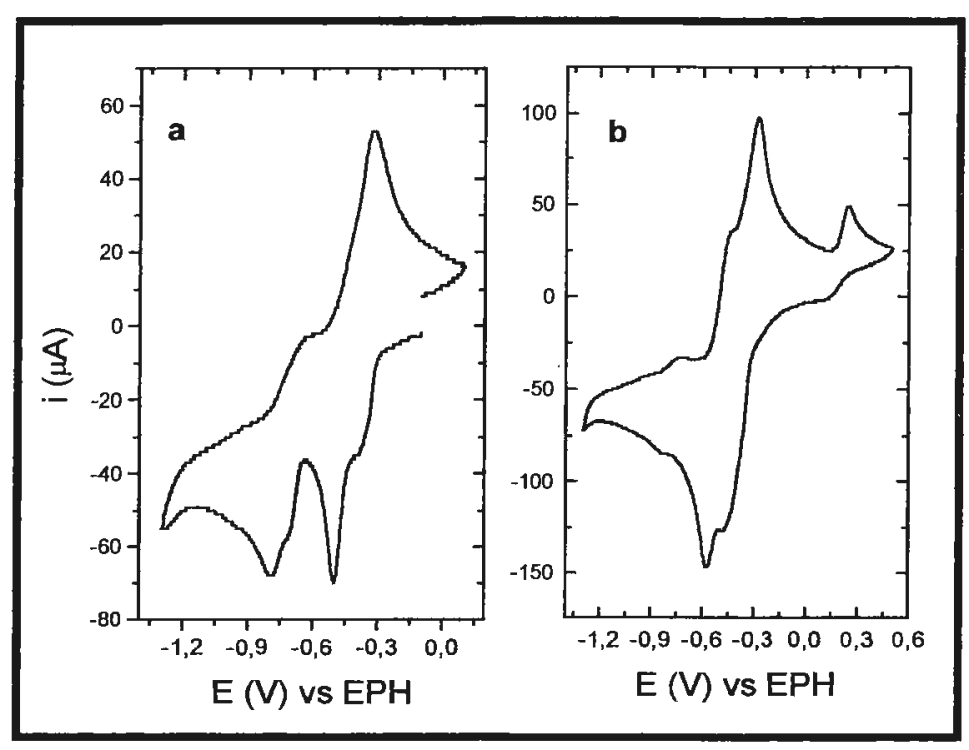

figura 54: Voltamogramas cíclicos em DMF (TEAP $0,1 \mathrm{~mol} \mathrm{dm}^{-3}$ ) com $v=100$ mV/s. a- $\mathrm{H}_{2}$ TBzPyP; b- $\mathrm{H}_{2}$ TMeOBzPyP.

A espectroeletroquímica da $\mathrm{H}_{2}$ TMeOBzPyP evidencia que a primeira redução é processo da entrada de 2 elétrons no macrociclo porfirínico, pois observa-se o desaparecimento da banda Soret e o aparecimento de uma banda em $770 \mathrm{~nm}$. A segunda redução tem efeito no espectro eletrônico muito semelhante ao verificado para a $\mathrm{CuTCH}_{3} \mathrm{BzPyP}$, com duas bandas na região da Soret. A figura 55 apresenta os espectros eletrônicos resolvidos no tempo para a eletrólise da $\mathrm{H}_{2}$ TMeOBzPyP.

É necessário um maior aprofundamento nos estudos de voltametria cíclica e espectroeletroquímica para uma melhor atribuição dos processos de eletroquímicos das bases livres, uma vez que a literatura não formece dados suficientes para uma comparação. 


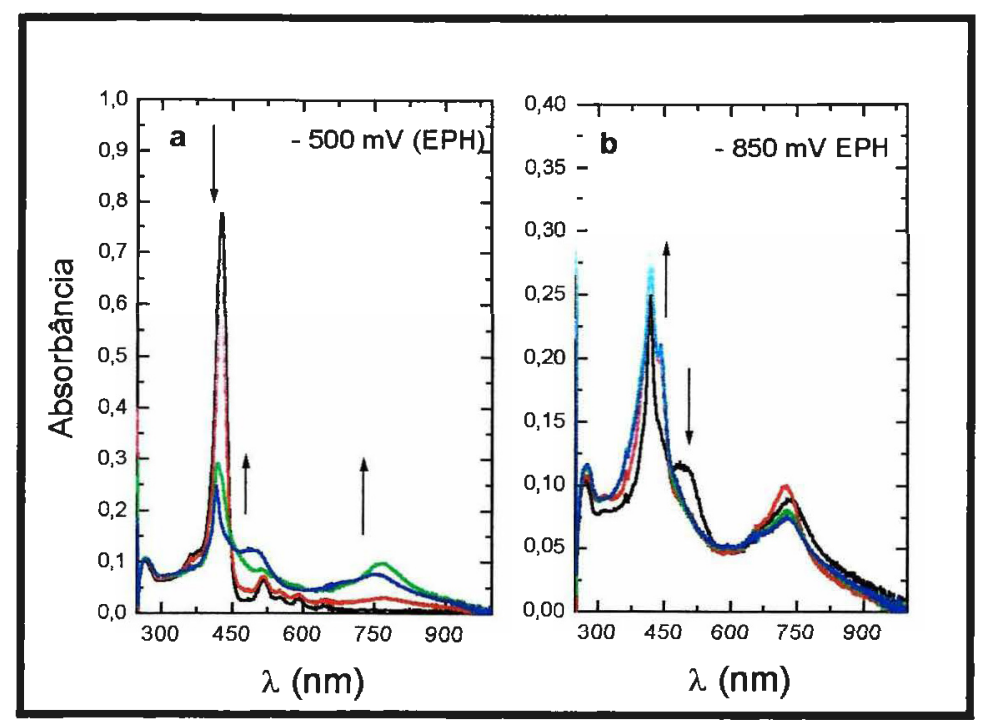

figura 55: Espectros Eletrônicos resolvidos no tempo da eletrólise da $\mathrm{H}_{2}$ TMeOBzPyP $\left(0,15 \mathrm{mmol} \mathrm{dm}^{-3}\right)$ em DMF/TEAP $0,1 \mathrm{~mol} \mathrm{dm}^{-3}$.

\subsubsection{Eletroquímica da Fe"'TBzPyP e Mn"'TBzPyP}

Os voltamogramas da Fe"l'TBzPyP e Mn"'TBzPyP diferem dos voltamogramas da ZnTBzPyP e CuTBzPyP, uma vez que os metais coordenados são eletroativos na faixa de potencial analisada $(0,8$ a $-1,4 \mathrm{~V}$ vs $E P H)$.

A onda de redução $\mathrm{Fe}^{3+} / \mathrm{Fe}^{2+}$ possui metade da intensidade de corrente da primeira redução do ligante (anel porfirínico), sendo mais uma evidência que essa etapa envolve dois elétrons. Apenas mais uma onda de redução é observada, indicando que as reduções dos piridinios ocorrem simultaneamente para esse derivado, pois a onda de redução não apresenta indícios de ser sobreposição de dois processos que ocorrem em potenciais próximos. Entretanto, a intensidade de corrente dessa onda é menor que a esperada, indicando o envolvimento de três elétrons nesse processo e não quatro.

Uma pequena onda é observada próxima da onda referente à redução do anel porfirínico. Descartou-se a possibilidade de ser proveniente de impureza $\left(\mathrm{H}_{2} \mathrm{TBzPyP}\right.$, não metalada), uma vez que está em um potencial mais elevado do que no voltamograma da $\mathrm{H}_{2}$ TBzPyP (seção 3.4.3). Como pode ser observado na figura 56 , as ondas de oxidação referentes ao pares redox do ligante porfirínico são deformadas, indicando a ocorrência de mais de um processo nesses potenciais. Mais uma vez, é possivel atribuir essas deformações nas ondas anódicas aos produtos de redução dos anéis piridínio, na figura $56 \mathrm{~b}$ percebe-se que ao varrermos apenas até a onda de redução do macrociclo a respectiva onda de oxidação é muito melhor definida. 


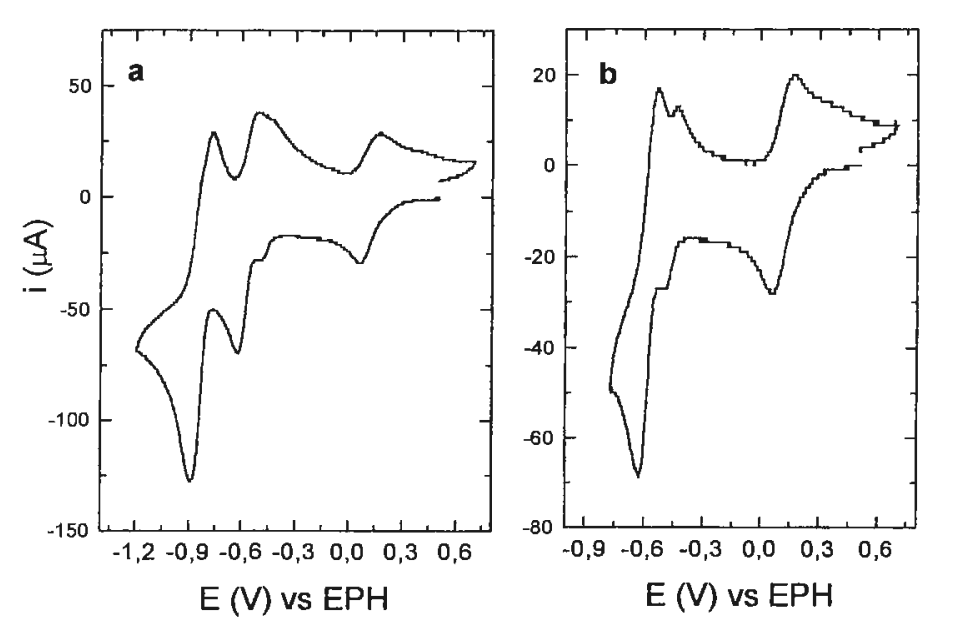

figura 56: Voltamogramas cíclicos da Fe $\mathrm{I}^{\mathrm{II}} \mathrm{TBzPyP}$ em DMF (TEAP $0,1 \mathrm{~mol} \mathrm{dm}^{-3}$ ). a$0,7 \vee a-1,2 \vee(v=50 \mathrm{mV} / \mathrm{s}) ; b-0,7 \mathrm{~V}$ a $-0,8 \mathrm{~V}(v=50 \mathrm{mV} / \mathrm{s})$.

O voltamogramas cíclico da Mn"llTBzPyP (figura 57) apresenta processo de redução envolvendo 5 elétrons no total, são similares aos apresentados por Kadish e coautores $^{121}$. As ondas referentes ao par redox $\mathrm{Mn}^{3+} / \mathrm{Mn}^{2+}$ são pouco definidas, com baixa intensidade de corrente. O segundo processo de redução do ligante porfirínico apresenta intensidade de corrente similar à da primeira redução, indicando que o processo envolve dois elétrons. Não foram identificados outros processos de redução nas diferentes velocidades de varredura. Kadish relata uma sobreposição de três processos na segunda redução do ligante porfirínico envolvendo dois elétrons no total. Essa sobreposição seria devido ao equilíbrio entre os contra-íons da porfirina ( $\mathrm{Cl}^{-}$) e do eletrólito suporte $\left(\mathrm{ClO}_{4}{ }^{-}\right)$, influenciando o potencial de redução dos anéis piridínio $^{121}$. Apesar do sistema utilizado no estudo da Mn ${ }^{11 ! T B z P y P}$ possuir os mesmos ânions observou-se apenas um processo nas condições estudadas.

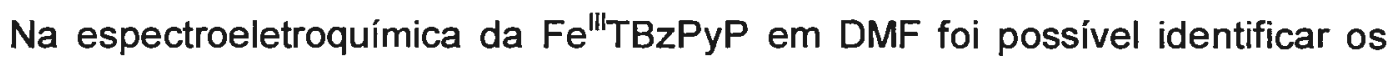
três processos de redução previstos na voltametria cíclica. A redução do metal central $\left(\mathrm{Fe}^{3+} / \mathrm{Fe}^{2+}\right)$ é verificada com o aumento da banda Soret $(438 \mathrm{~nm})$ e deslocamento para a região do violeta das bandas $Q$. A figura $58 \mathrm{~b}$ apresenta os espectros característicos da redução do anel porfirínico com desaparecimento da banda Soret, e o aparecimento de duas bandas $(473 \mathrm{~nm}$ e $795 \mathrm{~nm})$ referentes à espécie FeTBzPyP ${ }^{2+}$. A redução do anel piridínio (figura 58c) causa o desaparecimento da banda em $795 \mathrm{~nm} e$ o deslocamento hipsocrômico da banda em $473 \mathrm{~nm}$ para $438 \mathrm{~nm}$ e aumento da absortividade por mol dessa banda. Os espectros obtidos após as reduções do ligante porfirínico são equivalentes aos apresentados para a ZnTBzPyP. 


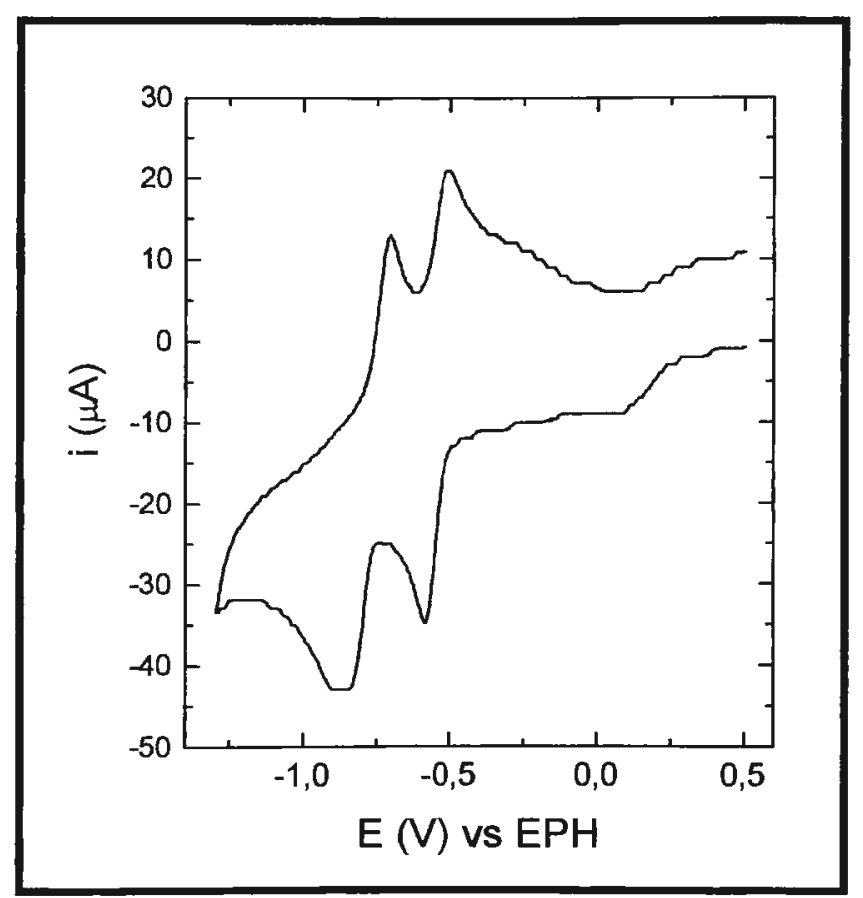

figura 57: Voltamograma ciclico da Mn'TBzPyP em DMF (TEAP $0,1 \mathrm{~mol} \mathrm{dm}^{-3}$ ), $v=100 \mathrm{mV} / \mathrm{s}$.

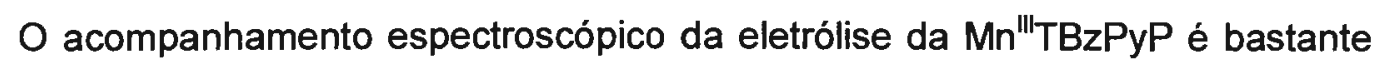
similar ao da Fe"l'TBzPyP. A onda de redução do par $\mathrm{Mn}^{3+} / \mathrm{Mn}^{2+}$ é evidenciada pela eletrólise em -200 mV (EPH). Nota-se um aumento de intensidade na banda de transferência de carga (472 nm), menor definição no desdobramento da banda Soret $(370 \mathrm{~nm})$ e aumento da intensidade na banda $Q(0,0)$, similares ao observados na literatura $^{121}$. As duas reduções posteriores referentes ao ligante porfirínico produzem espécies que têm espectros eletrônicos similares aos discutidos para a ZnTBzPyP e Fe"l'TBzPyP (figura 59).

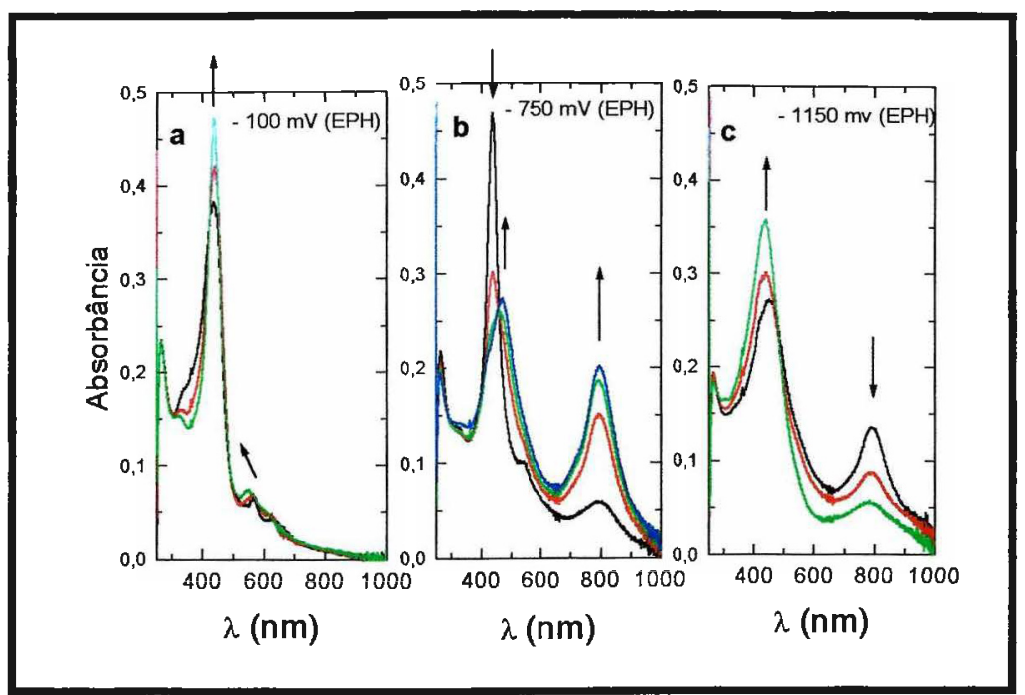

figura 58: Espectros eletrônicos resolvidos no tempo da eletrólise da Fe"TBzPyP $\left(0,10 \mathrm{mmol} \mathrm{dm}^{-3}\right)$ em DMF/TEAP $0,1 \mathrm{~mol} \mathrm{dm}^{-3}$. 


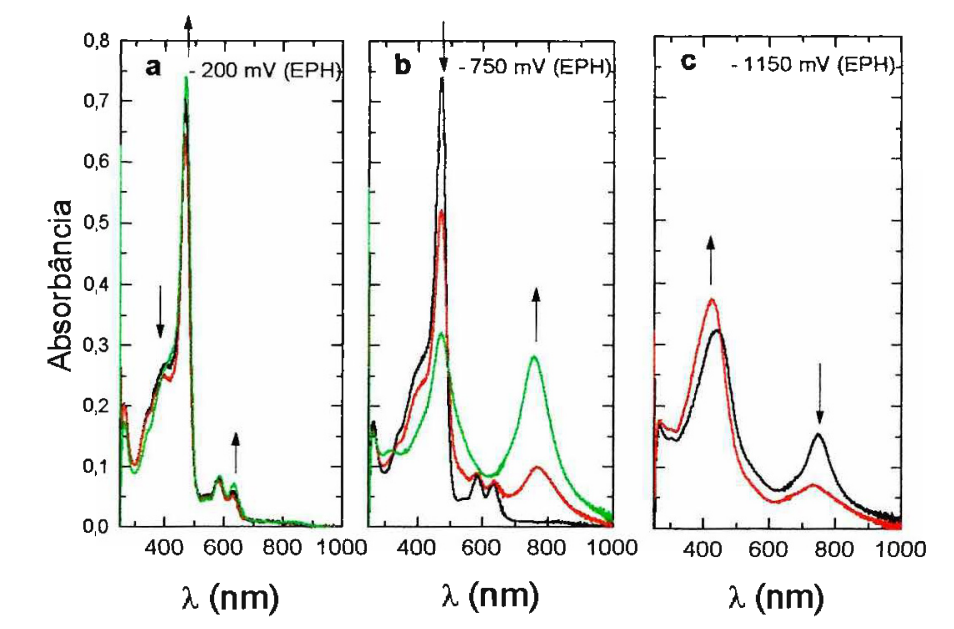

figura 59: Espectros eletrônicos resolvidos no tempo da eletrólise da Mn"'TBzPyP $\left(0,18 \mathrm{mmol} \mathrm{dm}^{-3}\right)$ em DMF/TEAP $0,1 \mathrm{~mol} \mathrm{dm}^{-3}$.

\subsection{Espectroscopia Vibracional (I.R. e Raman Ressonante)}

O espectro na região do infravermelho tem grande utilidade na caracterização de porfirinas e metaloporfirinas substituídas, principalmente na identificação dos grupos funcionais substituintes ${ }^{134,135}$. Além disso, a técnica permite verificar se houve redução do anel porfirínico ${ }^{136}$ e inferir sobre a estrutura e a conformação eletrônica da molécula $^{137}$. O estudo apresentado nesse item procura complementar a caracterização e atribuição dos espectros vibracionais na região do infravermelho das porfirinas piridinio substituídas na forma base livre iniciado em trabalho anterior ${ }^{22}$. Foram importantes no trabalho de análise comparativa a inserção dos espectros de I.R. dos novos derivados porfirínicos sintetizados além da obtenção dos espectros Raman Ressonante dos derivados benzil piridínio substituídos obtidos.

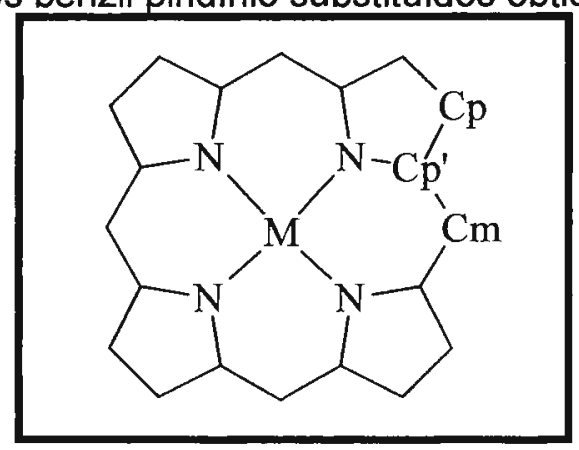

figura 60: Estrutura da porfirina e designações dos átomos utilizados nas atribuiçōes das vibrações do anel ${ }^{138}$.

O espectro na região do infravermelho de porfirinas meso substituidas apresenta grande número de bandas na região de $1.100-1250 \mathrm{~cm}^{-1}$, referentes às vibrações do anel porfirinico e deformações angulares C-H. A região de 1350-1600 
$\mathrm{cm}^{-1}$ possui bandas com origem nas "respiração" dos anéis aromáticos. Toda porfirina meso substituída apresenta banda intensa em $800 \mathrm{~cm}^{-1}$, devido à deformação angular fora do plano $\mathrm{Cp}-\mathrm{H}^{139}$ (figura 60).

As metaloporfirinas apresentam bandas sensiveis aos diferentes metais coordenados; estas bandas sofrem deslocamentos conforme a natureza do metal $^{137,140}$. Esse efeito está relacionado às pequenas alterações eletrônicas no macrociclo, causadas pelas interações indutivas e mesoméricas entre o metal e o sítio de coordenação, e também à geometria do anel porfirínico na coordenação do metal. Porfirinas coordenadas com Pd, Pt ou Ni tendem a uma geometria planar, aumentando o caráter $\pi$ das ligações do macrociclo e deslocando as bandas sensiveis para regiões de maior energia. Outros metais, como $\mathrm{Zn}$ e Ag, localizam-se fora do plano do macrociclo porfirínico, diminuindo o caráter $\pi$ do anel, o que resulta em deslocamentos para regiões de menor energia.

$\mathrm{Na}$ região de $1000 \mathrm{~cm}^{-1}$ encontram-se duas bandas referentes aos estiramentos do anel porfirínico, que apresentam grande sensibilidade ao metal coordenado ${ }^{137},{ }^{141}$. Estas bandas são importantes na identificação de porfirinas $\mathrm{N}$-pirrol alquiladas (um possivel subproduto na reação de alquilação da $\mathrm{H}_{2} \operatorname{TPyP}^{22}$ ), uma vez que essas porfirinas apresentam menor simetria, ocorrendo o desdobramento das duas bandas em três. As três bandas são menos sensiveis à substituição do metal coordenado, pois o sítio de coordenação é menos constrito ${ }^{141}$.

Os espectros no infravermelho de porfirinas $\mathrm{N}$-pirrol alquiladas apresentam desdobramentos das bandas referentes às demais vibrações do anel porfirínico devido à menor simetria deste ${ }^{141}$. Estas bandas desdobram-se, geralmente, em duas: uma referente aos três pirróis equivalentes e outra ao pirrol alquilado.

Todas as porfirinas analisadas possuem apenas duas bandas na região de $1000 \mathrm{~cm}^{-1}$ : uma banda de menor intensidade em $1003 \mathrm{~cm}^{-1}$ e outro em $970 \mathrm{~cm}^{-1}$, atribuídas às vibrações $v\left(C p^{\prime}-N\right)$ e $v\left(C p-C p^{\prime}\right)$. Esse padrão indica que o nitrogêrnio pirrólico das porfirinas não foi alquilado.

A análise e atribuições das bandas dos espectros obtidos para as porfirinas benzilpiridínio substituídas, $\mathrm{H}_{2}$ TMPyP e $\mathrm{H}_{2}$ TPyP são baseadas em comparações de atribuições realizadas por outros autores para a $H_{2}$ TPP e outros derivados. A nomenclatura utilizada segue a proposta por Ogoshi e co-autores ${ }^{138}$ em trabalho sobre metaloporfinas.

Ampliando o estudo apresentado anteriormente ${ }^{22}$, foram obtidos os espectros de infravermelho em pastilha de $\mathrm{KBr}$ de todas as porfirinas benzilpiridinio substituidas 
sintetizadas nesse trabalho. Foram obtidos os espectros raman ressonante do sólido puro das bases livres com o intuito de contribuir na discussão do efeito do substituinte nas vibrações do macrociclo. Outro fator de interesse no espectro raman ressonante é que é possível encontrar na literatura análise dos espectros da $\mathrm{H}_{2} \mathrm{TMPyP}^{142}$, enquanto que as referências de IR estão limitadas às $\mathrm{H}_{2}$ TPP e seus derivados.

A linha do laser de Ar utilizada na excitação da amostra no espectro raman possui um comprimento de onda $(457 \mathrm{~nm}$ ) próximo aos máximos das bandas Soret, o que propicia uma ressonância entre o cromóforo (anel porfirínico) e a onda de excitação, resultando numa intensificação das bandas referentes as vibrações do anel porfirínico e dos piridínios. Os substituintes benzilicos não devem participar dessa ressonância e provavelmente as bandas referentes ao anel benzílico não devem estar intensificadas nos espectros raman apresentados nessa tese.
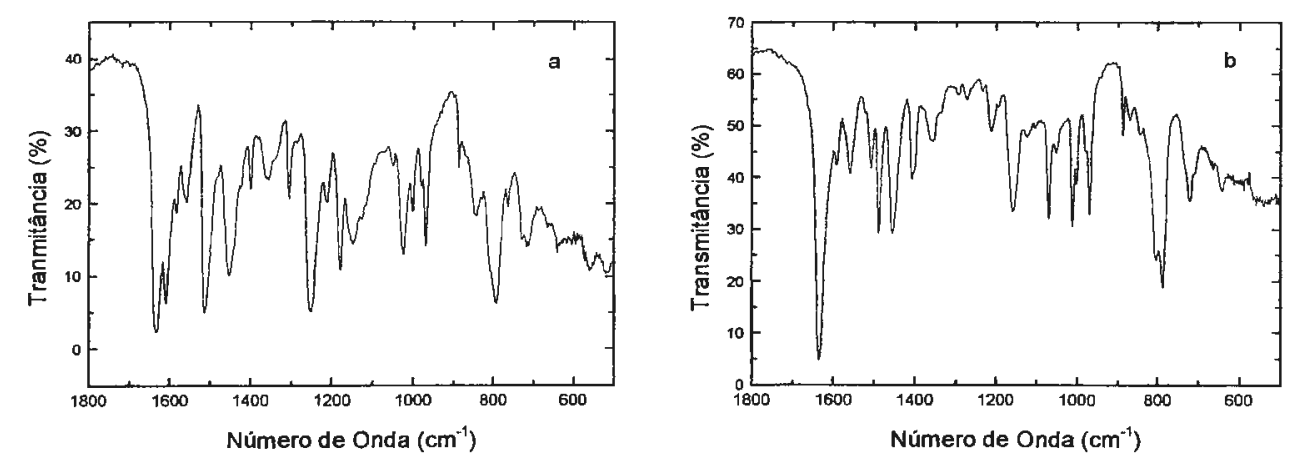

figura 61: Espectros de I.R. em pastilha de $\mathrm{KBr}$; $\mathrm{a}-\mathrm{H}_{2} \mathrm{TBrBzPyP} ; \mathrm{b}-\mathrm{H}_{2} \mathrm{TMeOBzPyP}$.

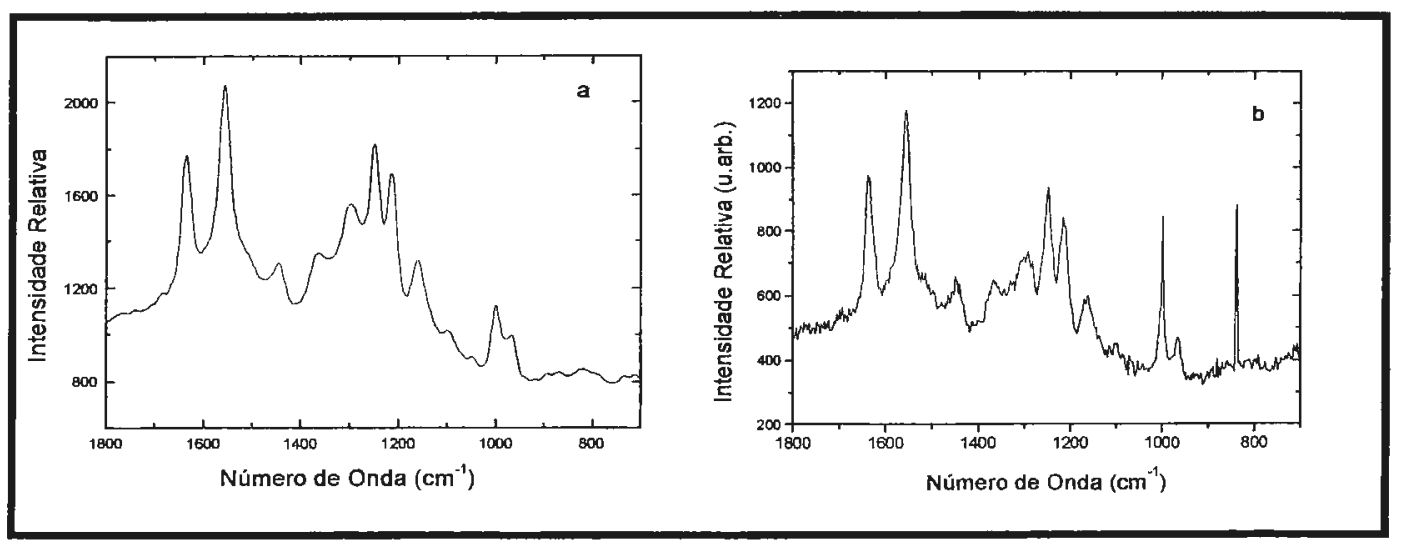

figura 62: Espectros de raman ressonante; $a-\mathrm{H}_{2} \mathrm{TBrBzPyP} ; \mathrm{b}-\mathrm{H}_{2} \mathrm{TNO}_{2} \mathrm{BzPyP}$.

As tabelas 16, 17 e 18 resumem as bandas analisadas dos espectros obtidos e suas respectivas propostas de atribuição.

Todos os espectros obtidos apresentam bandas largas e intensas em $3400 \mathrm{~cm}^{-1}$ e em $1635 \mathrm{~cm}^{-1}$, atribuídas ao estiramento e à deformação angular da água, respectivamente, $v(\mathrm{OH})$ e $\delta(\mathrm{OH})^{134}$. A presença dessas bandas justifica a 
correção dos valores obtidos de análise elementar, adicionando moléculas de água de hidratação na fórmula molecular. $\mathrm{O}$ espectro de I.R. da $\mathrm{H}_{2}$ TPyP apresenta bandas referentes à água bem menos intensas, pois o composto possui apenas uma água de hidratação na sua composição nominal.

tabela 16: Bandas e atribuições dos espectros de infravemelho

\begin{tabular}{|c|c|c|c|c|}
\hline atribuicoes & $\begin{array}{l}\mathrm{H}_{2} T \mathrm{P} \text { P } \\
y\left(\mathrm{~cm}^{-1}\right)\end{array}$ & $\begin{array}{l}\mathrm{H}_{2} \mathrm{TMP}^{-1} \mathrm{P} \\
\mathrm{y}\left(\mathrm{cm}^{-1}\right)\end{array}$ & $\begin{array}{c}H_{2} \text { TphEtPyP } \\
\left.\text { (cm }{ }^{-1}\right)\end{array}$ & $\begin{array}{c}\mathrm{H}_{2} \text { TPAPRPP } \\
\mathrm{v}\left(\mathrm{cm}^{-1}\right)\end{array}$ \\
\hline$\delta(\mathrm{CCN}) ; \delta(\mathrm{OH})$ & -- & 1641 (MF) & $1635(\mathrm{MF})$ & 1635 (MF) \\
\hline$v(C-C)$ aromático & - & - & $1602(0)$ & $1602(0)$ \\
\hline$v(C-C)$ piridina & 1594 (MF) & - & - & - \\
\hline ? & -_ & $1571(\mathrm{~m})$ & $\ldots$ & . \\
\hline$v(C-C)$ aromático & $1555(f)$ & $1561(\mathrm{~m})$ & $1561(\mathrm{~m})$ & $1562(\mathrm{~m})$ \\
\hline$v(C p-C p)$ & 1542 (f) & $\ldots$ & - & - \\
\hline$v\left(C p-C p^{\prime}\right) ; v\left(C p^{\prime}-N\right)$ & - & $1510(\mathrm{~m})$ & $1509(\mathrm{~m})$ & $1508(\mathrm{~m})$ \\
\hline$v(C-C)$ fenilico & - & -- & $1498(m)$ & $1497(\mathrm{~m})$ \\
\hline$\delta(C C N) ; v\left(C p^{\prime}-N\right)$ & $1470(\mathrm{~m})$ & $1462(F)$ & $1454(F)$ & $1454(F)$ \\
\hline$\delta(C p-H)$ & $1404(F)$ & $1401(m)$ & $1402(\mathrm{~m})$ & $1402(\mathrm{~m})$ \\
\hline$\delta(\mathrm{Cp}-\mathrm{H})$ & $1351(\mathrm{~m})$ & $1354(\mathrm{~m})$ & $1355(\mathrm{~m})$ & $1359(\mathrm{~m})$ \\
\hline$?$ & -- & $1331(\mathrm{~m})$ & $\otimes$ & $\otimes$ \\
\hline$?$ & - & $1278(\mathrm{~m})$ & $1293(f)$ & -_- \\
\hline ? & $1212(f)$ & $1217(\mathrm{~m})$ & $1216(\mathrm{~m})$ & 1215 (f) \\
\hline$?$ & 1189 (f) & - & -.- & $-\ldots$ \\
\hline$\delta(C-H)$ piridínico & 1157 (f) & $1183(F)$ & $1167(\mathrm{~m})$ & $1162(F)$ \\
\hline ? & - & 1120 (f) & $1116(f)$ & $\theta$ \\
\hline$\delta(C C N)=v\left(C_{n}^{\prime}-N\right)$ & $1082(f)$ & 1070 (f) & $1080(f)$ & $\otimes$ \\
\hline ? & $1069(\mathrm{~m})$ & 1055 (f) & $1054(f)$ & $\otimes$ \\
\hline$?$ & -- & - & 1029 (f) & $\otimes$ \\
\hline$v\left(C p^{\prime}-N\right)$ & 1004 (f) & $1003(\mathrm{~m})$ & $1003(\mathrm{~m})$ & $1003(\mathrm{~m})$ \\
\hline$\delta(\mathrm{N}-\mathrm{H})$ & 980 (o) & $980(0)$ & $980(0)$ & $981(0)$ \\
\hline$v\left(C p-C p^{\prime}\right) ; v\left(C p^{\prime}-N\right)$ & $971(F)$ & 970 (MF) & $969(\mathrm{~F})$ & $970(F)$ \\
\hline def. $\pi$ do anel & $883(\mathrm{~m})$ & $887(\mathrm{~m})$ & $888(\mathrm{~m})$ & $887(\mathrm{~m})$ \\
\hline$\pi \mathrm{CH}$ & $843(f)$ & $861(\mathrm{~m})$ & $866(\mathrm{~m})$ & $862(\mathrm{~m})$ \\
\hline$\delta(\mathrm{C}-\mathrm{H})$ fora do plano & 799 (F) & $800(F)$ & $807(F)$ & $809(F)$ \\
\hline$\delta(\mathrm{C}-\mathrm{H})$ fora do plano & $786(F)$ & $\otimes$ & 796 (F) & $792(F)$ \\
\hline$\delta(\mathrm{C}-\mathrm{H})$ fora do plano & - & -- & $752(\mathrm{~m})$ & $753(\mathrm{~m})$ \\
\hline$\delta(C-H)$ fora do plano & $724(m)$ & $731(\mathrm{~m})$ & -- & $734(\mathrm{~m})$ \\
\hline$\delta(\mathrm{C}-\mathrm{H})$ fora do plano & - & $716(F)$ & $701(F)$ & $702(F)$ \\
\hline$\delta(\mathrm{C}-\mathrm{H})$ fora do plano & $660(\mathrm{~m})$ & - & - & -- \\
\hline
\end{tabular}

$\otimes$ bandas encobertas; ? bandas sem atribuição.

intensidade das bandas:(o) ombro; (f) fraca; (m) média; (F) forte; (MF) muito forte.

A banda intensa e larga em $3400 \mathrm{~cm}^{-1}$ dificulta a análise dos estiramentos $v(\mathrm{C}-\mathrm{H})$ do espectro que aparecem na região de $3000 \mathrm{~cm}^{-1}$, encobrindo e diminuindo a definição das bandas.

A banda em $1635 \mathrm{~cm}^{-1}$ está na mesma posição que a banda referente ao estiramento aromático $v(\mathrm{C}=\mathrm{C})$ dos anéis piridínio ${ }^{141}$ (também chamada de respiração do anel ${ }^{143}$ ), resultando numa banda deformada e que varia entre a $\mathrm{H}_{2}$ TMPyP e as porfirinas benzilpiridínio substituídas. Essa variação é esperada pois os efeitos 
indutivos dos grupos benzila e metila são distintos, resultando numa distribuição de carga no nitrogênio piridínico também diferenciada. $\mathrm{Na}_{2} \mathrm{H}_{2}$ TMPyP essa banda aparece em $1641 \mathrm{~cm}^{-1}$, enquanto nas benzilpiridínio porfirinas estão na região de $1635 \mathrm{~cm}^{-1}$. $\mathrm{Na} \mathrm{H}_{2}$ TPyP (não existe carga no nitrogênio piridínico), a banda é observada em região de menor energia $\left(1594 \mathrm{~cm}^{-1}\right)$, evidenciando uma ligação $C=C$ mais fraca em comparação com anel piridínio.

tabela 17: Bandas e atribuiçōes dos espectros de infravemelho

\begin{tabular}{|c|c|c|c|c|}
\hline atribuiços & $\begin{array}{c}{ }_{2} \text { B BrpyP } \\
y\left(\mathrm{~cm}^{-1}\right)\end{array}$ & $\begin{array}{c}\mathrm{H}_{2} \mathrm{TCH}_{3} \mathrm{BrPyP} \\
v\left(\mathrm{~cm}^{-1}\right)\end{array}$ & $\begin{array}{c}H_{2} T_{\text {GIBZPYP }} \\
v\left(\mathrm{~cm}^{-1}\right)\end{array}$ & $\begin{array}{c}\mathrm{H}_{2} \text { TBrBzPyP } \\
v\left(\mathrm{~cm}^{-1}\right)\end{array}$ \\
\hline$\delta(\mathrm{CCN}) ; \delta(\mathrm{OH})$ & 1634 (MF) & 1635 (MF) & $1634(\mathrm{MF})$ & 1635 (MF) \\
\hline$v(C-C)$ aromático & - & $1615(0)$ & $1596(F)$ & $1593(0)$ \\
\hline$v(C-C)$ piridina & - & -- & - & -- \\
\hline$v(C-C)$ aromático & $1559(\mathrm{~m})$ & $1560(\mathrm{~m})$ & $1559(\mathrm{~m})$ & $1560(\mathrm{~m})$ \\
\hline$v\left(C p-C p^{\prime}\right) ; v\left(C p^{\prime}-N\right)$ & 1508 (m) & $1509(\mathrm{~m})$ & $1508(\mathrm{~m})$ & $1508(\mathrm{~m})$ \\
\hline$v(C-C)$ fenílico & 1497 (m) & - & $1492(F)$ & $1490(F)$ \\
\hline$\delta(C C N) ; v\left(C p^{\prime}-N\right)$ & $1453(F)$ & $1455(F)$ & $1456(F)$ & $1456(F)$ \\
\hline$v(C-C)$ fenílico & - & - & $1411(\mathrm{~m})$ & - \\
\hline$\delta(\mathrm{Cp}-\mathrm{H})$ & $1402(\mathrm{~m})$ & $1402(f)$ & $1402(\mathrm{~m})$ & $1407(\mathrm{~m})$ \\
\hline$\delta(\mathrm{Cp}-\mathrm{H})$ & $1362(\mathrm{~m})$ & 1355 (f) & $1363(f)$ & $1359(f)$ \\
\hline ? & 1341 (f) & - & -- & - \\
\hline$?$ & - & $1279(f)$ & $1277(f)$ & $1274(f)$ \\
\hline$?$ & $1212(\mathrm{~m})$ & 1212 (f) & $1211(\mathrm{~m})$ & 1213 (f) \\
\hline ? & - & 1189 (f) & - & - \\
\hline$\delta(C-H)$ piridínico & $1156(m)$ & $1157(\mathrm{~m})$ & $1159(\mathrm{~m})$ & $1160(F)$ \\
\hline$?$ & $1126(f)$ & $1127(f)$ & $1123(f)$ & $1123(f)$ \\
\hline$\delta(C C N) ; v\left(C p^{\prime}-N\right)$ & -- & -- & $1088(m)$ & $1071(F)$ \\
\hline$?$ & 1052 (f) & $1051(f)$ & 1051 (f) & 1052 (f) \\
\hline ? & 1029 (f) & $1022(f)$ & $1016(\mathrm{~m})$ & $1012(F)$ \\
\hline$v\left(C p^{\prime}-N\right)$ & $1002(\mathrm{~m})$ & $1003(\mathrm{~m})$ & $1002(\mathrm{~m})$ & $1003(\mathrm{~m})$ \\
\hline$\delta(\mathbf{N}-\mathrm{H})$ & 979 (o) & 980 (o) & 980 (o) & 979 (0) \\
\hline$v\left(C p-C p^{3}\right) ; v\left(C p^{3}-N\right)$ & $970(F)$ & $970(F)$ & $970(F)$ & $970(F)$ \\
\hline def. $\pi$ do anel & $888(\mathrm{~m})$ & $888(\mathrm{~m})$ & $887(\mathrm{~m})$ & $888(\mathrm{~m})$ \\
\hline$\pi \mathrm{CH}$ & $868(\mathrm{~m})$ & $869(\mathrm{~m})$ & 849 (f) & $845(\mathrm{~m})$ \\
\hline$\delta(\mathrm{C}-\mathrm{H})$ fora do plano & $805(F)$ & $803(0)$ & & $805(F)$ \\
\hline$\delta(C-H)$ fora do plano & 792 (o) & $792(F)$ & $791(F)$ & $788(F)$ \\
\hline$\delta(\mathrm{C}-\mathrm{H})$ fora do plano & 749 (F) & $761(f)$ & -- & - \\
\hline$\delta(C-H)$ fora do plano & 735 (0) & $731(\mathrm{~m})$ & $7239(\mathrm{~m})$ & $722(\mathrm{~m})$ \\
\hline$\delta(C-H)$ fora do plano & $700(F)$ & - & 712 (o) & $710(\mathrm{~m})$ \\
\hline $\begin{array}{c}\delta(\mathrm{C}-\mathrm{H}) \text { fora do plano } \\
v(\mathrm{C}-\mathrm{Cl})\end{array}$ & $642(\mathrm{~m})$ & - & $507(\mathrm{~m})$ & - \\
\hline alcisy $=$ & & & - & $494(m)$ \\
\hline
\end{tabular}

$\otimes$ bandas encobertas; ? bandas sem atribuição.

intensidade das bandas:(o) ombro; (f) fraca; (m) média; (F) forte; (MF) muito forte.

Devido a sua grande intensidade, essa banda encobre parcialmente a banda referente ao estiramento $v(C=C)$ do anel fenílico ${ }^{134}$ nas porfirinas benzilpiridínio substituídas. Entretanto, nas maiorias das porfirinas analisadas é possível verificar a presença dessa banda como um ombro. É fácil atribuir a banda ao estiramento fenílico, pois ela apresenta uma grande variação de posição e intensidade em função 
dos substituinte e não está presente na $\mathrm{H}_{2}$ TMPyP. Podemos observar nas tabelas 16 , 17 e 18 que os substituintes mais pesados são responsáveis por maiores deslocamentos para região de mais baixa energia (outros fatores como eletronegatividade, também estão envolvidos nos deslocamentos observados) ${ }^{143}$.

tabela 18: Bandas e atribuições dos espectros de infravemelho

\begin{tabular}{|c|c|c|c|c|}
\hline atribuiçoes & $\begin{array}{c}\mathrm{H}_{2} \mathrm{NO}_{2} \mathrm{BzP} \mathrm{PP} \\
v\left(\mathrm{~cm}^{-1}\right)\end{array}$ & $\begin{array}{c}\mathrm{H}_{2} \mathrm{TMeOBZPyP} \\
y\left(\mathrm{~cm}^{-1}\right)\end{array}$ & $\begin{array}{c}\mathrm{H}_{2} \mathrm{TCO}_{2} \mathrm{HBz}_{\mathrm{P} y \mathrm{P}} \\
\left(\mathrm{cm}^{-1}\right)\end{array}$ & $\begin{array}{c}\mathrm{H}_{2} \text { TCNBZPyP } \\
\left(\mathrm{cm}^{-1}\right)\end{array}$ \\
\hline$v(\mathrm{C} \equiv N)$ & - & - & - & $2228(F)$ \\
\hline$v(C=0)$ & -- & - & 1705 (MF) & - \\
\hline$\delta(\mathrm{CCN}) ; \delta(\mathrm{OH})$ & 1635 (MF) & 1634 (MF) & 1634 (MF) & 1634 (MF) \\
\hline$v(\mathrm{C}-\mathrm{C})$ aromático & $1607(0)$ & 1610 (MF) & $1615(\mathrm{o})$ & $1612(0)$ \\
\hline ? & --- & $1584(\mathrm{~m})$ & $1578(\mathrm{~m})$ & -- \\
\hline$v(\mathrm{C}-\mathrm{C})$ aromático & $1560(\mathrm{~m})$ & $1560(\mathrm{~m})$ & $1560(\mathrm{~m})$ & $1560(\mathrm{~m})$ \\
\hline$v_{\text {as }}(\mathrm{O}-\mathrm{N}-\mathrm{O})$ & 1519 (MF) & - & - & - \\
\hline$v(C-C)$ fenílico & - & 1514 (MF) & - & -- \\
\hline$v\left(C p-C p^{3}\right) ; v\left(C p^{3}-N\right)$ & & $\otimes$ & $1508(\mathrm{~m})$ & $1505(\mathrm{~m})$ \\
\hline$\delta(\mathrm{CCN}) ; v\left(\mathrm{Cp}^{2}-\mathrm{N}\right)$ & $1456(F)$ & $1454(F)$ & $1455(F)$ & $1455(F)$ \\
\hline$v(C-C)$ fenílico & -- & $1426(0)$ & $1419(\mathrm{~m})$ & $1416(\mathrm{~m})$ \\
\hline$\delta(\mathrm{Cp}-\mathrm{H})$ & $1402(\mathrm{~m})$ & $1401(\mathrm{~m})$ & $1402(\mathrm{~m})$ & $1403(\mathrm{~m})$ \\
\hline$\delta(\mathrm{Cp}-\mathrm{H})$ & $\otimes$ & $1358(\mathrm{~m})$ & $1367(\mathrm{~m})$ & $1360(f)$ \\
\hline$v_{s}(O-N-O)$ & 1349 (MF) & - & - & -- \\
\hline$?$ & - & $1306(\mathrm{~m})$ & - & - \\
\hline$?$ & $1287(\mathrm{~m})$ & - & $1272(\mathrm{~m})$ & $1283(f)$ \\
\hline$v_{\text {as }}(C-O-C)$ & - & 1252 (MF) & - & - \\
\hline$\delta\left(-\mathrm{OCH}_{3}\right)$ & $1211(\mathrm{~m})$ & $\begin{array}{l}1213(\mathrm{~m}) \\
1181(\mathrm{~F})\end{array}$ & $\begin{array}{l}1216(\mathrm{~m}) \\
1176(\mathrm{o})\end{array}$ & $1211(f)$ \\
\hline$\delta(\mathbf{C}-\mathbf{H})$ piridínico & $1163(F)$ & $1149(\mathrm{~m})$ & $1162(\mathrm{~m})$ & $1160(F)$ \\
\hline$?$ & $1108(\mathrm{~m})$ & $1126(0)$ & $1112(f)$ & - \\
\hline$\delta(C C N) ; v\left(C p^{3}-N\right)$ & 1071 (f) & - & - & -- \\
\hline ? & 1051 (f) & $1051(f)$ & $1053(f)$ & $1051(f)$ \\
\hline$v_{s}(C-O-C)$ & - & $1025(F)$ & - & -- \\
\hline$?$ & $1016(f)$ & $\otimes$ & 1019 (f) & $1021(f)$ \\
\hline$v\left(C p^{\prime}-N\right)$ & $1003(\mathrm{~m})$ & $1002(\mathrm{~m})$ & $1002(\mathrm{~m})$ & $1002(\mathrm{~m})$ \\
\hline$\delta(N-H)$ & 981 (o) & $980(0)$ & 981 (o) & $980(0)$ \\
\hline$v\left(C p-C p^{\prime}\right) ; v\left(C p^{\prime}-N\right)$ & $970(F)$ & $970(\mathrm{~F})$ & $970(\mathrm{~F})$ & $970(\mathrm{~F})$ \\
\hline def. $\pi$ do anel & $887(f)$ & $888(\mathrm{~m})$ & $888(\mathrm{~m})$ & $888(f)$ \\
\hline$\pi \mathrm{CH}$ & $860(\mathrm{~m})$ & $844(\mathrm{~m})$ & $859(\mathrm{~m})$ & $854(\mathrm{~m})$ \\
\hline$\delta(\mathrm{C}-\mathrm{H})$ fora do plano & $801(F)$ & $\otimes$ & $803(F)$ & $\otimes$ \\
\hline$\delta(\mathrm{C}-\mathrm{H})$ fora do plano & $\otimes$ & $794(F)$ & $776(F)$ & $797(F)$ \\
\hline$\delta(C-H)$ fora do plano & $745(m)$ & 764 (f) & $752(F)$ & - \\
\hline$\delta(C-H)$ fora do plano & $722(\mathrm{~m})$ & $730(\mathrm{~m})$ & $731(\mathrm{~m})$ & $729(\mathrm{~m})$ \\
\hline$\delta(\mathrm{C}-\mathrm{H})$ fora do plano & $699(\mathrm{~m})$ & $715(\mathrm{~m})$ & $702(\mathrm{~m})$ & $713(\mathrm{~m})$ \\
\hline
\end{tabular}

$\otimes$ bandas encobertas; ? bandas sem atribuição.

intensidade das bandas:(o) ombro; (f) fraca; (m) média; (F) forte; (MF) muito forte.

A deformação angular da água $\delta(\mathrm{OH})$ não é ativa no espectro raman, sendo possivel observar apenas a banda referente ao estiramento do anel piridínio, os números de onda observados coincidem com o espectro infravermelho (tabela 19). As 
bandas referentes ao anel fenílico não são observadas no espectro raman pois essas não foram intensificadas pela ressonância do laser com a banda Soret.

Outra banda que apresenta um deslocamento significativo em função do grupo alquila é a banda forte em $1470 \mathrm{~cm}^{-1}$ para a $\mathrm{H}_{2}$ TPyP, $1462 \mathrm{~cm}^{-1}$ para a $\mathrm{H}_{2}$ TMPyP e $1453-1456 \mathrm{~cm}^{-1}$ para as demais porfirinas benzil piridínio substituídas. Essa banda é atribuída à deformação angular $\delta(\mathrm{CCN})$ do anel piridínico em combinação com o estiramento do anel porfirínico $v\left(C p^{\prime}-N\right)$. Os deslocamentos observados reforçam a atribuição da deformação do anel piridínico, que deve sentir uma maior influência do substituinte do que a vibração do anel porfirínico.

tabela 19: Bandas e atribuições dos espectros de raman ressonante

\begin{tabular}{|c|c|c|c|c|}
\hline atribuiçôes & $\begin{array}{l}\mathrm{H}_{2} \text { TMPYP } \\
v\left(\mathrm{~cm}^{-1}\right)\end{array}$ & $\begin{array}{c}\mathrm{H}_{2} \text { TBzPyP } \\
v\left(\mathrm{~cm}^{-1}\right)\end{array}$ & $\begin{array}{c}\mathrm{H}_{2} \mathrm{TCH}_{3} \text { BzPyP } \\
v\left(\mathrm{~cm}^{-1}\right)\end{array}$ & $\begin{array}{c}\mathrm{H}_{2} \mathrm{TMeOBzPyP} \\
v\left(\mathrm{~cm}^{-1}\right)\end{array}$ \\
\hline$\delta$ (piridinico) & $1642(\mathrm{~m})$ & $1636(F)$ & $1637(\mathrm{~m})$ & $1636(\mathrm{~F})$ \\
\hline$v(C p-C p)$ & 1554 (MF) & 1557 (MF) & 1556 (MF) & 1557 (MF) \\
\hline$\ddot{\delta}$ (piridinico) & 1501 (f) & $\otimes$ & $\otimes$ & $\theta$ \\
\hline$v\left(C p-C p^{\prime}\right)$ & 1448 (f) & 1448 (f) & 1446 (f) & 1446 (f) \\
\hline$v_{s}\left(C p^{3}-N\right)$ & 1360 (f) & 1364 (f) & 1362 (f) & $1365(f)$ \\
\hline$\delta($ pir $)$ & $1297(\mathrm{~m})$ & $1294(m)$ & $1294(\mathrm{~m})$ & $1300(\mathrm{~m})$ \\
\hline$v(\mathrm{Cm}$-pir) & $1250(F)$ & $1247(F)$ & $1250(F)$ & $1249(F)$ \\
\hline$\delta$ (piriridinico) & $1221(\mathrm{~m})$ & $1216(\mathrm{~m})$ & $1216(\mathrm{~m})$ & $1217(\mathrm{~m})$ \\
\hline$\delta($ pir $) ; v\left(\mathrm{~N}^{+}-\mathrm{CH}_{2}\right)$ & $1189(\mathrm{~m})$ & $1160(\mathrm{~m})$ & $1160(\mathrm{~m})$ & 1153 (f) \\
\hline$\delta_{s}(C p-H)$ & --- & $1100(f)$ & $1096(f)$ & 1091 (f) \\
\hline$v_{s}(C p-C m)$ & $1000(\mathrm{~m})$ & $1001(\mathrm{~m})$ & $999(m)$ & $1001(\mathrm{~m})$ \\
\hline$?$ & $964(\mathrm{~m})$ & $965(\mathrm{~m})$ & $965(\mathrm{~m})$ & 968 (f) \\
\hline
\end{tabular}

\begin{tabular}{|c|c|c|c|c|}
\hline atribuiçoes & $\begin{array}{c}\mathrm{H}_{2} \mathrm{CNBZ}^{2} \mathrm{PyP} \\
y\left(\mathrm{~cm}^{1}\right)\end{array}$ & $\begin{array}{c}\mathrm{H}_{2} \mathrm{TNO}_{2} \mathrm{BzPyP} \\
\times\left(\mathrm{cm}^{-1}\right)\end{array}$ & $\begin{array}{c}\mathrm{F}_{2} \text { BrBzPyP } \\
v\left(\mathrm{~cm}^{-1}\right)\end{array}$ & $\begin{array}{c}\mathrm{H}_{2} \mathrm{TCO} \mathrm{CO}_{2} \mathrm{BZPyP} \\
v\left(\mathrm{~cm}^{-1}\right)\end{array}$ \\
\hline$\delta$ (piriridinico) & $1637(\mathrm{~F})$ & $1636(F)$ & $1637(\mathrm{~F})$ & $1637(\mathrm{~m})$ \\
\hline$v(C p-C p)$ & 1558 (MF) & 1556 (MF) & 1556 (MF) & 1556 (MF) \\
\hline$\delta($ piriridinico) & 1505 (f) & $1497(f)$ & $\otimes$ & $\otimes$ \\
\hline$\left(C p-C p^{\prime}\right)$ & $1447(\mathrm{~m})$ & $1448(f)$ & $1445(f)$ & $1445(f)$ \\
\hline$v_{s}\left(C p^{\prime}-N\right)$ & 1365 (f) & 1367 (f) & 1366 (f) & 1361 (f) \\
\hline$\delta($ pir $)$ & $1298(\mathrm{~m})$ & $1295(\mathrm{~m})$ & $1298(\mathrm{~m})$ & $1298(\mathrm{~m})$ \\
\hline$v(\mathrm{Cm}-\mathrm{pir})$ & $1250(F)$ & $1248(F)$ & $1250(F)$ & $1250(F)$ \\
\hline$\delta$ (piriridínico) & $1215(\mathrm{~m})$ & $1216(\mathrm{~m})$ & $1215(F)$ & $1215(F)$ \\
\hline$\delta($ pir $), v\left(\mathrm{~N}^{+}-\mathrm{CH}_{2}\right)$ & $1160(\mathrm{~m})$ & $1165(f)$ & $1160(\mathrm{~m})$ & $1163(\mathrm{~m})$ \\
\hline$\delta_{s}(\mathrm{Cp}-\mathrm{H})$ & 1101 (f) & 1101 (f) & 1101 (f) & - \\
\hline$v_{s}\left(C p^{y}-C m\right)$ & $1000(\mathrm{~m})$ & $1000(F)$ & $1000(\mathrm{~m})$ & $1001(\mathrm{~m})$ \\
\hline$?$ & $964(\mathrm{~m})$ & $965(f)$ & $966(\mathrm{~m})$ & $967(\mathrm{~m})$ \\
\hline
\end{tabular}

$\otimes$ bandas encobertas; ? bandas sem atribuição.

intensidade das bandas:(o) ombro; (f) fraca; (m) média; (F) forte; (MF) muito forte.

Duas bandas no espectro raman atribuídas por Nakamoto ${ }^{142}$ à deformação do anel piridínico (Epiridínio) na região de 1220 a $1150 \mathrm{~cm}^{-1}$ também apresentam deslocamento em função do substituinte, aparecendo novamente bandas em região de 
maior energia no espectro da $\mathrm{H}_{2}$ TMPyP e de menor energia para as benzil piridínio substituídas.

No espectro de infravermelho, é possivel notar mais uma banda sensível aos substituintes benzílicos na região de $1150 \mathrm{~cm}^{-1}$. Essa banda, atribuída à deformação no plano $\delta(\mathrm{C}-\mathrm{H})$ do anel piridínico, deve ter uma contribuição da deformação $\delta(\mathrm{C}-\mathrm{H})$ do anel fenílico. A vibração possui maior energia nas porfirinas com substituintes nitro e ciano, grupos aceptores de elétrons. A ordem de energia pode ser relacionada ao caráter doador/aceptor de elétrons dos substituintes.

Nos espectros de infravermelho foi possivel identificar a banda referente à deformação $\delta(\mathrm{N}-\mathrm{H})$ no plano em $980 \mathrm{~cm}^{-1}$. Essa banda desaparece nas porfirinas metaladas e nas bases livres sempre é encontrada como um ombro na banda de respiração do anel porfirinico em $970 \mathrm{~cm}^{-1}$. Essa banda não é ativa no espectro raman, e na região de $970-1000 \mathrm{~cm}^{-1}$ são apenas observadas as duas bandas referentes à respiração do anel porfirinico.

Foi possivel identificar as bandas características dos substituintes benzílicos ${ }^{134}$ : em $2229 \mathrm{~cm}^{-1}$, banda intensa devido a $v(\mathrm{C} \equiv \mathrm{N})$ aromático; em $1705 \mathrm{~cm}^{-1}$, banda intensa devido ao estiramento $v(C=O)$ do ácido carboxílico; em 1520 e $1349 \mathrm{~cm}^{-1}$, bandas intensas devido a vas e $v_{\mathrm{s}}(\mathrm{O}-\mathrm{N}-\mathrm{O})$ respectivamente, característica de grupo nitro; em 1253 e $1027 \mathrm{~cm}^{-1}$, bandas intensas devido a $v_{\text {as }}$ e $v_{\mathrm{s}}(\mathrm{C}-\mathrm{O}-\mathrm{C})$ respectivamente, característica de grupo metóxi aromático. $\mathrm{Em} 506 \mathrm{~cm}^{-1}$, podemos identificar a banda referente ao $v(\mathrm{C}-\mathrm{Cl})$ e em $494 \mathrm{~cm}^{-1}$ referente ao $v(\mathrm{C}-\mathrm{Br})^{135}$.

\subsection{Ressonância Magnética Nuclear (RMN- ${ }^{1} \mathrm{H}$ )}

A espectroscopia de $\mathrm{RMN}^{1}{ }^{1} \mathrm{H}$ é uma importante ferramenta na caracterização de porfirinas, fornecendo informações sobre a densidade eletrônica da molécula, suas interações com outras moléculas de interesse e sua estrutura. É cada vez maior o uso de técnicas de RMN para caracterizar e analisar o estado de agregação das porfirinas em solução ou mesmo sua interação com diferentes biomoléculas, como DNA e proteínas.

Nesse estudo procurou-se caracterizar as porfirinas benzil piridínio substituídas a partir da análise dos espectros de $\mathrm{RMN}^{-1} \mathrm{H}$ e a influência dos solventes, concentração e temperatura nos deslocamentos químicos $(\delta)$ dos prótons. A obtenção dos novos derivados permitiu uma ampliação do estudo da correlação entre o efeito eletrônico dos substituintes benzílicos e os deslocamentos químicos observados para as porfirinas benzil piridínio substituídas ${ }^{22}$. 
No caso de alquilação de piridil porfirinas, o espectro de $\mathrm{RMN}-{ }^{1} \mathrm{H}$ pode facilmente diferenciar o cátion piridínio da piridina. A carga positiva no nitrogênio piridínico diminui a densidade eletrônica nos prótons do anel, deslocando seu sinal para campos mais baixos ${ }^{144}$. Os prótons equivalentes nas posições 3,5 em relação ao nitrogênio piridínico são mais sensiveis à ação da carga que os prótons equivalentes da posição 2,6 . Um anel piridínico ${ }^{145}$ não alquilado ligado ao anel porfirínico na posição meso apresenta bandas em 9,02 ppm (2,6 piridina) e 8,16 ppm (3,5 piridina), enquanto que o derivado metilado tem picos em 9,59 ppm (2,6 N-metilpiridinio) e 9,12 ppm (3,5 $\mathrm{N}$-metilpiridínio). A figura 63 apresenta as estruturas das porfirinas estudadas e a identificação dos prótons adotada neste trabalho.

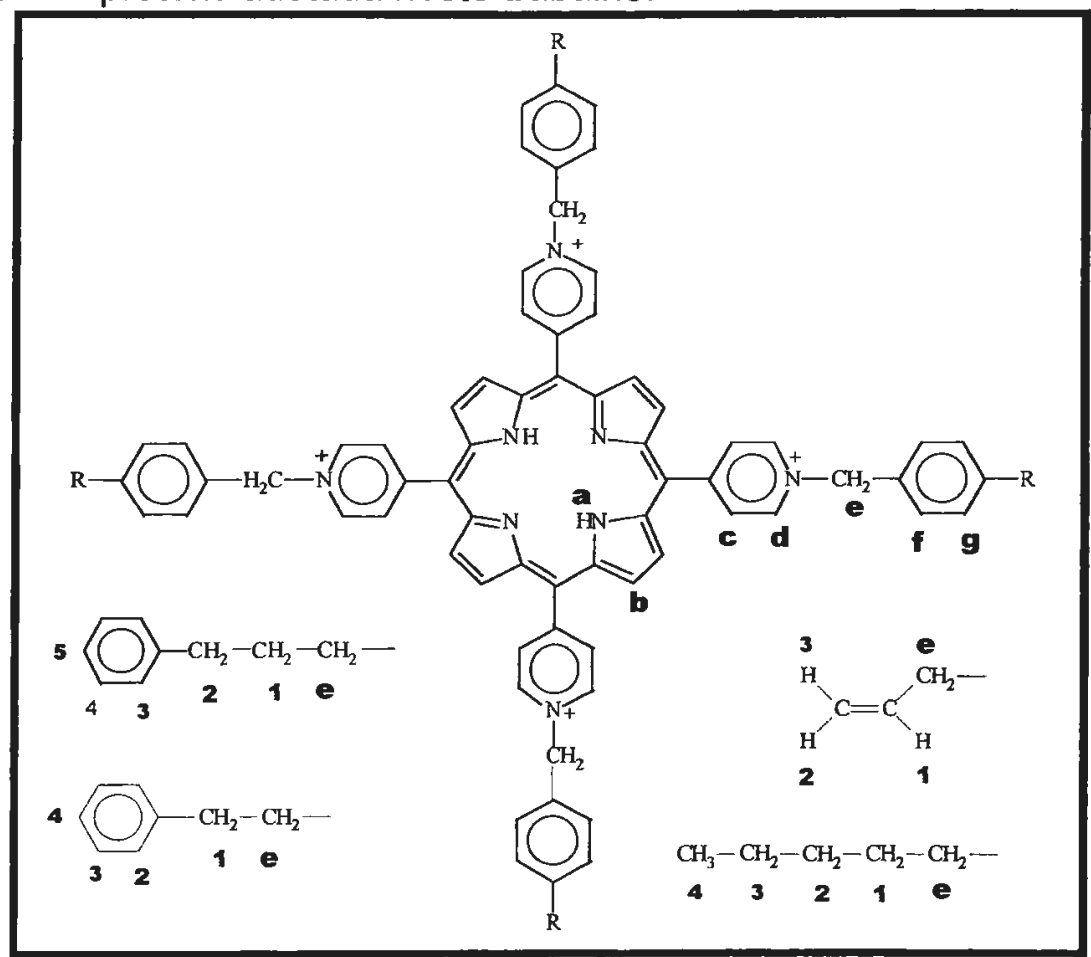

figura 63: Estrutura das porfirinas estudadas e identificação dos prótons atribuídos por RMN.

Analisando os espectros das porfirinas benzilpiridínio substituidas ${ }^{22}$ observa-se que os prótons da piridina são do tipo $A A^{\prime} B B^{,{ }^{146}}$, porém o espectro apresenta dupletes do tipo $A B$, com valores de $J$ próximos a $8 \mathrm{~Hz}$ nas condições de temperatura analisada. Os sinais dos substituintes benzílicos também apresentam comportamento $A B$, com exceção da $\mathrm{H}_{2}$ TCNBzPyP e da $\mathrm{H}_{2}$ TBrBzPyP, nas quais ocorre acoplamento de segunda ordem entre os prótons meta e orto, e a $\mathrm{H}_{2} \mathrm{TBzPyP}$, que possui um hidrogênio em posição para, formando um sistema ABC. A figura 64 apresenta um exemplo de espectro de $\mathrm{RMN}-{ }^{1} \mathrm{H}$ das porfirinas benzilpiridínio substituídas obtido em DMSO-d . $^{-}$ 


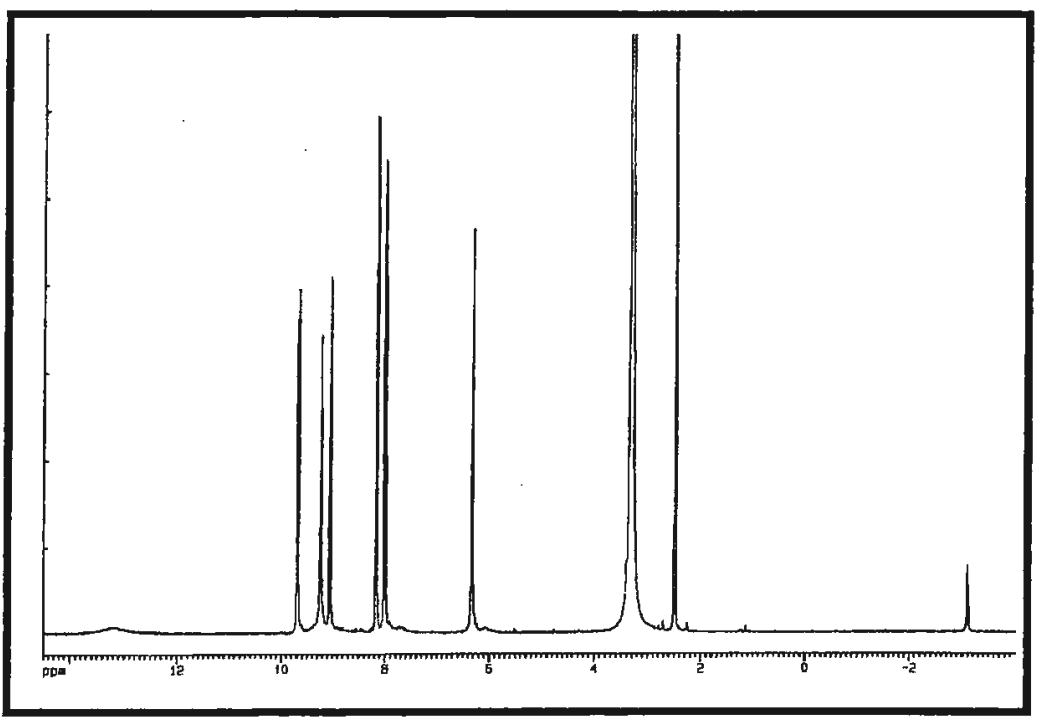

figura 64: Espectro de $\mathrm{RMN}^{-}{ }^{1} \mathrm{H}$ da $\mathrm{H}_{2} \mathrm{TCO}_{2} \mathrm{HTBzPyP}$. As atribuições estão na tabela 20.

Em DMSO- $d_{6}$ as porfirinas piridínio substituídas apresentam deslocamento dos sinais dos prótons do espectro de $\mathrm{RMN}^{-1} \mathrm{H}$ em função da concentração. A figura 65 ilustra esse efeito apresentando os espectros de $\mathrm{RMN}-{ }^{1} \mathrm{H}$ da $\mathrm{H}_{2}$ TCNBzPyP em DMSO$d_{6}$ em diferentes concentrações, para avaliar o efeito da diluição da porfirina nos deslocamentos químicos dos prótons.

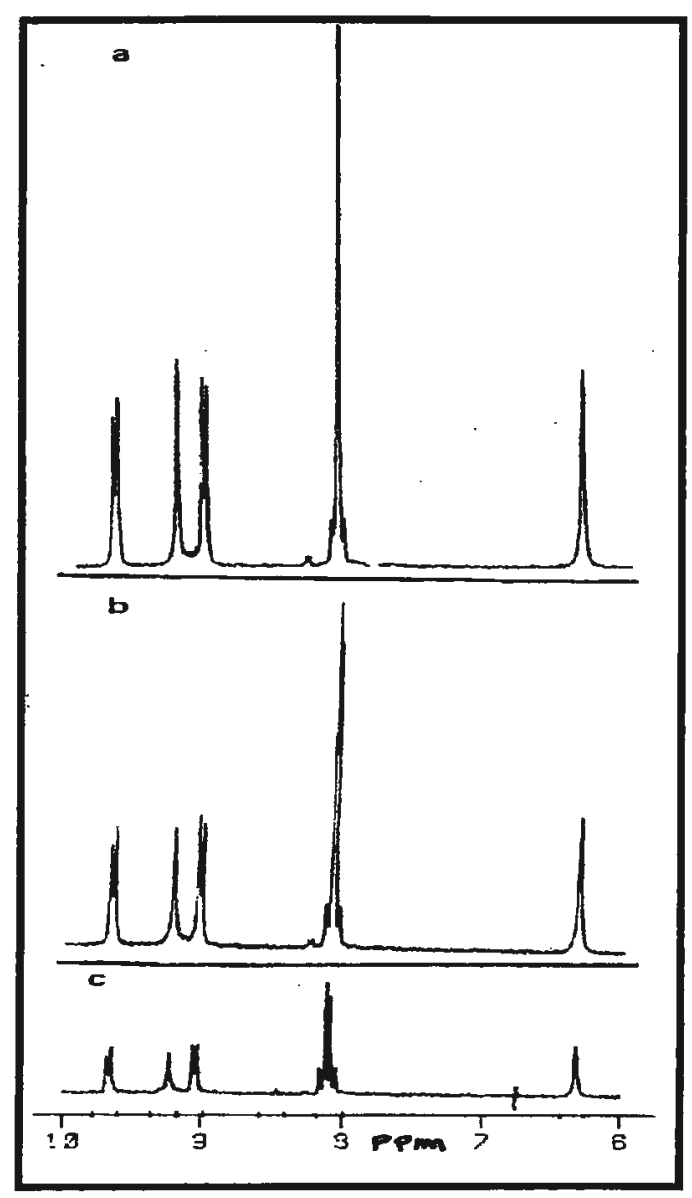

figura 65: Espectros de RMN-1H (200 MHZ) da $\mathrm{H}_{2}$ TCNBzPyP em DMSO- $\mathrm{d}_{6}$ em função da concentração: a- $5,0 \mathrm{mmol} \mathrm{dm}^{-3} ; b-1,7 \mathrm{mmol} \mathrm{dm}^{-3}$; c- $0,29 \mathrm{mmol} \mathrm{dm}^{-3}$. 
Observa-se na tabela 20 que quanto maior a concentração da porfirina, os prótons deslocam-se para campo baixo (maior frequência). Esse efeito, entretanto, não é uniforme, sendo mais pronunciado para os prótons d e e, que estão mais próximos do nitrogênio piridínico. A relação entre a proximidade da carga e o maior efeito de concentração indica que o fenômeno deve estar associado à solvatação da porfirina. O DMSO, por ser um solvente polar, interage principalmente com a fração polar da porfirina, e a mudança nas condições de solvatação (concentração) implica em uma maior alteração no ambiente químico dessa fração da molécula.

tabela 20: Dados e atribuições de $\mathrm{RMN}_{-}{ }^{1} \mathrm{H}$ da $\mathrm{H}_{2}$ TCNBzPyP em DMSO, em função da concentração

\begin{tabular}{|c|c|c|c|c|c|c|c|}
\hline $\begin{array}{l}\text { Concentraçáo } \\
\mathrm{mmol} \mathrm{dm}^{-3}\end{array}$ & $(\mathrm{ppm})$ & $\begin{array}{c}\mathrm{b} \\
(\mathrm{ppm})\end{array}$ & $\begin{array}{c}c \\
(p p m)\end{array}$ & $\begin{array}{c}d \\
(p p m)\end{array}$ & $\begin{array}{c}e \\
(\mathrm{pem})\end{array}$ & (ppm) & $\begin{array}{c}\mathrm{g} \\
(\mathrm{ppm})\end{array}$ \\
\hline 8,1 & $-3,094 \mathrm{~s}$ & $9,275 \mathrm{~s}$ & $9,082 d$ & $9,727 d$ & $6,380 \mathrm{~s}$ & $8,159 d^{\prime}$ & $8,114 d$ \\
\hline 5,0 & $-3,099 \mathrm{~s}$ & $9,269 \mathrm{~s}$ & $9,076 \mathrm{~d}$ & $9,714 d$ & $6,368 \mathrm{~s}$ & $8,156 d^{\prime}$ & $8,109 d^{\prime}$ \\
\hline 1,7 & $-3,102 \mathrm{~s}$ & $9,259 \mathrm{~s}$ & $9,069 \mathrm{~d}$ & $9,701 d$ & $6,352 \mathrm{~s}$ & $8,153 d$ & $8,098 d$ \\
\hline 0,29 & $-3,105 \mathrm{~s}$ & $9,249 \mathrm{~s}$ & $9,061 d$ & $9,681 \mathrm{~d}$ & $6,331 \mathrm{~s}$ & $8,154 \mathrm{~d}$ & $8,083 d$ \\
\hline
\end{tabular}

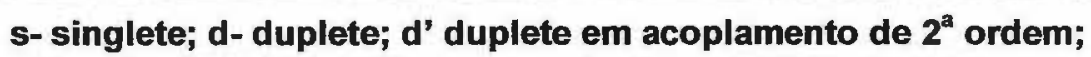

solvente: DMSO- $d_{6}$; Valores em relação ao DMSO: $\delta=2,43 \mathrm{ppm} ; \mathrm{t}=24^{\circ} \mathrm{C}$.

Os prótons benzílicos $\mathbf{f}$ e $\mathbf{g}$ da $\mathrm{H}_{2}$ TCNBzPyP, porém, apresentaram um comportamento anômalo com a variação de concentração, uma vez que observou-se uma maior separação dos picos referentes as posições 3,5 e 2,6 do anel fenílico (f e g), como pode ser observado na figura 65.

Para que se possa comparar a influência do substituinte nos valores dos deslocamentos químicos das porfirinas analisadas, evitando-se distorções, padronizou-se as condições de obtenção dos espectros de $\mathrm{RMN}-{ }^{1} \mathrm{H}$, utilizando DMSO$d_{6}$ como solvente, com a concentração de porfirina de $5 \mathrm{mmol} \mathrm{dm}^{-3}$ e temperatura de $24^{\circ} \mathrm{C}$.

Observa-se, pela tabela 21, que os deslocamentos químicos dos prótons das porfirinas estudadas seguem uma ordem dependente do caráter aceptor/doador de elétrons do substituinte benzílico em para (posição 4). Quanto maior o caráter doador, em campo mais alto (protegido, de menor frequência) se encontra o sinal do próton. 
tabela 21: Dados e atribuições de $\mathrm{RMN}^{-1} \mathrm{H}$.

\begin{tabular}{|c|c|c|c|c|c|c|c|}
\hline Porfinina & $\begin{array}{c}a \\
(\mathrm{ppm})\end{array}$ & $\begin{array}{c}b \\
(\mathrm{ppm})\end{array}$ & $\begin{array}{c}\mathrm{c} \\
(\mathrm{ppm})\end{array}$ & $\begin{array}{c}d \\
(\mathrm{ppm})\end{array}$ & $\begin{array}{c}\mathrm{e} \\
(\mathrm{ppm})\end{array}$ & $(\mathrm{fpm})$ & $\begin{array}{c}g \\
(p p m)\end{array}$ \\
\hline $\mathrm{H}_{2} \mathrm{TMeOBzPyP}$ & $-3,121 \mathrm{~s}$ & $9,191 \mathrm{~s}$ & $9,024 d$ & $9,695 d$ & $6,188 \mathrm{~s}$ & $7,900 \mathrm{~d}$ & $7,186 \mathrm{~d}$ \\
\hline $\mathrm{H}_{2} \mathrm{TCH}_{3} \mathrm{BzPyP}$ & $-3,117 \mathrm{~s}$ & $9,209 \mathrm{~s}$ & $9,029 d$ & $9,651 d$ & $6,195 \mathrm{~s}$ & $7,814 d$ & $7,448 d$ \\
\hline $\mathrm{H}_{2}$ TBzPyP & $-3,109 \mathrm{~s}$ & $9,222 \mathrm{~s}$ & $9,049 d$ & $9,733 d$ & $6,277 \mathrm{~s}$ & $7,922 d$ & $7,610 \mathrm{~m}$ \\
\hline $\mathrm{H}_{2} \mathrm{TCIBzPyP}$ & $-3,114 \mathrm{~s}$ & $9,223 \mathrm{~s}$ & $9,045 d$ & $9,733 d$ & $6,274 \mathrm{~s}$ & $7,991 \mathrm{~d}$ & $7,718 d$ \\
\hline $\mathrm{H}_{2} \mathrm{TBrBzPyP}$ & $-3,112 \mathrm{~s}$ & $9,234 \mathrm{~s}$ & $9,047 d$ & $9,683 d$ & $6,234 \mathrm{~s}$ & 7,919 d' & $7,850 d^{\prime}$ \\
\hline $\mathrm{H}_{2} \mathrm{TCO}_{2} \mathrm{HBzPyP}$ & $-3,097 \mathrm{~s}$ & $9,254 \mathrm{~s}$ & $9,069 d$ & $9,701 d$ & $6,344 \mathrm{~s}$ & $8,016 \mathrm{~d}$ & $8,184 d$ \\
\hline $\mathrm{H}_{2} \mathrm{TCNBzPyP}$ & $-3,099 \mathrm{~s}$ & $9,269 \mathrm{~s}$ & $9,076 d$ & $9,714 d$ & $6,368 \mathrm{~s}$ & $8,109 d^{\prime}$ & $8,156 d^{\prime}$ \\
\hline $\mathrm{H}_{2} \mathrm{TNO}_{2} \mathrm{Bz} \mathrm{PyP}$ & $-3,093 \mathrm{~s}$ & $9,272 \mathrm{~s}$ & $9,091 d$ & $9,733 d$ & $6,430 \mathrm{~s}$ & $8,196 d$ & $8,493 d$ \\
\hline $\mathrm{H}_{2}$ TPhPrPyP & $-3,105 \mathrm{~s}$ & $9,216 \mathrm{~s}$ & $9,011 d$ & $9,605 d$ & $5,047 \mathrm{t}$ & & \\
\hline $\mathrm{H}_{2}$ TPhEtPyP & $-3,099 \mathrm{~s}$ & $9,131 \mathrm{~s}$ & $9,005 d$ & $9,534 d$ & $5,270 \mathrm{t}$ & & \\
\hline $\mathrm{H}_{2}$ TMPyP & $-3,117 \mathrm{~s}$ & $9,175 \mathrm{~s}$ & $8,952 d$ & $9,453 d$ & & & \\
\hline $\mathrm{H}_{2}$ TPnPyP & $-3,094 \mathrm{~s}$ & $9,242 \mathrm{~s}$ & $9,020 d$ & $9,566 \mathrm{~d}$ & $4,956 \mathrm{t}$ & & \\
\hline $\mathrm{H}_{2}$ TAIPyP & $-3,091 \mathrm{~s}$ & $9,251 \mathrm{~s}$ & $9,052 d$ & $9,553 d$ & $5,682 d$ & & \\
\hline
\end{tabular}

s- singlete; d- duplete; d' duplete em acoplamento de $2^{\mathrm{a}}$ ordem; t- triplete; m- multiplete. $\mathrm{H}_{2} \mathrm{TCO}_{2} \mathrm{BzPyP}: \delta \mathrm{OH}=13,24 \mathrm{ppm}$ $\mathrm{H}_{2}$ TMeOBzPyP: $\delta \mathrm{OCH}_{3}=3,87$ ppm; $\mathrm{H}_{2} \mathrm{TCH}_{3} \mathrm{BzPyP} \delta \mathrm{CH}_{3}=2,43$ ppm; $\mathrm{H}_{2}$ TPhEtPyP: $\delta \mathrm{H1}=3,64 \mathrm{ppm}(\mathrm{t}) ; \delta \mathrm{H2}, \mathrm{H3}, \mathrm{H} 4=7,49 \mathrm{ppm}(\mathrm{m})$; $\mathrm{H}_{2}$ TPhPrPyP: $\delta$ H1= 2,63 ppm (m); $\delta$ H2 = 2,98 ppm (t); $\delta$ H3,H4,H5 = 7,40 ppm (m); $\mathrm{H}_{2}$ TPnPyP: $\delta \mathrm{H} 1=2,30 \mathrm{ppm}(\mathrm{m}) ; \delta \mathrm{H2}, \mathrm{H3}=1,56 \mathrm{ppm}(\mathrm{m}) ; \delta \mathrm{H3}=1,03 \mathrm{ppm}(\mathrm{t})$; $H_{2}$ TAIPyP: $\delta H 1=6,51 \mathrm{ppm}(\mathrm{m}) ; \delta H 2=5,71 \mathrm{ppm}$ (d); $\delta H 3=5,83 \mathrm{ppm}$ (d); solvente: DMSO-d $d_{6}$; Valores em relação ao DMSO: $\delta=2,49 \mathrm{ppm} ; t=24^{\circ} \mathrm{C}$.

A relação entre os deslocamentos químicos de prótons e o efeito doador/aceptor de elétrons já havia sido observada em sais de benzilpiridinio substituídos, para os prótons 2,6 do anel piridínico ${ }^{144}$.

No presente estudo, constatou-se que todo o anel porfirínico sofre influência do substituinte. Como pode ser observado na figura 66 , existe uma correlação entre os deslocamentos químicos dos prótons e o parâmetro $\sigma$ de Hammett ${ }^{29}$. ${ }^{32}$. Os valores de $\sigma$ estão relacionados com a densidade de carga no anel, e têm sido correlacionados com os sinais de prótons ou carbono- $13^{147}$.

Foram determinados (tabela 22) os valores de $\rho$ (coeficiente angular) e os coeficientes de correlação $(r)$ em função deslocamentos químicos dos prótons e o parâmetro $\sigma$ de Hammett. Os gráficos obtidos são apresentados na figura 66. A boa correlação apresentada indica a transmissão do efeito eletrônico dos substituintes benzílicos aos prótons do anel porfirínico, apesar da longa distância entre os substituintes e o macrociclo. 

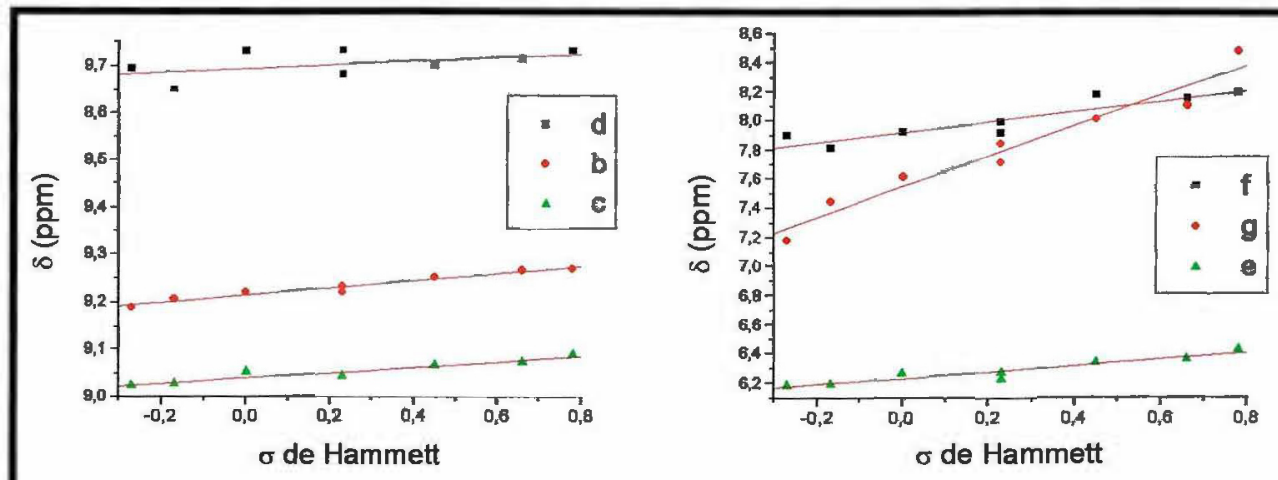

figura 66: Gráfico da correlação entre o parâmetro $\sigma$ de Hammett e os deslocamentos químicos dos prótons das porfirinas benzilpiridínio substituídas. As letras correspondem à nomenclatura adotada na tabela 21 e figura 63.

Os valores de $r$ obtidos para cada um dos prótons porfirínicos devem ser analisados considerando-se o número de pontos experimentais (no caso, oito substituintes benzilicos), para se determinar se a reta obtida por regressão linear representa o fenômeno observado. Baseando-se em uma tabela de teste para coeficientes de correlação, verifica-se que para oito amostras um valor de $r$ de 0,507 significa que a reta obtida tem $80 \%$ de probabilidade de ser a melhor reta. Para valores de $r$ acima de 0,834 a "certeza" passa a $99 \%$, e para $r$ superior a 0,925 a confiabilidade da reta obtida por regressão linear passa a $99,9 \%$. Sob esse enfoque, a análise da tabela 22 mostra que apenas os prótons 2,6 piridinicos não obedecem uma boa correlação com os parâmetros $\sigma$ de Hammett.

tabela 22: Valores de r e de $\rho$ referentes aos gráficos da figura 66.

\begin{tabular}{ccc}
\hline Prótons & $\rho(\mathrm{ppm})$ & $r$ \\
\hline a & $0,024 \pm 0,005$ & 0,8832 \\
b & $0,075 \pm 0,006$ & 0,9797 \\
c & $0,058 \pm 0,007$ & 0,9554 \\
d & $0,039 \pm 0,027$ & 0,5054 \\
e & $0,22 \pm 0,03$ & 0,9462 \\
f & $0,36 \pm 0,06$ & 0,9130 \\
g & $1,05 \pm 0,10$ & 0,9742 \\
\hline
\end{tabular}

A correlação entre os valores de $\sigma$ de Hammett e os deslocamentos químicos dos prótons de porfirinas meso substituídas foi observada por Walker e co-autores para derivados da $\mathrm{H}_{2} \operatorname{TPP}^{148}$. Analisando o espectro de seis porfirinas tetra para fenilsubstituídas, foram correlacionados os deslocamentos químicos dos prótons 
pirrólicos internos $(\mathrm{NH})$ e externos $(\mathrm{CH})$, apresentando valores de $\rho$ negativos. Ou seja, quanto maior o caráter doador de elétrons do substituinte, maior o valor de $\delta$ (mais deslocado para campo baixo).

O efeito dos substituintes observado por Walker ${ }^{148}$ para os prótons pirrólicos $\mathrm{NH}$ e $\mathrm{CH}$ da $\mathrm{H}_{2}$ TPP e seus derivados p-substituídos, é inverso do que ocorre com os sinais dos prótons orto e meta fenílicos contendo grupos doadores de elétrons ligados na posição para do anel, que são deslocados para campo alto. O mesmo efeito inverso é observado por Katrinsky ${ }^{144}$ nos deslocamentos químicos dos prótons de sais de piridínio substituídos. Walker demonstrou com este comportamento anômalo dos prótons pirrólicos que a transmissão dos efeitos eletrônicos do substituinte para 0 sistema $\pi$ da porfirina ocorre, preferencialmente, por indução e não por ressonância.

As porfininas benzilpindinio substituídas analisadas apresentam valores de $\rho$ positivos para todos os prótons observados, como mostram a figura 66 e a tabela 22 . Neste caso, a transmissão dos efeitos eletrônicos do substituinte ao anel pindínico deve ser através de efeito indutivo, uma vez que a ligação entre os dois anéis é feita pelo grupo $\mathrm{CH}_{2}$, com carbono $\mathrm{sp}^{3}$, que dificulta a ressonância entre os mesmos. Entretanto, se somente esse efeito fosse o responsável pelo deslocamento dos sinais dos prótons, este deveria seguir os valores tabelados por Katrinsky ${ }^{144}$, que não têm nenhuma correlação com o parâmetro $\sigma$ de Hammett.

A transmissão do efeito eletrônico do substituinte benzílico para os prótons do macrociclo deve ser feita através do espaço. A ligação $\mathrm{CH}_{2}$ possibilita ao grupo benzílico adotar uma conformação espacial em relação aos anéis piridínico e porfirínico, que origina uma maior proximidade entre o grupo benzílico com os prótons piridínicos, assim como com os prótons externos pirrólicos, permitindo, portanto, que a corrente eletrônica do anel benzílico desloque os sinais desses prótons. A hipótese de alteração na corrente eletrônica do macrociclo é descartada pela pouca variação apresentada pelos deslocamentos dos prótons internos, enquanto que no caso da $\mathrm{H}_{2}$ TPP $^{148}$ o valor de $\rho$ para os prótons pirrólicos internos é cerca de três vezes maior que o dos prótons externos. A baixa influência no deslocamento dos prótons internos reforça a proposta de transmissão do efeito via espaço, uma vez que o anel benzílico não tem como ficar próximo da região interna do macrociclo, tendo maior influência sobre a região externa.

A síntese das base livres $\mathrm{H}_{2}$ TPhEtPyP e $\mathrm{H}_{2}$ TPrPhPyP tinha como principal objetivo concluir o estudo da correlação dos parâmetros $\sigma$ de Hammett e os deslocamentos químicos dos prótons das porfirinas benzilpiridínio substituídas. 


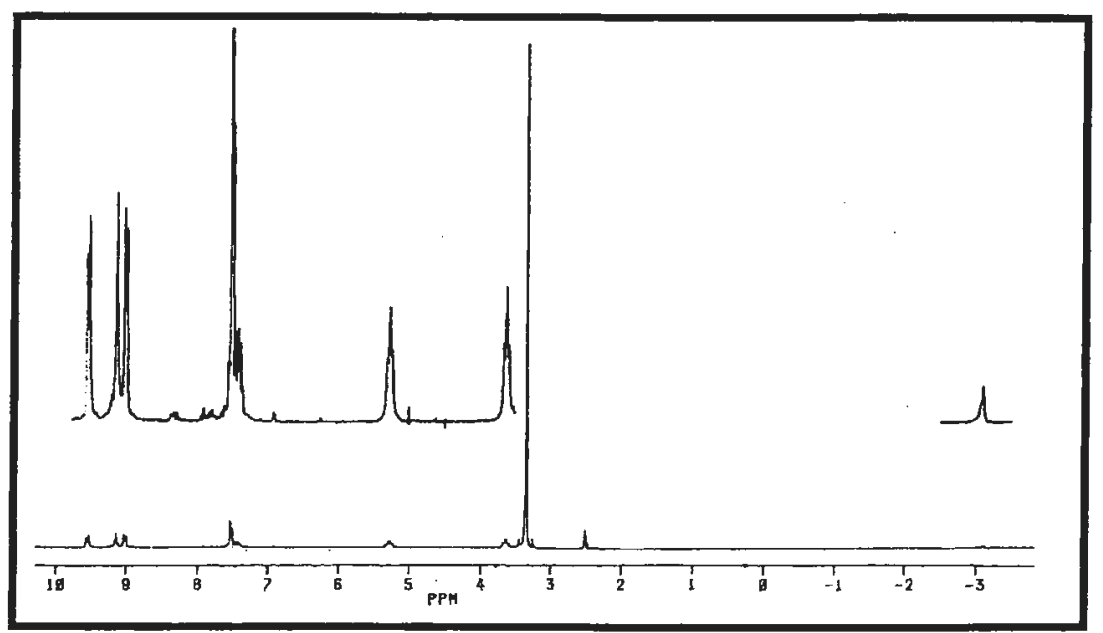

figura 67: Espectro de RMN- ${ }^{1} \mathrm{H}$ da $\mathrm{H}_{2}$ TPhEtPyP $\left(5,0 \mathrm{mmol} \mathrm{dm}^{-3}\right)$ em DMSO-d 6 . As atribuições estão na tabela 21.

Os deslocamentos químicos obtidos para a série $\mathrm{H}_{2}$ TBzPyP, $\mathrm{H}_{2}$ TPhEtPyP e $\mathrm{H}_{2}$ TPhPrPyP evidenciam a hipótese da transmissão via espaço. Se o efeito fosse via ligação (ressonância), deveríamos observar para os prótons do anéis porfirínico e piridínio ( $\mathbf{a}, \mathbf{b}, \mathbf{c}$, e d) uma relação direta entre a distância do anel fenílico ao grupo piridínio e o deslocamento químico dos prótons mencionados. Logo, os prótons da $\mathrm{H}_{2}$ TBzPyP deveriam se situar em campo mais baixo, em seguida estariam os prótons da $\mathrm{H}_{2}$ TPhEtPyP e em campo mais alto os prótons da $\mathrm{H}_{2}$ TPhPrPyP. Entretanto, observamos que os sinais dos prótons da $\mathrm{H}_{2}$ TPhPrPyP se encontram em campo mais baixo do que os respectivos sinais da $\mathrm{H}_{2}$ TPhEtPyP (ver tabela 21), sendo mais uma evidência de que a posição relativa no espaço entre o anel fenílico e o anel piridínico é a responsável pela correlação com parâmetros de Hammett observados nas porfirinas benzilpiridínio substituidas.

Surfactantes catiônicos possuindo na porção hidrofilica sais de piridínio com um substituinte benzílico, etilfenil e propilfenil apresentam conformação espacial semelhante à observada para as porfirinas, com o grupo ferilico voltado para a superfície micelar, sendo mais uma evidência a corroborar com o modelo proposto ${ }^{149}$.

O baixo coeficiente de correlação encontrado para os prótons 2,6 piridínicos, podem significar uma somatória de efeitos, além do efeito anisotrópico do anel benzilico sobre o piridínico, a variação da densidade de carga no nitrogênio piridínico em virtude do caráter aceptor/doador de elétrons do substituinte benzílico. Esta variação na carga positiva do anel piridínico afeta principalmente as posições orto e para, daí esses efeitos não serem observados nos prótons 3,5 do anel piridínico.

Os valores de $\rho$ apresentados na tabela 22 são considerados significativos, apesar de baixos, pois os deslocamentos químicos observados estão dentro da resolução do aparelho. Além disso, o valor de $\rho$ apresentado por Walker para os 
prótons pirrólicos $(\rho \cong 0,0688 \mathrm{ppm})$ tem a mesma ordem de grandeza dos verificados para os prótons pirrólicos e piridínicos das porfirinas benzil piridínio substituídas.

Os acoplamentos $\left(\mathrm{J}_{\mathrm{HH}}\right)$ tiveram seus valores determinados para a interação dos prótons 2,6 (equivalentes) e 3,5 (também equivalentes) dos anéis piridínico e benzílico. Não foram verificados alterações significativas nos valores de $J_{H H}$ dos prótons piridínicos, como mostra a tabela 23 .

tabela 23: Valores de $\mathrm{J}_{\mathrm{HH}}$ para as porfirinas estudadas

\begin{tabular}{|c|c|c|}
\hline Porfirinas & $\begin{array}{c}y_{H H} \text { anel pridinico } \\
(\mathrm{Hz})\end{array}$ & $\begin{array}{c}J_{H H} \text { anel berzilice } \\
(H z)\end{array}$ \\
\hline $\mathrm{H}_{2}$ TMeOBzPyP & 6,6 & 8,7 \\
\hline $\mathrm{H}_{2} \mathrm{TCH}_{3} \mathrm{BzPyP}$ & 6,7 & 8,0 \\
\hline $\mathrm{H}_{2} \mathrm{TBz}$ PyP & 6,6 & 7,7 \\
\hline $\mathrm{H}_{2} \mathrm{TClBzPyP}$ & 6,5 & 8,4 \\
\hline $\mathrm{H}_{2} \mathrm{TBrBzPyP}$ & 6,6 & - \\
\hline $\mathrm{H}_{2} \mathrm{TCO}_{2} \mathrm{HBzPyP}$ & 6,5 & 8,2 \\
\hline $\mathrm{H}_{2}$ TCNBzPyP & 6,4 & - \\
\hline $\mathrm{H}_{2} \mathrm{TNO}_{2} \mathrm{BzPyP}$ & 6,7 & 8,8 \\
\hline $\bar{H}_{2}$ TPhEtPyP & 6,7 & - \\
\hline $\mathrm{H}_{2} \mathrm{TPhPrPyP}$ & 6,3 & -- \\
\hline $\mathrm{H}_{2} \mathrm{TMPyP}$ & 6,5 & - \\
\hline $\mathrm{H}_{2}$ TAIPyP & 6,6 & - \\
\hline $\mathrm{H}_{2} \mathrm{TPnPyP}$ & 6,7 & - \\
\hline
\end{tabular}

A tabela 24 apresenta os deslocamentos quimicos dos prótons da $\mathrm{H}_{2}$ TCNBzPyP em diferentes concentrações nos solventes DMSO-d $\mathrm{d}_{6}, \mathrm{D}_{2} \mathrm{O}$ e $\mathrm{CD}_{3} \mathrm{OD}$. Observa-se que o efeito do solvente é crítico nos deslocamentos químicos dos prótons e que a interação entre o solvente e a porfirina é diferenciada para cada solvente.

Entretanto, devido ao efeito anisotrópico do DMSO, não existe correlação entre os deslocamentos químicos dos prótons da $\mathrm{H}_{2}$ TCNBzPyP com as respectivas constantes dielétricas $(\mu)$. 
tabela 24: Deslocamentos químicos ( $\delta$ ) de $\mathrm{RMN}-{ }^{1} \mathrm{H}$ da $\mathrm{H}_{2} \mathrm{TCNBzPyP}$ variandose solventes e concentrações.

\begin{tabular}{|c|c|c|c|c|c|c|c|}
\hline $\begin{array}{l}\text { Concentraçáo } \\
\left(\mathrm{mmol} \mathrm{dm}^{3}\right)\end{array}$ & $\begin{array}{c}\mathrm{a} \\
(\mathrm{ppm})\end{array}$ & $\begin{array}{c}\mathrm{b} \\
(\mathrm{ppm})\end{array}$ & $\begin{array}{c}c \\
(p p m)\end{array}$ & $\begin{array}{c}d \\
(p p m)\end{array}$ & $\begin{array}{c}e \\
(p p m)\end{array}$ & $(\mathrm{ppm})$ & $\begin{array}{c}\mathrm{g} \\
(\mathrm{ppm})\end{array}$ \\
\hline $8,1^{2}$ & $-3,094 \mathrm{~s}$ & $9,275 \mathrm{~s}$ & $9,082 d$ & $9,727 d$ & $6,380 \mathrm{~s}$ & $8,159 d^{\prime}$ & $8,114 d$ \\
\hline $5,0^{2}$ & $-3,099 \mathrm{~s}$ & $9,269 \mathrm{~s}$ & $9,076 d$ & $9,714 d$ & $6,368 \mathrm{~s}$ & $8,156 d^{\prime}$ & $8,109 d^{\prime}$ \\
\hline $1,7^{a}$ & $-3,102 \mathrm{~s}$ & $9,259 \mathrm{~s}$ & $9,069 d$ & $9,701 d$ & $6,352 \mathrm{~s}$ & $8,153 d$ & $8,098 d$ \\
\hline $0,29^{a}$ & $-3,105 \mathrm{~s}$ & $9,249 \mathrm{~s}$ & $9,061 d$ & $9,681 d$ & $6,331 \mathrm{~s}$ & $8,154 d$ & $8,083 d$ \\
\hline $1,3^{\circ}$ & - & * & $8,843 d$ & $9,259 d$ & $6,123 \mathrm{~s}$ & $7,839 d$ & $7,716 d$ \\
\hline $0,83^{b}$ & - & * & $8,843 d$ & $9,259 d$ & $6,123 \mathrm{~s}$ & $7,840 \mathrm{~d}$ & $7,715 \mathrm{~d}$ \\
\hline $0,083^{b}$ & - & * & $8,840 \mathrm{~d}$ & $9,258 d$ & $6,121 \mathrm{~s}$ & $7,838 \mathrm{~d}$ & $7,712 \mathrm{~d}$ \\
\hline $1,1^{\mathrm{c}}$ & - & * & $9,034 \mathrm{~d}$ & $9,553 d$ & $6,339 \mathrm{~s}$ & $8,034 \mathrm{~s}^{\prime}$ & $8,024 \mathrm{~s}^{\prime}$ \\
\hline $0,11^{c}$ & - & * & $9,034 \mathrm{~d}$ & $9,551 \mathrm{~d}$ & $6,332 d$ & $8,030 s^{\prime}$ & $8,030 \mathrm{~s}^{\prime}$ \\
\hline $0,055^{c}$ & - & * & $9,040 \mathrm{~d}$ & $9,548 d$ & - & $8,028 s^{\prime}$ & $8,028 \mathrm{~s}^{3}$ \\
\hline
\end{tabular}

s- singlete; $d$ - duplete; d' duplete em acoplamento de $2^{n}$ ordem; ${ }^{*}$ não aparece; solventes: a- DMSO-d $\mathrm{d}_{6}$; b- $\mathrm{D}_{2} \mathrm{O}$; $\mathrm{c}-\mathrm{CD}_{3} \mathrm{OD}$;

valores em relação ao TMS: $\delta=0,000 \mathrm{ppm} ; t=24^{\circ} \mathrm{C}$.

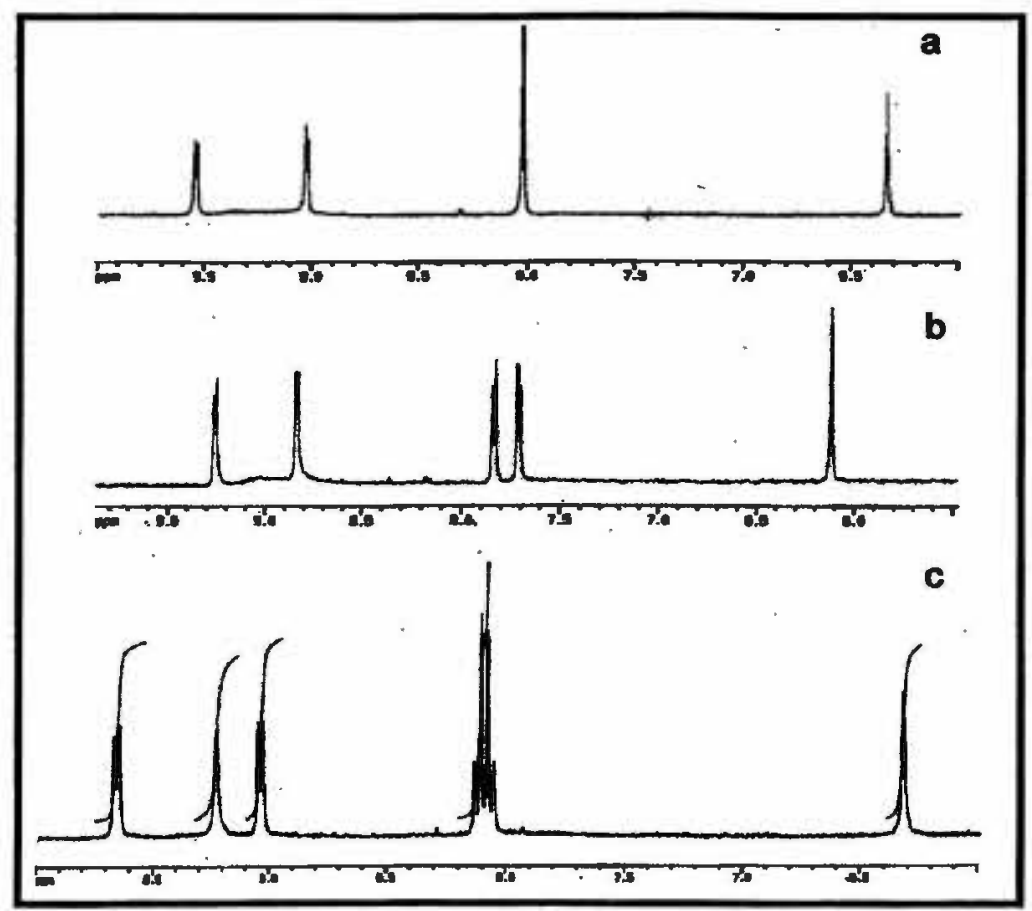

figura 68: Espectros de RMN- ${ }^{1} \mathrm{H}$ da $\mathrm{H}_{2}$ TCNBzPyP em a- $C D_{3} \mathrm{OD}$; b- $\mathrm{D}_{2} \mathrm{O}$; c- DMSO-d . $^{\text {. }}$

Observando a tabela 24 e a figura 68 , nota-se que os prótons a e b não apresentam sinais em água e metanol, fato diretamente relacionado com o caráter prótico do solvente. O próton interno do anel porfirínico é ácido, em solventes próticos ocorre uma troca rápida entre os prótons do solvente e do macrociclo, não sendo captado pela técnica de RMN nas condições empregadas. 
O sinal referente aos prótons externos do macrociclo apresentam um sinal largo, não sendo possivel determinar o seu deslocamento químico na temperatura de obtenção dos espectros $\left(24^{\circ} \mathrm{C}\right)$ em metanol e água.

Além da variação nos deslocamentos químicos observada para cada solvente, nota-se comportamentos distintos para diferentes concentrações nos solventes $D_{2} \mathrm{O} e$ $\mathrm{CD}_{3} \mathrm{OD}$ em relação ao já discutido para as soluções em DMSO- $\mathrm{d}_{6}$.

Nos solventes $D_{2} \mathrm{O}$ e $C_{3} \mathrm{OD}$ não se observa variação dos deslocamentos químicos com o aumento da concentração, indicando que a interação desses solventes com a porfirina é significativamente diferente da interação porfirina/DMSO. Esse resultado pode ser considerado anômalo, uma vez que o aumento da concentração deve aumentar o efeito anisotrópico dos macrociclos em relação aos outros, devido a maior aproximação das moléculas.

Outro dado que comprova a diferença de solvatação em cada solvente é o comportamento dos prótons do anel benzílico (prótons f e g). Enquanto que em DMSO observamos um acoplamento $A B$ de segunda ordem que vai separando com a diluição, em $\mathrm{D}_{2} \mathrm{O}$ observou-se dois dupletes separados e bem definidos um sistema $A B$ de primeira ordem, com $J_{H H}=8,2 \mathrm{~Hz}$, que não depende da concentração de porfirina. Já em metanol, os prótons $\mathbf{f}$ e $\mathbf{g}$ apresentam o mesmo deslocamento químico, não se observando variação significativa com o aumento da concentração. $\mathrm{Em}$ concentração de $0,11 \mathrm{mmol} / \mathrm{L}$ o sinal observado é um singlete, enquanto que em $1,1 \mathrm{mmol} / \mathrm{L}$ o sinal observado é um duplete (ou dois singletes) com $5 \mathrm{~Hz}(0,01 \mathrm{ppm}) \mathrm{de}$ diferença.

Além das diferenças de solvatação que deve ocorrer em cada solução, essa variação no perfil espectral dos prótons do anel benzílico em diferentes solventes pode estar relacionada a conformações específicas do anel em relação ao anel porfirínico. O que significa dizer que para cada solvente existe uma conformação mais estável para $\circ$ anel benzílico. Vale a pena lembrar que a ligação $\mathrm{CH}_{2}$ entre o anel e o nitrogênio piridínico permite uma grande liberdade de rotação do anel, havendo um grande número de conformações possiveis.

Pode-se observar na figura 69 que o aumento da temperatura ocasiona o aparecimento de um pico largo atribuídos aos prótons pirrólicos externos. 


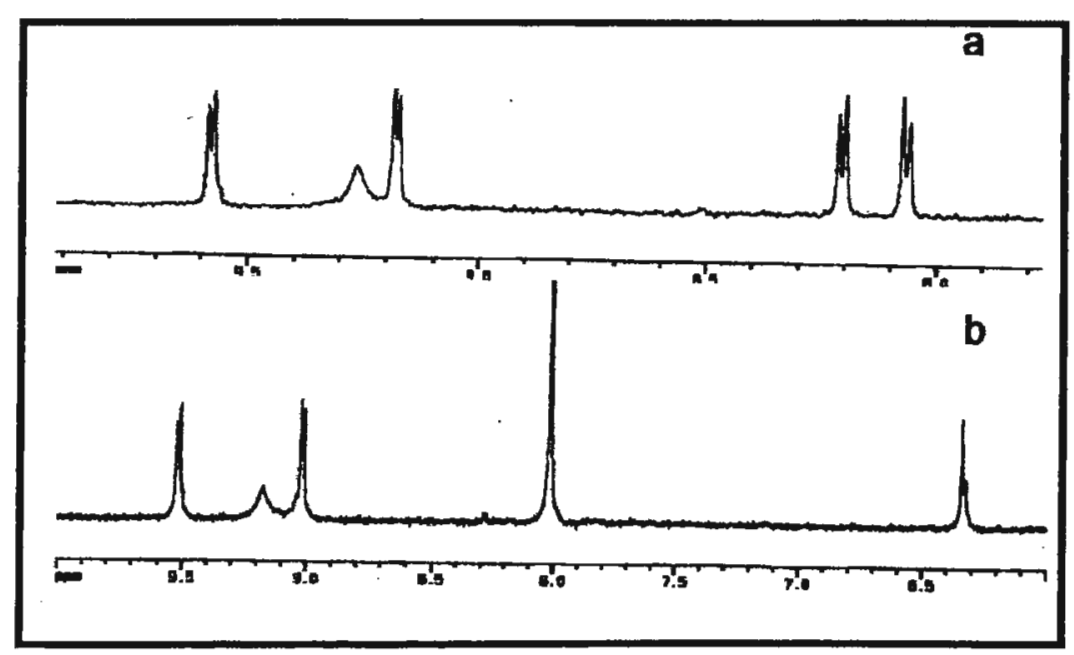

figura 69: Espectros de RMN- ${ }^{1} \mathrm{H}$ da $\mathrm{H}_{2} \mathrm{TCNBzPyP}\left(50^{\circ} \mathrm{C}\right)$ em a- $\mathrm{CD}_{3} \mathrm{OD}$; b- $\mathrm{D}_{2} \mathrm{O}$.

Com objetivo de obter maiores informações sobre o efeito da temperatura nos espectros de $\mathrm{RMN}^{-1} \mathrm{H}$ das porfirinas benzil piridinio substituídas, também foram obtidos os espectros da $\mathrm{H}_{2} \mathrm{TCH}_{3} \mathrm{BzPyP}$ em $\mathrm{CD}_{3} \mathrm{OD}$ vanando-se a temperatura.

A maior diferenciação entre os espectros obtidos nos solventes DMSO e $C D_{3} \mathrm{OD}$ está na posição e no formato do pico referente ao próton pirrólico da porfirina. Enquanto que em DMSO, o pico é um singlete bem resolvido com deslocamento químico igual a 9,21 ppm, em metanol observa-se uma banda larga com deslocamento igual a 9,35 ppm, sendo coerente com a observação feita para a $\mathrm{H}_{2}$ TCNBzPyP em $\mathrm{D}_{2} \mathrm{O}$ e $\mathrm{CD}_{3} \mathrm{OD}$.

O alargamento do pico deve-se ao equilibrio tautomérico do anel porfirínico ${ }^{150,{ }^{151}}$. Quando a velocidade do equilíbrio é rápida em relação a escala do experimento de RMN, observa-se apenas uma banda referente aos prótons pirrólicos, pois eles são equivalentes; com abaixamento da temperatura e conseqüente diminuição na velocidade do equilíbrio, começam a ser definidos dois picos um referente ao pirrol protonado e outro ao pirrol deprotonado. Nos espectros em temperaturas intermediárias nota-se que a banda se alarga, quase desaparece, ocorrendo a coalescência das bandas ${ }^{152}$.

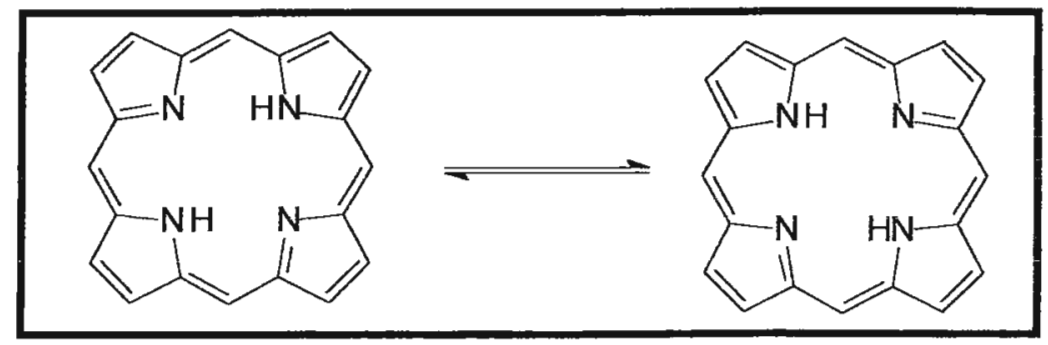

figura 70: Tautomeria do anel porfirínico 
Esse equilibrio ocorre independentemente do solvente, entretanto a velocidade de troca dos hidrogênios internos parece depender do caráter prótico do solvente. À temperatura ambiente $\left(25^{\circ} \mathrm{C}\right)$ os espectros de piridínio porfirinas em DMSO ${ }^{40}$ apresentam um singlete definido referente ao próton pirrólico, enquanto que em solventes próticos como água e metanol, a banda é larga, sendo necessário uma maior temperatura para obter uma melhor definição do pico ${ }^{44}$.

Analisando-se os espectros obtidos entre as temperaturas de $210 \mathrm{~K}$ a $340 \mathrm{~K}$, notou-se apenas alterações significativas no pico referente ao próton pirrólico. Essa variação já era esperada devido ao equilíbrio tautoménico do anel porfirínico. Os picos referentes aos prótons piridínicos e ao próton 2,6 benzílico apresentam um pequeno deslocamento para campo baixo (maior energia), como pode ser comprovado na tabela 25. A figura 71 ilustra a variação dos espectros em função da temperatura.

tabela 25: Dados e atribuições de $\mathrm{RMN}-{ }^{1} \mathrm{H}$ da $\mathrm{H}_{2} \mathrm{TCH}_{3} \mathrm{BzPyP}$ em $\mathrm{CD}_{3} \mathrm{OD}$.

\begin{tabular}{|c|c|c|c|c|c|c|c|}
\hline $\begin{array}{c}\text { Temperatura } \\
\mathrm{K}\end{array}$ & $\begin{array}{l}\mathrm{CH}_{3} \\
(\mathrm{ppm})\end{array}$ & $\begin{array}{c}\mathrm{b} \\
\text { (ppm) }\end{array}$ & $\begin{array}{c}\mathrm{C} \\
(\mathrm{ppm})\end{array}$ & $\begin{array}{c}\mathrm{d} \\
(\mathrm{ppm})\end{array}$ & $\begin{array}{c}\text { e } \\
\text { (ppm) }\end{array}$ & $\begin{array}{c}f \\
(\mathrm{ppm})\end{array}$ & $\begin{array}{c}\mathrm{g} \\
(\mathrm{ppm})\end{array}$ \\
\hline 340 & $2,46 \mathrm{~s}$ & $9,11 \mathrm{~s}$ & $8,94 d$ & $9,43 d$ & $6,18 \mathrm{~s}$ & $7,72 \mathrm{~d}$ & $7,46 d$ \\
\hline 320 & $2,47 \mathrm{~s}$ & $9,13 \mathrm{~s}$ & $8,96 \mathrm{~d}$ & $9,45 \mathrm{~d}$ & $6,18 \mathrm{~s}$ & $7,73 d$ & $7,47 d$ \\
\hline 302 & $2,47 \mathrm{~s}$ & $9,35 \mathrm{~b}$ & $8,97 d$ & $9,49 \mathrm{~d}$ & $6,19 \mathrm{~s}$ & $7,76 \mathrm{~d}$ & $7,47 d$ \\
\hline 290 & $2,47 \mathrm{~s}$ & $9,34 \mathrm{~b}$ & $8,97 d$ & $9,49 d$ & $6,19 \mathrm{~s}$ & $7,76 \mathrm{~d}$ & $7,47 d$ \\
\hline 270 & $2,47 \mathrm{~s}$ & $9,38 \mathrm{~s} ; 9,01 \mathrm{~s}$ & $8,99 \mathrm{~d}$ & $9,52 d$ & $6,19 \mathrm{~s}$ & $7,78 \mathrm{~d}$ & $7,48 d$ \\
\hline 250 & $2,47 \mathrm{~s}$ & $9,42 \mathrm{~s} ; 9,04 \mathrm{~s}$ & $9,00 \mathrm{~d}$ & $9,55 d$ & $6,19 \mathrm{~s}$ & $7,79 d$ & $7,48 d$ \\
\hline 230 & $2,47 \mathrm{~s}$ & $9,44 \mathrm{~s} ; 9,06 \mathrm{~s}$ & $9,01 d$ & $9,58 \mathrm{~d}$ & $6,18 \mathrm{~s}$ & $7,81 \mathrm{~d}$ & $7,48 \mathrm{~d}$ \\
\hline 210 & $2,47 \mathrm{~s}$ & $9,46 \mathrm{~s} ; 9,08 \mathrm{~s}$ & $9,02 d$ & $9,61 d$ & $6,18 \mathrm{~s}$ & $7,82 d$ & $7,47 d$ \\
\hline
\end{tabular}

s- singlete; $d$ - duplete; b- banda larga; solvente: $\mathrm{CD}_{3} \mathrm{OD}$; valores em relação ao TMS: $0,00 \mathrm{ppm}$.

A presença da banda larga no espectro de $\mathrm{RMN}-{ }^{1} \mathrm{H}$ da $\mathrm{H}_{2} T M P y P$ em $\mathrm{D}_{2} \mathrm{O}^{40}$ foi inicialmente atribuída à formação de dímeros, entretanto essa hipótese deve ser descartada com o espectro da $\mathrm{H}_{2} \mathrm{TCH}_{3}$ BzPyP em metanol, pois segundo a mesma referência, esse solvente não propicia a formação de dímeros das porfirinas piridínio substituídas. Posteriormente ${ }^{153}$, Kano e colaboradores reconhecem o seu equivoco, atribuindo a banda larga ao equilíbrio tautomérico dos prótons internos das porfirinas. 


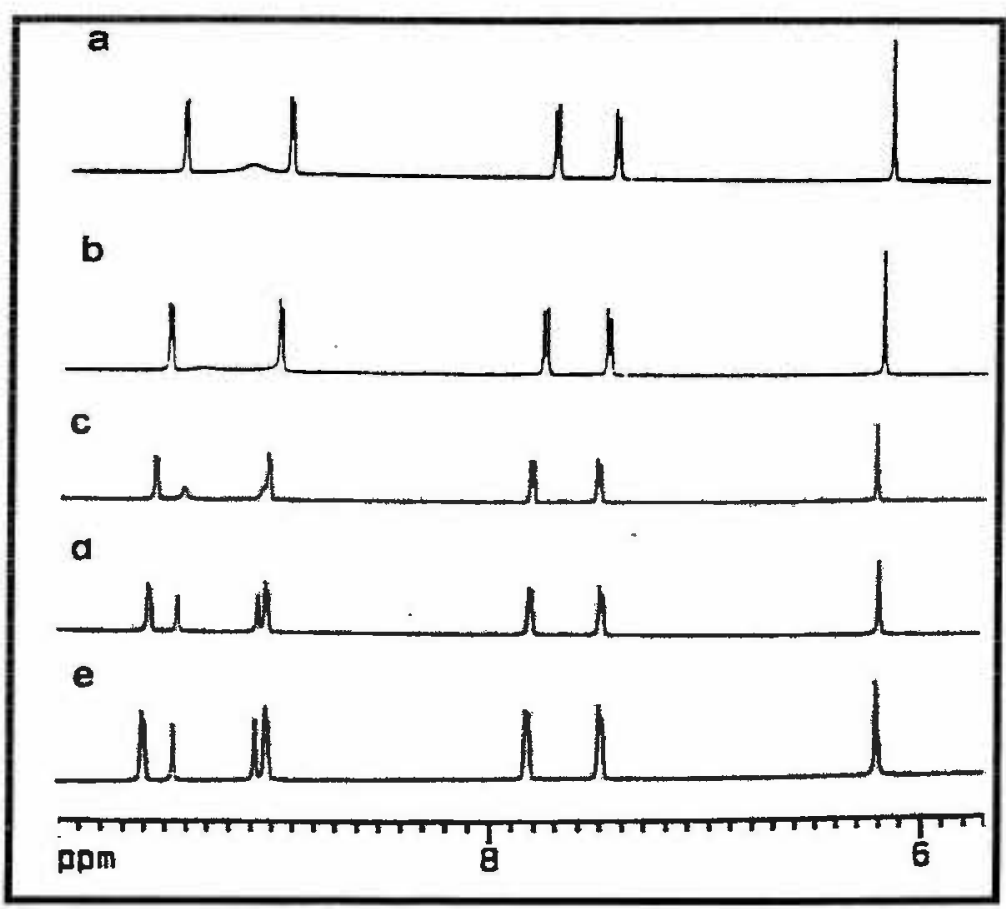

figura 71: Espectros de RMN- ${ }^{1} \mathrm{H}$ (500 MHZ) da $\mathrm{H}_{2} \mathrm{TCH}_{3} \mathrm{BzPyP}$ em $\mathrm{CD}_{3} \mathrm{OD}$ em função da temperatura; a- 310 K; b- $290 \mathrm{~K}$; c- $270 \mathrm{~K}$; d- $250 \mathrm{~K}$; e- $230 \mathrm{~K}$

\subsection{Interação com Surfactantes}

A caracterização da interação das porfirinas piridínio substituídas com surfactantes iônicos e não iônicos é importante para a avaliação do efeito eletrostático (coulômbico) e hidrofóbico desses derivados nas interações com macromoléculas em sistemas complexos. Os resultados prelimiriares obtidos nesse estudo podem ajudar na análise e caracterização dessas porfirinas nas interações com proteínas, membranas e outras biomoléculas, fundamentais nos estudos para aplicações terapêuticas das porfirinas catiônicas.

Outro fator importante é a caracterização das propriedades fotofísicas desses derivados em meio micelar, avaliando a possibilidade de aplicação como fotossensibilizadores em sistemas micro-heterogêneos.

Foram investigadas as interações das porfirinas catiônicas piridinio substituidas em meios micelar e pré-micelar de surfactantes catiônico (CTAB), aniônico (SDS) e de dois surfactantes não iônicos (Triton X-100 e PTE), representados na figura 72. A principal diferença estrutural entre os dois surfactantes não iônicos é a presença de um anel aromático no Triton X-100, enquanto que o PTE não apresenta ligações insaturadas ou anéis aromáticos. Com isso esperava-se verificar se a natureza das interações entre as porfirinas catiônicas e os surfactantes não iônicos é essencialmente de natureza hidrofóbica, ou se há um componente relevante da interação $\pi-\pi$ entre anéis aromáticos. 


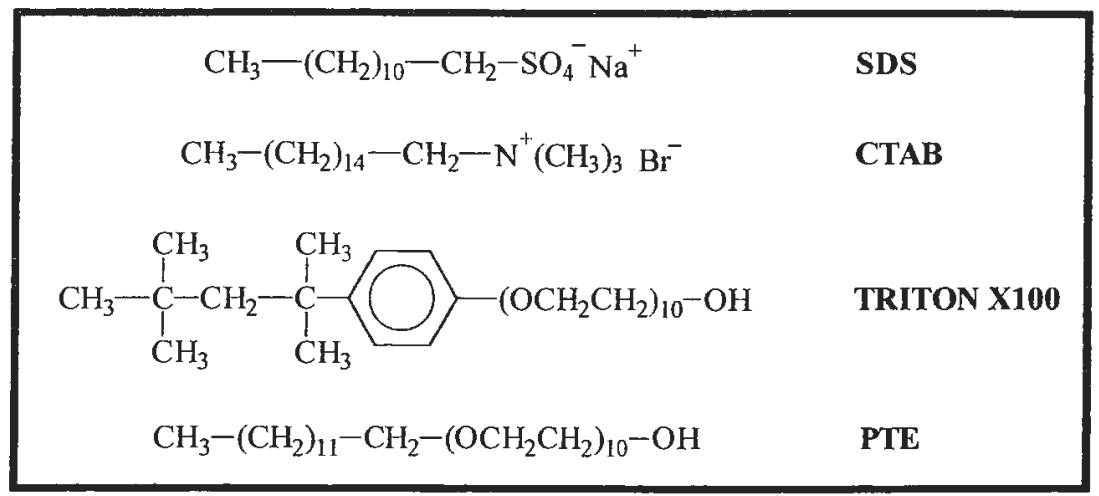

figura 72: Estruturas dos surfactantes empregados neste estudo.

As interações foram avaliadas por espectroscopia eletrônica de absorção e de emissão, por RMN- ${ }^{1} \mathrm{H}$ e por fotólise por pulso de laser. Também foram avaliadas as constantes de supressão do estado excitado triplete dos zinco derivados na presença de $\mathrm{MV}, \mathrm{BV}, \mathrm{COA}_{5} \mathrm{Cl}$ e AQS em meio micelar e determinados o $\Phi_{\Delta}$ para essas porfirinas em meio de SDS e Triton X100.

Foram determinados os valores de cmc para o SDS e Triton X100 na ausência e na presença de algumas porfirinas piridínio substituídas em concentrações de $8 \times$ $10^{-6}$ e $1 \times 10^{-4} \mathrm{~mol} \mathrm{dm}^{-3}$, que são as concentrações típicas de porfirina utilizadas nos experimentos de espectroscopia eletrônica e $\mathrm{RMN}-{ }^{1} \mathrm{H}$, respectivamente (tabela 26 ).

Para a determinação da $\mathrm{cmc}$ do SDS foi utilizada a técnica condutométrica e o valor determinado para o surfactante puro condiz com 0 da literatura $\left(8,0 \times 10^{-3} \mathrm{~mol} \mathrm{dm}^{-3}\right)^{154}$. Não se verificou alteração significativa nos valores da $\mathrm{cmc}$ na presença das porfirinas analisadas, $\mathrm{H}_{2}$ TMPyP, $\mathrm{H}_{2}$ TBzPyP, $\mathrm{H}_{2}$ TMeOBzPyP e $\mathrm{H}_{2}$ TCNBzPyP. No experimento contendo porfirina na concentração de $1 \times 10^{-4} \mathrm{~mol}$ $\mathrm{dm}^{-3}$ é possivel verificar a precipitação do agregado porfirina/micela em concentrações baixas de SDS. Aumentando-se continuamente a concentração de SDS percebe-se que a partir do momento que a proporção porfirina/SDS ultrapassa a relação 1:4, o aumento da condutividade cresce linearmente (ver figura 73). Aparentemente, a presença das porfirinas não modifica o grau de dissociação iônica do surfactante na micela $^{111}$, pois os valores de $\alpha$ determinados, não apresentam variação significativa, oscilando entre 0,35 e 0,37 .

$\mathrm{A} \mathrm{cmc}$ foi determinada pelo método tensiométrico para o surfactante não iônico Triton $\times 100$, na ausência e na presença das porfirinas. Nos sistemas em que a concentração da porfirina é de $10^{-4} \mathrm{~mol} \mathrm{dm}^{-3}$ há uma pequena diminuição no valor da cmc, que pode ser negligenciada na análise dos experimentos realizados. Para o Triton X100 em solução aquosa sem a adição de porfirinas o valor determinado condiz com o valor relatado na literatura $\left(2,4 \times 10^{-4} \mathrm{~mol} \mathrm{dm}^{-3}\right)^{154}$. 
Não foram determinados experimentalmente os valores da $\mathrm{cmc}$ dos surfactantes CTAB e PTE, sendo considerados os valores estabelecidos na literatura ${ }^{154}, 1 \times 10^{-4} \mathrm{~mol} \mathrm{dm}^{-3}$ para o PTE e $9,8 \times 10^{-4} \mathrm{~mol} \mathrm{dm}^{-3}$ para o CTAB.

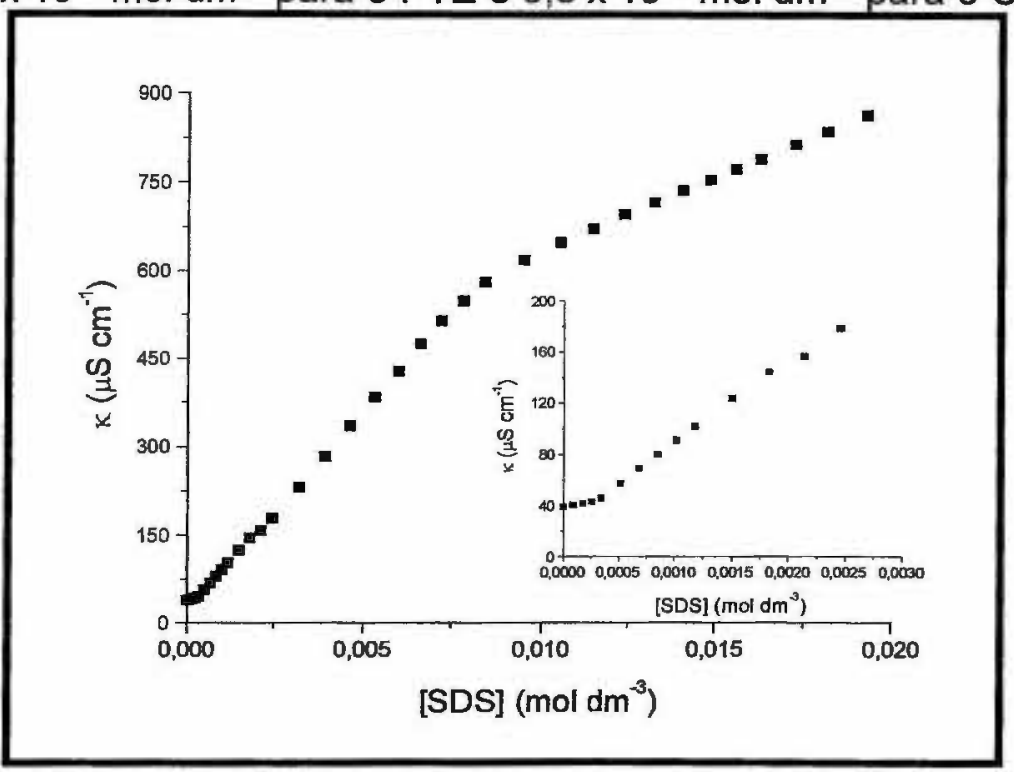

figura 73: Gráfico da variação da condutividade em função da concentração de SDS em solução aquosa contendo $\mathrm{H}_{2} \mathrm{TCNBzPyP} 1 \times 10^{-4} \mathrm{~mol} \mathrm{dm}^{-3}$. A região de menor concentração dde SDS foi ampliada para melhor visualização.

tabela 26: Valores de cmc de SDS e do Triton nos sistemas estudados

\begin{tabular}{|c|c|c|c|}
\hline Sistema & $\mathrm{cmc}\left(\mathrm{mol} \mathrm{dm^{-3 } )}\right.$ & Sistema & $\mathrm{cmc}\left(\mathrm{mol} \mathrm{dm^{-3 } )}\right.$ \\
\hline SDS & $8,3 \times 10^{-3}$ & Triton & $2,4 \times 10^{-4}$ \\
\hline $\mathrm{SDS}+\mathrm{H}_{2} \mathrm{TMPyP}^{1}$ & $8,4 \times 10^{-3}$ & Triton $+\mathrm{H}_{2} \mathrm{TBz} \mathrm{PyP}^{1}$ & $2,4 \times 10^{-4}$ \\
\hline $\mathrm{SDS}+\mathrm{H}_{2} \mathrm{TMPyP}^{2}$ & $8,7 \times 10^{-3}$ & Triton $+\mathrm{H}_{2} \mathrm{TBZPyP}^{2}$ & $2,3 \times 10^{-4}$ \\
\hline $\mathrm{SDS}+\mathrm{H}_{2} \mathrm{TBz} P \mathrm{PP} \mathrm{P}^{1}$ & $8,3 \times 10^{-3}$ & Triton + $\mathrm{H}_{2} \mathrm{TMeOBzPyP}^{1}$ & $2,3 \times 10^{-4}$ \\
\hline $\mathrm{SDS}+\mathrm{H}_{2} \mathrm{TBz} \mathrm{PyP} \mathrm{P}^{2}$ & $8,4 \times 10^{-3}$ & Triton + $\mathrm{H}_{2} \mathrm{TMeOBzPyP}^{2}$ & $1,9 \times 10^{-4}$ \\
\hline $\mathrm{SDS}+\mathrm{H}_{2} \mathrm{TCNBzPyP}^{1}$ & $8,4 \times 10^{-3}$ & Triton $+\mathrm{H}_{2} \mathrm{TCNBzPyP}^{1}$ & $2,4 \times 10^{-4}$ \\
\hline $\mathrm{SDS}+\mathrm{H}_{2} \mathrm{TCNBzPyP} \mathrm{P}^{2}$ & $8,5 \times 10^{-3}$ & Triton $+\mathrm{H}_{2}$ TCNBzPyP ${ }^{2}$ & $2,1 \times 10^{-4}$ \\
\hline $\mathrm{SDS}+\mathrm{H}_{2} \mathrm{TMeOBzPyP}^{2}$ & $8,4 \times 10^{-3}$ & 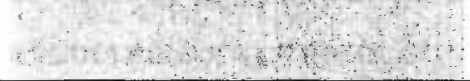 & \\
\hline
\end{tabular}

${ }^{1}\left[\right.$ porfirina] $=8 \times 10^{-6} \mathrm{~mol} \mathrm{dm}^{-3} ;{ }^{2}[$ porfirina $]=1 \times 10^{-4} \mathrm{~mol} \mathrm{dm}^{-3}$.

\subsubsection{Espectros Eletrônicos de Absorção}

Os espectros eletrônicos de absorção evidenciam a ausência de interação entre as porfirinas piridínio substituídas e o surfactante catiônico CTAB. Não se observa deslocamento significativo dos máximos de absorção para nenhum derivado (tabela 27). Verifica-se, entretanto, um pequeno aumento da intensidade das bandas e pequena variação entre a intensidade relativa das bandas $Q_{y}(0,0)$ e $Q_{x}(1,0)$, indicativo 
de uma mudança na solvatação das porfininas em relação ao meio aquoso. A presença do CTAB em concentrações duas ordens de grandeza acima da cmc, deve alterar a estrutura de solvatação do solvente, ocasionando essas pequenas alterações espectroscópicas. A não interação entre as porfininas piridínio substituídas e o CTAB já era esperada devido a presença de cargas positivas tanto na porfinina quanto na superfície da micela, ocorrendo uma repulsão coulômbica entre as espécies

tabela 27: Máximos de absorção $\left(\lambda_{\mathrm{max}}\right)$ das porfirinas base livre em água e em solução aquosa contendo CTAB.

\begin{tabular}{|c|c|c|c|c|c|c|}
\hline Porfintias & solvente & $\begin{array}{l}\text { Seret } \\
(\text { nn) }\end{array}$ & $\begin{array}{r}(, 1,0) \\
(n m)\end{array}$ & $\begin{array}{l}Q,(0,0) \\
(n m)\end{array}$ & $\begin{array}{c}Q \times 1(1,0) \\
(n m)\end{array}$ & $\begin{array}{c}Q_{x}(0,0) \\
(\mathrm{nm})\end{array}$ \\
\hline \multirow[t]{3}{*}{$\mathrm{H}_{2}$ TPPS } & Agua & 412 & 515 & 551 & 579 & 633 \\
\hline & CTAB $^{1}$ & 416 & 514 & 550 & 586 & 642 \\
\hline & $\mathrm{CTAB}^{2}$ & 401 & 519 & 554 & 594 & 652 \\
\hline \multirow[t]{2}{*}{$\mathrm{H}_{2}$ TMPyP } & Água & 421 & 517 & 557 & 583 & 641 \\
\hline & CTAB $^{1}$ & 421 & 518 & 555 & 583 & 639 \\
\hline \multirow[t]{2}{*}{$\mathrm{H}_{2}$ TAIPyP } & Água & 423 & 519 & 557 & 584 & 639 \\
\hline & CTAB $^{1}$ & 424 & 519 & 557 & 585 & 640 \\
\hline $\mathrm{H}_{2} \mathrm{TPnPyP}$ & Água & 422 & 518 & 557 & 585 & 638 \\
\hline \multirow{2}{*}{$\mathrm{H}_{2} \mathrm{PhEtPyP}$} & $\begin{array}{c}\text { CTAB } \\
\text { Água }\end{array}$ & $\overline{424}$ & $\overline{519}$ & $\overline{557}$ & $\overline{584}$ & $\overline{641}$ \\
\hline & CTAB $^{1}$ & 424 & 519 & 556 & 585 & 641 \\
\hline \multirow[t]{2}{*}{$\mathrm{H}_{2} \mathrm{PhPrPyP}$} & Água & 424 & 525 & 557 & 584 & 641 \\
\hline & CTAB $^{1}$ & 424 & 519 & 556 & 584 & 641 \\
\hline \multirow[t]{2}{*}{$\mathrm{H}_{2} \mathrm{TMeOBzPyP}$} & Água & 424 & 519 & 557 & 585 & 643 \\
\hline & CTAB $^{1}$ & 425 & 520 & 556 & 584 & 642 \\
\hline \multirow[t]{2}{*}{$\mathrm{H}_{2} \mathrm{TCH}_{3} \mathrm{Bz} \mathrm{PyP}$} & Água & 425 & 520 & 557 & 585 & 641 \\
\hline & CTAB $^{1}$ & 425 & 520 & 558 & 583 & 641 \\
\hline \multirow[t]{2}{*}{$\mathrm{H}_{2}$ TBzPyP } & Água & 425 & 520 & 557 & 584 & 642 \\
\hline & CTAB $^{1}$ & 425 & 519 & 557 & 585 & 641 \\
\hline \multirow[t]{2}{*}{$\mathrm{H}_{2} \mathrm{TBrBzPyP}$} & Água & 426 & 520 & 558 & 585 & 641 \\
\hline & CTAB $^{1}$ & 426 & 520 & 559 & 584 & 641 \\
\hline \multirow{2}{*}{$\mathrm{H}_{2}$ TCNBzPyP } & Água & 427 & 521 & 559 & 585 & 643 \\
\hline & $\mathrm{CTAB}^{1}$ & 427 & 521 & 558 & 586 & 642 \\
\hline \multirow[t]{2}{*}{$\mathrm{H}_{2} \mathrm{TNO}_{2} \mathrm{BzPyP}$} & Água & 428 & 521 & 560 & 587 & 641 \\
\hline & $\mathrm{CTAB}^{1}$ & 427 & 521 & 559 & 583 & 640 \\
\hline
\end{tabular}

${ }^{1}[\mathrm{CTAB}]=5,0 \times 10^{-3} \mathrm{~mol} \mathrm{dm}^{-3} ;{ }^{2}$ [CTAB] $=2,5 \times 10^{-5} \mathrm{~mol} \mathrm{dm}^{-3}$.

Já a porfirina aniônica $\mathrm{H}_{2}$ TPPS, apresenta forte interação com o surfactante catiônico, sendo possível caracterizar a formação de um agregado porfirinasurfactante em concentraçōes pré micelares. Esse agregado pré micelar foi caracterizado como um agregado-H por espectroscopia eletrônica, resonance lightscatering, rendimento quântico e tempo de vida de fluorescência por Periasamy e co autores $^{66}$. A figura 74 apresenta os espectros de absorção da $\mathrm{H}_{2}$ TPPS em diversas concentrações de CTAB. Em concentrações de CTAB na ordem de $2,5 \times 10^{-5} \mathrm{~mol}$ $\mathrm{dm}^{-3}$ observa-se a banda Soret deslocada para o azul $\left(\lambda_{\text {máx }}=401 \mathrm{~nm}\right)$ e deslocamento das bandas $Q$ para o vermelho. O deslocamento hipsocrômico da banda Soret foi 
atribuído à formação de agregados- $\mathrm{H}$, em que os monômeros estão alinhados cofacialmente, ou seja os momentos de transição estão perpendiculares ao eixo central do macrociclo ${ }^{66}$. As zincoporfirinas piridínio substituídas analisadas também não apresentam alteração espectroscópica relevante quando em solução contendo CTAB.

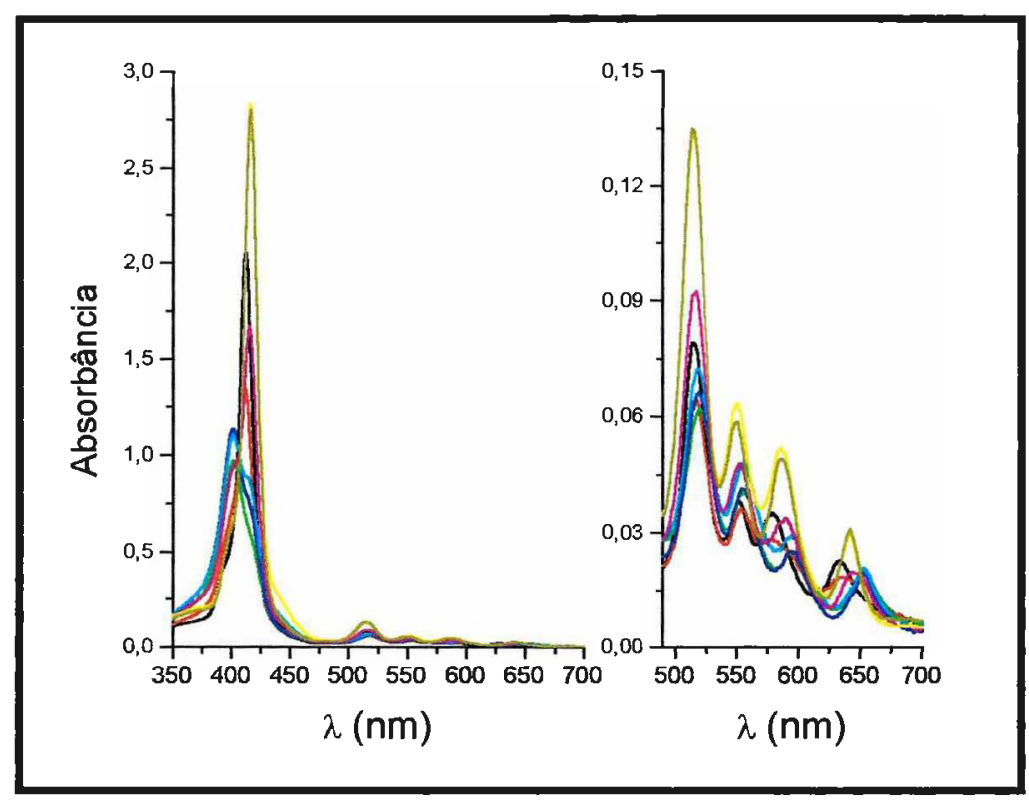

figura 74: Espectros eletrônicos de absorção da $\mathrm{H}_{2}$ TPPS em diversas concentrações de CTAB. A região das bandas $Q$ foi ampliada para melhor visualização.

O comportamento das soluções das porfirinas piridínio substituídas na faixa de absorção estudada $\left(6,0\right.$ a $\left.9,0 \mu \mathrm{mol} \mathrm{dm}^{-3}\right)$ varia significativamente de acordo com a concentração de SDS. Em concentrações relativamente baixas de surfactante (2,5 a 10 vezes a concentração de porfirina) observa-se a precipitação da porfirina. Neste caso, cada monômero de SDS deve agir como um contra-íon da porfirina, sendo a proporção porfirina/SDS ideal no agregado formado de 1:4. Nessa faixa de concentração observa-se uma turvação da solução, uma diminuição drástica da intensidade de absorção além de um aumento da linha base dos espectros obtidos.

Com o aumento da concentração de SDS há a dissolução do precipitado, havendo a formação de um agregado em solução ainda em concentrações abaixo da cmc. Dentre toda a série de porfirinas piridínio substituídas observa-se três perfis espectroscópicos na região da banda Soret distintos para esse agregado pré micelar (ver tabela 28), enquanto que o perfil das bandas $Q$ é semelhante para toda a série, observando-se um deslocamento para o vermelho de todas as bandas e a intensidade relativa apresentando perfil etio.

Em concentração pré micelar as porfirinas $\mathrm{H}_{2}$ TPnPyP, $\mathrm{H}_{2}$ TAIPyP, $\mathrm{H}_{2}$ TPhEtPyP, $\mathrm{H}_{2}$ TPrPhPyP, $\mathrm{H}_{2}$ TBzPyP, $\mathrm{H}_{2}$ TBrBzPyP e $\mathrm{H}_{2} \mathrm{TCH}_{3}$ BzPyP formam agregados que 
apresentam a banda Soret deslocada para o azul, um comportamento semelhante ao observado para o sistema $\mathrm{H}_{2}$ TPPS e CTAB, com o máximo da banda Soret próximo a $400 \mathrm{~nm}$. Outra série apresenta uma banda Soret larga e com baixa intensidade, entretanto, com máximo de absorção muito similar ao observado para as porfirinas em soluçōes concentradas de SDS. Entre as porfirinas que apresentam esse comportamento está a $\mathrm{H}_{2} \mathrm{TMPyP}$, sendo coerente com o relatado na literatura para o mesmo sistema ${ }^{66}$, e a $\mathrm{H}_{2} \mathrm{TMeOBzPyP}$. O terceiro perfil é verificado para as porfirinas $\mathrm{H}_{2} \mathrm{TNO}_{2} \mathrm{BzPyP}$ e $\mathrm{H}_{2} \mathrm{TCNBzPyP}$, com a banda Soret deslocada para o vermelho em relação aos espectros das respectivas porfirinas em solução concentrada de SDS.

tabela 28: Máximos de absorção $\left(\lambda_{\max }\right)$ das porfirinas base livre em solução aquosa contendo SDS.

\begin{tabular}{|c|c|c|c|c|c|c|}
\hline Porfirinas & solvente & $\begin{array}{l}\text { Soret } \\
(n n)\end{array}$ & $\begin{array}{c}Q_{1}(1,0) \\
(\mathrm{nm})\end{array}$ & $\begin{array}{l}Q, 0,0) \\
(\mathrm{nm})\end{array}$ & $\begin{array}{c}Q_{\times}(1,0) \\
(n n)\end{array}$ & $\begin{array}{c}Q, 0,0) \\
(n m)\end{array}$ \\
\hline $\mathrm{H}_{2}$ TPPS & $\mathrm{SDS}^{1}$ & 413 & 515 & 552 & 580 & 635 \\
\hline \multirow[t]{2}{*}{$\mathrm{H}_{2}$ TMPyP } & $\mathrm{SDS}^{1}$ & 426 & 518 & 555 & 589 & 643 \\
\hline & SDS $^{2}$ & 423 & 520 & 554 & 592 & 648 \\
\hline \multirow[t]{2}{*}{$\mathrm{H}_{2}$ TAIPyP } & $\mathrm{SDS}^{1}$ & 429 & 520 & 559 & 590 & 643 \\
\hline & $\mathrm{SDS}^{2}$ & 401 & 520 & 562 & 593 & 651 \\
\hline \multirow[t]{2}{*}{$\mathrm{H}_{2}$ TPnPyP } & $\mathrm{SDS}^{1}$ & 434 & 526 & 561 & 594 & 651 \\
\hline & $\mathrm{SDS}^{2}$ & 394 & 521 & 560 & 593 & 651 \\
\hline \multirow[t]{2}{*}{$\mathrm{H}_{2}$ PhEtPyP } & $\mathrm{SDS}^{1}$ & 433 & 523 & 561 & 592 & 648 \\
\hline & $\mathrm{SDS}^{2}$ & 402 e 434 & 522 & 558 & 595 & 651 \\
\hline \multirow{2}{*}{$\mathrm{H}_{2} \mathrm{PhPrPyP}$} & SDS $^{1}$ & 435 & 526 & 562 & 595 & 652 \\
\hline & SDS $^{2}$ & 397 & 526 & 562 & 594 & 651 \\
\hline \multirow{2}{*}{$\mathrm{H}_{2}$ TMeOBzPyP } & $\operatorname{SDS}^{1}$ & 431 & 522 & 559 & 592 & 647 \\
\hline & $\mathrm{SDS}^{2}$ & 429 & 526 & 560 & 594 & 652 \\
\hline \multirow[t]{2}{*}{$\mathrm{H}_{2} \mathrm{TCH}_{3}$ BzPyP } & SDS $^{1}$ & 433 & 524 & 556 & 592 & 648 \\
\hline & SDS $^{2}$ & 404 & 525 & 563 & 596 & 654 \\
\hline \multirow[t]{2}{*}{$\mathrm{H}_{2}$ TBzPyP } & SDS $^{1}$ & 433 & 523 & 560 & 592 & 649 \\
\hline & SDS $^{2}$ & 408 & 526 & 563 & 594 & 652 \\
\hline \multirow[t]{2}{*}{$\mathrm{H}_{2}$ TBrBzPyP } & SDS $^{1}$ & 434 & 525 & 562 & 595 & 652 \\
\hline & SDS $^{2}$ & 403 & 525 & 562 & 595 & 652 \\
\hline \multirow[t]{2}{*}{$\mathrm{H}_{2} \mathrm{TCNBzPyP}$} & SDS $^{1}$ & 434 & 523 & 560 & 593 & 650 \\
\hline & SDS $^{2}$ & 442 & 526 & 561 & 596 & 652 \\
\hline \multirow{2}{*}{$\mathrm{H}_{2} \mathrm{TNO}_{2} \mathrm{BzPyP}$} & SDS $^{1}$ & 435 & 524 & 563 & 593 & 652 \\
\hline & SDS $^{2}$ & 443 & 527 & 563 & 595 & 652 \\
\hline
\end{tabular}

${ }^{1}[S D S]=1,0 \times 10^{-1} \mathrm{~mol} \mathrm{dm}^{-3} ;{ }^{2}[S D S]=5,0 \times 10^{-4} \mathrm{~mol} \mathrm{dm}^{-3}$.

Em concentrações de SDS acima da $\mathrm{cmc}\left(8 \mathrm{mmol} \mathrm{dm}^{-3}\right.$, condição 1 da tabela acima) há a formação de uma nova espécie que é atribuída ao agregado porfirina/micela, caracterizado por um novo perfil espectral. Esse perfil é semelhante para toda a série de porfirinas piridínio substituídas, com a banda Soret deslocada de 5 a $12 \mathrm{~nm}$ para o vermelho em relação ao espectro em solução aquosa. As bandas $Q$ também aparecem deslocadas para o vermelho, entretanto há uma melhor definição das bandas $Q_{y}(0,0)$ e $Q_{x}(1,0)$, com uma maior separação entre as bandas e inversão 
de intensidade relativa, obtendo-se um espectro do tipo etio, perfil semelhante ao observado para os solventes orgânicos. Observa-se um ligeiro aumento na absortividade por mol de todas as bandas (ver figura 76).

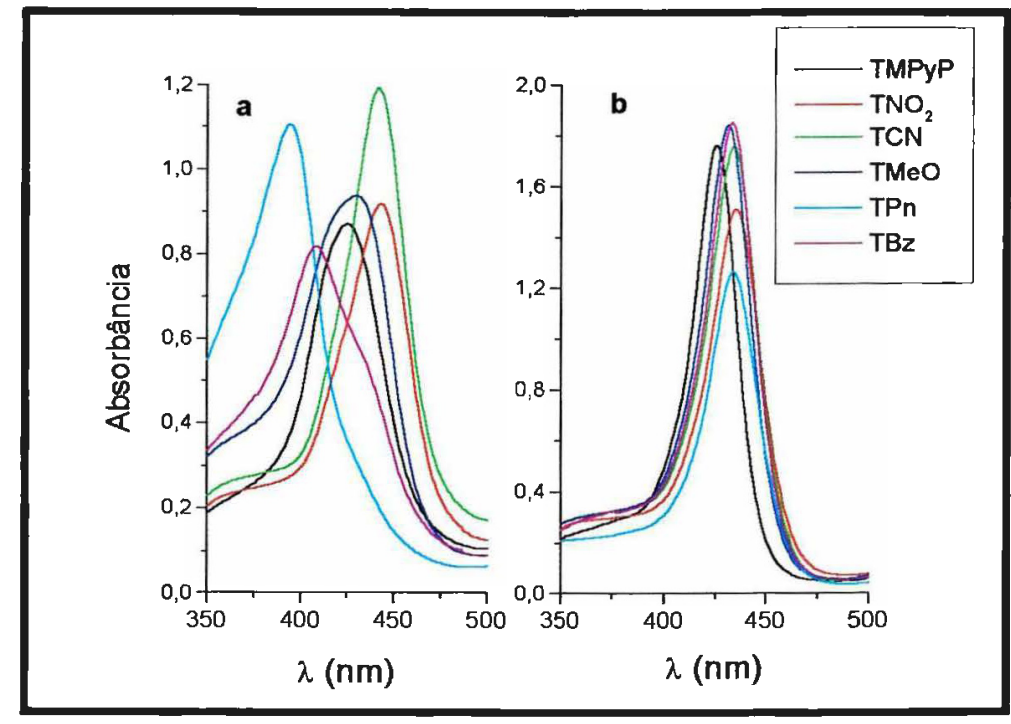

figura 75: Espectros de emissão das porfirinas catiônicas em solução de SDS: a- $[S D S]=5,0 \times 10^{-4} \mathrm{~mol} \mathrm{dm}^{-3} ; \mathrm{b}-[S D S]=1,0 \times 10^{-1} \mathrm{~mol} \mathrm{dm}^{-3}$

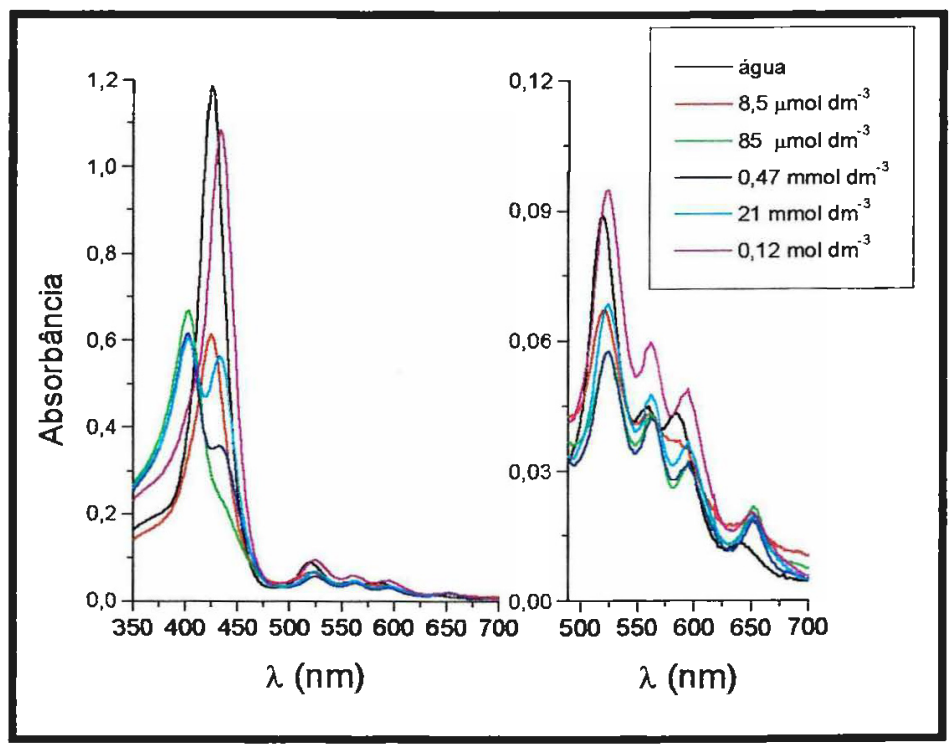

figura 76: Espectros eletrônicos da $\mathrm{H}_{2} \mathrm{TBrBzPyP}$ em solução aquosa contendo diferentes concentrações de SDS. A região das bandas $Q$ foi ampliada para melhor visualização.

Se ao invés de preparar uma série de soluções com concentrações diferentes de SDS, realiza-se uma titulação mantendo-se constante a concentração de porfirina, aumentando-se a concentração de SDS na solução final e agitando-se a solução final durante um minuto antes de qualquer medida, verifica-se um comportamento dependente da cinética de associação porfirina/micela. Nota-se que é lenta a 
solubilização do precipitado porfirina/SDS, o que compromete a observação do equilíbrio entre o agregado premicelar e o agregado porfirina/micela.

Entretanto, ao se iniciar a titulação em concentrações em que já ocorre a associação porfirina/SDS é possível verificar os três tipos de associações distintos entre as porfirinas e os monômeros do surfactante, bem como o equilibrio com a formação de micelas e a respectiva incorporação da porfirina.

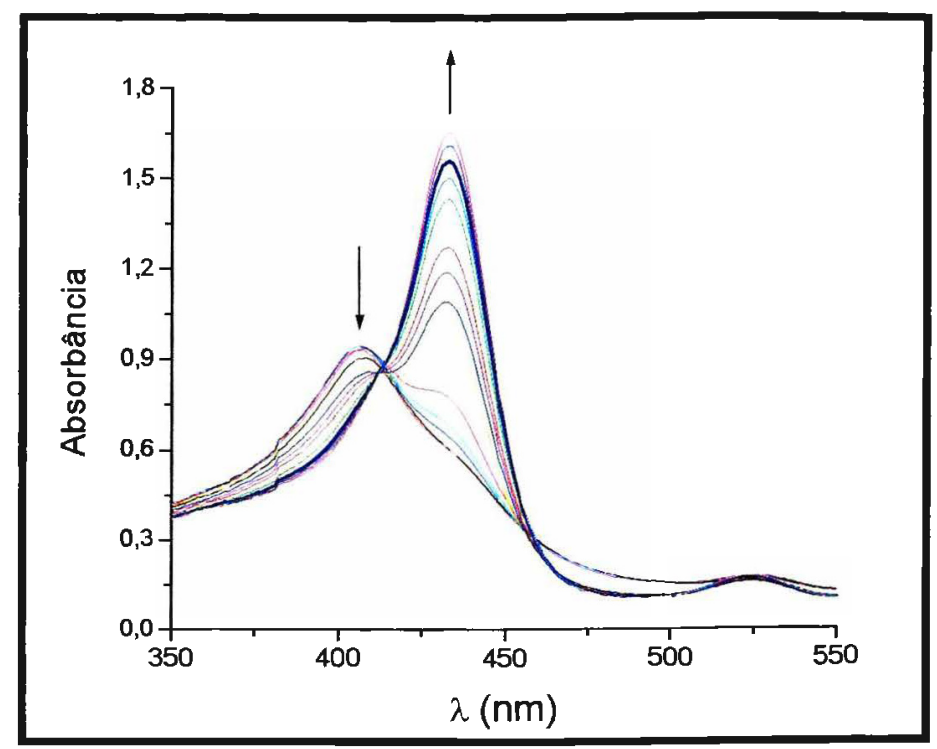

figura 77: Espectros eletrônicos de solução aquosa de $\mathrm{H}_{2} \mathrm{TBz} P y P\left(9 \mu \mathrm{mol} \mathrm{dm}{ }^{-3}\right)$ durante titulação com SDS;1,0 × $10^{-4} \mathrm{~mol} \mathrm{dm}^{-3}<$ [SDS] $<2,5 \times 10^{-2} \mathrm{~mol} \mathrm{dm}^{-3}$.

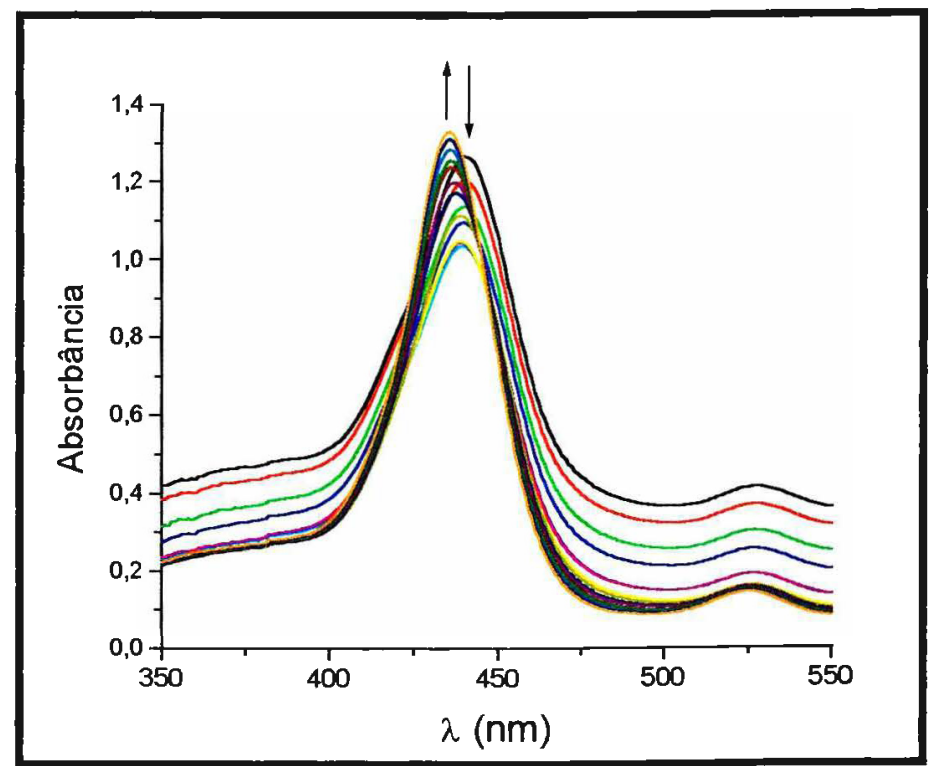

figura 78: Espectros eletrônicos de solução aquosa de $\mathrm{H}_{2}$ TCNBzPyP $\left(7,5 \mu \mathrm{mol} \mathrm{dm}^{-3}\right)$ durante titulação com SDS;

$1,0 \times 10^{-4} \mathrm{~mol} \mathrm{dm}^{-3}<$ [SDS] $<2,5 \times 10^{-2} \mathrm{~mol} \mathrm{dm}^{-3}$. 
A figura 77 apresenta os espectros eletrônicos da $\mathrm{H}_{2}$ TBzPyP durante a titulação com SDS. É possível identificar um isosbéstico em $413 \mathrm{~nm}$ indicando o equilíbrio entre a espécie associada em concentração pre-micelar e a formação do agregado micelar. Entretanto, nem todas as porfirinas apresentam comportamento semelhante. As porfirina $\mathrm{H}_{2}$ TMPyP, $\mathrm{H}_{2} \mathrm{TMeOBzPyP}, \mathrm{H}_{2} \mathrm{TNO}_{2} B z P y P$ e $\mathrm{H}_{2} \mathrm{TCNBzPyP}$, que não apresentam agregado pre-micelar com deslocamento da banda Soret para o azul, não apresentam isosbésticos bem definidos na transição entre o agregado premicelar e o agregado micelar, como mostra as figuras 78 e 79 . Em ambas as situações, nota-se uma diminuição da absorbância da banda referente ao agregado pré micelar, uma quebra brusca de comportamento, aparecendo a banda referente ao agregado em meio micelar, com aumento da absorbância desta banda conforme a adição de surfactante.

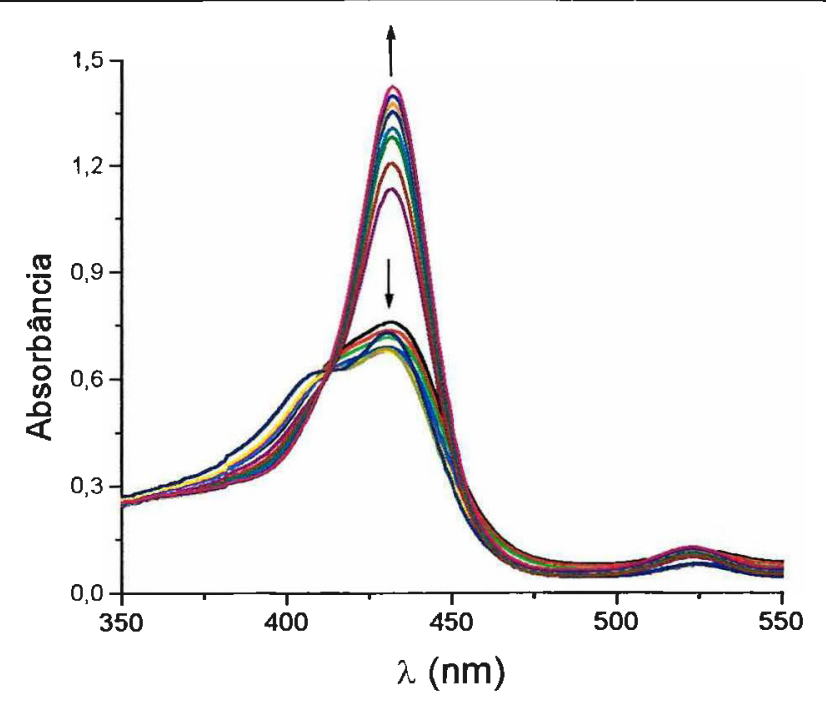

figura 79: Espectros eletrônicos de solução aquosa de $\mathrm{H}_{2} \mathrm{TMeOBzPyP}$ $\left(7,5 \mu \mathrm{mol} \mathrm{dm}^{-3}\right)$ durante titulação com SDS;

$1,0 \times 10^{-4} \mathrm{~mol} \mathrm{dm}^{-3}<$ [SDS] $<2,5 \times 10^{-2} \mathrm{~mol} \mathrm{dm}^{-3}$.

Todas as zincoporfirinas analisadas apresentam todas 0 mesmo comportamento espectral em relação à variação de concentração de SDS. Em concentrações baixas de SDS ocorre a precipitação da porfirina, a redissolução acontece em concentrações de SDS a partir de $5 \times 10^{-5} \mathrm{~mol} \mathrm{dm}^{-3}$, ou seja a partir da relação porfirina/surfactante 1:8. Também é verificada a formação agregados pré micelares para as zincoporfirinas, entretanto o perfil espectral da série estudada é muito semelhante entre si, com a banda Soret mais larga, com baixa intensidade $e$ deslocada cerca de $3 \mathrm{~nm}$ em relação a banda Soret da metaloporfirina em meio micelar de SDS (figura 80). 
A partir de concentrações de SDS acima de $1 \times 10^{-2} \mathrm{~mol} \mathrm{dm}^{-3}$ o perfil espectral das zincoporfirinas não apresenta novas mudanças. $O$ deslocamento batocrômico da banda Soret observado na série é de $11 \mathrm{~nm}$, enquanto que as bandas $\mathrm{Q}$ sofrem um deslocamento menor, entre 5 e $7 \mathrm{~nm}$.

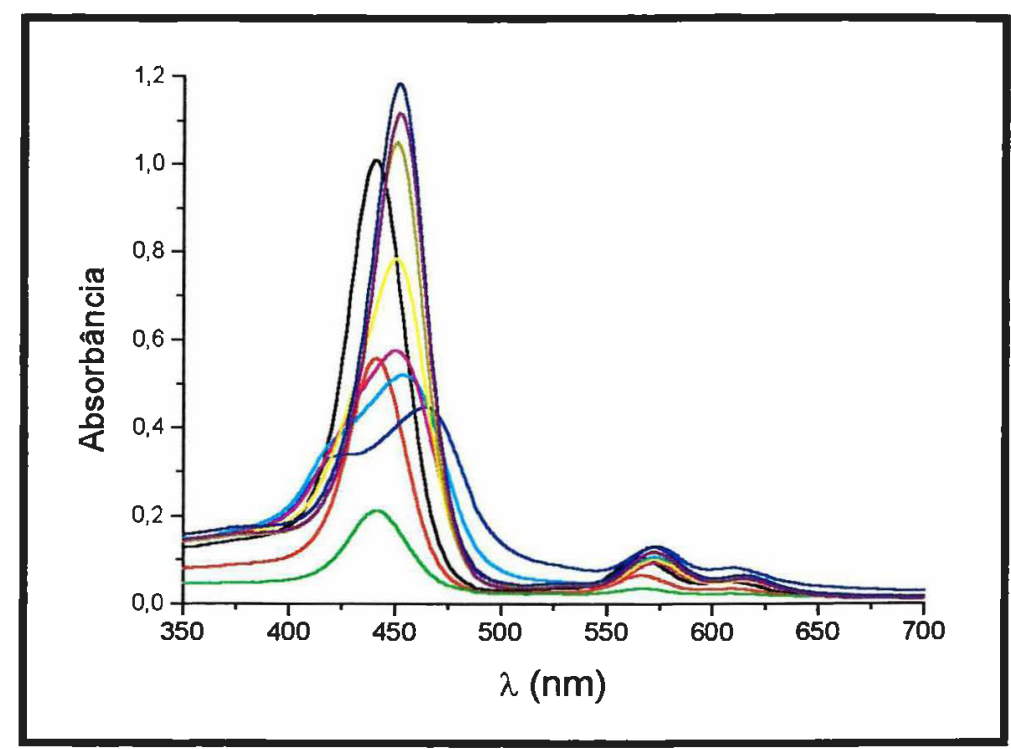

figura 80: Espectro eletrônico da ZnTBzPyP em solução aquosa contendo diferentes concentrações de SDS.

O comportamento dos espectros de absorção apresentado pelas porfirinas piridínio substituídas em solução aquosa contendo surfactantes não iônicos, Triton X100 ou PTE, evidencia a ocorrência de formação de agregado entre a porfirina e a micela do surfactante. Para a maioria dos derivados piridínio substituídos ocorre deslocamento batocrômico da banda Soret, entre 1 e $7 \mathrm{~nm}$, pequeno aumento da intensidade das bandas, separação das bandas $Q$ e intensidade relativa das bandas correspondente ao perfil etio. Não há evidencia de formação de agregados pré micelares.

A interação porfirina surfactante nesse caso é devido à interação de van der Waals entre a porfirina e o surfactante, sendo dependente do caráter hidrofóbico e do tamanho do grupo ligado ao nitrogênio piridínico. Os espectros da $\mathrm{H}_{2} T M P y P$ em solução aquosa são idênticos aos obtidos em soluções contendo Triton X100 ou PTE em concentrações cerca de 100 vezes acima da $\mathrm{cmc}$, indicando que essa porfirina não apresenta interação com surfactantes não iônicos. Já porfirinas de tamanho intermediários como a $\mathrm{H}_{2}$ TAIPyP e $\mathrm{H}_{2}$ TPnPyP apresentam pequena alteração espectroscópica, com deslocamento da banda Soret de 1 e $2 \mathrm{~nm}$, respectivamente, além da inversão da intensidade relativa das bandas $Q_{y}(0,0)$ e $Q_{x}(1,0)$. Os demais substituintes apresentaram mudanças mais drásticas nos espectros eletrônicos como pode ser verificado na tabela 29. 
tabela 29: Máximos de absorção ( $\lambda_{\text {máx }}$ ) das porfirinas base livre em solução aquosa contendo PTE ou Triton X100.

\begin{tabular}{|c|c|c|c|c|c|c|}
\hline Porfininas & sistema & $\begin{array}{l}\text { Soret } \\
\text { (nm) }\end{array}$ & $\begin{array}{l}\text { Q(1,0) } \\
(n m)\end{array}$ & $\begin{array}{c}Q_{y}(0,0) \\
(n m)\end{array}$ & $\begin{array}{c}Q_{x}(1,0) \\
(n m)\end{array}$ & $\begin{array}{c}Q_{x}(0,0) \\
(\mathrm{nm})\end{array}$ \\
\hline \multirow[t]{2}{*}{$\mathrm{H}_{2}$ TPPS } & $\mathrm{PTE}^{1}$ & & & & & \\
\hline & Triton $\times 100^{2}$ & 418 & 514 & 549 & 589 & 644 \\
\hline \multirow[t]{2}{*}{$\mathrm{H}_{2}$ TMPyP } & PTE & 421 & 517 & 557 & 584 & 641 \\
\hline & Triton $\times 100$ & 421 & 517 & 557 & 583 & 640 \\
\hline \multirow[t]{2}{*}{$\mathrm{H}_{2}$ TAIPyP } & PTE & 424 & 519 & 555 & 585 & 643 \\
\hline & Triton X100 & 424 & 518 & 552 & 586 & 642 \\
\hline \multirow[t]{2}{*}{$\mathrm{H}_{2}$ TPnPyP } & PTE & 424 & 518 & 552 & 586 & 642 \\
\hline & Triton $\times 100$ & 424 & 518 & 555 & 565 & 642 \\
\hline \multirow[t]{2}{*}{$\mathrm{H}_{2}$ PhEtPyP } & PTE & 427 & 519 & 555 & 590 & 646 \\
\hline & Triton X100 & 428 & 519 & 555 & 590 & 645 \\
\hline \multirow[t]{2}{*}{$\mathrm{H}_{2} \mathrm{PhPrPyP}$} & PTE & 429 & 520 & 556 & 592 & 647 \\
\hline & Triton $\times 100$ & 430 & 520 & 557 & 591 & 647 \\
\hline \multirow[t]{2}{*}{$\mathrm{H}_{2} \mathrm{TMeOBzPyP}$} & PTE & 430 & 521 & 551 & 591 & 648 \\
\hline & Triton $\times 100$ & 430 & 520 & 557 & 591 & 647 \\
\hline \multirow[t]{2}{*}{$\mathrm{H}_{2} \mathrm{TCH}_{3} \mathrm{Bz} \mathrm{PyP}$} & PTE & 430 & 521 & 557 & 591 & 648 \\
\hline & Triton $\times 100$ & 431 & 521 & 557 & 592 & 646 \\
\hline \multirow[t]{2}{*}{$\mathrm{H}_{2}$ TBzPyP } & PTE & 428 & 520 & 556 & 586 & 646 \\
\hline & Triton X100 & 429 & 521 & 557 & 590 & 646 \\
\hline \multirow[t]{2}{*}{$\mathrm{H}_{2}$ TBrBzPyP } & PTE & 433 & 523 & 558 & 593 & 649 \\
\hline & Triton X100 & 433 & 522 & 559 & 592 & 648 \\
\hline \multirow[t]{2}{*}{$\mathrm{H}_{2}$ TCNBzPyP } & PTE & 429 & 521 & 555 & 589 & 646 \\
\hline & Triton X100 & 430 & 521 & 556 & 587 & 647 \\
\hline \multirow[t]{2}{*}{$\mathrm{H}_{2} \mathrm{TNO}_{2} \mathrm{BzPyP}$} & PTE & 431 & 522 & 558 & 590 & 647 \\
\hline & Triton $\times 100$ & 432 & 521 & 559 & 589 & 648 \\
\hline
\end{tabular}

${ }^{1}[\mathrm{PTE}]=3,3 \times 10^{-2} \mathrm{~mol} \mathrm{dm}^{-3} ;{ }^{2}\left[\right.$ riton X100] $=3,4 \times 10^{-2} \mathrm{~mol} \mathrm{dm}^{-3}$.

Outro fator interessante é que não há diferença apreciável de comportamento das porfirinas entre os dois surfactantes não iônicos estudados, pois verifica-se para alguns derivados uma diferença de $1 \mathrm{~nm}$ apenas na banda Soret, indicando uma maior interação com o Triton X100. Esse resultado indica que interação $\pi-\pi$ que pode ocorrer entre $\circ$ anel fenílico da porfirina e $\circ$ anel fenílico do detergente não apresenta contribuição significativa na formação do agregado (figura 81).

As zincoporfirinas apresentam comportamento similar às bases livres em relação aos surfactantes não iônicos, ocorrendo apenas formação de um agregado porfirina/micela, com deslocamento para o vermelho das bandas Soret e $Q$ (figura 82). Novamente, percebe-se a influência do tamanho do substituinte, uma vez que a ZnTMPyP não apresenta alteração espectroscópica significativa em meio contendo os detergentes não iônicos. 


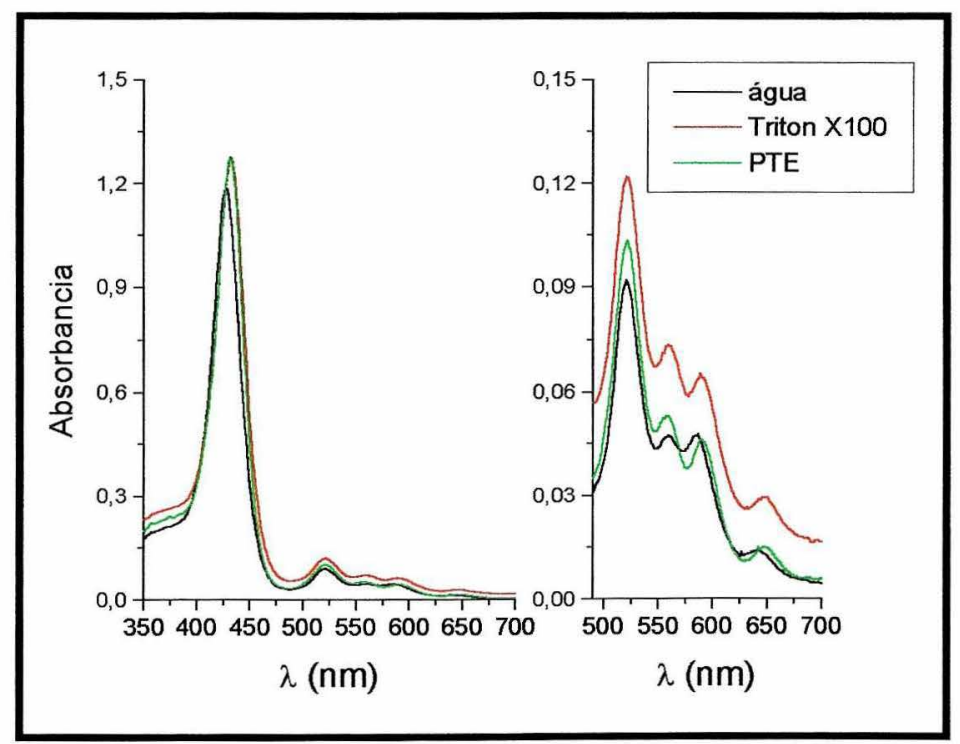

figura 81: Espectros eletrônicos da $\mathrm{H}_{2} \mathrm{TNO}_{2} \mathrm{BzPyP}$ em solução aquosa, solução contendo Triton X100 e solução contendo PTE. A região das bandas $Q$ foi ampliada para melhor visualização.

tabela 30: Máximos de absorção $\left(\lambda_{\text {máx }}\right)$ das zincoporfirinas em solução aquosa contendo CTAB, SDS, PTE ou Triton X100.

\begin{tabular}{|c|c|c|c|c|}
\hline Porfirina & Sistema & Soret $(\mathrm{nm})$ & $\mathrm{Q}(1,0)(\mathrm{nm})$ & $\mathrm{Q}(0,0)(\mathrm{nm})$ \\
\hline \multirow[t]{6}{*}{ ZnTMPyP } & Água & 436 & 563 & 607 \\
\hline & CTAB $^{1}$ & 436 & 563 & 607 \\
\hline & $\operatorname{SDS}^{2}$ & 444 & 567 & 608 \\
\hline & $\mathrm{SDS}^{3}$ & 441 & 565 & 607 \\
\hline & $\mathrm{PTE}^{4}$ & 436 & 564 & 605 \\
\hline & Triton $\times 100^{5}$ & 436 & 563 & 605 \\
\hline \multirow[t]{6}{*}{ ZnTMeOBzPyP } & Água & 439 & 564 & 608 \\
\hline & CTAB $^{1}$ & 439 & 564 & 608 \\
\hline & SDS $^{2}$ & 450 & 570 & 613 \\
\hline & SDS $^{3}$ & 451 & 573 & 615 \\
\hline & $\mathrm{PTE}^{4}$ & 447 & 569 & 613 \\
\hline & Triton $\times 100^{5}$ & 448 & 569 & 613 \\
\hline \multirow[t]{6}{*}{ ZnTBzPyP } & Água & 441 & 566 & 609 \\
\hline & CTAB $^{1}$ & 441 & 566 & 609 \\
\hline & SDS $^{2}$ & 452 & 572 & 614 \\
\hline & $\mathrm{SDS}^{3}$ & 450 & 572 & 612 \\
\hline & $\mathrm{PTE}^{4}$ & 444 & 568 & 610 \\
\hline & Triton $\times 100^{5}$ & 447 & 568 & 611 \\
\hline \multirow{6}{*}{$\mathrm{ZnTNO}{ }_{2} \mathrm{BzPyP}$} & Água & 444 & 567 & 610 \\
\hline & CTAB $^{1}$ & 444 & 567 & 610 \\
\hline & $\mathrm{SDS}^{2}$ & 455 & 574 & 616 \\
\hline & $\mathrm{SDS}^{3}$ & 456 & 574 & 618 \\
\hline & PTE $^{4}$ & 451 & 571 & 614 \\
\hline & Triton $\times 100^{5}$ & 452 & 571 & 614 \\
\hline
\end{tabular}

${ }^{1}[\mathrm{CTAB}]=5,0 \times 10^{-3} \mathrm{~mol} \mathrm{dm}^{-3} ;{ }^{2}[\mathrm{SDS}]=1,0 \times 10^{-1} \mathrm{~mol} \mathrm{dm}^{-3} ;{ }^{3}[\mathrm{SDS}]=5,0 \times 10^{-4}$ mol dm ${ }^{-3} ;{ }^{4}[$ PTE $]=3,3 \times 10^{-2} \mathrm{~mol} \mathrm{dm}^{-3} ;{ }^{5}$ Triton X100] $=3,4 \times 10^{-2} \mathrm{~mol} \mathrm{dm}^{-3}$. 


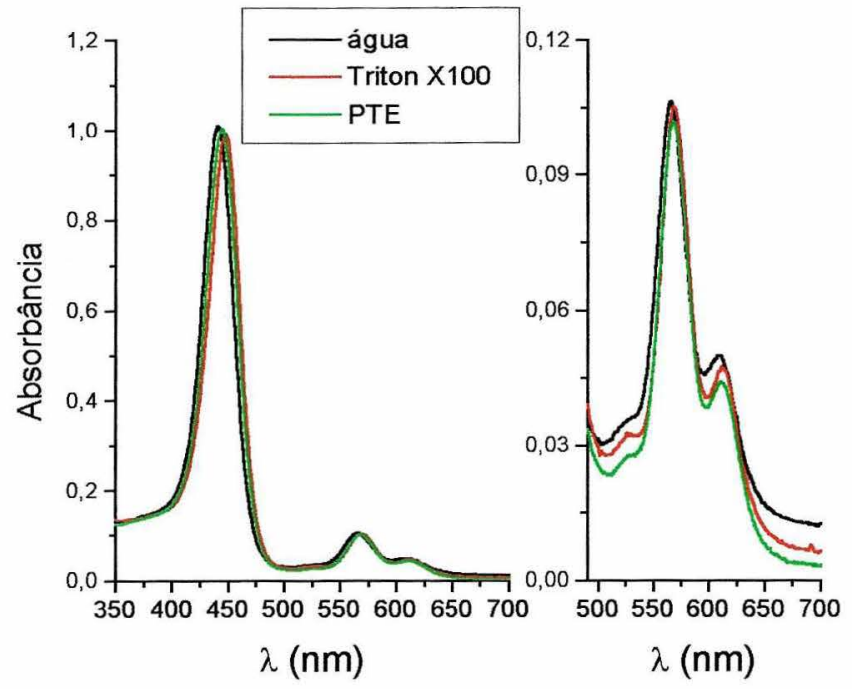

figura 82: Espectros eletrônicos da ZnTBzPyP em solução aquosa, solução contendo Triton X100 e solução contendo PTE. A região das bandas $Q$ foi ampliada para melhor visualização.

\subsubsection{Espectros Eletrônicos de Emissão}

Foram obtidos os espectros de emissão nas mesmas condições de concentração de porfirina e de surfactante em que foram realizados os espectros de absorção, para os detergentes SDS e Triton X100. A excitação foi realizada sempre na banda $Q$ mais intensa da porfirina estudada, com absorbância variando entre $0,1 \mathrm{e}$ 0,15 , evitando distorções do espectro obtido devido a efeitos de filtro interno. A análise da emissão dos sistemas porfirina/surfactante confirmam as hipóteses evidenciadas pelos espectros de absorção.

A análise da evolução dos espectros de emissão das base livres das porfirinas piridínio substituídas com o aumento da concentração de SDS mostra que toda a série apresenta comportamento similar. Inicialmente, observa-se uma diminuição drástica da intensidade de emissão, devido a formação do precipitado, com cada monômero de SDS agindo como contra-íon da porfirina.

Com a concentração de SDS cerca de dez vezes maior que a porfirina observa-se a dissolução do precipitado, o espectro de emissão apresenta duas bandas bem definidas, sendo bastante distinto do espectro de emissão obtido em água. Ainda nessa condição, nota-se que as intensidades de emissão são menores do que as correspondentes intensidades em solução aquosa. Nessa faixa de concentração de SDS é atribuída a existência de um agregado pré micelar, que apresenta um rendimento quântico de fluorescência menor do que a porfirina em solução aquosa. Essa menor intensidade de emissão pode ser explicada pela 
supressão porfirina-porfirina, sendo razoável supor a formação de agregados que permitam interações e acoplamentos eletrônicos entre os macrociclos porfirínicos.

É importante salientar que nessas mesmas condições de concentração é possível identificar três comportamentos distintos dos espectros de absorção, para a série de porfirinas estudadas, ocorrendo deslocamentos da banda Soret da ordem de até $30 \mathrm{~nm}$, esses deslocamentos também são explicados pelo acoplamento eletrônico entre os sistemas porfirínicos. De acordo com as características dos deslocamentos da banda Soret, propõe-se uma classificação dos agregados formados seguindo as observações feitas por Periasamy e co autores para os agregados formados pelas porfirinas aniônicas $\mathrm{H}_{2}$ TPPS e $\mathrm{H}_{2}$ TPPC e os surfactantes Triton X100 e CTAB ${ }^{66}$.

Agregados que apresentam deslocamento da banda Soret para a região do azul indicam um arranjo cofacial entre as porfirinas, com forte acoplamento dos monômeros e com os momentos de transição perpendiculares ao eixo central do anel porfirínico. Esses agregados são denominados agregados- $\mathrm{H}$. Já as porfirinas $\mathrm{H}_{2} \mathrm{TNO}_{2} \mathrm{BzPyP}$ e $\mathrm{H}_{2} \mathrm{TCNBzPyP}$ formam agregados que apresentam deslocamento batocrômico da banda Soret, indicando que o momento de transição e as linhas que unem os centros dos monômeros estão paralelos, ou seja o arranjo das porfirinas é lado a lado, formando o chamado agregado-J.

Um terceiro tipo de agregado, provavelmente sem uma distribuição regular dos monômeros, resulta em uma banda Soret larga e de menor intensidade. Esse tipo de agregado ocorre com as porfirinas $\mathrm{H}_{2}$ TMPyP, $\mathrm{H}_{2} \mathrm{TMeOBzPyP}$ e também com os zinco derivados.

Com o aumento da concentração de SDS, ultrapassando os valores da $\mathrm{cmc}$, há um aumento da intensidade da emissão para toda a série de porfirinas piridínio substituídas, indicando a existência de um novo agregado porfirina/surfactante, provavelmente com a porfirina na forma de monômeros independentes associados às micelas de SDS. As duas bandas de emissão, diferentemente do espectro em solução aquosa, estão separadas e bem definidas, similar aos espectros observados em solução de solventes orgânicos. Não há deslocamento significativo das bandas em relação ao agregado pré micelar, ocorrendo somente um aumento de intensidade. Em uma avaliação qualitativa, a porfirina associada à micela de SDS apresenta rendimento quântico de fluorescência maior do que a porfirina em meio aquoso e o ambiente de solvatação é semelhante ao solventes orgânicos, evidenciando uma menor interação com a água (figura 83). Observação semelhante para o sistema $\mathrm{H}_{2}$ TMPyP/SDS corroborou com a hipótese de Kano e co-autores ${ }^{39}$ acerca da dimerização dessa porfirina em meio aquoso, sendo o SDS um dos agentes capazes de manter a porfirina na forma monomérica. 


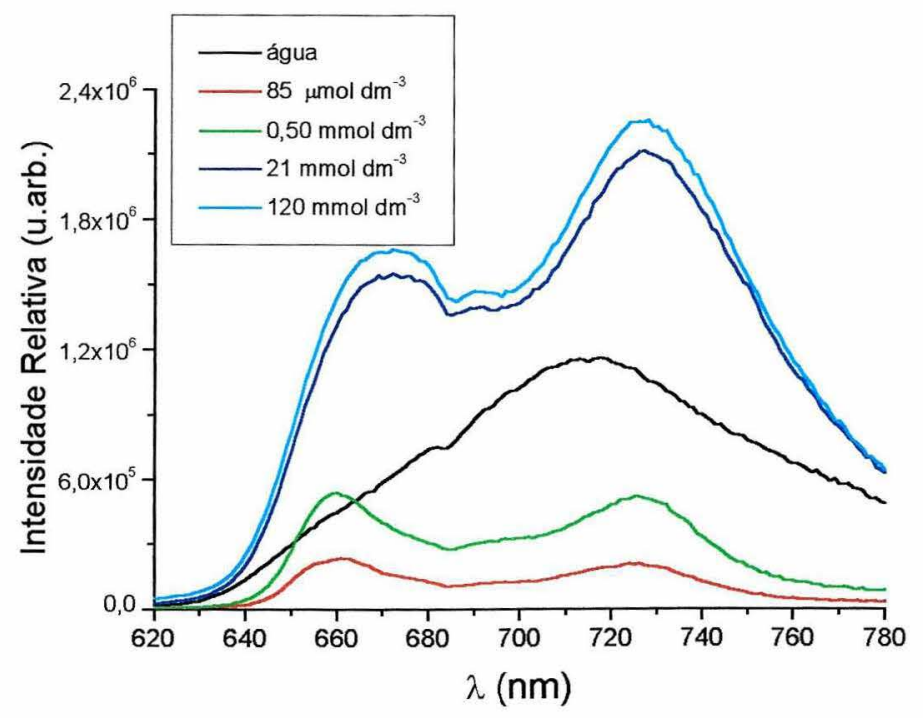

figura 83: Espectro eletrônico de emissão da $\mathrm{H}_{2} \mathrm{TCH}_{3} \mathrm{BzPyP}$ em solução aquosa e solução aquosa contendo SDS em diferentes concentrações.

Novamente, o comportamento apresentado pelas porfirinas em Triton X100 é similar para toda série no que se refere ao espectro de emissão. O espectro de emissão das porfirinas em solução aquosa contendo Triton X100 em concentrações menores que a cmc não apresenta variações se comparado com o espectro em solução aquosa, entretanto, o aumento da concentração de Triton X100 ultrapassando a cmc modifica o espectro de emissão obtido. Observa-se uma separação e definição das duas bandas $Q$, com aumento da intensidade da emissão, indicando um maior rendimento quântico de fluorescência (figura 84). Esse comportamento espectroscópico pode ser atribuído ao meio em que o macrociclo porfirínico se encontra, associado à micela, sofrendo a influência de uma solvatação não aquosa e com elevado caráter hidrofóbico. As duas porfirinas piridínio substituídas que já tinham apresentado baixa ou nenhuma interação com o Triton X100 na análise dos espectros eletrônicos, a $\mathrm{H}_{2}$ TMPyP e a $\mathrm{H}_{2}$ TAIPyP, não apresentam alterações espectroscópicas significativas, comprovando a baixa interação devido ao baixo caráter hidrofóbico dos grupos metil e alil. 


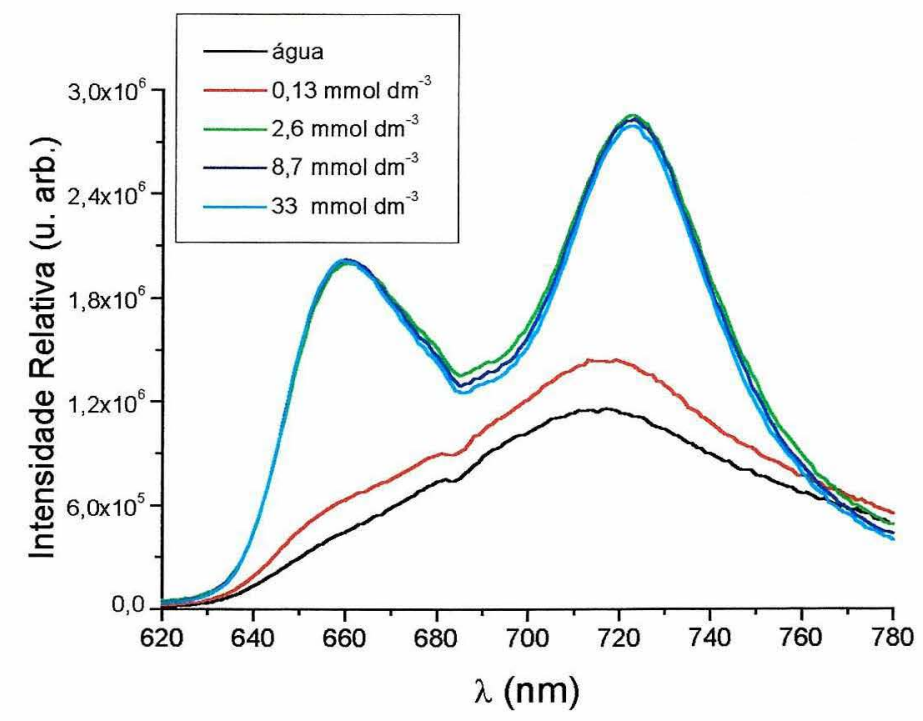

figura 84: Espectro eletrônico de emissão da $\mathrm{H}_{2} \mathrm{TCH}_{3} \mathrm{BzPyP}$ em solução aquosa e solução aquosa contendo Triton $\mathrm{X} 100$ em diferentes concentrações.

A tabela 31 apresenta os máximos de emissão determinados para as porfirinas base livres em meio micelar de SDS e Triton X100. É interessante notar que em SDS as bandas encontram-se bastante deslocadas para o vermelho em relação ao mesmo derivado em SDS. Comparando-se os espectros obtidos em solventes orgânicos como metanol e DMSO, as bandas de emissão em meio micelar possuem uma menor energia, apresentando deslocamento batocrômico ao longo de toda a série.

Os valores dos máximos de emissão não foram determinados para as zincoporfirinas analisadas, pois mesmo em concentrações muito acima da cmc em Triton X100 e em SDS não há uma definição da banda suficiente para a distinção dos máximos de emissão sem o uso dos cálculos de deconvolução (figura 85).

Em SDS observa-se a formação de precipitado, seguida da dissolução desse precipitado com o aumento da concentração do detergente. Assim como para as bases livres, os espectros obtidos em concentração de SDS abaixo da cmc apresentam baixa intensidade de fluorescência, entretanto não ocorre a definição das bandas. Para a concentração de SDS acima da cmc nota-se um aumento da intensidade relativa das bandas, indicando que a zincoporfirina em meio micelar também apresenta rendimento quântico de fluorescência maior do que a porfirina em meio aquoso. A ZnTMPyP é a única das zincoporfirinas piridínio substituídas que apresenta espectro de emissão com as duas bandas bem definidas em SDS, podendo-se determinar os máximos de emissão. 
tabela 31: Máximos de emissão $\left(\lambda_{\text {máx }}\right)$ das porfirinas piridínio substituídas em solução aquosa contendo SDS ${ }^{1}$ ou Triton $\mathrm{X100}^{2}$.

\begin{tabular}{|c|c|c|c|}
\hline Porfirinas & Sistema & $\mathrm{Q}(0,0)(\mathrm{nm})$ & $\mathrm{Q}(0,1)(\mathrm{nm})$ \\
\hline \multirow[t]{2}{*}{$\mathrm{H}_{2}$ TMPyP } & SDS & 659 & 719 \\
\hline & Triton $\times 100$ & -- & -- \\
\hline \multirow{2}{*}{$\mathrm{H}_{2}$ TAIPyP } & SDS & 663 & 724 \\
\hline & Triton $\times 100$ & -- & -- \\
\hline \multirow[t]{2}{*}{$\mathrm{H}_{2}$ TPnPyP } & SDS & 672 & 727 \\
\hline & Triton $\times 100$ & 656 & 715 \\
\hline \multirow{2}{*}{$\mathrm{H}_{2} \mathrm{PhEtPyP}$} & SDS & 673 & 728 \\
\hline & Triton $\times 100$ & 658 & 719 \\
\hline \multirow[t]{2}{*}{$\mathrm{H}_{2} \mathrm{PhPrPyP}$} & SDS & 686 & 751 \\
\hline & Triton $\times 100$ & 680 & 743 \\
\hline \multirow[t]{2}{*}{$\mathrm{H}_{2}$ TMeOBzPyP } & SDS & 666 & 723 \\
\hline & Triton $\times 100$ & 659 & 721 \\
\hline \multirow[t]{2}{*}{$\mathrm{H}_{2} \mathrm{TCH}_{3} \mathrm{BzPyP}$} & SDS & 672 & 728 \\
\hline & Triton $\times 100$ & 661 & 722 \\
\hline \multirow[t]{2}{*}{$\mathrm{H}_{2}$ TBzPyP } & SDS & 670 & 728 \\
\hline & Triton $\times 100$ & 661 & 720 \\
\hline \multirow[t]{2}{*}{$\mathrm{H}_{2}$ TBrBzPyP } & SDS & 685 & 750 \\
\hline & Triton $\times 100$ & 680 & 744 \\
\hline \multirow[t]{2}{*}{$\mathrm{H}_{2}$ TCNBzPyP } & SDS & 668 & 729 \\
\hline & Triton $\times 100$ & 664 & 723 \\
\hline \multirow[t]{2}{*}{$\mathrm{H}_{2} \mathrm{TNO}_{2} \mathrm{Bz} \mathrm{PyP}$} & SDS & 673 & 729 \\
\hline & Triton $\times 100$ & 663 & 723 \\
\hline \multirow[t]{2}{*}{ ZnTMPyP } & SDS & 635 & 676 \\
\hline & Triton $\times 100$ & -- & -- \\
\hline \multirow[t]{2}{*}{ ZnTMeOBzPyP } & SDS & -- & -- \\
\hline & Triton X100 & 637 & 678 \\
\hline
\end{tabular}

${ }^{1}[\mathrm{SDS}]=1,0 \times 10^{-1} \mathrm{~mol} \mathrm{dm}^{-3} ;{ }^{2}\left[\right.$ Triton X100] $=3,4 \times 10^{-2} \mathrm{~mol} \mathrm{dm}^{-3}$.

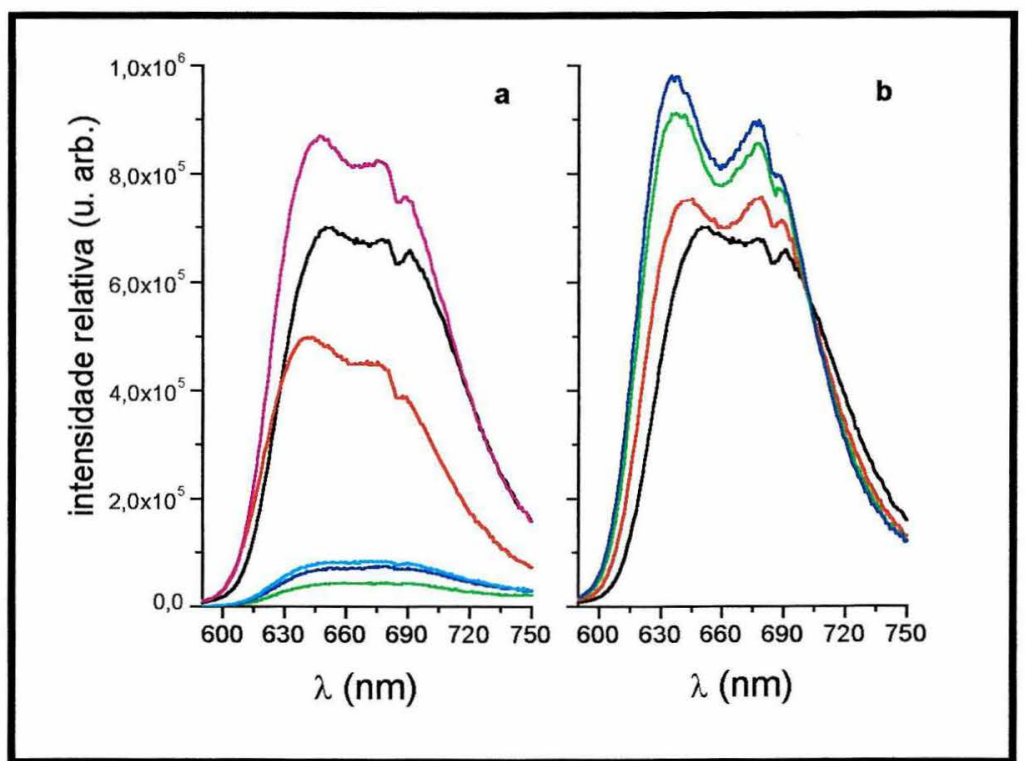

figura 85: Espectros eletrônicos de emissão da ZnTMeOBzPyP em solução aquosa (linha preta), em concentrações diferentes de SDS em solução aquosa (a) e em concentrações diferentes de Triton X100 em solução aquosa (b). 
Já em Triton $\mathrm{X} 100$, nota-se que ao se atingir concentrações superiores à $\mathrm{cmc}$ há um aumento da intensidade de emissão, e deslocamento das bandas para o violeta, evidenciando a interação metaloporfirina/micela, entretanto a definição das bandas ainda é insuficiente para a determinação dos máximos de emissão. A ZnTMPyP não apresentou nenhuma alteração espectroscópica em relação ao espectro em solução aquosa quando em solução contendo o surfactante não iônico Triton X100.

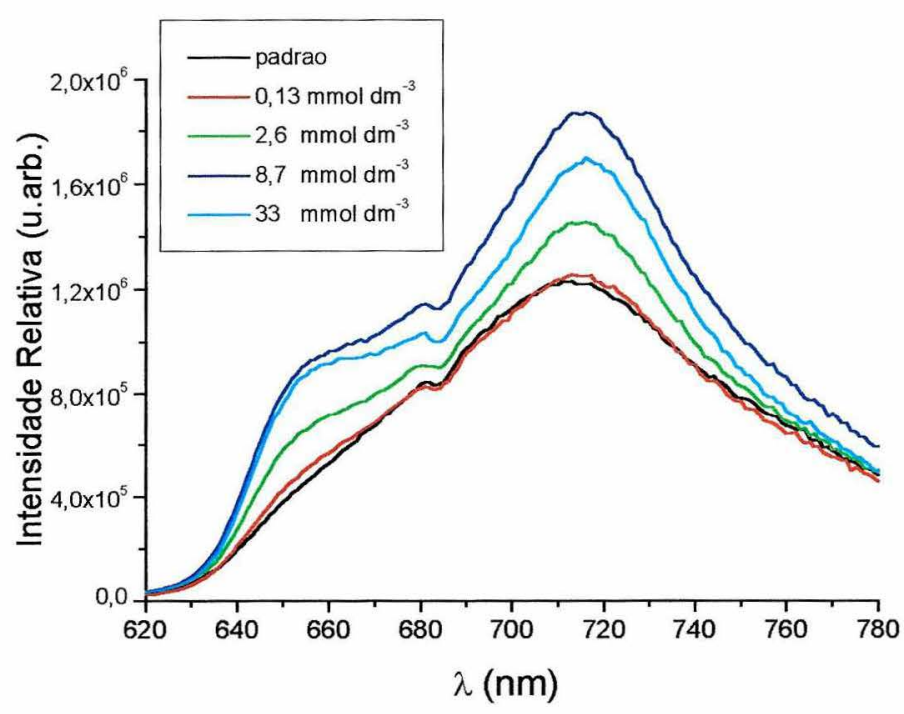

figura 86: Espectros eletrônicos de emissão da $\mathrm{H}_{2}$ TAIPyP em solução aquosa e em solução aquosa contendo Triton X100 em diferentes concentrações.

\subsubsection{RMN- ${ }^{1} H$}

Com a finalidade de caracterizar melhor o comportamento das porfirinas piridínio substituídas em sua interação com as micelas dos surfactantes foi realizado uma série de experimentos de $\mathrm{RMN}-{ }^{1} \mathrm{H}$ que consiste em acompanhar a variação do sinal dos deslocamentos químicos dos prótons dos surfactantes ${ }^{110,155}$ ( $\Delta \delta=\delta_{\text {surfactante }}$ $\delta_{\text {surfactante+sonda }}$ ) em função da concentração de porfirina em solução.

Apesar do caráter dinâmico do sistema estudado, pois as micelas são formadas e dispersam-se constantemente, experimentos semelhantes a esse têm sido utilizados na elucidação da posição preferencial de certos corantes em relação a micela ${ }^{110,156}$

Os experimentos foram realizados para os surfactantes SDS e Triton X100 e para as porfirinas $\mathrm{H}_{2}$ TMPyP, $\mathrm{H}_{2}$ TBzPyP, $\mathrm{H}_{2}$ TCNBzPyP e $\mathrm{H}_{2}$ TMeOBzPyP, além dos supressores catiônicos MV e BV no caso do SDS. 


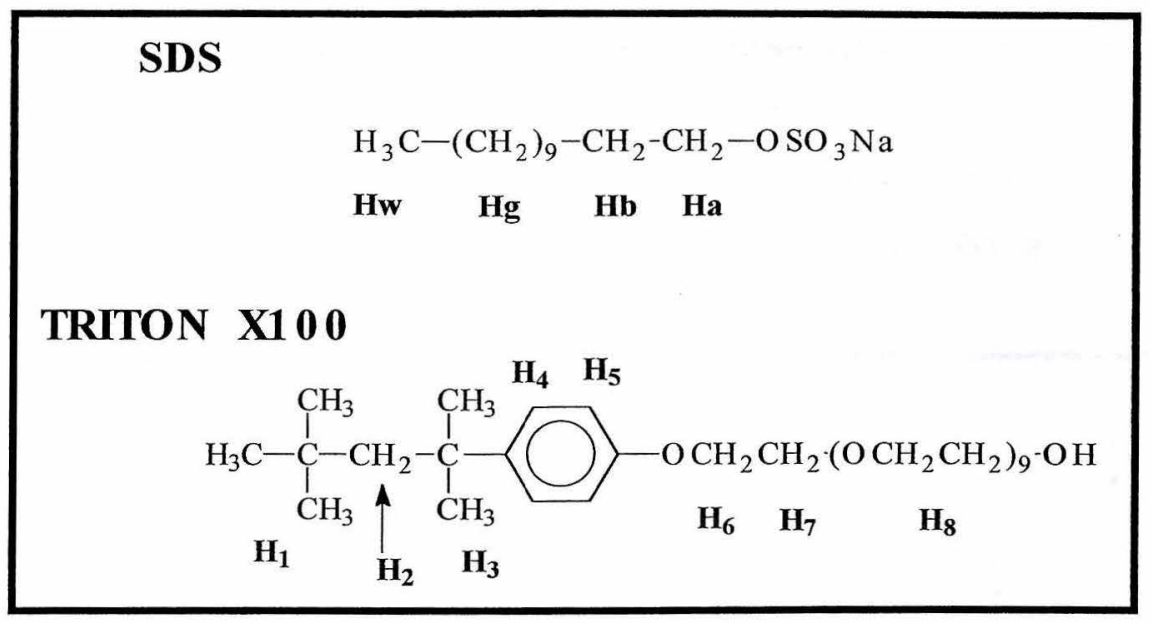

figura 87: Estruturas dos surfactantes SDS e Triton X100 e as designações de seus respectivos prótons.

De modo geral, os deslocamentos químicos dos prótons do SDS variam linearmente em função da concentração da porfirina ou do corante viologênio utilizado (figura 88). Entretanto, os coeficientes lineares obtidos evidenciam uma maior influência exercida sobre a região apolar e interna das moléculas (tabela 32), sendo um resultado inusitado. Como todas as sondas utilizadas são catiônicas e a micela apresenta a superfície externa carregada negativamente, esperava-se que as sondas catiônicas permanecessem preferencialmente na região externa da micela ${ }^{61,62}$. Com isso, os prótons que deveriam sentir mais intensamente a presença da porfirina seriam os prótons $\mathrm{Ha}$ e $\mathrm{Hb}$. Nota-se, porém, que apesar de $\mathrm{Ha}$ apresentar um variação do deslocamento químico significativa em função da concentração da porfirina, o deslocamento químico de $\mathrm{Hb}$ não sofre variação significativa, indicando que esse próton não sente a presença da porfirina na micela. Além disso, os prótons da região hidrofóbica $\mathrm{Hg}$ e $\mathrm{Hw}$ sofrem variação dos deslocamentos químicos de cinco a seis vezes maior do que $\mathrm{Ha}$.

tabela 32: Valores dos coeficientes lineares dos gráficos de $\Delta \delta$ dos prótons de SDS em função da concentração da sonda (porfirina ou viologênio).

\begin{tabular}{|c|c|c|c|c|}
\hline Sonda & $\mathrm{Hz} \mathrm{mol}^{-1} \mathrm{dm}^{3}$ & $\begin{array}{c}\mathrm{Hb} \\
\mathrm{Hol} \\
\mathrm{z} \mathrm{dm}^{3}\end{array}$ & $\mathrm{~Hz} \mathrm{~mol}^{1 / 1} \mathrm{dm}^{3}$ & $\mathrm{~Hz} \mathrm{~mol}^{-1} \mathrm{dm}^{3}$ \\
\hline $\mathrm{H}_{2}$ TBzPyP & 3600 & $x$ & -24500 & -22200 \\
\hline $\mathrm{H}_{2}$ TCNBzPyP & $X$ & $X$ & -13200 & -11900 \\
\hline $\mathrm{H}_{2}$ TmeOBzPyP & 3150 & $X$ & -20400 & -19200 \\
\hline $\mathrm{H}_{2}$ TMPyP & 3900 & $X$ & -35000 & -28000 \\
\hline ZnTMPyP & 4100 & $x$ & -34050 & -27600 \\
\hline MV & $-81^{*}$ & -460 & -1250 & -1000 \\
\hline BV & -687 & -2330 & -3200 & -2480 \\
\hline
\end{tabular}

reta não apresenta correlação boa; $X$ coeficiente aproximadamente 0 . 
Mesmo as sondas menores como MV e BV aparentemente apresentam fração significativa no interior da micela, pois os prótons internos sentem com mais intensidade a influência da concentração do que os prótons externos. Entretanto, nesse caso, o próton $\mathrm{Hb}$ apresenta variação linear em função do aumento da concentração dos viologênios substituídos.
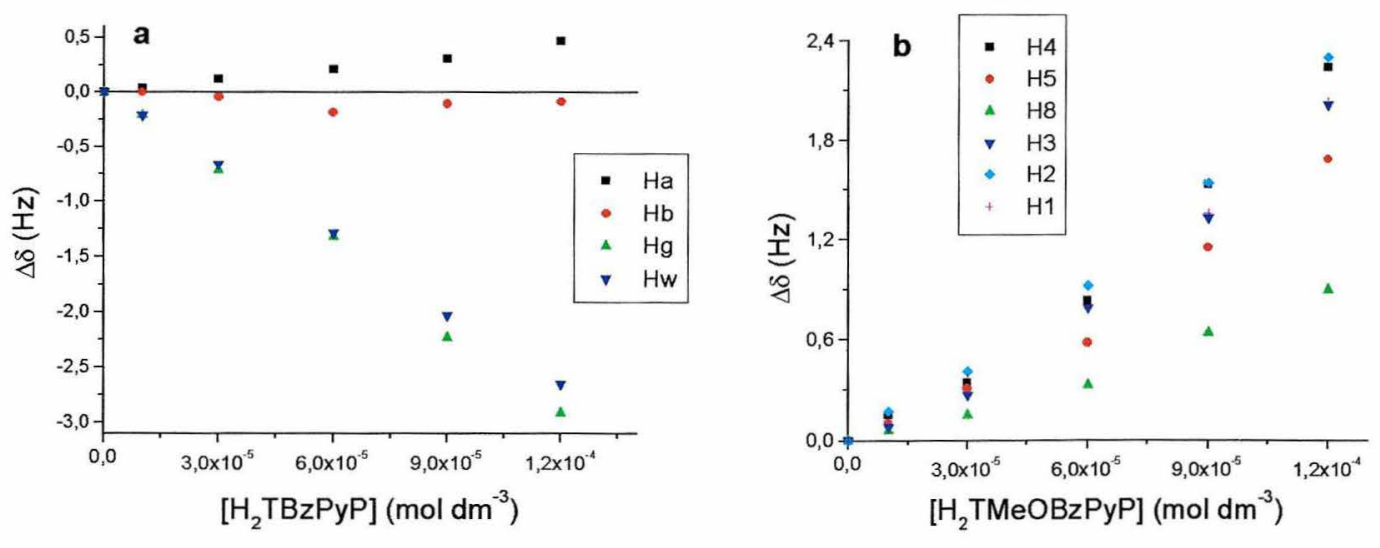

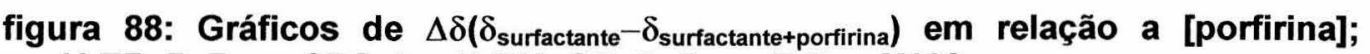
$a-\mathrm{H}_{2}$ TBzPyP em SDS; $b-\mathrm{H}_{2}$ TMeOBzPyP em Triton X100.

Apesar da distribuição do surfactante na micela não ser necessariamente linear, podendo a cadeia estar curvada, com os carbonos finais voltados próximos a superfície, essa configuração do surfactante não explica a maior influência sentida por esses prótons.

Esse resultado leva a um novo modelo, indicando que a partir da interação eletrostática entre a porfirina e o surfactante, pode-se formar agregados iônicos que são posteriormente envolvidos pela micela; uma parte significativa das porfirinas ficam no interior das micelas, enquanto que outra fração, menor, liga-se preferencialmente à camada externa das micelas.

Esse modelo contempla não só as observações obtidas nos experimentos de $\mathrm{RMN}^{-1} \mathrm{H}$, mas também as evidências observadas nos espectros de emissão e absorção das porfirinas nas presenças das micelas. Como foi apresentado nas seções 3.7.1 e 3.7.2, as porfirinas piridínio substituídas formam três tipos de agregados diferentes com o SDS dependendo da relação das concentrações da porfirina/surfactante. Em concentrações baixas de SDS, relação porfirina:SDS em torno de $1: 4$, ocorre a precipitação de agregados porfirina/surfactante, com o SDS agindo como contra-íon das cargas periféricas do macrociclo (figura 89). 


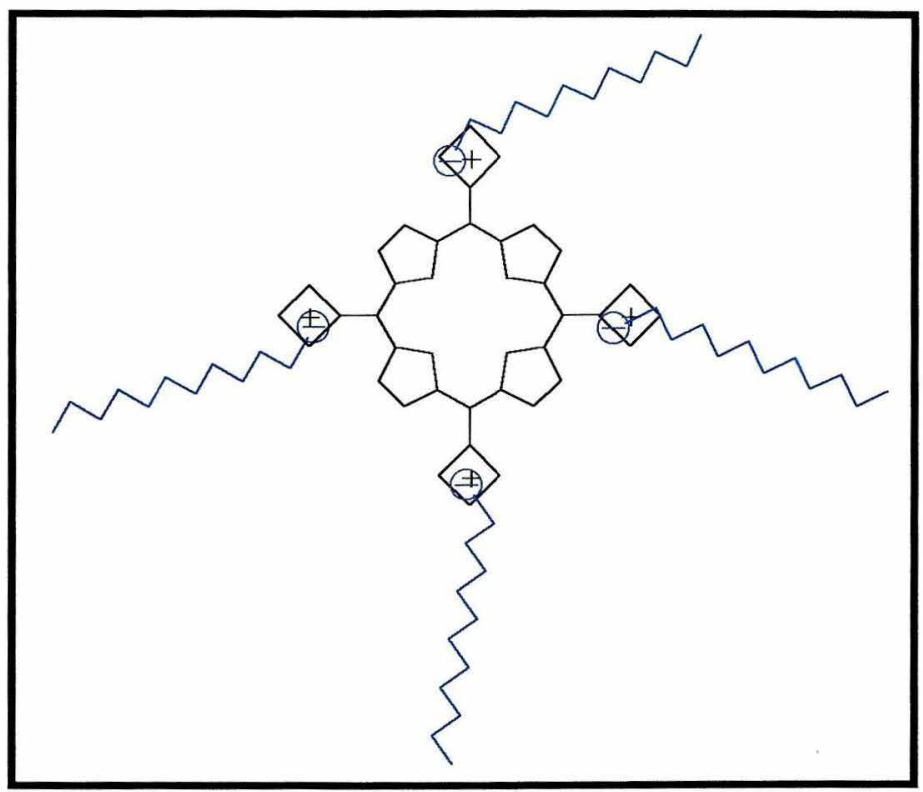

figura 89: Modelo representando o agregado insolúvel de porfirina e SDS .

Com o aumento da concentração do surfactante, passando-se para uma relação porfirina:SDS superior a 1:10, ocorre a solubilização da porfirina, com a formação de agregados pré-micelares com associações entre porfirinas, provavelmente mediadas pela presença de monômeros de surfactante, diminuindo a repulsão eletrostática. Essa observação é suportada pela mudança no perfil espectral observada, indicando a ocorrência de agregados do tipo $\mathrm{J}$ ou do tipo $\mathrm{H}$ (figura 90).

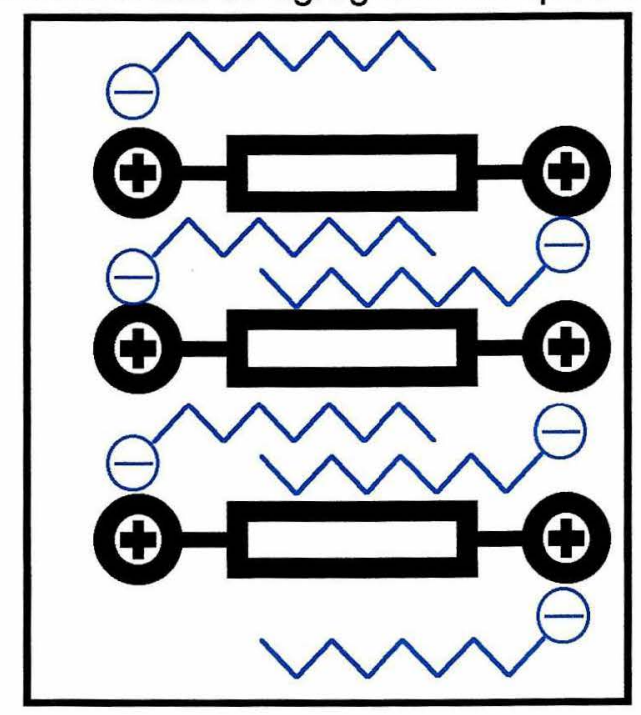

figura 90: Modelo da estrutura dos agregados pré-micelares do tipo $\mathrm{H}$ entre as porfirinas piridínio substituídas e o SDS.

A associação das porfirinas piridínio substituídas e os monômeros de SDS nesses agregados pré-micelares constitui um núcleo bastante hidrofóbico ao redor do qual poderia ser formada a micela de SDS, justificando a inserção preferencial da porfirina no interior da micela. Esse mecanismo justifica o equilíbrio entre duas espécies (agregado pré-micelar e agregado micelar) observado durante o aumento da 
concentração de SDS. A porfirina em meio micelar deve se encontrar na forma monomérica, não ocorrendo interações entre os macrociclos, como mostram os espectros de absorção e emissão. Esse modelo justifica o perfil espectral característico de meio hidrofóbico observado para toda a série de porfirinas em SDS (figura 91).

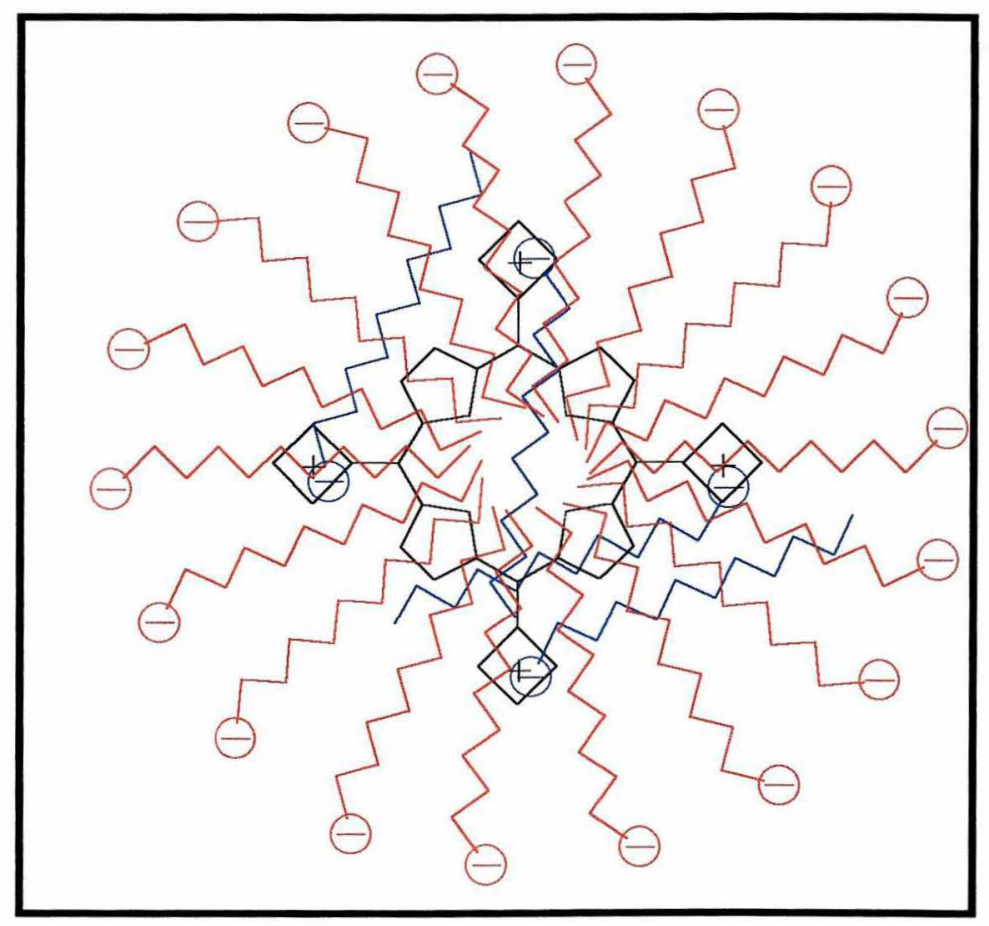

figura 91: Modelo representando a inserção do agregado porfirina/SDS em uma micela de SDS.

Esse modelo também está de acordo com a diminuição do tempo de vida do estado triplete das porfirinas em concentrações micelares de SDS, indicando um maior contato com o supressor oxigênio molecular, que apresenta maior concentração no interior das micelas em relação ao meio aquosa. Além disso, as porfirinas em meio micelar de SDS não são suprimidas pelo aceptores de elétrons MV e AQS, indicando uma barreira no encontro dessas espécies com a porfirina incorporada na micela (ver seção 3.7.4). Também foi verificada uma maior eficiência de formação de ${ }^{1} \mathrm{O}_{2}$ para as porfirinas em meio micelar de SDS (ver 3.7.5).

Vale ressaltar, entretanto, que a presença do macrocilo porfirínico no interior da micela de SDS deve causar uma aumento considerável do volume da micela, uma vez que a distância entre duas extremidades opostas da $\mathrm{H}_{2}$ TBzPyP é da mesma ordem de grandeza do diâmetro de uma micela de SDS em meio aquoso. Com as técnicas utilizadas nesse trabalho não foi possivel observar essa alteração nas micelas de SDS, sendo possível a utilização de outras técnicas para confirmar esse modelo, como por exemplo espalhamento de raios- $X$.

Recentemente, Tabak e colaboradores demonstraram a partir de uma série de espectros de emissão, absorção $\mathrm{RMN}^{-1} \mathrm{H}$ e ressonância por espalhamento de luz que 
a porfirina $\mathrm{H}_{2}$ TPPS deve se situar na região hidrofóbica das micelas de CTAC (cloreto de cetilmetilamônio) ${ }^{157}$.

tabela 33:Valores dos coeficientes lineares dos gráficos de $\Delta \delta$ dos prótons de Triton X100 em função da concentração de porfirina.

\begin{tabular}{ccccccccccc}
\hline Sonda & $H 1$ & $\mathrm{H} 2$ & $\mathrm{H}$ & $\mathrm{H}$ & $\mathrm{H}$ & $\mathrm{H}$ & $\mathrm{H}$ & $\mathrm{H}$ & $\mathrm{H}$ \\
\hline $\mathrm{H}_{2}$ TBzPyP & 18000 & 16600 & 16000 & 19500 & $12000^{*}$ & 4000 & 9400 & 16600 \\
$\mathrm{H}_{2}$ TCNBzPyP & 9700 & 10600 & 9500 & 11100 & 8900 & $\mathrm{X}$ & $\mathrm{X}$ & 5000 \\
$\mathrm{H}_{2}$ TmeOBzPyP & 17000 & 19200 & 17000 & 19000 & 14600 & $\mathrm{X}$ & $\mathrm{X}$ & 7800 \\
$\mathrm{H}_{2}$ TMPyP & $\mathrm{X}$ & $\mathrm{X}$ & $\mathrm{X}$ & $\mathrm{X}$ & $\mathrm{X}$ & $\mathrm{X}$ & $1800^{*}$ & $\mathrm{X}$ \\
\hline
\end{tabular}

* reta não apresenta correlação boa; $X$ coeficiente aproximadamente 0 .

Em Triton X100 os prótons que apresentam maior variação de deslocamento químico em função da concentração de porfirina também são os prótons da região mais hidrofóbica da molécula, ou seja da região interna, entretanto a diferença em relação ao prótons dos grupos éter que ficam na região mais externa da micela é menos acentuada, chegando a ser da mesma ordem de grandeza para o caso da $\mathrm{H}_{2}$ TBzPyP. Novamente, percebe-se que a interação entre as porfirinas catiônicas e as micelas de Triton X100 está relacionada com com o caráter hidrofóbico do substituinte piridínico e que a $\mathrm{H}_{2}$ TMPyP não apresenta interação com esse surfactante, com os prótons desde não sentindo a influência da presença dessa porfirina em solução.

\subsubsection{Fotólise por Pulso de Laser}

Foram obtidos os tempos de vida do estado triplete das zincoporfirinas piridínio substituídas em solução aquosa de $\mathrm{NaCl}\left(0,05 \mathrm{~mol} \mathrm{dm}^{-3}\right)$ contendo os surfactantes SDS $\left(0,05 \mathrm{~mol} \mathrm{dm}^{-3}\right)$ ou Triton $\times 100\left(0,02 \mathrm{~mol} \mathrm{dm}^{-3}\right)$, ou seja em concentrações bem acima da cmc. Os experimentos foram realizados em equilíbrio com o ar atmosférico, portanto, em contato com $\mathrm{O}_{2}$, resultando em tempos de vida da ordem de $\mu \mathrm{s}$, devido a supressão do estado triplete das zincoporfirinas pelo $\mathrm{O}_{2}$.

tabela 34:Tempo de vida do estado triplete $\left(\tau_{T}\right)$ das zincoporfirinas em solução aquosa de $\mathrm{NaCl}\left(0,05 \mathrm{~mol} \mathrm{dm}^{-3}\right)$ em ausência e na presença de surfactantes.

\begin{tabular}{|c|c|c|c|}
\hline Porfirinas & $\begin{array}{l}\text { Triton } \times 100 \\
0,02 \mathrm{~mol} \mathrm{dm}^{3}\end{array}$ & $\begin{array}{c}\text { SDS } \\
0,05 \mathrm{~mol} \mathrm{dm}^{3}\end{array}$ & Auséncia de surfactantes \\
\hline ZnTMPyP & $3,2 \mu \mathrm{s}$ & $2,7 \mu \mathrm{s}$ & $3,2 \mu \mathrm{s}$ \\
\hline ZnTMeOBzPyP & $5,6 \mu \mathrm{s}$ & $2,5 \mu \mathrm{s}$ & $3,2 \mu \mathrm{s}$ \\
\hline ZnTBzPyP & $4,9 \mu \mathrm{s}$ & $2,5 \mu \mathrm{s}$ & $3,2 \mu \mathrm{s}$ \\
\hline ZnTCNBzPyP & $4,5 \mu \mathrm{s}$ & $2,5 \mu \mathrm{s}$ & $3,3 \mu \mathrm{s}$ \\
\hline $\mathrm{ZnTNO}{ }_{2} \mathrm{BzPyP}$ & $4,9 \mu \mathrm{s}$ & $2,5 \mu \mathrm{s}$ & $2,9 \mu \mathrm{s}$ \\
\hline
\end{tabular}

Os dados da tabela 34 mostram efeitos distintos dos detergentes SDS e Triton X100 nos tempos de vida do estado triplete das zincoporfirinas piridínio substituídas. Toda a série apresenta uma diminuição de cerca de $20 \%$ dos valores de $\tau_{\mathrm{T}}$ quando em 
solução de SDS. Entretanto, em Triton X100 há um significativo aumento nos valores determinados de $\tau_{\mathrm{T}}$, exceto para a ZnTMPyP, que como já foi discutido, não apresenta interação com esse surfactante não iônico.

Esse aumento do tempo de vida do estado triplete pode ser atribuído a uma diferença de difusão ou solubilidade do $\mathrm{O}_{2}$ em meio micelar ou ainda significar uma alteração estrutural eletrônica do macrociclo, diminuindo a constante de decaimento triplete-singlete.

Não há variação do perfil dos espectros de absorção dos transientes das zincoporfirinas em meio micelar ou em solução aquosa Observa-se somente um pequeno deslocamento para vermelho dos máximos da bandas, seguindo o observado para os espectros de absorção do estado fundamental.

Também foram determinadas as constantes de supressão do estado triplete das zincoporfirinas pelos supressores analisados em solução aquosa de $\mathrm{NaCl}(0,05$ mol $\mathrm{dm}^{-3}$ ), MV, BV, $\mathrm{CoA}_{5} \mathrm{Cl}$ e AQS, adicionando-se os surfactantes ao sistema em concentrações bem acima da cmc. Todas as medidas foram realizadas com concentração fixa de detergente (SDS, $0,05 \mathrm{~mol} \mathrm{dm}^{-3}$ e Triton X100, 0,02 $\mathrm{mol} \mathrm{dm}^{-3}$ ), e a força iônica do meio foi mantida constante em $0,05 \mathrm{~mol} \mathrm{dm}^{-3}$. As medidas foram realizadas mantendo-se as soluções em equilíbrio com $\circ \mathrm{O}_{2}$ atmosférico, e portanto, as concentrações dos supressores utilizadas são relativamente altas (ver seção 2.3.7).

Não foi possível realizar os experimentos com os supressores $\mathrm{BV}$ e $\mathrm{COA}_{5} \mathrm{Cl}$ em solução aquosa de SDS, pois estes são insolúveis nesse meio na concentração requerida para se observar variação do tempo de vida do estado triplete das zincoporfirinas. Já em relação ao supressor MV em solução aquosa de SDS não há para nenhuma das zincoporfirinas estudadas variação do tempo de vida, mesmo na concentração limite do supressor $0,05 \mathrm{~mol} \mathrm{dm}^{-3}$, não ocorrendo supressão nas condições empregadas. Esse resultado evidencia que 0 agregado metaloporfirina/micela formado em SDS apresenta uma estrutura que dificulta o contato entre a porfirina e o supressor MV, diminuindo a constante de supressão para valores inferiores a $8 \times 10^{5} \mathrm{dm}^{3} \mathrm{~mol}^{-1} \mathrm{~s}^{-1}$, que é o limite do experimento nas condições adotadas.

Não é observada variação do tempo de vida do estado triplete das zincoporfirinas com a adição do supressor AQS em presença de SDS em solução. Nesse caso, a redução da constante de supressão em mais de 3 ordens de grandeza é esperada uma vez que tanto o AQS quanto a micela são carregadas negativamente, ocorrendo uma repulsão eletrostática e os resultados apresentados até agora indicam que a porfirina está inserida na micela, portanto, inacessivel ao supressor. É razoável supor que em solução aquosa contendo SDS em concentração acima da $\mathrm{cmc}$ a ação 
supressora do AQS seja desprezível em relação ao estado excitado das zincoporfirinas piridínio substituídas.

As medidas de supressão realizadas em Triton X-100 (ver tabela 35) confirmam a não ocorrência de interação entre a ZnTMPyP e o surfactante, pois as constantes são idênticas às obtidas em solução salina. Já para a as porfirinas benzilpiridínio substituídas há redução de uma ordem de grandeza nos valores das constantes e não se verifica diferenciação em relação aos substituintes aceptores de elétrons. Possivelmente o ambiente em que se encontra a porfirina na micela é que deve determinar o processo de supressão. Em relação as constantes de supressão do MV em Triton X100, devido ao seu baixo valor as variações do tempo de vida estão dentro do erro da medida, e as concentrações utilizadas estão no limite da força iônica, impedindo uma determinação mais precisa. Entretanto, diferentemente do caso discutido para o próprio MV e para o AQS em SDS, verifica-se variação no tempo de vida do estado triplete em função da concentração de MV, não sendo posível somente possível obter uma correlação razoável para uma determinação precisa da constante de supressão.

tabela 35: Constantes de supressão $\left(k_{Q}\right)$ do estado triplete excitado das zincoporfirinas piridínio substituídas em solução aquosa de $\mathrm{NaCl}\left(0,05 \mathrm{~mol} \mathrm{dm}^{-3}\right)$, na presença e na ausência de Triton X100 $\left(0,02 \mathrm{~mol} \mathrm{dm}^{-3}\right)$.

\begin{tabular}{|c|c|c|c|c|}
\hline Porfirinas & $\begin{array}{c}\mathrm{MV} \\
\mathrm{k}_{\mathrm{o}}\left(\mathrm{dm}^{3} \mathrm{~mol}^{-1} \mathrm{~s}^{-1}\right)\end{array}$ & $\frac{\mathrm{BV}}{\mathrm{k}_{\mathrm{Q}}\left(\mathrm{dm}^{3} \mathrm{~mol}^{-1} \mathrm{~s}^{-1}\right)}$ & $\begin{array}{c}\mathrm{CoA}_{5} \mathrm{Cl} \\
\mathrm{k}_{\mathrm{Q}}\left(\mathrm{dm}^{3} \mathrm{~mol}^{1} \mathrm{~s}^{-1}\right)\end{array}$ & $\begin{array}{c}\text { AQS } \\
k_{Q}\left(\mathrm{dm}^{3} \mathrm{~mol}^{-1} \mathrm{~s}^{-1}\right)\end{array}$ \\
\hline ZnTMPyP' $^{\prime}$ & $1,5 \times 10^{7}$ & $1,0 \times 10^{8}$ & $1,4 \times 10^{8}$ & $2,6 \times 10^{9}$ \\
\hline ZnTMPyP ${ }^{2}$ & $1,2 \times 10^{7}$ & $1,0 \times 10^{8}$ & $1,2 \times 10^{8}$ & $1,0 \times 10^{8}$ \\
\hline ZnTMeOBzPyP ${ }^{1}$ & $1,0 \times 10^{7}$ & $1,2 \times 10^{8}$ & $1,3 \times 10^{8}$ & $3,7 \times 10^{9}$ \\
\hline ZnTMeOBzPyP ${ }^{2}$ & $\cong 10^{6}$ & $9,0 \times 10^{6}$ & $9,7 \times 10^{6}$ & $4,3 \times 10^{7}$ \\
\hline ZnTBzPyP ${ }^{1}$ & $9,1 \times 10^{6}$ & $9,5 \times 10^{7}$ & $1,2 \times 10^{8}$ & $3,2 \times 10^{9}$ \\
\hline ZnTBzPyP ${ }^{2}$ & $\cong 10^{6}$ & $1,1 \times 10^{7}$ & $2,1 \times 10^{7}$ & $6,8 \times 10^{7}$ \\
\hline ZnTCNBzPyP ${ }^{1}$ & $4,1 \times 10^{6}$ & $4,2 \times 10^{7}$ & $5,9 \times 10^{7}$ & $7,0 \times 10^{9}$ \\
\hline ZnTCNBzPyP ${ }^{2}$ & $\cong 10^{6}$ & $1,1 \times 10^{7}$ & $1,2 \times 10^{7}$ & $6,7 \times 10^{7}$ \\
\hline $\mathrm{ZnTNO}_{2} \mathrm{BzPyP}^{1}$ & $3,5 \times 10^{6}$ & $4,4 \times 10^{7}$ & $5,9 \times 10^{7}$ & $2,8 \times 10^{9}$ \\
\hline $\mathrm{ZnTNO}_{2} \mathrm{BzPyP}^{2}$ & $\cong 10^{6}$ & $5,1 \times 10^{6}$ & $1,9 \times 10^{7}$ & $2,8 \times 10^{7}$ \\
\hline
\end{tabular}

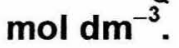

$k_{\mathrm{Q}} \pm 10 \% ;{ }^{1}[\mathrm{NaCl}]=0,05 \mathrm{~mol} \mathrm{dm}^{-3} ;^{2}[\mathrm{NaCl}]=0,05 \mathrm{~mol} \mathrm{dm}^{-3}$ e $[$ Triton $\times 100]=0,02$

As constantes de supressão das zincoporfirinas em relação ao AQS na presença de Triton X100 apresentam redução acentuada em relação a redução observada para os supressores catiônicos. Provavelmente ocorre alguma interação 
entre a AQS e o Triton $\times 100$, dificultando a interação da metaloporfirina com o supressor. Essa hipótese é reforçada pelo efeito apresentado pela a ZnTMPyP, a qual todos os experimentos anteriores indicam uma não interação com os surfactantes não iônicos, que também apresenta diminuição da constante de supressão pelo AQS quando na presença de Triton X100, embora em menor extensão do que o observado para as porfirinas benzilpiridínio substituídas. De todo modo, o efeito do surfactante não iônico é mais acentuado para o supressor aniônico do que o verificado para os supressores catiônicos.

\subsubsection{Determinação de Rendimento Quântico de Formação de ${ }^{1} \mathrm{O}_{2}$}

Foram determinados os rendimentos quânticos de formação de ${ }^{1} \mathrm{O}_{2}\left(\Phi_{\Delta}\right)$ das porfirinas e zincoporfirinas em meio aquoso contendo $\operatorname{SDS}\left(0,1 \mathrm{~mol} \mathrm{dm}^{-3}\right)$ e Triton $\mathrm{X} 100\left(0,02 \mathrm{~mol} \mathrm{dm}^{-3}\right)$. O método utilizado é o mesmo descrito e discutido para as porfirinas em água (ver seção 3.3.1). Esses resultados permitem avaliar o comportamento do estado excitado triplete das porfirinas em meio micelar e sua reatividade com $0 \mathrm{O}_{2}$. A potenciabilidade de aplicação dessas espécies em terapia fotodinâmica depende da sua capacidade de formação de ${ }^{1} \mathrm{O}_{2}$, uma vez que essa é a espécie responsável pela morte das células tumorais. Vale lembrar que o meio micelar é um modelo de ambiente encontrado em vesículas, lisossomos e associações com proteínas, sendo um dado importante a ser avaliado.

Além de alteração nos valores de $\Phi_{\Delta}$ determinados, também foi observada ligeira variação nos tempos de vida do estado excitado ${ }^{1} \mathrm{O}_{2}\left(\tau_{\Delta}\right)$, de acordo com o meio. Entretanto, os valores de $\tau_{\Delta}$ não apresentaram variação significativa em função da porfirina em estudo, o que garante uma maior credibilidade ao método aplicado. É necessário salientar que as correlações apresentadas entre as intensidades de fosforescência do ${ }^{1} \mathrm{O}_{2}$ no tempo zero $\left(\mathrm{l}_{\mathrm{o}}\right)$ e a potência de excitação do laser em $532 \mathrm{~nm}$ $\left(P_{\circ}\right)$ foram sempre lineares, indicando não haver outro processo concorrendo com a transferência de energia do estado triplete da porfirina para o $\mathrm{O}_{2}$ molecular encontrado em solução. 


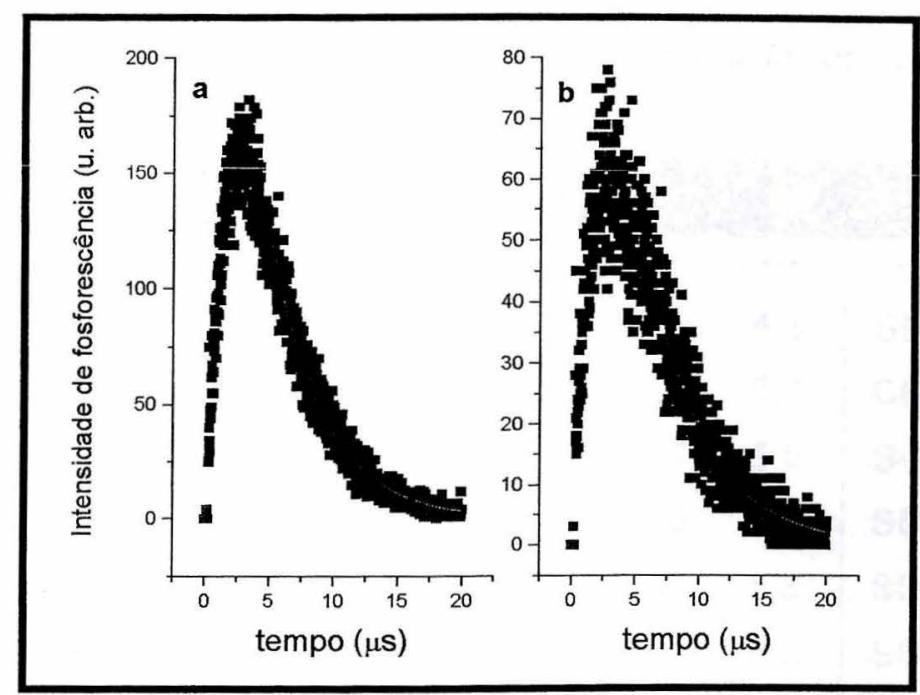

figura 92: Decaimento de emissão de fosforescência do ${ }^{1} \mathrm{O}_{2} \mathrm{em} 1270 \mathrm{~nm}$. a- $\mathrm{H}_{2}$ TMeOBzPyP em SDS; b - $\mathrm{H}_{2}$ TPnPyP em Triton X100.

A tabela a seguir apresenta um resumo dos valores de $\tau_{\Delta}$ e $\Phi_{\Delta}$ para as porfirinas e zincoporfirinas avaliadas em meio micelar. Nota-se que em SDS os valores de $\Phi_{\Delta}$ são consideravelmente maiores para todas as espécies estudadas, até mesmo para a $\mathrm{H}_{2}$ TPPS, que não apresenta interação com o surfactante por serem ambos aniônicos. Essa observação concorda com os dados recentes obtidos pra a $\mathrm{H}_{2}$ TMPyP em SDS em solução de água deuterada ${ }^{70}$. Uma interação mais efetiva entre $\circ \mathrm{O}_{2}$ molecular e o estado triplete das porfirinas em meio de SDS já era esperado uma vez que os tempos de vida do estado triplete são menores nesse meio na presença de $\mathrm{O}_{2}$.

A porfirina deve se encontrar na região apolar da micela, dado que concorda com as observações dos espectros de emissão, absorção e de $\mathrm{RMN}^{-1} \mathrm{H}$, ou seja, situada em um meio em que a concentração de $\mathrm{O}_{2}$ é maior. Essa situação favorece os choques do gás dissolvido e a porfirina no estado excitado e justifica o menor tempo de vida do estado triplete das zincoporfirinas analisadas. Esses dados não condizem com a presença da porfirina na superfície aniônica da micela, uma vez que nesta região a concentração de $\mathrm{O}_{2}$ deve ser menor do que em meio aquoso, devido a alta polaridade do meio.

Os valores elevados de $\Phi_{\Delta}$ devem-se a uma configuração diferenciada da porfirina nesse meio que aumenta a eficiência de formação da espécie excitada ${ }^{1} \mathrm{O}_{2}$, ou aumenta o rendimento quântico de formação do estado triplete da porfirina. Essa hipótese só pode ser confirmada com a determinação do $\Phi_{\mathrm{T}}$ das porfirinas em solução aquosa e em meio micelar. 
tabela 36: Rendimentos quântico relativo ${ }^{a}$ de formação de ${ }^{1} \mathrm{O}_{2}\left(\Phi_{\Delta}\right)$ e tempo de vida de ${ }^{1} \mathrm{O}_{2}\left(\tau_{\Delta}\right)$.

\begin{tabular}{|c|c|c|c|c|c|c|c|c|c|}
\hline Porf & elo & $\Phi_{4}$ & $\tau($ is & meio & Tox & T. (us) & melo & $\Phi$ & 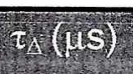 \\
\hline $\mathrm{H}_{2}$ TMPyP & $\mathrm{D}_{2} \mathrm{O}$ & 0,74 & 60 & -- & -- & -- & -- & -- & -- \\
\hline $\mathrm{H}_{2}$ TMPyP & $\mathrm{H}_{2} \mathrm{O}$ & 0,74 & 4,4 & Triton $\times 100$ & 0,79 & 4,8 & SDS & 0,95 & 4,1 \\
\hline H.TPPS & $\mathrm{H}_{2} \mathrm{O}$ & 0,66 & 4,2 & Triton $\times 100$ & 0,35 & 5,7 & SDS & 0,68 & 4,2 \\
\hline $\mathrm{H}_{2} \mathrm{TMeOBzPyP}$ & $\mathrm{H}_{2} \mathrm{O}$ & 0,67 & 4,3 & Triton $\times 100$ & 0,37 & 5,5 & SDS & 0,91 & 4,1 \\
\hline $\mathrm{H}_{2}$ TBzPyP & $\mathrm{H}_{2} \mathrm{O}$ & 0,64 & 4,5 & Triton $\times 100$ & 0,55 & 5,2 & SDS & 0,95 & 4,2 \\
\hline $\mathrm{H}_{2}$ TCNBzPyP & $\mathrm{H}_{2} \mathrm{O}$ & 0,61 & 4,3 & Triton $\times 100$ & 0,55 & 5,3 & SDS & 0,81 & 4,1 \\
\hline $\mathrm{H}_{2} \mathrm{TNO}_{2} \mathrm{BzPyP}$ & $\mathrm{H}_{2} \mathrm{O}$ & 0,66 & 4,4 & Triton X100 & 0,31 & 5,2 & SDS & 0,69 & 4,3 \\
\hline $\mathrm{H}_{2}$ TAIPyP & $\mathrm{H}_{2} \mathrm{O}$ & 0,76 & 4,4 & Triton $\times 100$ & 0,58 & 5,4 & SDS & 0,77 & 4,0 \\
\hline $\mathrm{H}_{2} \mathrm{TPn}$ & $\mathrm{H}_{2} \mathrm{O}$ & 0,90 & 4,4 & Triton X100 & 0,98 & 5,2 & SDS & 1,0 & 4,1 \\
\hline ZnTMPyP & $\mathrm{H}_{2} \mathrm{O}$ & 0,87 & 4,5 & Triton X100 & 0,85 & 5,3 & SDS & 0,93 & 4,5 \\
\hline ZnTMeOBzPyP & $\mathrm{H}_{2} \mathrm{O}$ & 0,75 & 4,3 & Triton X100 & 0,57 & 5,3 & SDS & 0,85 & 4,4 \\
\hline ZnTBzPyP & $\mathrm{H}_{2} \mathrm{O}$ & 0,73 & 4,4 & Triton X100 & 0,52 & 5,2 & SDS & 0,86 & 4,3 \\
\hline ZnTCNBzPyP & $\mathrm{H}_{2} \mathrm{O}$ & 0,78 & 4,3 & Triton $\times 100$ & 0,44 & 5,7 & SDS & 0,93 & 4,3 \\
\hline $\mathrm{ZnTNO}{ }_{2} \mathrm{BzPyP}$ & $\mathrm{H}_{2} \mathrm{O}$ & 0,51 & 4,4 & Triton X100 & 0,41 & 5,3 & SDS & 0,67 & 4,3 \\
\hline
\end{tabular}
$\Phi_{\Delta}$ e $\tau_{\Delta} \pm 10 \%$.

a $-\Phi_{\Delta}$ da $\mathrm{H}_{2}$ TMPyP em $\mathrm{D}_{2} \mathrm{O}=0,74^{70}$ e $\Phi_{\Delta}$ da $\mathrm{H}_{2}$ TMPyP em $\mathrm{H}_{2} \mathrm{O}=0,74^{48}$; valores de

Já os valores de $\Phi_{\Delta}$ para os derivados porfirínicos na presença de Triton $X 100$ mostram-se menores do que os respectivos valores em água, com exceção das porfirinas alquil substituídas. Como já era de se esperar as porfirinas $\mathrm{H}_{2} \mathrm{TMPyP}$, $\mathrm{H}_{2}$ TAIPyP e ZnTMPyP não apresentam alteração nos valores de $\Phi_{\Delta}$ em Triton X100, estando estas espécies muito provavelmente em solução aquosa e não interagindo com o surfactante como as demais evidências espectroscópicas já discutidas evidenciam. Já a $\mathrm{H}_{2}$ TPnPyP apresenta um aumento de formação de ${ }^{1} \mathrm{O}_{2}$, um comportamento anômalo frente as demais porfirinas analisadas.

Os valores cerca de $25 \%$ menores de $\Phi_{\Delta}$ para as porfirinas e zincoporfirinas benzilpiridínio substituídas estão de acordo com os maiores tempo de vida do estado triplete observado para as zincoporfirinas na presença de $\mathrm{O}_{2}$. Aparentemente, as porfirinas associadas ao surfactante não iônico interagem de forma menos efetiva com - $\mathrm{O}_{2}$ presente em solução, havendo uma menor supressão do estado triplete e uma menor eficiência na formação da espécie reativa ${ }^{1} \mathrm{O}_{2}$. Esses resultados podem estar relacionados com a região em que a porfirina se encontra na micela, devendo estar próxima do ambiente polar, onde deve ocorrer ligações de $\mathrm{H}$ entre as moléculas de água e os grupos éter. Ambientes viscosos com alta quantidade de ligações de $\mathrm{H}$ 
contém uma menor concentração de $\mathrm{O}_{2}$ dissolvido, como é o caso do etileno glicol e da glicerina ${ }^{48}$.

\subsubsection{Interação Porfirina $x$ AQS}

Foram acompanhadas as mudanças espectrais durante a adição de solução aquosa de 2-sulfonato antraquinona de sódio (AQS) em solução aquosa de porfirina base livre e de zincoporfirina $\left(10^{-5} \mathrm{~mol} \mathrm{dm}^{-3}\right)$ em força iônica controlada de $\mathrm{NaCl} 0,05$

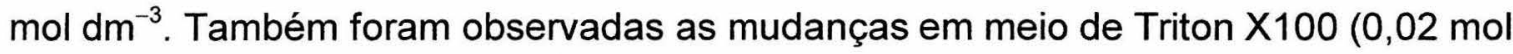
$\left.\mathrm{dm}^{-3}\right)$ e SDS $\left(0,05 \mathrm{~mol} \mathrm{dm}^{-3}\right)$.

No experimento em solução salina observa-se deslocamento para o vermelho da banda Soret e das bandas $Q$, bem como diminuição da intensidade da banda Soret, mesmo em concentrações baixas de AQS (a partir de $2,5 \mu \mathrm{mol} \mathrm{dm}{ }^{-3}$ ). Não foi possível determinar a constante de associação entre as espécies, não havendo a formação de isosbésticos, sendo que o aumento da concentração de AQS acarreta em deslocamentos batocrômicos sucessivos, sempre com diminuição da intensidade da banda Soret. Não foi possível determinar a constante de associação a partir da aplicação do método de Rose Drago ${ }^{158,159}$. As retas obtidas evidenciam a formação de agregados com diferentes estequiometrias. Com o aumento da concentração de antraquinona (cerca de $30 \mu \mathrm{mol} \mathrm{dm}{ }^{-3}$ ) nota-se a precipitação da porfirina, com elevação da linha base e brusca redução da intensidade da banda Soret. Para as bases livres observa-se mudança no perfil das bandas $Q$, com perfil etio substituindo o perfil phyllo (figura 93).

Em Triton X100, também observa-se os deslocamentos para a região do vermelho, entretanto é necessário uma concentração cerca de dez vezes maior de AQS para se observar as primeiras modificações, corroborando com a diminuição da constante de supressão entre as zincoporfirinas e o surfactante aniônico. As interações porfirina/Triton X100 e AQS/Triton X100 dificultam a formação do agregado entre a porfirina e o AQS (figura 94). Mesmo assim, ainda é possivel verificar a precipitação, com a concentração de AQS a partir de $1 \mathrm{mmol} \mathrm{dm}^{-3}$. 


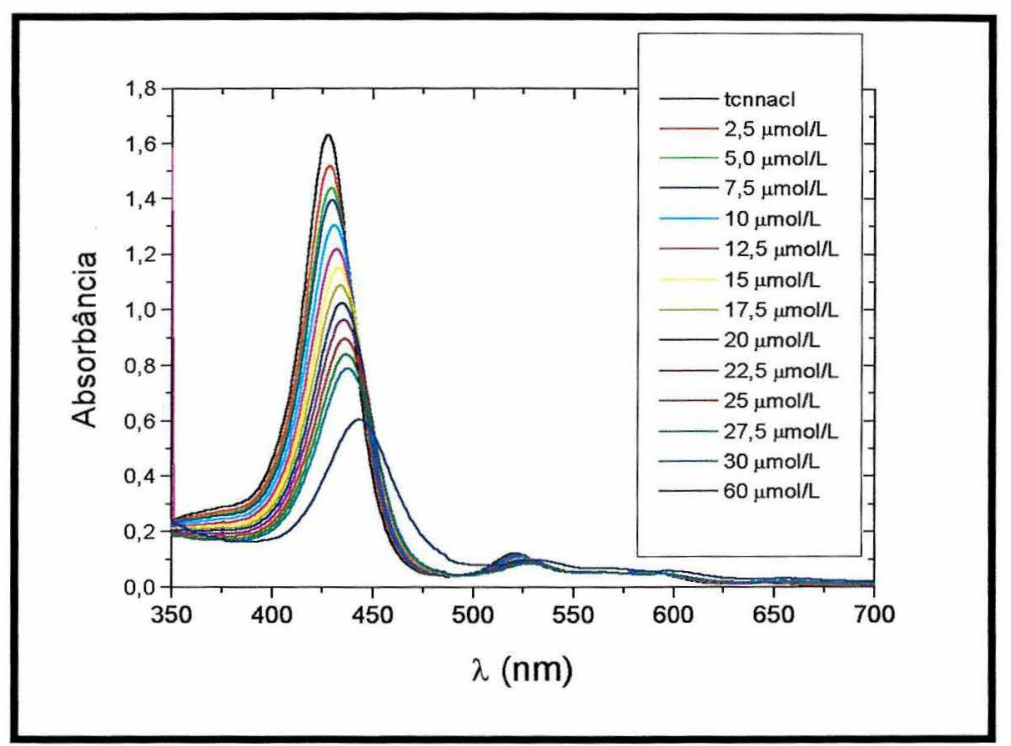

figura 93: Espectros eletrônicos de absorção da $\mathrm{H}_{2} \mathrm{TCNBzPyP}$ em função da concentração de $\mathrm{AQS}$, em solução aquosa de $\mathrm{NaCl}$, com força iônica constante de 0,05 mol dm ${ }^{-3}$.

Em SDS, entretanto não foram observadas mudanças espectrais, mesmo em concentrações de $A Q S$ da ordem de $0,5 \mathrm{mmol} \mathrm{dm}^{-3}$, indicando não haver interação entre a porfirina catiônica e o AQS (figura 95).

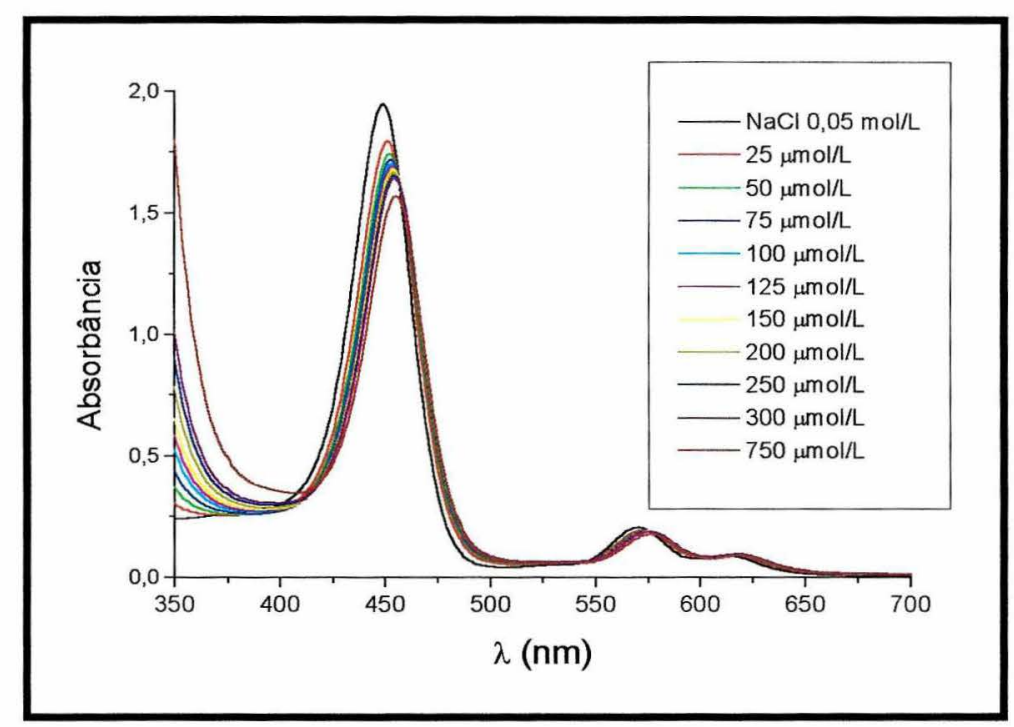

figura 94:Espectros eletrônicos de absorção da ZnTBzPyP em função da concentração de AQS, em solução aquosa de $\mathrm{NaCl}$ e Triton X100 $\left(0,02 \mathrm{~mol} \mathrm{dm}^{-3}\right)$, com força iônica constante de $0,05 \mathrm{~mol} \mathrm{dm}^{-3}$. 


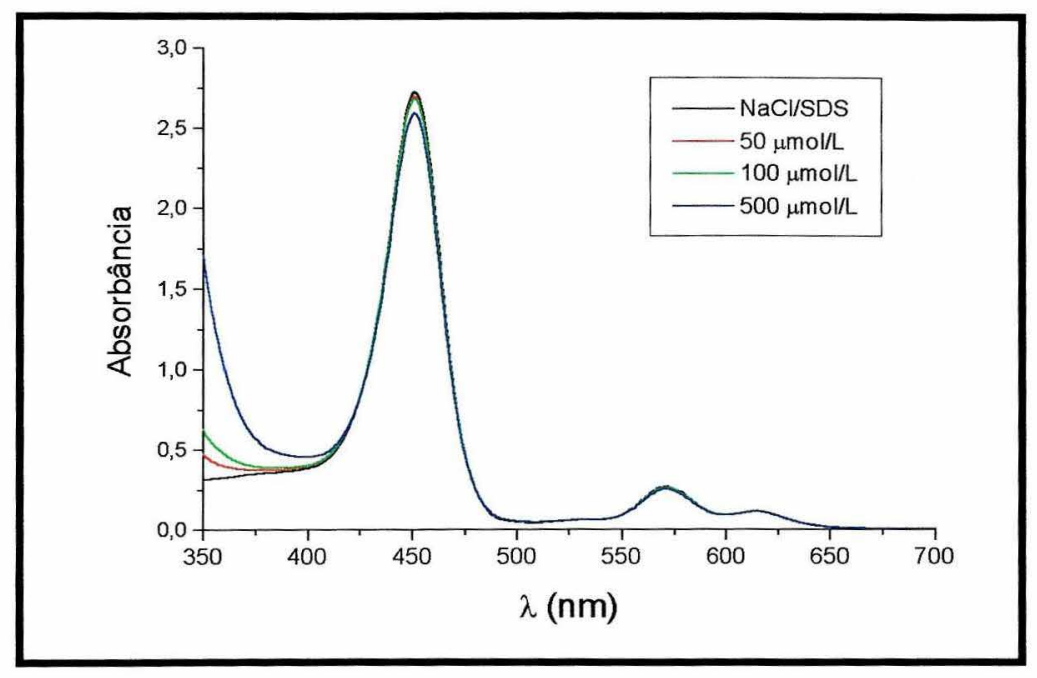

figura 95: Espectros eletrônicos de absorção da ZnTMeOBzPyP em função da concentração de AQS, em solução aquosa de $\mathrm{NaCl}$ e SDS $\left(0,05 \mathrm{~mol} \mathrm{dm}^{-3}\right)$, com força iônica constante de $0,05 \mathrm{~mol} \mathrm{dm}^{-3}$. 


\section{Considerações Finais}

As propriedades fotofísicas das porfirinas benzilpiridínio substituídas e seus zinco derivados são muito semelhantes à da $\mathrm{H}_{2} \mathrm{TMPyP}$, variando apenas o comprimento de onda máximo das bandas para a região do vermelho. Esse deslocamento indica uma expansão da nuvem $\pi$ do anel macrociclo e depende do caráter aceptor/doador de elétrons do grupo localizado na posição para do anel benzílico. Grupos aceptores de elétrons como nitro e ciano, permitem uma maior expansão da nuvem eletrônica, obtendo-se bandas mais deslocadas para a região de menor energia. Esse comportamento é observado para as bandas de absorção, emissão fluorescente, emissão fosforescente e absorção do estado triplete.

O perfil espectral $e$ a intensidade das bandas não dependem da concentração de porfirina, indicando a presença de apenas uma espécie em solução aquosa, a forma monomérica. Assim, como a $\mathrm{H}_{2} \mathrm{TMPyP}$ as demais porfirinas piridínio substituídas estudadas não agregam em solução aquosa. Os espectros de emissão apresentam bandas mal resolvidas e nossas observações estão de acordo com a proposta de Vergeldt e colaboradores ${ }^{57}$ em que ocorre uma interação eletrônica entre o estado excitado singlete e um estado de transferência de carga, ocasionando uma distorção dos níveis vibracionais e aumentando o decaimento térmico (não radioativo) $\mathrm{S}_{1} \rightarrow \mathrm{S}_{0}$.

Os valores de tempo de vida do estado triplete na presença e na ausência de $\mathrm{O}_{2}$ são similares para a ZnTMPyP e as zincoporfirinas benzilpiridínio substituídas com exceção da $\mathrm{ZnTNO}_{2}$ BzPyP que apresenta um tempo de vida baixo devido a um processo de transferência de energia intermolecular para o grupo nitro. Esse efeito só é verificado na ausência de $\mathrm{O}_{2}$, não interferindo no processo de desativação do estado triplete pelo oxigênio, processo responsável pela formação do ${ }^{1} \mathrm{O}_{2}$.

As constantes de supressão do estado triplete determinadas para as porfirinas piridínio substituídas e aceptores de elétrons catiônicos e aniônicos apresentam a mesma ordem de grandeza para os derivados ZnTMPyP, ZnTMeOBzPyP e ZnTBzPyP, porém os derivados que apresentam substituintes aceptores de elétrons, $\mathrm{ZnTNO}_{2}$ BzPyP e ZnTCNBzPyP, apresentam valores diferenciados de constante de supressão, indicando menor reatividade com espécies catiônicas e maior com espécies aniônicas. Esse efeito pode ser atribuído à menor densidade de carga presente no anel benzílico, devido efeito do grupo substituinte. Esse pode ser um indicativo da influência diferenciada dos substituintes benzílicos nas reações e 
interações com macromoléculas, ampliando as possibilidades de aplicações desta série de porfirinas.

Devido à presença de grupos hidrofóbicos nas posições periféricas essa nova classe de porfirina apresenta agregação em função da concentração de eletrólito. Porfirinas que apresentam substituintes mais volumosos são mais susceptíveis à presença de eletrólito, ocorrendo precipitação em condições de menor força iônica. Outro fator importante é dependência do ânion do eletrólito na formação de agregados das porfirinas benzilpiridínio substituídas, seguindo a série liotrópica de precipitação de proteínas $^{114}$. Essas observações são importantes pois as aplicações em terapia fotodinâmica ou estudos de interação com macromoléculas dependem da forma em que se encontra a porfirina em solução e geralmente são realizadas em meio de força iônica controlada. Essas porfirinas não agregam em $\mathrm{NaCl} 0,1 \mathrm{~mol} \mathrm{dm}^{-3}$, entretanto a ZnTMeOBzPyP, ZnTCNBzPyP e $\mathrm{ZnTNO}_{2} \mathrm{BzPyP}_{\mathrm{P}}$ formam agregados em solução contendo $\mathrm{NaNO}_{3} 0,1 \mathrm{~mol} \mathrm{dm}^{-3}$. Nossos experimentos confirmam que a $\mathrm{H}_{2}$ TMPyP não sofre alterações em função da concentração de ânions pequenos como $\mathrm{Cl}^{-}$, ou $\mathrm{NO}_{3}{ }^{-}$.

Os parâmetros eletroquímicos determinados para a nova série de porfirinas piridinio substituídas indicam haver pequena variação nos potenciais redox dos zinco(II) e cobre(II) derivados estudados. As variações seguem 0 caráter aceptor/doador de elétrons e as duas ondas em potenciais menores sofrem maior influência do substituinte, essas observações corroboram com a proposta de Kadish e colaboradores $^{17}$ de que a primeira onda corresponde à redução do macrociclo com a inserção de dois elétrons e as ondas seguintes são devido a adição de quatro elétrons, dois a dois, nos anéis piridínio e portanto mais susceptiveis a influência do substituinte benzílico.

Como não há variação significativa do potencial redox do macrociclo para as porfirinas benzilpiridínio substituídas em relação aos derivados da $\mathrm{H}_{2} T M P y P$ e não foram verificadas alterações significativas nos valores de $\mathrm{pK}_{\mathrm{a} 3}$ e $\mathrm{pK}_{\mathrm{a} 4}$ para as porfirinas piridínio substituídas ${ }^{22}$ pode-se concluir que não há variação significativa da corrente do anel em toda a série. Aplicando o modelo proposto por Harriman e colaboradores ${ }^{16}$ as cargas do anel piridínio devem estar delocalizadas no anel porfirínico, diminuindo o caráter hidrofóbico do anel e explicando a baixa interação da $\mathrm{H}_{2}$ TMPyP com moléculas não iônicas e a não formação de homoagregados em solução aquosa. Desse modo, a auto agregação observada para as porfirina benzilpiridínio substituídas em solução aquosa contendo eletrólitos se deve principalmente às interações de van der Waals dos substituintes periféricos. 
Essa interação hidrofóbica dos substituintes periféricos justifica a interação das porfirinas benzilpiridínio substituídas com os detergentes não iônicos Triton X100 e PTE, enquanto que a $\mathrm{H}_{2}$ TMPyP e seus derivados não apresentam agregação com esses detergentes. Essa propriedade dessa nova série de porfirinas piridínio substituídas torna-a promissora no estudo da interação com macromoléculas e carregadores de drogas com alto caráter hidrofóbico, ampliando as aplicações possíveis na terapia fotodinâmica e talvez possibilitando a obtenção de sistemas com maior especificidade para o tratamento de alguns tumores. Vale a pena lembrar que as propriedades fotofísicas medidas nessas condições apresentam-se ainda favoráveis para aplicação fotodinâmica.

$\mathrm{O}$ rendimento quântico de formação de ${ }^{1} \mathrm{O}_{2}\left(\Phi_{\Delta}\right)$ das bases livres e zinco derivados das porfirinas benzil piridínio substituídas é ligeiramente menor do que o verificado para a $\mathrm{H}_{2} T M P y P$ e a $Z n T M P y P$, respectivamente. Os valores de $\Phi_{\Delta}$ determinados variam entre 0,60 e 0,90 , sendo mais um fator favorável para a continuidade do estudo da aplicação desses complexos em sistemas de terapia fotodinâmica.

A interação entre essas porfirinas e o surfactante aniônico, SDS, também apresenta peculiaridades em relação a $\mathrm{H}_{2}$ TMPyP. Em meio micelar os deslocamentos das bandas dos espectros eletrônicos para a região do vermelho são mais acentuados indicando um maior grau de interação. Em condições pré micelares algumas porfirinas apresentam propriedades espectroscópicas semelhantes a agregados do tipo $\mathrm{J}$ ou $\mathrm{H}$, dependendo do substituinte. As propriedades fotofísicas desses agregados devem ser melhor estudadas, sendo necessários outros experimentos.

A análise global dos dados espectroscópicos dos diferentes agregados formados entre as porfirinas piridínio substituídas e o SDS, em função da concentraçõa do surfactante, permite a proposição de um novo modelo de formação de incorporação dessas porfirinas catiônicas nas micelas aniônicas de SDS. Os resultados apresentados neste trabalho indicam que a porfirina se encontra na forma monomérica, preferencialmente no interior das micelas de SDS, e a proposta deste trabalho é que a formação de um agregado pré-micelar porfirina/SDS, com alto caráter hidrofóbico e atenuamento das cargas positivas, permite a incorporação da porfirina na micela. Esse modelo deve, necessariamente, alterar o volume da micela em comparação com SDS em solução aquosa e experimentos de esplahamento de raios $X$ e outras técnicas para determinação do tamanho das micelas devem ser aplicados para confirmar este modelo.

De modo geral pode-se concluir que essa nova série de porfirinas apresenta propriedades fotofísicas e redox semelhantes à $\mathrm{H}_{2} \mathrm{TMPyP}$, com pouca alteração no 
macrociclo porfirínico. Entretanto, as porfirinas benzilpiridínio substituídas possuem potencial de interação com macromoléculas diferenciado e dependente dos substituintes benzílicos, tornando-se interessante o estudo de aplicações em terapia fotodinâmica.

Paralelamente, deve-se iniciar o estudo da interação dessas porfirinas com as principais macromoléculas que apresentam interação com a $\mathrm{H}_{2}$ TMPyP, DNA e melanina, além de estruturas que são promissores carregadores de drogas como o BSA, ciclodextrinas e lisossomos. Os resultados apresentados nessa tese indicam que as porfirinas benzilpiridinio apresentaram atividade fotossensibilizadora equivalente a $\mathrm{H}_{2}$ TMPyP e seus metaloderivados, contudo apresentaram propriedades de interação com essas macromoléculas peculiares.

Outra aplicação que já está sendo desenvolvida no grupo para a nova série de porfirinas benzilpiridínio substituídos é a formação de pares iônicos com ftalocianinas em diversos solventes, e o estudo da viabilidade de aplicar esse sistema como modelo do special pair do sistema fotossintético. 


\section{Referências Bibliográficas}

K. Kalyanasundaram, Inorg. Chem., 1984, 23, 2453.

N. N. Kruk, B. M. Dzhagarov, V. A. Galievsky, V. S. Chirvony, e P. Y. Turpin, J. Photochem. Photobiol. B:, 1998, 42, 181.

R. Bonnet, Chem. Soc. Rev., 1995, 24, 19.

J. B. Verlhac, A. Gaudemer, e I. Kraljic, N. J. Chim., 1984, 8, 401.

J. Mosinger e Z. Micka, J. Photochem. Photobiol. A:; 1997, 107, 77.

S. Sehlstedt, S. K. Kim, P. Carter, J. Goodisman, J. F. Vollano, B. Nordén, e J. C. Dabrowiak, Biochem., 1994, 33, 417.

A. S. Ito, G. C. Azzellini, S. C. Silva, O. Serra, e A. G. Szabo, Biophys. Chem., 1992, 45, 79.

I. E. Borissevitch, T. T. Tominaga, e C. C. Schmitt, J. Photochem. Photobiol. A: 1998, 114, 201.

A. Harriman, G. Porter, e P. Walters, J. Chem. Soc. Faraday Trans. I, 1983, 79, 1335.

T. H. Tran-Thi, Coord. Chem. Rev., 1997, 160, 53.

1 K. Kalyanasundaram, J. Chem. Soc., Faraday Trans. 2, 1983, 79, 1365.

2 R. F. Pasternack, P. R. Herbon, P. Boyd, G. Engasser, L. Francesconi, E. Gibbs, P. Fasella, G. C. Ventura, e L. C. Hinds, J. Am. Chem. Soc., 1972, 94, 4511.

R. F. Pasternack, L. Francesconi, D. Raff, e E. Spiro, Inorg. Chem., 1973, 12, 2406.

H. Baker, P. Hambright, e L. Wagner, J. Am. Chem. Soc., 1973, 95, 5942.

P. Hambright and E. B. Fleisher, Inorg. Chem., 1970, 9, 1757.

P. Worthington, P. Hambright, R. F. X. Williams, J. Reid, C. Burnham, A. Shamin, J. Turay, D. M. Bell, R. Kirkland, R. G. Little, N. Datta-Gupta, e U. Eisner, J. Inorg. Biochem., 1980, 12, 281.

7 K. M. Kadish, B. G. Mayia, C. Araullo, D. Sazou, J. M. Barbe, e R. Guillard, Inorg. Chem., 1989, 28, 2528.

8 K. M. Kadish, D. Sazou, Y. M. Liu, A. Saioadi, M. Ferhat, e R. Guilard, Inorg. Chem., 1988, 27, 2313.

9 K. M. Kadish, D. Sazou, Y. M. Liu, A. Saioadi, M. Ferhat, e R. Guilard, Inorg. Chem., 1988, 27, 1198.

M. C. Richoux, P. Neta, A. Harriman, S. Baral, e P. Hambright, J. Phys. Chem., 1986, 90, 2462.

1 G. C. Azzellini, 'Síntese de Porfirinas e Metaloporfirinas N-Alquilpiridil Substituídas: Estudo da Influência dos Substituintes Alquílicos em Processo de 
Fotossenssibilização', Tese de Doutoramento, Instituto de Química-USP, São Paulo, 1992.

R. M. Liegel, 'Porfirinas e Metaloporfirinas Catiônicas Aquossolúveis: Síntese e Caracterização de Derivados Benzilpiridínio substituídos', Dissertação de Mestrado, Instituto de Química-USP, São Paulo, 1996.

Y. Ridente, G. C. Azzellini, e A. S. Ito, Pigment Cell. Res., 1993, 6, 134.

L. Stryer, 'Biochemistry', W.H. Freeman, Nova York, 1995.

D. Voet and J. G. Voet, 'Biochemistry', John Wiley and Sons, Nova York, 1995. IUPAC, J. Am. Chem. Soc., 1960, 82, 5581.

A. D. Adler, F. R. Longo, J. D. Finarelli, e L. Korsakoff, J. Org. Chem., 1967, 32, 476.

J. S. Lindsey, H. C. Hsu, P. C. Kearney, e A. M. marguerettaz, J. Org. Chem., 1987, 52, 827.

29 R. Boyd e R. Morrison, 'Química Orgânica', Fundação Caloustre Gulberian, Lisboa, 1990.

30 K. P. C. Vollhardt e N. E. Schore, 'Organic Chemistry - Structure and Function', W.H. Freeman, Nova York, 1998.

31 P. Sykes, 'Guia de Mecanismos da Química Orgânica', Ao Livro Técnico, São Paulo, 1969.

32 J. March, 'Advanced Organic Chemistry: Reactions, Mechanisms and Structure', Ed. Wiley Interscience, Nova York, 1992.

L. R. Milgrom, J. P. Hill, e P. J. F. Dempsey, Tetrahedron, 1994, 50, 13447.

J. Juillard, em 'Reccommended Methods for Purification of Solvents and Test for Impurities', ed. J. F. Coetzee, Pergamon Press, Nova York, 1982.

S. Dovidauskas, 'Química Supramolecular de Porfirino-Clusters', Tese de Doutoramento, Instituto de Química-USP, São Paulo, 2001.

L. R. R. Essias, 'Complexos Modelo para Hemoproteínas Respiratórias: N Alquilpiridilporfirinas', Dissertação de Mestrado, Instituto de Química-USP, São Paulo, 1986.

37 M. Gouterman, em 'The Porphyrins', vol.3, ed. D. Dolphin, Nova York, 1978.

38 J. E. Falk, 'Porphyrins e Metalloporphyrins', Elsevier, Amsterdam, 1964.

39 K. Kano, T. Miyake, K. Uomoto, T. Sato, e T. Ogawa, Chem. Lett., 1983, 1867.

40 K. Kano, T. Nakajima, M. Takei, e S. Hashimoto, Bull. Chem. Soc. Jpn., 1987, 60, 1281.

41 C. A. Parker, 'Photoluminescence of Solutions', Elsevier, Amsterdam, 1968.

42 N. J. Turro, 'Modern Molecular Photochemistry', Benjamin/Cummings, Mento Park, 1978.

43 J. N. Demas, J. Chem. Educ., 1983, 60, 803.

44 K. Kano, M. Takei, e S. Hashimoto, J. Phys. Chem., 1990, 94, 2181. 
A. Harriman, J. Chem. Soc., Faraday Trans. 1, 1981, 77, 369.

L. M. Hadel, 'Laser Flash Photolysis' em "Handbook of Organic Photochemistry", ed. J. C. Scaiano, CRC, Boca Raton, 1989.

R. Bonneau, J. Wirz, e A. D. Zuberbühler, Pure \& Appl. Chem., 1997, 69, 979. F. Wilkinson, W. P. Helman, e A. B. Ross, J. Phys. Ref. Data, 1993, 22, 133. W. Spiller, H. Kliesh, D. Wöhrle, S. Hackbarth, B. Röder, e G. Schnurpfeil, J. Porphyrins and Phthalocyanines, 1998, 2, 145.

C. Tanielian, C. Wolff, e M. Esch, J. Phys. Chem., 1996, 100, 6555. W. I. White, em 'The Porphyrins', vol.5, ed. D. Dolphin, Nova York, 1978.
A. losif e U. Grummt, J. Prakt. Chem., 1997, 339, 420.

D. W. Dixon e V. Steullet, J. Inorg. Biochem., 1998, 69, 25.

R. F. Pasternack, E. J. Gibbs, A. Gaudemer, A. Antebi, S. Bassner, L. De Poy, D. H. Turner, A. Williams, F. Laplace, L. H. Mansard, C. Merienne, e M. Perrée-Fauvet, J. Am. Chem. Soc., 1985, 107, 8179.

N. Foster, J. Magn. Res., 1984, 56, 140.

R. L. Brookfield, H. Ellul, e A. Harriman, J. Photochem., 1985, 31, 97.

F. J. Vergeldt, B. M. Koehorst, A. v. Hoek, e T. J. Schaafsma, J. Phys. Chem., 1995, 99, 4397.

K. P. S. Dancil, L. F. Hilario, R. G. Khouri, K. U. Mai, K. S. W. Nguyen, e A. M. Shachter, J. Heterocyclic Chem., 1997, 34, 749.

D. Attwood e A. T. Florence, 'Surfactant Systems', J.W. Arrowsmith, Bristol, 1983.

P. W. Atkins, 'Physical Chemistry', Oxford University Press, Oxford, 1990.

K. M. Kadish, G. B. Maiya, C. Araullo, e R. Guillard, Inorg. Chem., 1989, 28, 2725.

K. M. Kadish, B. G. Mayia, e C. Araullo, J. Phys. Chem., 1991, 95, 427.

S. Basu, T. K. Paul, e S. Roy, Indian J. Chem., 1989, 28A, 729.

T. Tominaga, S. Endoh, e H. Ishimaru, Bull. Chem. Soc. Jpn., 1991, 64, 942.

T. Hinoue, J. Kobayashi, T. Ozeki, e H. Watarai, Chem. Lett., 1997, 763.

N. C. Maiti, S. Mazumdar, e N. Periasamy, J. Phys. Chem. B, 1998, 102, 1528.

P. W. Bohn, Annu. Rev. Phys. Chem., 1993, 44, 37.

E. D. Sternberg e D. Dolphin, Tetrahedron, 1998, 54, 4151.

I. J. MacDonald e T. J. Dougherty, J. Porphyrins Phtalocyanines, 2001, 5, 105.

V. M. De Pauli, 'Estudos Fotofísicos da Meso-tetrakis(4-N-metilpiridil)porfirina e seus Complexos com Sistemas Micelares e com DNA', Dissertação de Mestrado, FFCLUSP, Ribeirão Preto, 2001.

K. Lang, P. Kubat, J. Mosinger, e D. M. Wagnerova, J. Photochem. Photobiol. A:; 1998, $119,47$. 
R. Edrei e S. Kimel, J. Photochem. Photobiol. B:, 1999, 50, 197.

R. Bonnet, A. N. Nizhnik, e S. G. White, J. Photochem. Photobiol. B:, 1990, 6, 79.

J. S. Trommel e L. G. Marzilli, Inorg. Chem., 2001, 40, 4374.

L. G. Marzilli, New J. Chem., 1990, 14, 409.

N. G. Angeli, M. G. Lagorio, E. A. San Román, e L. E. Dicelio, Photochem. Photobiol., 2000, 72, 49.

M. Merchat, G. Bertolini, P. Giacomini, A. Villanueva, e G. Jori, J. Photochem. Photobiol. B:, 1996, 153.

A. Minnock, D. I. Vernon, J. Schofield, J. Griffiths, J. H. Parish, e S. B. Brown, J. Photochem. Photobiol. B:, 1996, 32, 159.

F. N. Jiang, B. Allison, D. Liu, e G. J. Levy, J. Controlled Release, 1992, 19, 41.

R. K. Pandey, J. Porphyrins and Phythalocyanines., 2000, 4, 368.

E. Reddi, J. Photochem. Photobiol. B:, 1997, 37, 189.

2 I. E. Borissevitch, T. T. Tominaga, H. Imasato, e M. Tabak, J. Luminescence, 1996, 69, 65.

E. I. Borissevitch, T. T. Tominaga, H. Imasato, e M. Tabak, Anal. Chim. Acta, 1997, 343, 281.

G. R. Parr e R. F. Pasternack, Bioinorg. Chem., 1977, 7, 277.

K. Lang, P. Kubat, P. Lhoták, J. Mosinger, e D. M. Wagnerová, Photochem. Photobiol., 2001, 74, 558.

R. F. Pasternack e E. J. Gibbs, 'Metal-DNA Chemistry', ed. T. D. Tullins, ACS Series 402, Washington, 1989.

T. Uno, K. Hamasaki, M. Tanigawa, e S. Shimabayashi, Inorg. Chem., 1997, 36, 1676.

S. C. M. Gandini, V. E. Yushmanov, J. R. Perussi, M. Tabak, e I. E. Borissevitch, J. Inorg. Biochem., 1999, 73, 35.

O. Y. Fedoroff, A. Rangan, V. V. Chemeris, e L. H. Hurley, Biochem., 2000, 39, 15083.

M. A. Sari, J. P. Battioni, D. Dupré, D. Mansuy, e J. B. Le Pecq, Biochem., 1990, 29, 4205.

R. F. Pasternack, E. J. Gibbs, e J. J. Villafranca, Biochem., 1983, 22, 5409.

B. H. Yun, S. H. Jeon, T. S. Cho, S. Y. Yi, U. Sehlstedt, e S. K. Kim, Biophys. Chem., 1998, 70, 1.

S. C. M. Gandini, I. E. Borissevitch, J. R. Perussi, H. Imasato, e M. Tabak, J. Luminescence, 1998, 78, 53.

94 A. Villanueva, M. Cañete, C. Trigeiros, L. Rodriguez-Borlado, e A. Juarranz, Byopolimers, 1993, 33, 239.

F. Prat, C. C. Hou, e C. S. Foote, J. Am. Chem. Soc., 1997, 119, 5051. 
96

97

98

99

100

V. S. Chirvony, V. A. Galievsky, N. N. Kruk, B. M. Dzhagarov, e P. Y. Turpin, J. Photochem. Photobiol. B:, 1997, 40, 154.

E. Izbicka, R. T. Wheelhouse, E. Raymond, K. K. Davidson, R. A. Lawrence, D. Sun, B. E. Windle, L. H. Hurley, e D. D. Hoff, Cancer Res., 1999, 59, 639.

R. T. Wheelhouse, D. Sun, H. Han, F. X. Han, e L. H. Hurley, J. Am. Chem. Soc., 1998, 120,3261 .

U. Hofstra, R. B. M. Koehorst, e T. J. Schaafsma, Magn. Reson. Chem., 1987, 25, 1069.

J. F. Lipskier e T. H. Tran-Thi, Inorg. Chem., 1993, 32, 722.

T. H. Tran-Thi, J. F. Lipskier, D. Houde, C. Pépin, E. Keszel, e J. P. Jay-Gerin, J. Chem. Soc., Faraday Trans. 1, 1992, 88, 2129.

M. A. A. Azzellini, 'Fotoquímica Supramolecular: Transferência Eletrônica Fotoinduzida em Pares lônicos entre o Complexo Fac-Tris(2-Aminometilpiridina)Cobalto(III)/ Ânion', Tese de Doutoramento, Instituto de Quimica-USP, São Paulo, 1994.

A. I. Vogel, 'Análise Inorgânica Quantitativa', Editora Guanabara, Rio de Janeiro, 1981.

D. D. Perrin e W. L. F. Armarego, 'Purification of Laboratory Chemical', BetterworthHeinemann, Oxford, 1997.

A. I. Vogel, 'Practical Organic Chemistry', Longman S. \& T., London, 1989.

G. Pass e H. Suteliffe, 'Practical Inorganic Chemistry', Chapman and Hall, Nova York, 1974.

J. P. Mathieu, Bull. Soc. Chim. Fr., 1936, 463.

D. T. Sawyer e J. L. Roberts Jr, 'Experimental Electrochemistry for Chemists', John Wiley \& Sons, Nova York, 1974.

A. A. Gorman, I. Hamblett, C. Lambert, A. L. Prescott, M. A. J. Rodgers, e H. M. Spence, J. Am. Chem. Soc., 1987, 109, 3091.

L. P. Novaki e O. A. El Seoud, Phys. Chem. Chem. Phys., 1999, 1, 1957.

P. Lianos e J. Lang, J. Phys. Chem., 1985, 89, 5322.

J. W. Buchler, em 'Porphyrins and Metalloporphyrins', ed. K. M. Smith, Elsevier, Amsterdam, 1975.

V. E. Yushmanov, H. Imasato, T. T.T., e M. Tabak, J. Inorg. Biochem., 1996, 61, 233.

A. Voet, Chem. Rev., 1937, 20, 169.

A. L. Underwood e E. W. Anacker, J. Colloid Interface Science, 1987, 117, 243.

J. W. Bridges, 'The Determination of Quantum Yelds' em "Standards in Fluorescence Spectrometry", ed. J. N. Miller, Chapman and Hall, Nova York, 1981.

J. N. Demas e G. A. Crosby, J. Phys. Chem., 1971, 75, 991.

A. Harriman, J. Chem. Soc. Faraday Trans. I, 1981, 77, 1281. 
V. H. Houlding, K. Kalyanasundaram, M. Grätzel, e L. R. Milgrom, J. Phys. Chem., 1983, 87, 3175.

P. Neta e A. Harriman, J. Chem. Soc. Faraday Trans. 2, 1985, 81, 123.

E. V. Caemelbecke, W. Kutner, e K. M. Kadish, Inorg. Chem., 1993, 32, 438.

B. P. Neri e G. S. Wilson, Anal. Chem., 1972, 44, 1002.

K. M. Kadish, D. Sazou, Y. M. Liu, A. Saioadi, M. Ferhat, e R. Guilard, Inorg. Chem., $1988,27,686$.

P. T. Kissinger e W. R. Heineman, 'Electrochemical Methods: Fundamentals and Aplications', Dekker, 1984.

G. A. Mabbott, J. Chem. Educ., 1983, 60, 697.

D. H. Evans, K. M. O'Connell, R. A. Petersen, e M. J. Kelly, J. Chem. Educ., 1983, 60, 290.

127 R. L. Espinoza, 'Estudo das Interações do Benzotriazol com Amincomplexos de $\mathrm{Ru}(\mathrm{II}) /(\mathrm{III})$ e pentaciano ferrato (II)', Tese de Doutoramento, Instituto de Química-USP, São Paulo, 1985.

M. S. Takasugi, 'Efeito de Solventes na Química dos Cianoferratos', Tese de Doutoramento, Instituto de Química-USP, São Paulo, 1984.

R. S. Nicholson, Anal. Chem., 1966, 38, 1406.

R. S. Nicholson e I. Shain, Anal. Chem., 1964, 36, 706.

Y. Amao, T. Kamachi, e I. Okura, Inorg. Chim. Acta, 1998, 267, 257.

J. H. Fuhrop, K. M. Kadish, e D. G. Davis, J. Am. Chem. Soc., 1973, 95, 5140.

C. L. Bird e A. T. Kuhn, Chem. Soc. Rev., 1981, 10, 49.

R. M. Silverstein, 'Spectrometric Identification of Organic Compounds', Wiley, Nova York, 1991.

D. W. Thomas e A. E. Martell, J. Amer. Chem. Soc., 1956, 78, 1338.

L. A. Andersson, T. M. Loehr, R. G. Thompson, e S. H. Strauss, Inorg. Chem., 1990, 29, 2142.

J. Kincaid e K. Nakamoto, J. Inorg. Nucl. Chem., 1975, 29, 2142.

H. Ogoshi, Y. Saito, e K. Nakamoto, J. Chem. Phys., 1972, 57, 4194.

J. O. Alben, Annais New York Academy of Sciences, Nova York, 1973.

140 L. J. Boucher e J. J. Katz, J. Am. Chem. Soc., 1967, 89, 1340.

141 D. K. Lavallee, Inorg. Chem., 1978, 17, 231.

142 N. Blom, J. Odo, K. Nakamoto, e D. P. Strommen, J. Phys. Chem., 1986, 90, 2847.

143 L. J. Bellamy, 'The Infrared Spectra of Complex Molecules', Chapman and Hall, Nova York, 1975.

144 A. R. Katritzky e Z. Dega-Szafran, Magn. Reson. Chem., 1989, 27, 1090. 
C. Casas, B. Saint-James, C. Loup, C. J. Lacey, e B. Meunier, J. Org. Chem., 1993, 58, 2913.

146 G. D. Egorova, K. N. Solov'ev, e A. M. Shul'ga, Theor. Exp. Chem., 1975, 11, 77.

147 D. F. Ewing, em 'Correlation Analysis in Chemistry', ed. N. B. Chapman and J. Shorter, Plenum, Nova York, 1978.

148 F. A. Walker, V. L. Balke, e G. A. McDermott, Inorg. Chem., 1982, 21, 3342.

149 L. T. Okano, O. A. El Seoud, e T. K. Halstead, Colloid Polym. Sci., 1997, 275, 138.

150 R. J. Abraham, J. E. Hawkes, M. F. Hudson, e K. M. Smith, J. Chem. Soc. Perkin II, 1975, 204.

151 C. B. Storm e Y. Teklu, J. Amer. Chem. Soc., 1972, 94, 1745.

152 V. M. S. Gil e C. F. G. S. Geraldes, 'Ressonância Magnética Nuclear - Fundamentos, Métodos e Aplicações', Fundação Caloustre Gulberian, Lisboa, 1987.

153 K. Kano, H. Minamizono, T. Kitae, e S. Negi, J. Phys. Chem. A, 1997, $101,6118$.

154 P. Murkerjee e K. Mysels, 'Critical Micelle Concentrations of Aqueous Surfactant Systems', US Gov. Printing Office, Washington, 1971.

155 S. Possidonio, F. Siviero, e O. A. El Seoud, J. Phys. Org. Chem., 1999, 12, 325.

156 E. B. Tada, L. P. Novaki, e O. A. El Seoud, Langmuir, 2001, 17, 652.

157 S. C. M. Gandini, V. E. Yushmanov, I. E. Borissevitch, e M. Tabak, Langmuir, 1999, 15, 6233.

158 N. J. Rose e R. S. Drago, J. Am. Chem. Soc., 1959, 81, 6138.

159 N. J. Rose e R. S. Drago, J. Am. Chem. Soc., 1959, 81, 6141. 